\title{
End State Condition Report for Materials and Fuels Complex Facilities MFC-799, 799A, and 770C
}

October 2010

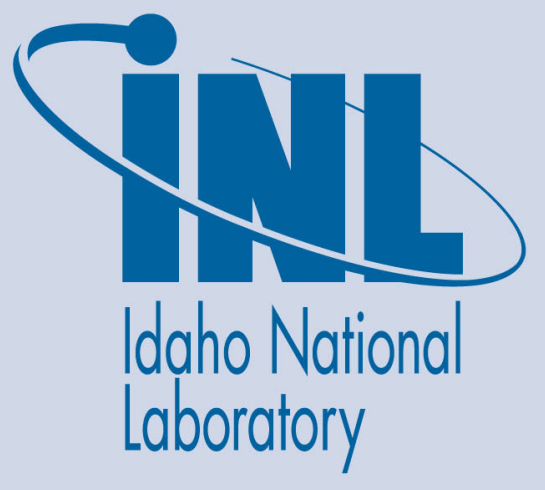

The INL is a U.S. Department of Energy National Laboratory operated by Battelle Energy Alliance 


\section{DISCLAIMER}

This information was prepared as an account of work sponsored by an agency of the U.S. Government. Neither the U.S. Government nor any agency thereof, nor any of their employees, makes any warranty, expressed or implied, or assumes any legal liability or responsibility for the accuracy, completeness, or usefulness, of any information, apparatus, product, or process disclosed, or represents that its use would not infringe privately owned rights. References herein to any specific commercial product, process, or service by trade name, trade mark, manufacturer, or otherwise, does not necessarily constitute or imply its endorsement, recommendation, or favoring by the U.S. Government or any agency thereof. The views and opinions of authors expressed herein do not necessarily state or reflect those of the U.S. Government or any agency thereof. 


\section{End State Condition Report for Materials and Fuels Complex Facilities MFC-799, 799A, and 770C}

October 2010

Idaho National Laboratory Idaho Falls, Idaho 83415

http://www.inl.gov

Prepared for the

U.S. Department of Energy

Office of Nuclear Energy

Under DOE Idaho Operations Office

Contract DE-AC07-05ID14517 



\begin{abstract}
The Materials and Fuels Complex (MFC) facilities MFC-799, "Sodium Processing Facility," (a single building consisting of two areas: the Sodium Process Area and the Carbonate Process Area); MFC-799A, "Caustic Storage Area," and MFC-770C, "Nuclear Calibration Laboratory," have been declared excess to future Department of Energy (DOE) Office of Nuclear Energy (NE) mission requirements. Transfer of these facilities from DOE-NE to the DOE Office of Environmental Management, and an associated schedule for doing so, have been agreed upon by the two offices.

This report documents completion of pre-transfer stabilization actions for buildings MFC-799, 799A, and 770C, as identified in Department of Energy Guide 430.1-5, "Transition Implementation Guide," and indicates that these facilities are ready for transfer from DOE-NE to the DOE Office of Environmental Management. The facilities are in a known, safe condition and information is provided to support efficient decommissioning and demolition planning, while minimizing the possibility of encountering unforeseen circumstances during the decommissioning and demolition activities.
\end{abstract}




\section{CONTENTS}

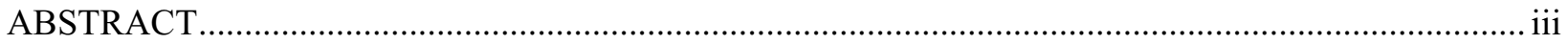

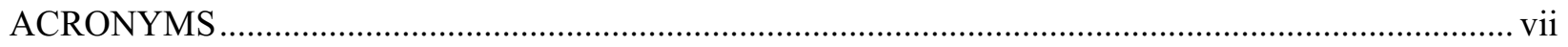

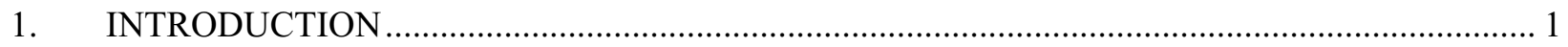

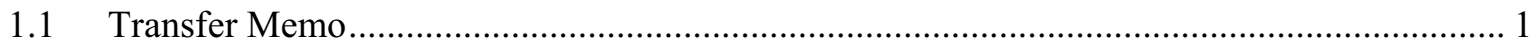

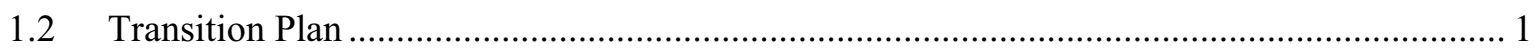

$1.3 \quad$ Facilities Condition and Hazards Assessment Report....................................................... 1

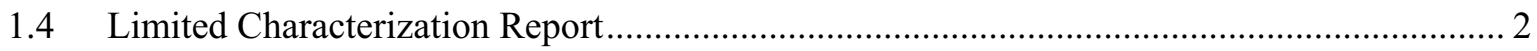

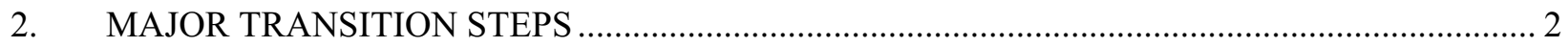

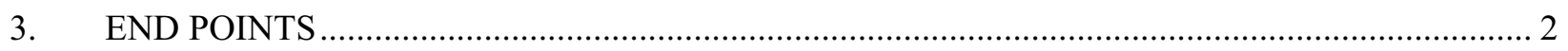

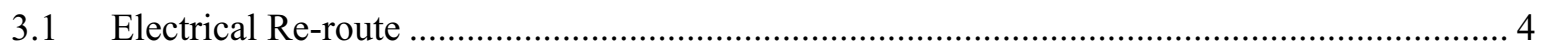

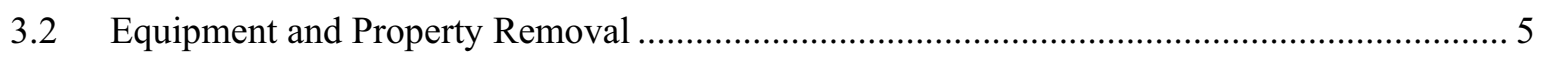

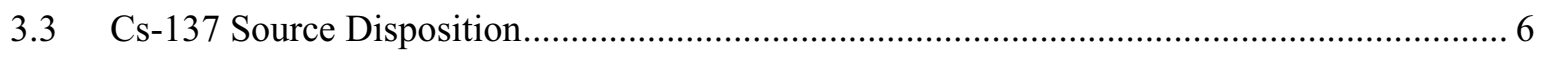

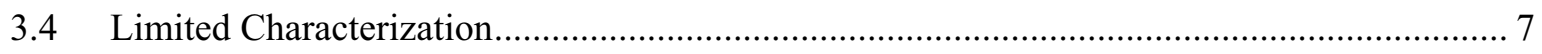

3.5 Resource Conservation and Recovery Act Permit Modification ........................................ 7

3.6 Joint Walk-Down and Final Transfer Memo ................................................................. 7

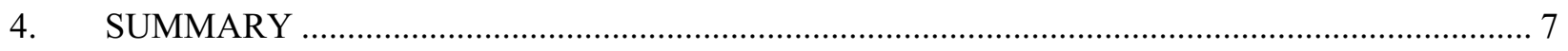

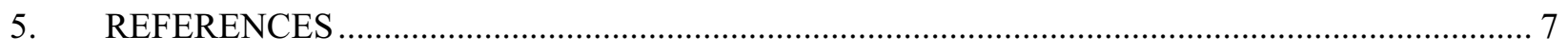

Appendix A, Facilities Condition and Hazards Assessment Report .................................................... 1

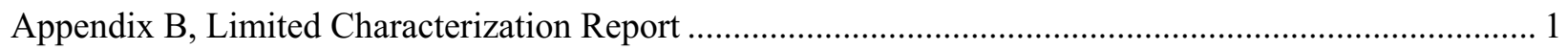

Appendix C, Cs-137 Source Disposition Documents ....................................................................... 1

\section{FIGURES}

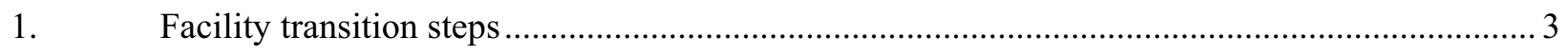

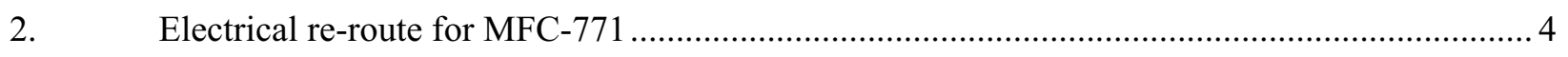

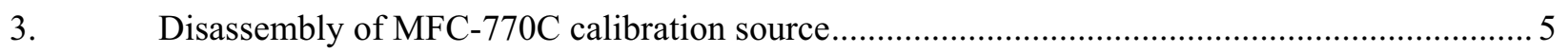




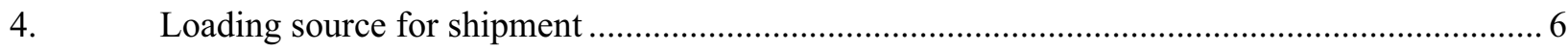




\section{ACRONYMS}

DOE Department of Energy

EM Office of Environmental Management (DOE)

INL Idaho National Laboratory

MFC Materials and Fuels Complex

NE Office of Nuclear Energy (DOE) 


\section{End State Condition Report for Materials and Fuels Complex Facilities MFC-799, 799A, and 770C}

\section{INTRODUCTION}

This report documents the completion of pre-transfer stabilization actions for Materials and Fuels Complex (MFC) buildings MFC-799, 799A, and 770C, as identified in Department of Energy (DOE) Guide 430.1-5, "Transition Implementation Guide," and indicates that these facilities are ready for transfer from DOE's Office of Nuclear Energy (NE) to the Office of Environmental Management (EM). The facilities are in a known, safe condition, and information is available to support efficient decommissioning and demolition planning.

The following four documents, along with this report, document and describe the process used to complete facility transition:

1. Memorandum from NE-32 to EM-1, "Transmittal of Approved Schedule for Transfer of Environmental Liabilities from the Office of Nuclear Energy (NE) to the Office of Environmental Management (EM)," dated July 8, 2009 (hereinafter referred to as Transfer Memo) (DOE 2009)

2. PLN-3352, "Transition Plan for Multiple Facilities at the Material and Fuels Complex, Advanced Test Reactor, Central Facilities Area, and Power Burst Facility," Revision 1, dated March 3, 2010 (hereinafter referred to as Transition Plan)

3. INL/EXT-09-17292, Facilities Condition and Hazards Assessment for Materials and Fuels Complex Facilities MFC-799, 799A, and 770C, Revision 1, dated June 2010 (hereinafter referred to as the Facilities Condition and Hazards Assessment Report; see Appendix A) (INL 2010a)

4. INL/EXT-10-19590, Hazardous Materials Verification and Limited Characterization Report on Sodium and Caustic Residuals in Materials and Fuel Complex Facilities MFC-799/799A, dated August 2010 (hereinafter referred to as the Limited Characterization Report; see Appendix B) (INL 2010b).

The following subsections provide a summary of information contained in each of these reports.

\subsection{Transfer Memo}

This memorandum establishes the schedule and terms and conditions for transfer of various environmental liabilities from NE to EM. Transfer of MFC-799, 799A, and 770C were proposed for Fiscal Year 2010.

\subsection{Transition Plan}

This plan defines the scope, responsibilities, and methodology to be used for developing, planning, and implementing the activities required for transfer of multiple Idaho National Laboratory (INL) facilities from NE to EM. These facilities are considered excess and not needed to support future NE activities and have been identified as "contaminated facility meeting criteria in 430.1B and ancillary facilities."

It discusses transition objectives and goals, major transition steps, and transition activities and processes, including stabilization subject areas with the criteria that establish stabilization end-points related to the physical condition of the facilities.

\subsection{Facilities Condition and Hazards Assessment Report}

This report provides a description of the current physical condition of the facilities and any hazards (i.e., material, chemical, nuclear, or occupational) that may be associated with past operations. It 
documents the conditions prior to transfer of the facilities from NE to EM and serves as the basis for disposition planning. The process used in obtaining this information included document searches, interviews, and facility walk-downs.

Based on the available information, documentation reviews, and the overall conditions observed during the facility walk-downs, it is concluded that these facilities may be disposed of at minimal risk to human health and safety and minimal risk to the environment.

\subsection{Limited Characterization Report}

This report is a companion to the Facilities Condition and Hazards Assessment (INL 2010a) and specifically responds to the requirement of Section 9.2, Item 6 , of that document to provide an updated verification of the residual hazardous materials remaining in the Sodium Processing Facility's processing system. The hazardous materials of concern are sodium and sodium hydroxide (caustic).

The information in this report supports end-point objectives identified in the Transition Plan (PLN-3352) and the deactivation and decommissioning Critical Decision Milestone 1, as specified in DOE Guide 413.3-8, "Environmental Management Cleanup Projects."

NOTE: Per DOE Guide 430.1-5, copies of both the Facilities Condition and the Hazardous Materials Verification and Limited Characterization Reports are included in their entirety as Appendixes $A$ and $B$, respectively, of this document.

\section{MAJOR TRANSITION STEPS}

DOE Guide 430.1-5 recommends an 11-step process that leads up to final facility transfer. This process is depicted in Figure 1.

Steps 1 through 8 are complete and details (to include the facilities walk-down checklists, photos, drawings, and other supporting documentation) are found in the Facilities Condition and Hazards Assessment and the Limited Characterization Reports (see Appendixes A and B). The Facilities Condition and Hazards Assessment Report also identifies open action items that need to be completed in order to satisfy the requirements of Step 9. These actions have been completed and are documented in the subsequent sections of this report.

This End State Report and a pending joint NE/EM pre-transfer walk-down of the facilities will establish the basis for completion of Step 10. Step 11 will be complete with the joint signing of a facility turnover correspondence. Both the joint walk-down and the turnover correspondence are being held in abeyance, pending EM receiving necessary funding to assume responsibility for the facilities.

\section{END POINTS}

The Facilities Condition and Hazards Assessment Report identified several actions that were needed in order to satisfy the stabilization criteria/end points. It also identified two administrative requirements that must be met prior to facility transfer. These are listed as follows:

1. Stabilization actions:

- Isolate and re-route electrical service for MFC-771, "Radioactive Storage Waste Facility"

- Remove stored equipment and property

- Disposition Cs-137 source contained in MFC-770C, "Nuclear Calibration Instrument Laboratory"

- Develop a limited characterization plan to verify caustic and sodium levels in MFC-799 and 799A tanks/vessels

- $\quad$ Transfer MFC-799 and 799A out of the PER 116 MFC Resource Conservation and Recovery Act Permit. 


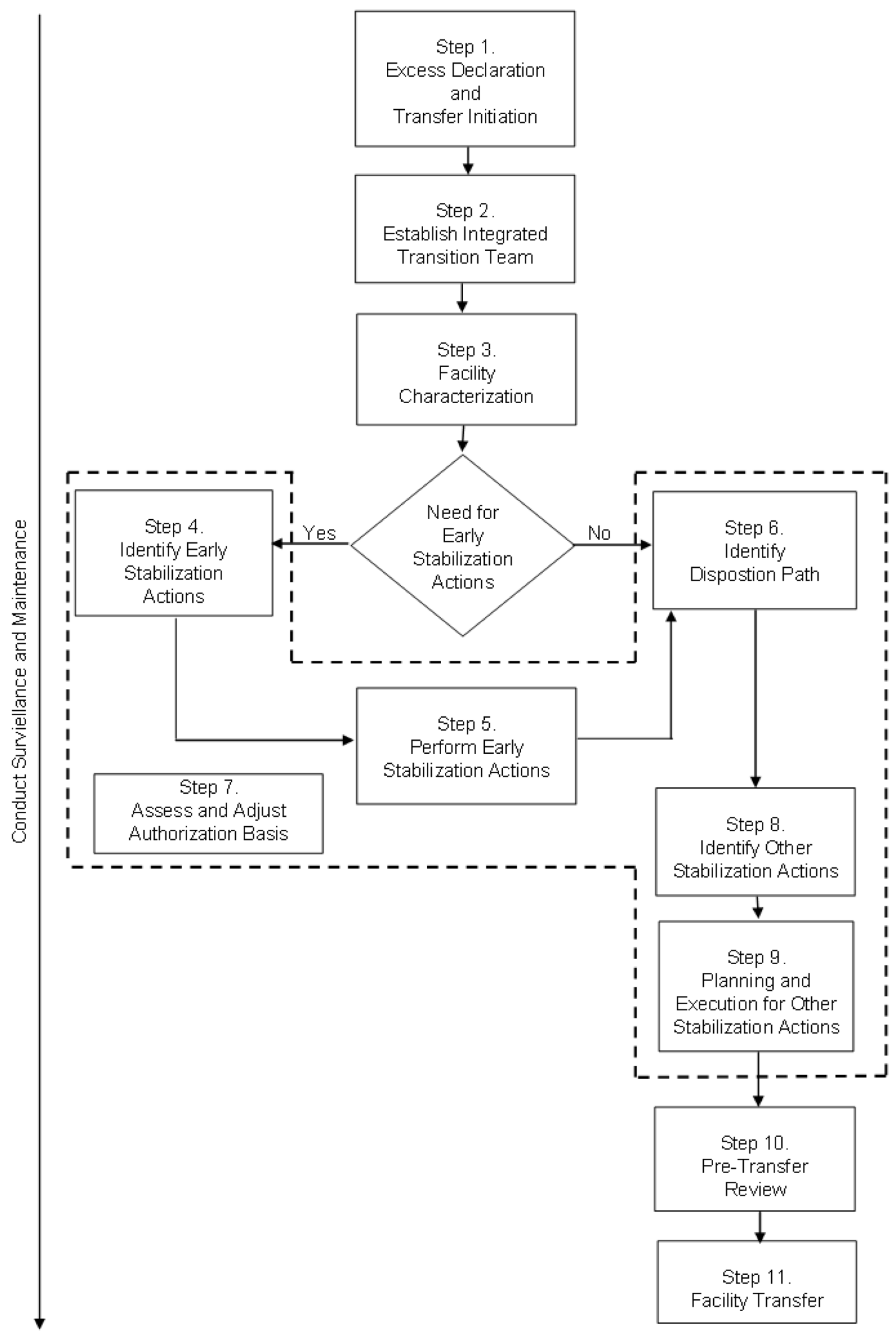

Figure 1. Facility transition steps. 
2. Administrative requirements:

- Perform joint NE/EM facility walk-down to confirm facilities are ready for transfer

- Execute final transfer memo, documenting the date of transfer and any other information pertinent to transfer of management responsibility.

A summary of actions taken and the current status for each of these items is discussed in the following subsections.

\subsection{Electrical Re-route}

An integrated project team was assembled in early Fiscal Year 2010 to develop an engineered design package to re-route the electrical supply power from MFC-799 to MFC-771 to ensure uninterrupted operations at the Radioactive Scrap and Waste Facility.

The design resulted in replacing the original three-phase, 600-V power feed into the MFC-799 electrical control center with a new service that bypasses MFC-799 altogether. This bypass service feeds from a new 50-amp breaker in Power Panel 110 and transits north along the MFC roadway via a newly installed 250-ft underground ductbank, which ties back into the underground transition (ductbank to RGS buried cable) located on the north side of the Sodium Processing Facility. This new ductbank contains two conduit lines housing 600-V copper cable.

Figure 2 shows the nearly complete re-route. Power Panel 110 is in the foreground and the new feeder breaker is positioned in the upper right corner of the panel.

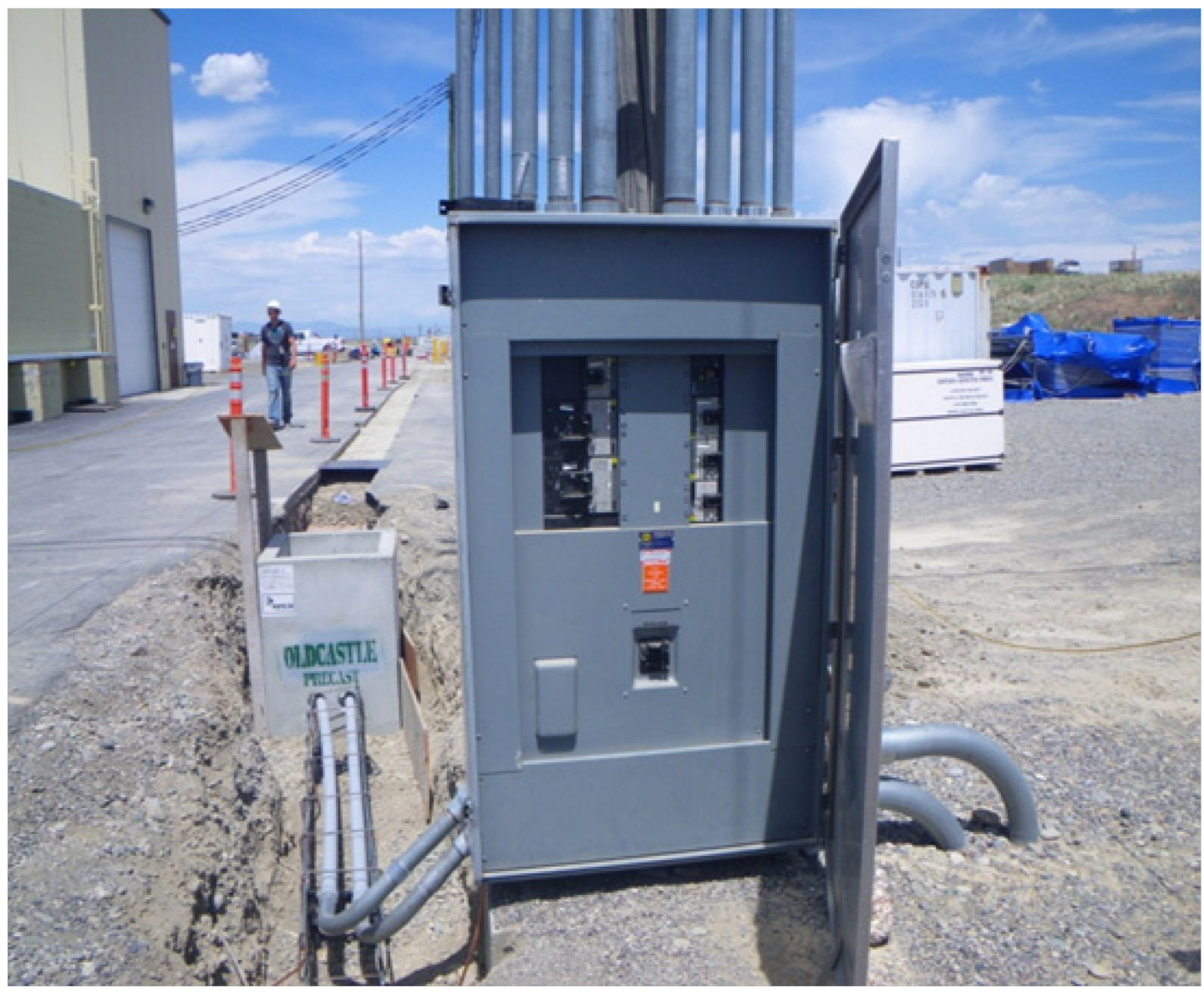

Figure 2. Electrical re-route for MFC-771. 
Additionally, two electrical handholes were installed at each end of the ductbank to accommodate the electrical tie-in, access, and drainage. Construction, installation, removal of previous portions of electrical system, continuity testing, and final facility turnover are complete and MFC nuclear operations has accepted the project.

\subsection{Equipment and Property Removal}

The following excess equipment and material items associated with MFC-799 were specifically called out in the Facilities Condition and Hazards Assessment Report:

- Daewoo BC30S electric forklift and charger

- $\quad$ Spacemaster II 5-ton single beam overhead electric hoist

- $\quad$ P\&H Beta HEVI-LIFT 500-lb overhead gantry crane

- $\quad$ P\&H Spectrum 1,000-lb pedestal crane.

Excess equipment associated with MFC-770C includes:

- JL Sheperd Model 81-12 beam calibrator (Serial No. 540)

- JL Sheperd Model 155 attenuator system (Serial No. 783) (with Cs-137 source).

The forklift and charging system is being retained by NE and is being relocated to MFC-793. The hoists and cranes are excess to NE needs and have been abandoned in place. These will be transferred to EM with the facility. The beam calibrator and attenuator system have been removed and dispositioned (Figure 3), as discussed in Section 3.3.

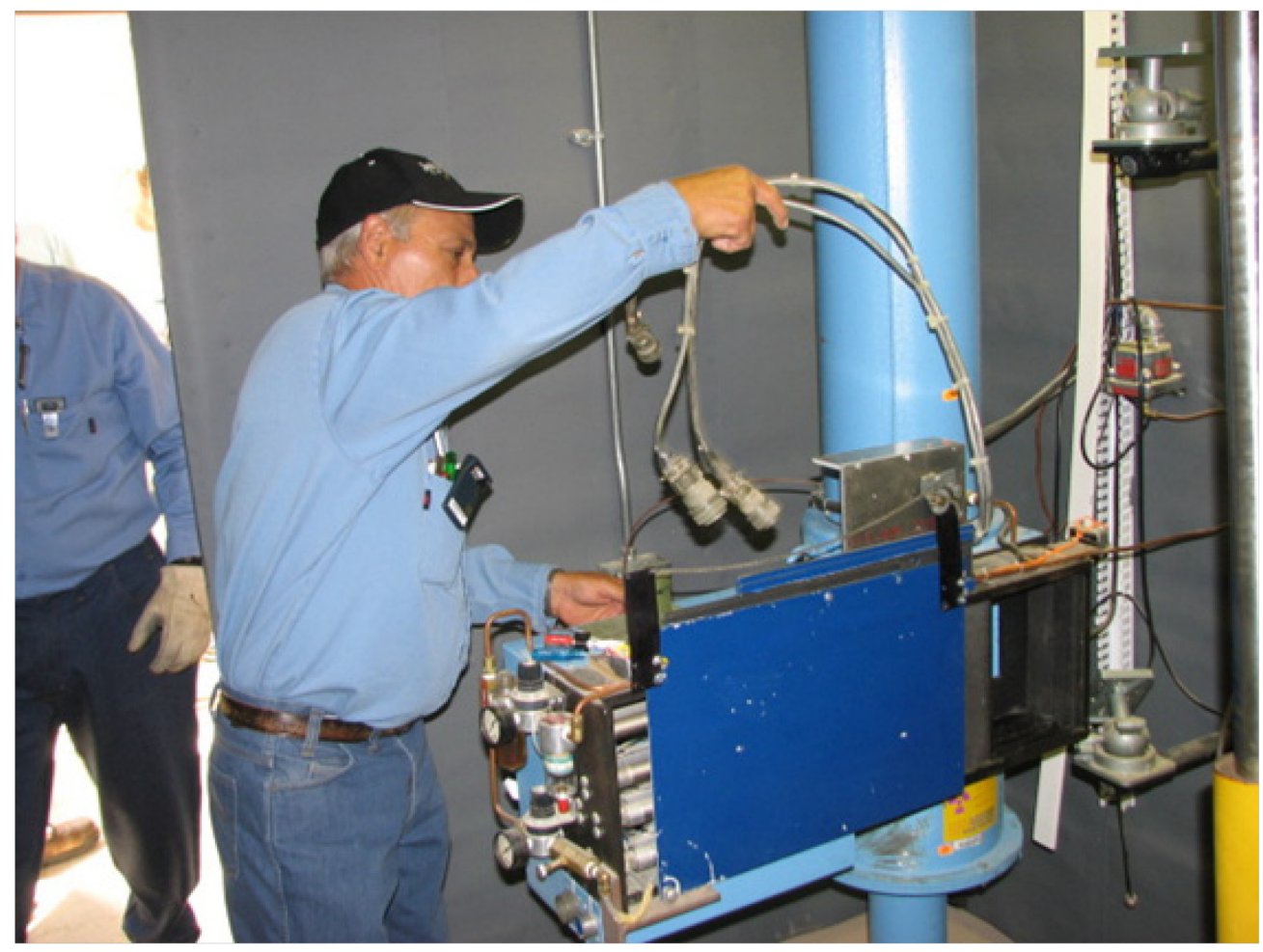

Figure 3. Disassembly of MFC-770C calibration source. 
MFC and contractor personnel walked the facilities on September 13, 2010, and confirmed that all other items of value that were previously stored in the facilities have been removed by their respective owners. Any items remaining are deemed abandoned and will be transferred for disposal with the facilities.

\subsection{Cs-137 Source Disposition}

Initial disposition activities focused on reuse of the beam calibrator and attenuator by transferring ownership of the equipment and source back to the original manufacturer with a resulting cost avoidance provided to the laboratory. However, the property disposition review determined that the equipment in its "as is" state was considered to be a nuclear sensitive and a non-proliferation item that could only be transferred from one government entity to another government entity. An exemption was initiated but not considered achievable in this Fiscal Year; therefore, the decision was made to disposition the source as waste.

Outside shipping services were necessary to accommodate the 94 curie quantity of cesium and the Type 'B' package. A contract was established with JL Shepherd and Associates to perform the shipment of the Cs-137 source to Nevada National Security Site for disposal in the underground burial facility. Waste profile NEID-CHCS137SS was approved on Aug 20, 2010, in a letter titled "Approval to Ship Battelle Energy Alliance (BEA) Low-Level Radioactive Waste to the Nevada Test Site (NTS)." A copy of the letter and the associated Integrated Waste Tracking System ship task are included as Appendix C.

The source was packaged and shipped to the Nevada National Security Site (Figure 4) by JL Shepherd and Associates on September 15, 2010.

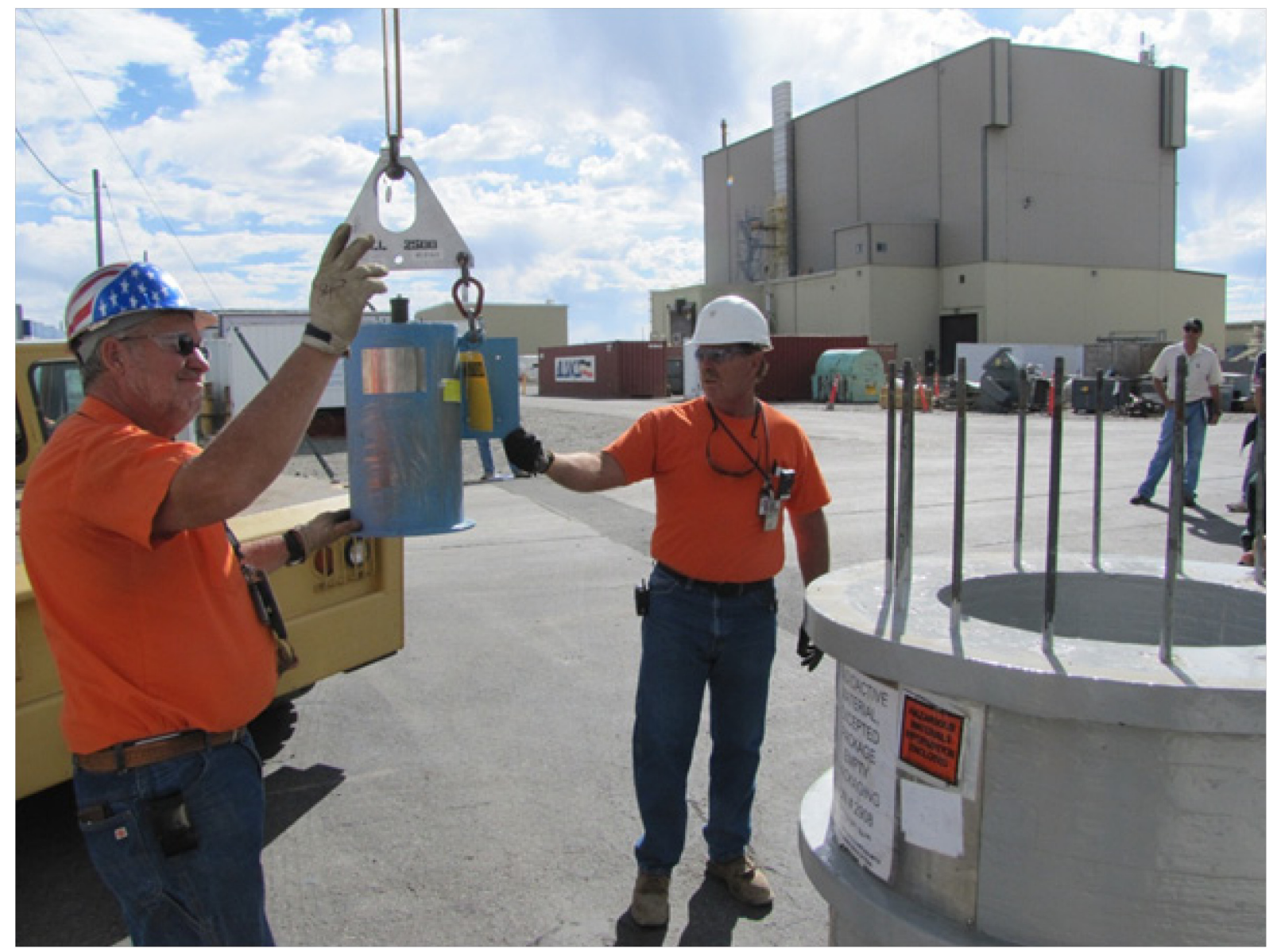

Figure 4. Loading source for shipment. 


\subsection{Limited Characterization}

The Limited Characterization Report discussed in Section 1 completes this requirement. A complete copy of this report is included as Appendix B.

\subsection{Resource Conservation and Recovery Act Permit Modification}

The Class 1 Permit Modification Request to remove MFC-799 and 799A from PER-116 MFC RCRA permit has been submitted to the DOE Idaho Operations Office for processing (BEA to DOE Idaho Operations Office letter dated July 29, 2010).

\subsection{Joint Walk-Down and Final Transfer Memo}

These actions will be completed upon confirmation that EM has received the funding required to assume surveillance and maintenance responsibility for the facilities.

\section{SUMMARY}

Each of the major transition steps (as presented in DOE Guide 430.1-5) has been completed for facilities MFC-799, 799A, and 770C. All pre-transfer end-points have been met; the facilities are isolated from surrounding structures and utilities; all known hazards have been identified, quantified, and stabilized to the extent practical; and the facilities are in known and stable conditions. They may be disposed of at minimal risk to human health and safety and minimal risk to the environment, and are ready for transfer from NE to EM for decommissioning and demolition.

\section{REFERENCES}

Battelle Energy Alliance to U.S. Department of Energy Idaho Operations Office letter, "SUBJECT: Contract No. DE-AC07-05ID14517 - Prerequisite to Facilitate Transfer of the Sodium Processing Facility, Materials and Fuels Complex 799, to CH2M-WG Idaho, LLC, per Battelle Energy Alliance, LLC Performance Evaluation and Measurement Plan," dated July 29, 2010.

DOE, 2009, Memorandum from NE-32 to EM-1, "Transmittal of Approved Schedule for Transfer of Environmental Liabilities from the Office of Nuclear Energy (NE) to the Office of Environmental Management (EM)," dated July 8, 2009.

DOE Guide 413.3-8, "Environmental Management Cleanup Projects," U.S. Department of Energy.

DOE Guide 430.1-5, “Transition Implementation Guide,” U.S. Department of Energy.

Idaho National Laboratory Materials and Fuels Complex HWMA/RCRA Partial Permit PER-116, Environmental Protection Agency Number ID4890008952, dated August 16, 2004, and modified on October 2, 2008.

INL, 2010a, Facilities Condition and Hazards Assessment for Materials and Fuels Complex Facilities MFC-799, 799A, and 770C, INL/EXT-09-17292, Revision 1, Idaho National Laboratory, June 2010.

INL, 2010b, Hazardous Materials Verification and Limited Characterization Report on Sodium and Caustic Residuals in Materials and Fuel Complex Facilities MFC-799/799A, INL/EXT-10-19590, Idaho National Laboratory, August 2010. 
PLN-3352, "Transition Plan for Multiple Facilities at the Material and Fuels Complex, Advanced Test Reactor, Central Facilities Area, and Power Burst Facility," Revision 1, Idaho National Laboratory, March 3, 2010.

U.S. Department of Energy National Nuclear Security Administration to U.S. Department of Energy Idaho Operations Office letter, "Approval to Ship Battelle Energy Alliance (BEA) Low-Level Radioactive Waste to the Nevada Test Site (NTS)," dated August 20, 2010. 


\section{Appendix A}

Facilities Condition and Hazards Assessment Report 
Facilities Condition and Hazards Assessment for Materials and Fuel Complex Facilities MFC-799, 799A, and 770C

June 2010 


\section{DISCLAIMER}

This information was prepared as an account of work sponsored by an agency of the U.S. Government. Neither the U.S. Government nor any

agency thereof, nor any of their employees, makes any warranty, expressed or implied, or assumes any legal liability or responsibility for the accuracy,

completeness, or usefulness, of any information, apparatus, product, or

process disclosed, or represents that its use would not infringe privately

owned rights. References herein to any specific commercial product,

process, or service by trade name, trade mark, manufacturer, or otherwise,

does not necessarily constitute or imply its endorsement, recommendation,

or favoring by the U.S. Government or any agency thereof. The views and

opinions of authors expressed herein do not necessarily state or reflect

those of the U.S. Government or any agency thereof. 
INL/EXT-09-17292

Revision 1

Facilities Condition and Hazards Assessment for Materials and Fuel Complex Facilities MFC-799, 799A, and $770 \mathrm{C}$

\author{
June 2010 \\ Idaho National Laboratory \\ Idaho Falls, Idaho 83415 \\ Prepared for the \\ U.S. Department of Energy \\ Office of Nuclear Energy \\ Under DOE Idaho Operations Office \\ Contract DE-AC07-05ID14517
}




\section{ABSTRACT}

The Materials and Fuel Complex (MFC) facilities MFC-799, Sodium Processing Facility (a single building consisting of two areas: the Sodium Process Area and the Carbonate Process Area); MFC-799A, Caustic Storage Area; and MFC-770C, Nuclear Calibration Laboratory, have been declared excess to future Department of Energy Office of Nuclear Energy mission requirements. Transfer of these facilities from NE to the Department of Energy Office of Environmental Management, and an associated schedule for doing so, have been agreed upon by the two offices. The prerequisites for this transfer are removal of nonexcess materials and chemical inventory, deinventory of the calibration source in $\mathrm{MFC}-770 \mathrm{C}$, and rerouting or isolation of utility and service systems.

This report provides a description of the current physical condition and any hazards (material, chemical, nuclear, or occupational) that may be associated with past operations of these facilities. This information will document the conditions at the time of transfer of the facilities from the Office of Nuclear Energy to the Office of Environmental Management and will serve as the basis for disposition planning. The process used in obtaining this information included document searches, interviews, and facility walk-downs.

MFC-799, 799A, and 770C are all structurally sound and associated hazardous or potentially hazardous conditions are well defined and well understood. All installed equipment items (e.g., tanks and filters) used to process hazardous materials remain in place and appear to have maintained their integrity. There is no evidence of leakage and all openings are properly sealed or closed off and connections are sound. The pits appear clean with no evidence of cracking or deterioration that could lead to migration of contamination.

Based on the available information/documentation reviewed and the overall conditions observed during the facility walk-downs, it is concluded that these facilities may be disposed of at minimal risk to human health and safety and the environment 


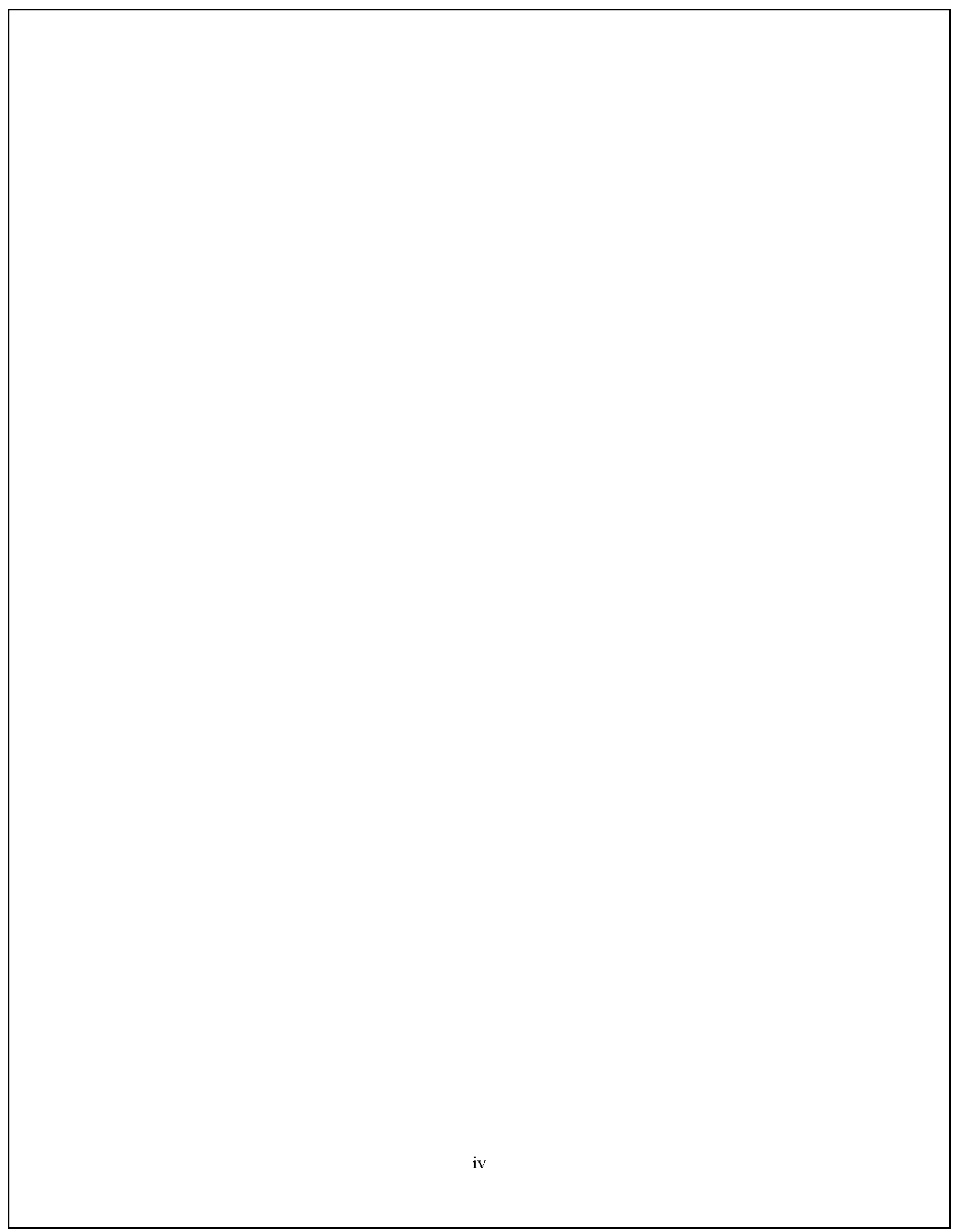

A-6 


\section{CONTENTS}

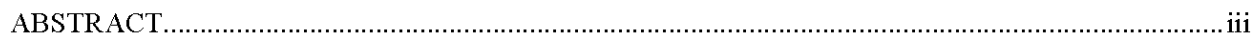

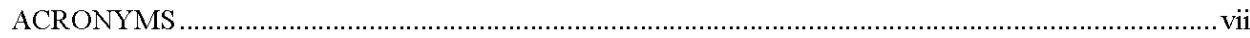

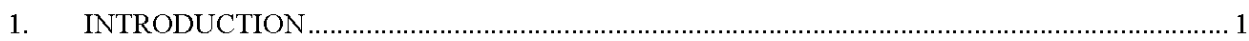

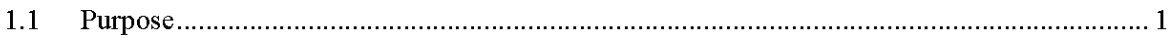

1.2 Location and Boundaries of Facilities Being Transferred .............................................. 1

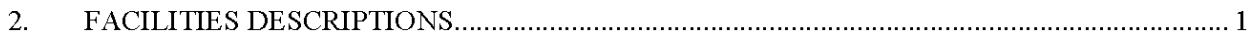

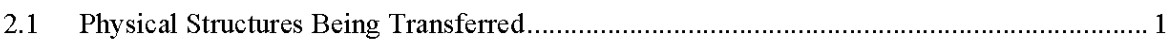

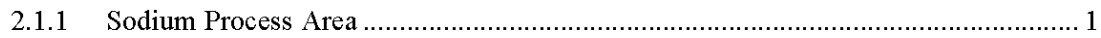

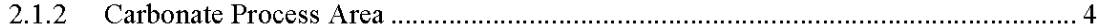

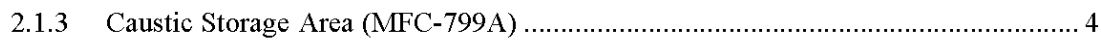

2.1.4 Nuclear Calibration Laboratory (MFC-770C) …................................................ 4

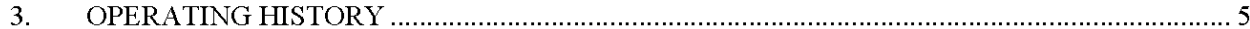

3.1 Sodium Process Facility Basic Process Description ....................................................... 5

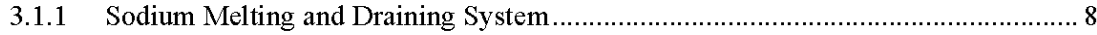

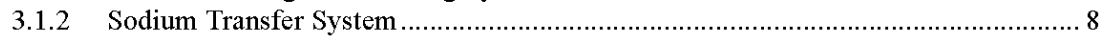

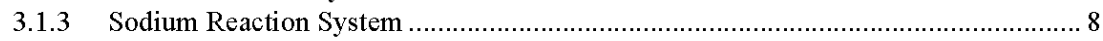

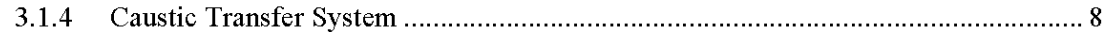

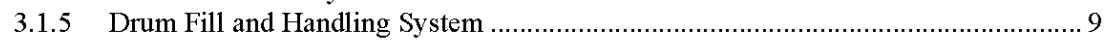

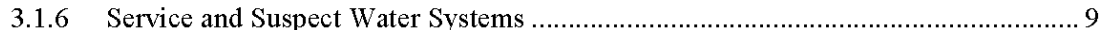

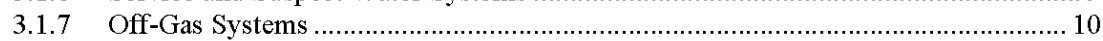

3.2 Caustic Storage Area Process Description .................................................................. 12

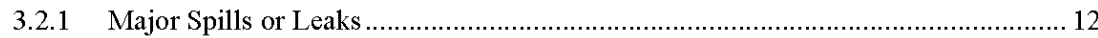

3.3 Nuclear Calibration Laboratory Basic Process Description.............................................. 12

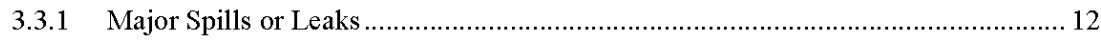

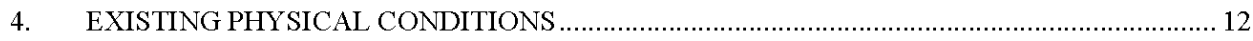

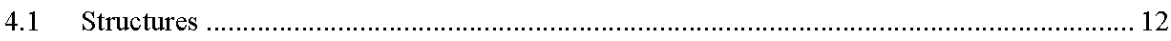

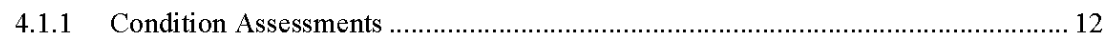

4.1.2 Engineered Protective Barriers and Systems ..................................................... 12

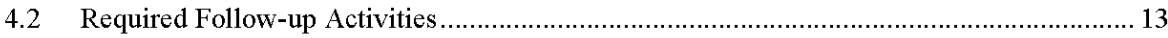

5. EXISTING HAZARDOUS RADIOLOGICAL AND CHEMICAL CONTAMINATION............. 13 


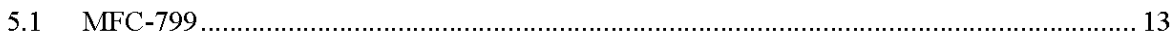

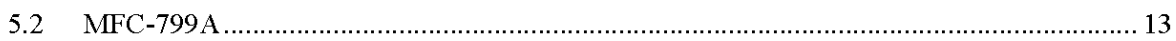

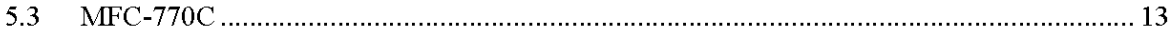

6. SPECIAL NUCLEAR AND FISSIONABLE MATERIALS INVENTORY ...........................13

7. HAZARDOUS MATERIALS, WASTE, AND CHEMICAL INVENTORIES .........................14

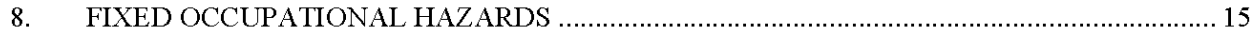

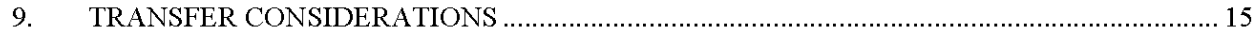

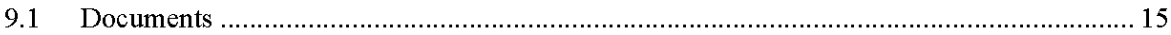

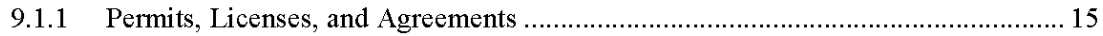

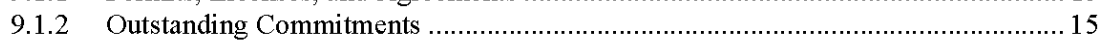

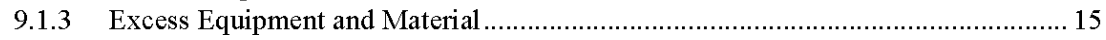

9.2 Stabilization and Other Required Actions Required for Transfer ................................ 16

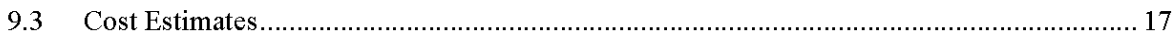

10. SUMMARY, CONCLUSIONS, AND RECOMMENDATIONS ....................................... 18

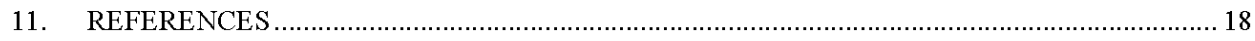

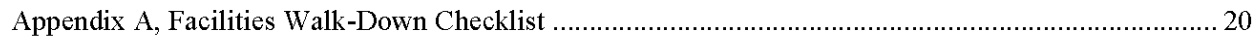

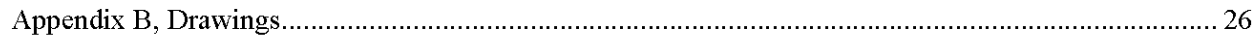

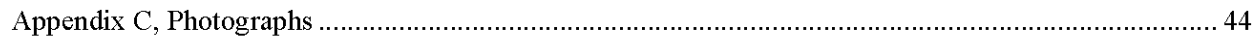

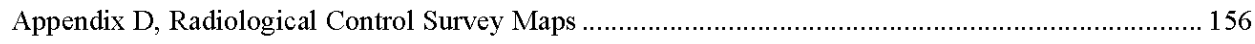

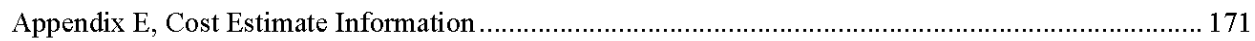

\section{FIGURES}

1. Location of facilities being transferred at the Materials and Fuels Complex ........................ 2

\section{TABLES}

1. Sodium Processing Facility summary operations details ......................................... 6

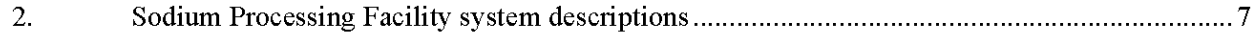

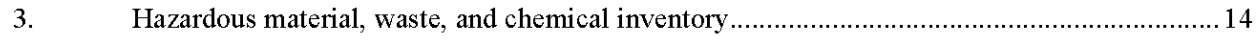




\section{ACRONYMS}

DOE Department of Energy

EBR-II Experimental Breeder Reactor-II

EM Office of Environmental Management (DOE)

HEPA high-efficiency particulate air

INL Idaho National Laboratory

MFC Materials and Fuels Complex

$\mathrm{Na} \quad$ sodium

NaK sodium-potassium

$\mathrm{NE} \quad$ Office of Nuclear Energy (DOE)

RCRA Resource Conservation and Recovery Act 


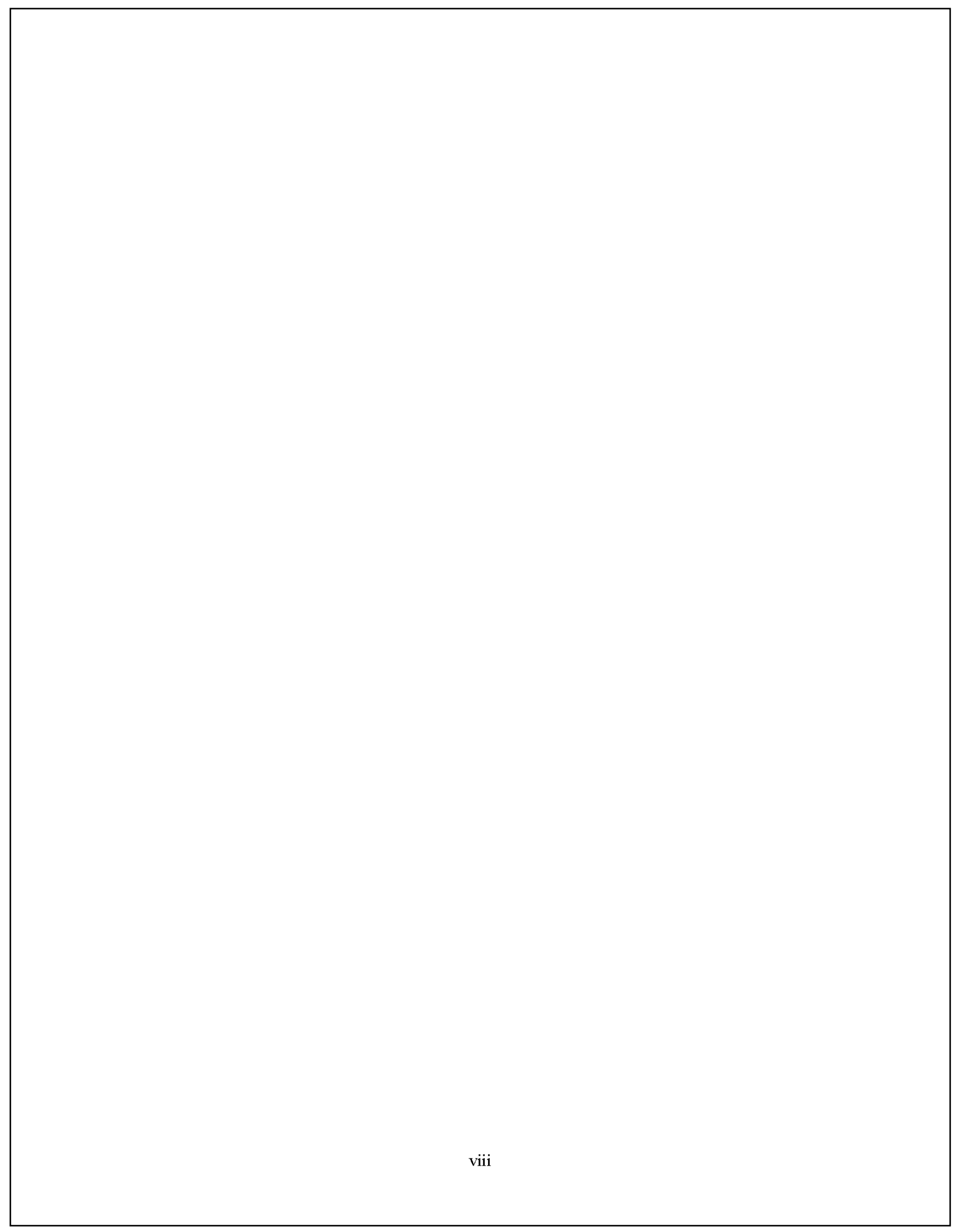

A-10 


\section{Facilities Condition and Hazards Assessment for Materials and Fuel Complex Facilities MFC-799, 799A, and $770 \mathrm{C}$}

\section{INTRODUCTION}

\subsection{Purpose}

The purpose of this report is to provide a detailed description of the Materials and Fuel Complex (MFC) facilities MFC-799, Sodium Processing Facility (a single building consisting of two areas: the Sodium Process Area and the Carbonate Process Area); MFC-799A, Caustic Storage Area; and MFC-770C Nuclear Calibration Laboratory. It also provides details of their current physical condition and any hazards (material, chemical, nuclear, or occupational) that may be associated with past operations. This information will document the conditions at the time of transfer of the facilities from the U.S. Department of Energy (DOE) Office of Nuclear Energy (NE) to the DOE Office of Environmental Management (EM) and will serve as the basis for disposition planning. The process used in obtaining this information included document searches, interviews, and facility walk-downs. A copy of the facility walk-down checklist is included in Appendix A of this report.

\subsection{Location and Boundaries of Facilities Being Transferred}

These structures as shown in Figure 1 are all part of or adjacent to the Sodium Processing Facility (SPF), which is located in the northwest corner of the MFC complex at the Idaho National Laboratory (INL) and are fairly isolated from the adjoining structures and facilities.

\section{FACILITIES DESCRIPTIONS}

\subsection{Physical Structures Being Transferred}

The Sodium Processing Facility (Building MFC-799) consists of one building with two designated areas used for hazardous waste/mixed waste container and tank storage, repackaging, and treatment. The two areas are the Sodium Process Area and the Carbonate Process Area. MFC-799A, Caustic Storage Area, consists of a single building containing a caustic storage tank over a spill containment pit and associated piping and pumping equipment. A separate exterior carbonate storage tank rests on a concrete pad next to the building. The Nuclear Calibration Laboratory (MFC-770C) is a $240-\mathrm{ft}^{2}$ single structure that is not directly associated with the operations or function of the Sodium Processing Facility. However, it is adjacent to these facilities and excess to mission requirements. Therefore, it is included in this transfer as a matter of efficiency. Descriptions of each building are provided in the following subsections.

\subsubsection{Sodium Process Area}

The Sodium Process Area was used for storage and treatment of hazardous waste/mixed waste in both containers and tanks. This area consists of an original four-roomed, L-shaped structure. An enclosed and covered, carbon steel-lined, concrete pad was later constructed where process equipment is located. The building is supported on a thickened-edge, reinforced-concrete pad. Three rooms in the Sodium Process Area were used for hazardous waste/mixed waste storage and treatment: the Barrel Holding Room, Sodium Melting and Draining Room, and Sodium Process Equipment Room. The fourth room is the Sodium Processing Facility Control Room. Each of these rooms is described briefly in the following subsections. Approximate overall dimensions of the enclosed Sodium Process Area are $65 \times 57 \mathrm{ft}$. Most 
of the exterior of the Sodium Processing Facility is constructed of galvanized-steel siding and roof panels on a structural steel frame. However, the Sodium Melting and Draining Room (the central room along the north wall) has 12 -in. thick reinforced-concrete block walls and an 8-in. thick reinforced-concrete slab roof.

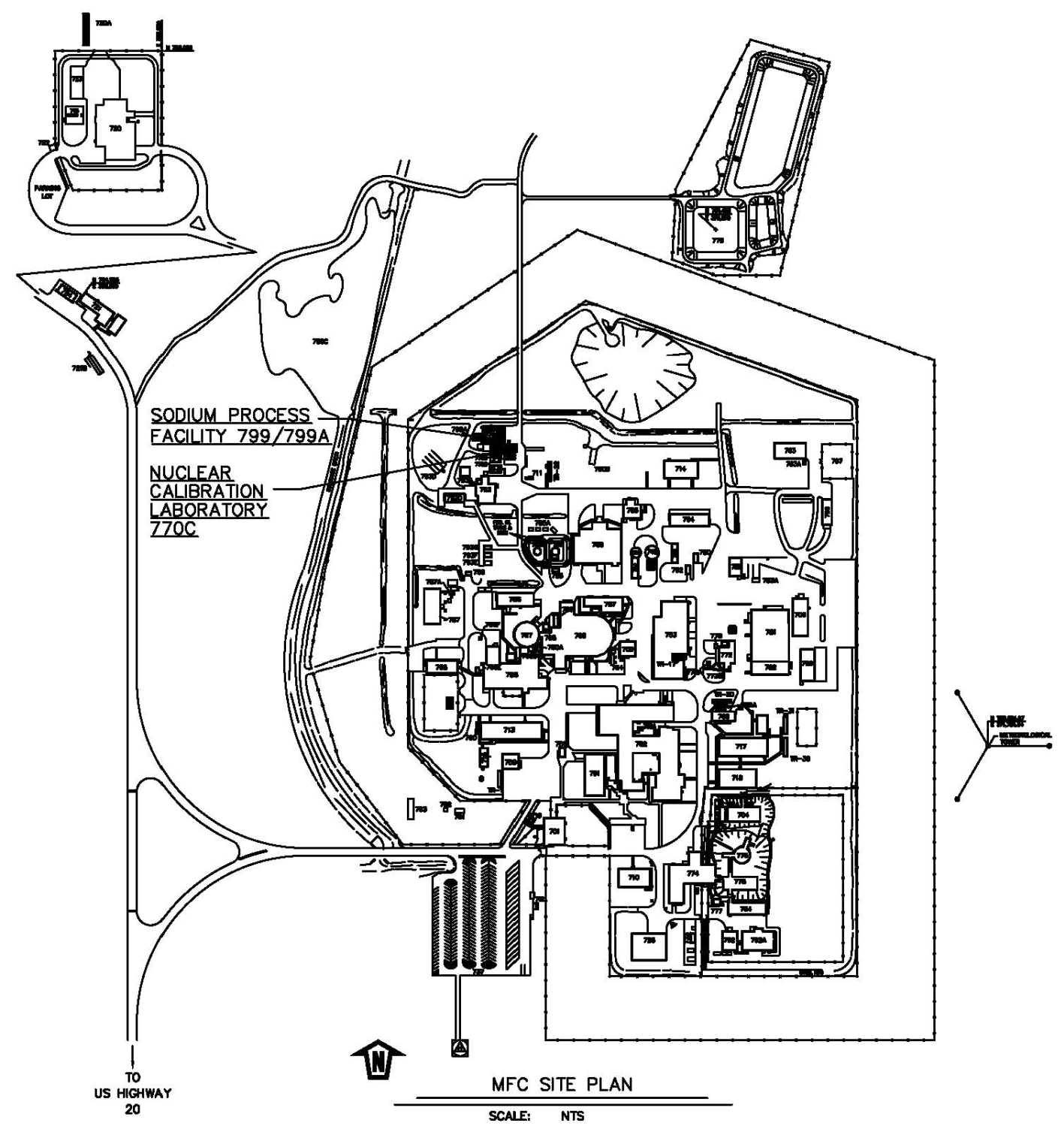

Figure 1. Location of facilities being transferred at the Materials and Fuels Complex. 
2.1.1.1 Barre/ Holding Room. The Barrel Holding Room was used to receive (store up to) 32 drums of hazardous waste/mixed waste. The dimensions of the room are $20 \mathrm{ft} 6 \mathrm{in} . \times 25 \mathrm{ft}$. The hazardous waste/mixed waste was brought into this area through a $10 \times 10$-ft sliding service door (east exterior wall), removed from the skid where they were received, and placed onto individual barrel dollies. Once placed on the dollies, the drums were moved into the Sodium Melting and Draining Room (the Sodium Processing Facility typically processed sodium $[\mathrm{Na}]$ and sodium-potassium $(\mathrm{NaK})$ alloy waste, but was permitted to process other alkali metals) through a $6 \times 6-\mathrm{ft}$ sliding door on the west wall of the Barrel Holding Room. In addition, the Barrel Holding Room also was the pathway for removal of the drained drums from the Sodium Melting and Draining Room as discussed in the next section. A 1,000-1b lift capacity jib crane is available for moving full drums (as needed) for sodium processing activities and maintenance support.

2.1.1.2 Sodium Melting and Draining Room. The Sodium Melting and Draining Room was used to melt and drain drums of alk ali metal hazardous waste/mixed waste. The dimensions of the room are $25 \times 22 \mathrm{ft}$. There were eight barrel container assemblies used to hold the drums of hazardous waste/mixed waste (typically $\mathrm{Na}$ and $\mathrm{NaK}$ ) while they melted and drained. There is a bridge crane used to transfer the drums into the barrel container assemblies. The crane has a capacity of $1,000 \mathrm{lb}$ and coverage of $15 \mathrm{ft}$ laterally and $18 \mathrm{ft}$ along the rail. The barrel container assemblies are arranged in two banks of four. A barrel draining manifold, which is insulated, served each of the two banks of four barrel assemblies. A flexible, stainless-steel line is provided at each barrel container assembly to connect the drum to the manifold. Each manifold (Manifold "A" on north side, Manifold "B" on south) is constructed of 3/4-in., Series-300, stainless steel pipe. A nitrogen purge is provided for each of the flexible barrel drain lines. The two barrel draining manifolds are combined into an insulated 1-in., Series-300, stainless-steel pipe, and, in turn, connected to the 5,000-gal sodium storage tank. The manifolds and 1-in. pipe are all sloped to drain into the 5,000-gal sodium storage tank. One drum can be drained through each manifold simultaneously.

2.1.1.3 Sodium Process Equipment Area. The Sodium Process Equipment Area was used to store and treat alkali metal hazardous waste/mixed waste. There are several major components in the sodium process area, including a 5,000-gal sodium storage tank, two 730-gal sodium day tanks (Tank A on west side, Tank B on east), sodium reaction vessel, 1,000-gal caustic cooling tank, 4,000-gal caustic storage tank, and the caustic off-gas system. The dimensions of the area are approximately $20 \times 57 \mathrm{ft}$ in an L-shaped configuration. The process area floor is a concrete pad and the process area secondary containment pits are lined with welded 3/16-in. carbon-steel plate. The building is supported on a thickened-edge, reinforced-concrete pad.

The sodium storage tank is a carbon-steel tank that received alkali metal from the barrel drain stations. The storage tank filled the day tanks, which fed the alkali metal to the reaction vessel at a rate of approximately 0.75 to $1.0 \mathrm{gal} / \mathrm{min}$. The reaction vessel converted the alkali metal to a liquid hydroxide waste form, which was then loaded into drums and allowed to cool to solidify. The caustic cooling tank and the caustic storage tank allowed for storage of caustic during reaction vessel shutdowns. The caustic storage tank was used for backup storage only. The caustic storage tank is located in a separate building (MFC-799A) just west of the Sodium Process Equipment Area.

The caustic off-gas system is composed of several components designed to remove moisture, entrained caustic, and caustic vapor, and provides a vent path for hydrogen from the reaction vessel. The caustic off-gas system is located on the wall, in the southwest corner of the Sodium Process Equipment Area.

2.1.1.4 Control Room. The dimensions of the Control Room are approximately $20 \times 10 \mathrm{ft}$. The Sodium Processing Facility Control Room houses the control computer and input/output front-end computer. An 
operator was in attendance whenever the process system was in operation. The control computer was programmed to provide the control and operator interface for the Sodium Processing Facility that allowed control of system pressures, valves, temperatures, and so forth. More detailed information as to interlocks, pressure, level, and temperature controls is provided in Appendix A, the process description, and Subsection D-2(d) of the Resource Conservation and Recovery Act (RCRA) Permit.

The primary power distribution panel is located in the control room. It should be noted that this power distribution panel is used for the main power distribution to the Radioactive Waste Storage Facility, which is located about $800 \mathrm{ft}$ to the northeast of the Sodium Processing Facility. The Radioactive Waste Storage Facility is a Security Category 1 facility; therefore, the power must be maintained and controlled at all times.

\subsubsection{Carbonate Process Area}

The Carbonate Process Area is an addition to the Sodium Processing Facility and is adjoined to the original structure to the south. Doors allow access between the original Sodium Processing Facility and the Carbonate Process Area. The Carbonate Process Area accommodated equipment for filling drums and provided storage of the hydroxide solution while it solidified. The Carbonate Process Area includes approximately $23 \times 25 \mathrm{ft}$ of main processing area with an associated upper mezzanine level and a shielded staging area of approximately $17 \times 16 \mathrm{ft}$.

The building height in the main processing and staging areas is approximately $31 \mathrm{ft}$. The other wing of the L-shaped structure adds approximately $30 \times 72 \mathrm{ft}$ of drum storage and handling area with room for forklift operations. There are two 5-ton trolley cranes in this area that were used for supporting maintenance operations. The building height in the second wing is approximately $12 \mathrm{ft}$. The building is placed on a reinforced-concrete pad capable of supporting a uniform live load of $500 \mathrm{lb} / \mathrm{ft}^{2}$. All sections of the Sodium Processing Facility meet the requirements of the UBC and Seismic Zone 2 or 2B.

Storage of empty and filled hydroxide drums was provided by two storage bays in the southeast area of the Carbonate Process Area. The storage bays are placed on a reinforced concrete pad with cinder block walls. Roll-up doors provide access to the Carbonate Process Area side of each bay, and an external roll-up door is available on the west bay. Permanent carbon-steel pans provided secondary containment for the liquid caustic drums stored in the bays. Poly platforms were placed inside the pans to allow forklift operation in the secondary containment areas and to elevate the caustic drums off the floor.

\subsubsection{Caustic Storage Area (MFC-799A)}

The Caustic Storage Area is a pre-engineered metal building that was added as part of the 1996 Sodium Processing Facility upgrade in support of the Experimental Breeder Reactor-II (EBR-II) shutdown. This conversion is discussed in detail in the following subsection. The facility is a single story, single room structure used to house a 4,000-gal storage tank within a containment pit and the associated piping and pumping equipment. There also is an external storage tank located on a concrete pad adjacent to the building. The exterior storage tank was never used.

\subsubsection{Nuclear Calibration Laboratory (MFC-770C)}

The Nuclear Calibration Laboratory is a $240-\mathrm{ft}^{2}$, single story facility constructed in the mid-1960s. MFC-770C houses a JL Sheperd Model 81-12 Beam Calibrator (Serial No. 540) and Model 155 Attenuator System (Serial No. 783), as well as a Cs-137 Source. This Cs-137 source was validated to be $200 \mathrm{Ci}$ on August 19, 1975. Based on a 30.3-year half-life, the Cs-137 Source should be approximately 94 $\mathrm{Ci}$ in strength. 


\section{OPERATING HISTORY}

\subsection{Sodium Process Facility Basic Process Description}

The Sodium Processing Facility was originally designed and built in the 1980 s for reacting the $290 \mathrm{~m}^{3}(77,000 \mathrm{gal})$ of primary sodium from the Fermi-1 Reactor in Detroit, Michigan, into a $50 \mathrm{wt} \%$ sodium hydroxide solution. This solidified sodium had been stored in 55-gal drums at Argonne National Laboratory-West (is now MFC) near Idaho Falls, Idaho since the early 1970s.

The sodium hydroxide was scheduled to be used to neutralize acid produced in the PUREX process at the Hanford site in Washington State. Because of a change in the PUREX mission, the sodium hydroxide was no longer required and the mission was abandoned before the Sodium Processing Facility became operational.

With the shutdown of EBR-II, the necessity for a facility for reacting the primary and secondary sodium was identified. In 1996, Argonne National Laboratory-West engineering and operations undertook the task of upgrading the existing Sodium Processing Facility to convert the sodium hydroxide to a dry, nonhazardous sodium carbonate waste that is acceptable for burial in the State of Idaho. Using thin film evaporator technology, the $50 \mathrm{wt} \%$ sodium hydroxide was combined with carbon dioxide in the reaction section of the thin film evaporator to form sodium carbonate product and water.

The sodium carbonate product and water were heated in the evaporation section of the thin film evaporator to remove the water and dry the sodium carbonate product into a powder. After testing the thin film evaporator for approximately 1 year, it was determined that this technology was not suitable due to plugging of equipment, minimal throughput, and powder containment issues. In 1998, it was decided to convert the sodium to a $70 \mathrm{wt} \%$ sodium hydroxide, a substance that solidifies at $65^{\circ} \mathrm{C}\left(150^{\circ} \mathrm{F}\right)$ and is acceptable for burial in Idaho.

The Sodium Processing Facility was modified and initial testing of the new process was successfully completed in November 1998 with nonradioactive sodium. Full production operations with FERMI sodium began on December 20, 1998.

Sodium could be introduced into the Sodium Processing Facility from two sources. The first source was the 208-L (55-gal) FERMI-1 barrels, which were melted and drained at the Sodium Processing Facility. The second source was the EBR-II primary and secondary sodium, which was transferred to the Sodium Processing Facility through a transfer line. The sodium was then injected into a nickel reaction vessel into a $70 \mathrm{wt} \%$ solution of sodium hydroxide. Water also was injected, maintaining the $70 \mathrm{wt} \%$ concentration by controlling the boiling point of the solution.

The sodium hydroxide was transferred from the reaction vessel into specially fabricated 269-L (71-gal) square drums, four to a pallet, and allowed to cool. The square drums occupied the same volume as the standard 208-L (55-gal) cylindrical drums; however, the square drums maximized utilization of the space on a pallet, minimizing the landfill space required for disposal. As part of the hazardous waste permit, daily drum samples were required to ensure solid sodium hydroxide was produced.

After completion of the secondary sodium processing, drum sampling revealed some liquid in drums that should have been solid. Upon investigation, it was determined that the liquid was due to inadvertent water addition into the reaction vessel, which diluted the sodium hydroxide concentration. In addition, the process was operated at temperatures that were too low, causing the sodium hydroxide concentration to fall below $69 \mathrm{wt} \%$ (the sodium hydroxide monohydrate crystallization concentration). At the lower sodium hydroxide concentration, not all of the solution solidifies at nominal ambient temperatures. 
The Sodium Processing Facility was shutdown in August 1999 to undergo upgrades to the process to ensure the cooled product drums solidify and liquid is not present. Process system upgrades included increasing the operating temperature from $177^{\circ} \mathrm{C}\left(350^{\circ} \mathrm{F}\right)$ to $191^{\circ} \mathrm{C}\left(375^{\circ} \mathrm{F}\right)$ and installing physical and computer controls to prevent inadvertent water addition. During this shutdown, modifications to the off-gas system also were performed. Sodium hydroxide carryover in the off-gas system attacked the borosilicate glass high-efficiency particulate air (HEPA) filters and required replacement after approximately 7 days. Off-gas system modifications included changing the HEPA filter media to Teflon, which is resistant to sodium hydroxide, and installing parallel HEPA filters to increase the operating time between HEPA filter changeouts.

The sodium was scheduled to be processed in five separate and distinct campaigns, based on their radiation levels. The FERMI-1 and EBR-II secondary sodium contained only low levels of radiation, while the EBR-II primary sodium had radiation levels of approximately 40 millirem per hour at 1 meter. Approximately $145 \mathrm{~m}^{3}$ ( $38,000 \mathrm{gal}$ ) of FERMI-1 primary sodium was processed initially to gain operator experience with the least radioactive sodium. Second, all of the $50 \mathrm{~m}^{3}(13,000 \mathrm{gal})$ EBR-II secondary sodium was processed. Next, approximately 106 to $125 \mathrm{~m}^{3}$ (28,000 to 33,000 gal) of FERMI-1 primary sodium was processed to validate modifications made to the Sodium Processing Facility. This was scheduled to start in June 2000 . Fourth, all of the $330 \mathrm{~m}^{3}(87,000$ gal) of EBR-II primary sodium was processed. Finally, the remaining FERMI-1 primary sodium, approximately 20 to $39 \mathrm{~m}^{3}(5,000$ to $10,000 \mathrm{gal}$ ) was processed as a flush of the Sodium Processing Facility systems.

In March 2001, the Sodium Processing Facility was placed in standby pending decisions on sodium treatment associated with the Remote Treatment Project/Remote-Handled Waste Disposition Project.

Table 1 summarizes the information related to materials handled and the various vessels used in the conversion of sodium to sodium hydroxide.

Table 1. Sodium Processing Facility summary operations details.

\begin{tabular}{|c|c|}
\hline Allowed Waste Types & $\begin{array}{l}\text { Sodium Processing Facility Sodium Storage Tank: Ignitable reactive, corrosive, or } \\
\text { toxic metal waste: Na NAK, NAOH, KOH } \\
\text { Sodium Day Tanks (2): Ignitable reactive, corrosive, or toxic metal waste: NA NAK, } \\
\text { NAOH, KOH } \\
\text { Sodium Reaction Vessel: Toxic metal waste: NA NAK, NAOH, KOH } \\
\text { Caustic Cooling Tank: Na NAK, NAOH, KOH } \\
\text { Sodium Processing Facility Caustic Storage Tank: Na NAK, NAOH, KOH } \\
\text { Water Holding Tank: Corrosive or toxic metal waste }\end{array}$ \\
\hline Hazardous Waste Codes & $\begin{array}{l}\text { Sodium Processing Facility Sodium Storage Tank: D001, D002, D003 } \\
\text { Sodium Day Tanks (2): D001, D003 } \\
\text { Sodium Reaction Vessel: D001, D002, D003 } \\
\text { Caustic Cooling Tank: D002 } \\
\text { Sodium Processing Facility Caustic Storage Tank: D002 } \\
\text { Water Holding Tank: D002 }\end{array}$ \\
\hline Process Codes & $\begin{array}{l}\text { Sodium Processing Facility Sodium Storage Tank: S02 } \\
\text { Sodium Day Tanks (2): S02 } \\
\text { Sodium Reaction Vessel: T01 } \\
\text { Caustic Cooling Tank: S02 } \\
\text { Sodium Processing Facility Caustic Storage Tank: S02 } \\
\text { Water Holding Tank: S02 }\end{array}$ \\
\hline
\end{tabular}


Table 1. (continued).

\begin{tabular}{|c|c|}
\hline Maximum Volume & $\begin{array}{l}\text { Sodium Processing Facility Sodium Storage Tank: } 5,000 \text { gal }(24 \text {-ft long } \times 6 \text {-ft } \\
\text { diameter) } \\
\text { Sodium Day Tanks (2): } 730 \text {-gal each }(10 \text {-ft high } \times 4 \text {-ft diameter) } \\
\text { Sodium Reaction Vessel: 1,080-gal }(11.5 \text {-ft high } \times 4 \text {-ft diameter) } \\
\text { Caustic Cooling Tank: } 4,000 \text {-gal (13-ft long } \times 7 \text {-ft diameter) } \\
\text { Sodium Processing Facility Caustic Storage Tank: 4,000-gal }(13 \text {-ft long } \times 7 \text {-ft } \\
\text { diameter) } \\
\text { Water Holding Tank: } 500 \text {-gal }(7.33 \text {-ft high } \times 4 \text {-ft diameter) }\end{array}$ \\
\hline $\begin{array}{l}\text { Tank Construction } \\
\text { Material }\end{array}$ & $\begin{array}{l}\text { Sodium Processing Facility Sodium Storage Tank: Carbon steel ( } 0.25 \text { in.) } \\
\text { Sodium Day Tanks (2): Carbon steel ( } 0.25 \text { in.) } \\
\text { Sodium Reaction Vessel: S-200 nickel ( } 0.25 \text { in.) } \\
\text { Caustic Cooling Tank: S-200 nickel ( } 0.13 \text { in.) } \\
\text { Sodium Processing Facility Caustic Storage Tank: S-300 stainless steel (0.25 in.) } \\
\text { Water Holding Tank: S-304 stainless steel (10 gauge) }\end{array}$ \\
\hline Activities Allowed & Storage, deactivation (ignitable/reactives), melt/drain, and neutralization \\
\hline $\begin{array}{l}\text { Secondary Containment } \\
\text { System Description }\end{array}$ & $\begin{array}{l}\text { Sodium Processing Facility Sodium Storage Tank and Sodium Day Tanks (2): Carbon } \\
\text { steel }(0.19 \text { in.) over sand floor and concrete walls }- \text { dimensions: } 41 \mathrm{ft} \times 16 \mathrm{ft} \times 1.5 \mathrm{ft}- \\
\text { capacity: } 7,360 \text {-gal } \\
\text { Sodium Reaction Vessel and Caustic Cooling Tank: Type }- \text { Carbon steel-lined } \\
(0.19 \mathrm{in} \text {.) compacted-sand floor pit and formed concrete walls - dimensions: } 21.5 \mathrm{ft} \times \\
13 \mathrm{ft} \times 14 \mathrm{ft}-\text { capacity: } 2,440 \text {-gal } \\
\text { Sodium Processing Facility Caustic Storage Tank: Type }- \text { carbon-stee } 1 \text { lined - } \\
\text { dimensions: } 12 \mathrm{ft} \times 17 \mathrm{ft} \times 3 \mathrm{ft}-\text { capacity: } 4,580 \text {-gal } \\
\text { Water Holding Tank: Capacity - drain into the Caustic Tank Pit. Caustic Tank Pit: } \\
\text { 2,440-gal - dimensions: } 21.5 \mathrm{ft} \times 13 \mathrm{ft} \times 14 \mathrm{ft}\end{array}$ \\
\hline
\end{tabular}

Table 2 provides a reference to major system drawings and photographs contained in Appendices B and $C$, respectively.

Table 2. Sodium Processing Facility system descriptions.

\begin{tabular}{|l|l|l|}
\hline \multicolumn{1}{|c|}{ System } & \multicolumn{1}{|c|}{ Drawings } & \multicolumn{1}{c|}{ Photos } \\
\hline $\begin{array}{l}\text { Sodium Process Facility General } \\
\text { Arrangement } \\
\text { Sodium Process Flow Diagram }\end{array}$ & $\begin{array}{l}\text { W7990-0207-ED-01 } \\
\text { E5274-0006-ED-06 }\end{array}$ & P1015404 through -444 \\
\hline Sodium Drum Melting and Draining System & E5274-0047-ED-01 & $\begin{array}{l}\text { P1015389 through -394 and - } \\
402\end{array}$ \\
\hline Drum Fill and Handling Systems & W7990-0229-ED-01 & $\begin{array}{l}\text { P1015298 through -300, -302, } \\
\text { and -307 }\end{array}$ \\
\hline Service and Suspect Water Systems & E5274-0179-ED-07 & P1015405 and -415 \\
\hline Off-Gas Systems & E5274-0054-ED-06 & $\begin{array}{l}\text { P1015318, -319, -321, -330, } \\
-337, \text { and }-343\end{array}$ \\
\hline Steam and Condensate System & E5274-0180-ED-03 & P1015312 and -322 \\
\hline Nitrogen System & E5274-0049-ED-08 & P1015392, -401, -402, and -414 \\
\hline
\end{tabular}

The following subsections provide information regarding the major systems for the Sodium Processing Facility. 


\subsubsection{Sodium Melting and Draining System}

Containerized $\mathrm{Na} / \mathrm{NaK}$ generally arrived at Sodium Processing Facility in 55-gal drums. The sodium melting and draining system was used to do the following:

- Melt $\mathrm{NA} / \mathrm{NaK}$ (which is solid at room temperature) in its storage container

- Remove $\mathrm{Na} / \mathrm{NaK}$ from its storage container

- Transfer it to the 5,000-gal sodium storage tank.

The same process occurred for the $\mathrm{NaK}$, except $\mathrm{NaK}$ is liquid at room temperature; therefore, "melting" NaK was not necessary. The transfer of containerized liquid $\mathrm{Na} / \mathrm{NaK}$ was by vacuum pump to the 5,000-gal sodium storage tank.

\subsubsection{Sodium Transfer System}

The sodium transfer system was used to transfer the waste $(\mathrm{Na} / \mathrm{NaK})$ from the 5,000-gal sodium storage tank to the 730 -gal sodium day tanks. Following completion of the melting and draining operation from the drums to the 5,000-gal sodium storage tank, the 5,000-gal sodium storage tank was pressurized with nitrogen. The pressurization provided the driving force to transfer the $\mathrm{Na} / \mathrm{NaK}$ from the 5,000 -gal sodium storage tank to the selected 730 -gal sodium day tank. The transfer rate was approximately 39 gallons per minute.

\subsubsection{Sodium Reaction System}

The sodium reaction system was used to do the following:

- Transfer $\mathrm{Na} / \mathrm{NaK}$ from the 730 -gal sodium day tanks to the 2,440 -gal reaction vessel, where it was converted to a hydroxide solution

- Transfer hydroxide to the drum fill station

- Transfer $50 \mathrm{wt} \%$ hydroxide to the 1,000 -gal caustic cooling tank and from the caustic cooling tank to the reaction vessel during startup.

When the reaction vessel was in operation, the 730-gal sodium day tank supplying the waste to the reaction vessel was pressurized with nitrogen gas. This provided the driving force for the $\mathrm{Na} / \mathrm{NaK}$ transfer and injection into the reaction vessel.

In the reaction vessel, the $\mathrm{Na} / \mathrm{NaK}$ reacted with water to produce sodium hydroxide/potassium hydroxide and hydrogen $\left(\mathrm{H}_{2}\right)$. Reaction: $\mathrm{Na}+2 \mathrm{H}_{2} \mathrm{O}+$ caustic $=>\mathrm{NaOH}+\mathrm{KOH}+\mathrm{H}_{2}$.

Nitrogen/steam was introduced into the injection nozzles to atomize the $\mathrm{Na} / \mathrm{NaK}$ upon injection into the reaction vessel to ensure the $\mathrm{Na} / \mathrm{NaK}$ would react completely beneath the surface of the hydroxide solution. The nitrogen left the reaction vessel via the caustic off-gas system along with the reaction-produced hydrogen and some water vapor.

The hydroxide in the reaction vessel was recirculated with approximately 1 to 2 gallons per minute of the 8 to 10 gallons per minute recirculated solution continuously diverted to either the drum fill station (during operation) or to the 1,000-gal caustic cooling tank (during shutdown operations).

\subsubsection{Caustic Transfer System}

The caustic transfer system began at the reaction-vessel solution caustic recirculation pump and piping where a portion of the hydroxide being recirculated was diverted to the drum fill station or to the 
1,000-gal caustic cooling tank. The caustic metering pump transferred the $50 \mathrm{wt} \%$ hydroxide solution form the 1,000-gal caustic cooling tank directly to the reaction vessel upon startup, or if backup hydroxide storage was needed. The 4,000-gal caustic storage tank was used (in an emergency only) to transfer hydroxide solution to or from the caustic storage tank to the reaction vessel. The caustic recirculation pump, metering pump, and the caustic cooling tank are located in the sodium process area and the caustic storage tank and caustic transfer pump are housed in MFC-799A, a building on the west side of Sodium Processing Facility.

\subsubsection{Drum Fill and Handling System}

The hydroxide solution was transferred to the drum fill station through a concentric pipe heat exchanger. The heat exchanger is an inner pipe (nickel) for high-temperature hydroxide and an outer pipe (stainless steel) for the coolant (water).

The high-temperature hydroxide (i.e., 360 to $375^{\circ} \mathrm{F}$ ) flowed from the caustic recirculation line to the drum fill station. At the drum fill station, the hydroxide exited into the drums at an approximate temperature of 200 to $225^{\circ} \mathrm{F}$. The reduction of the hydroxide temperature was by the counter-flow of coolant (water). Heat was removed from the cooling medium of the concentric pipe heat exchanger system via a shell and tube water heat exchanger.

The suspect exhaust off-gas system collected vapors from the enclosures (hood) for the drum fill and capping stations. From the hoods, the effluent (consisting mainly of minute quantities of hydroxide vapor and potentially some entrained particulate) was exhausted through a baghouse and HEPA filter to the atmosphere.

The product from the caustic transfer system was placed in drums via the drum fill and handling system, which included the drum filling station, capping station, survey and decontamination station, drum palletizing area, and storage areas.

\subsubsection{Service and Suspect Water Systems}

Two separate water systems - the service and suspect water systems - comprised the Sodium Processing Facility water system. The service water system was a clean potable water system and had the following two main functions in the sodium process area:

- Cooled the off-gas condenser

- Served as a heat sink for the shell and tube (concentric pipe) heat exchanger.

The service water supply delivers water to Sodium Processing Facility at approximately $100 \mathrm{psig}$ through galvanized-steel piping.

The suspect water system was potentially contaminated with radioactive constituents from the processed $\mathrm{Na} / \mathrm{NaK}$. Makeup water was supplied to a 500-gal holding water holding tank from the MFC deionized water system. [NOTE: This tank is shown on facility drawings, but was not observed on facility walk-down]. The suspect water system's main function was to provide water from the 500 -gal water holding tank for the following uses:

- Hydrolyze $\mathrm{Na} / \mathrm{NaK}$ in the reaction vessel

- Dewater and cleanse off-gas emissions from the reaction vessel

- Maintain water level in the scrubber. 
Sources of suspect water in the Sodium Processing Facility include the following:

- Condensed water vapor that is removed from the off-gas streams of the reaction vessel

- Water associated with cleanup activities associated with potentially-contaminated areas or surfaces.

The water system was used for cooling the vacuum pump inlets, off-gas condenser, caustic transfer system shell, tube heat exchanger, and for use in the scrubber.

\subsubsection{Off-Gas Systems}

Two separate off-gas systems were used to control effluent release from Sodium Processing Facility treatment operations. The system controlled effluents from the sodium process area and the suspect exhaust system controlled effluents from the sodium carbonate process area as described in the following subsections.

3.1.7.1 Caustic Off-Gas System. The caustic off-gas system was used to contain the gases and water vapor resulting from the conversion of $\mathrm{Na} / \mathrm{NaK}$ to hydroxides in the reaction vessel. It condensed and recovered water vapor for reuse and removed radioactive aerosol prior to the release of filtered gases to the atmosphere. Principle constituents in the caustic off-gas stream, as it exited the reaction vessel, were water vapor, hydrogen, and nitrogen. Hydrogen was a reaction product. Nitrogen was used to atomize the $\mathrm{Na} / \mathrm{NaK}$ in the reaction-vessel injection nozzles and to purge the reaction vessel to maintain low oxygen concentrations. The caustic off-gas system processed this stream and ultimately released hydrogen and nitrogen to the atmosphere and returned the condensed water vapor to the reaction process. Condensate was returned to the 500-gal water holding tank through a series of drain lines.

3.1.7.2 Suspect Exhaust System. The purpose of the suspect exhaust system was to control effluents that may be generated during the drum filling and capping processes. The off-gas consisted primarily of hydroxide vapor and particulate. The off-gas stream from the drum fill and capping stations exited the hoods surrounding the drum into the suspect exhaust system. This effluent was processed through a HEPA filtration system prior to release to the atmosphere. The effluent gas from the baghouse then passed through a HEPA filter that removed remaining particulate prior to discharge to the atmosphere.

3.1.7.3 Vent Systems. There are two independent vent systems associated with the Sodium Process Area (MFC-799) and 4,000-gal caustic storage tank (MFC-799A). All vent system piping is made of carbon steel. In the sodium process area, the vent systems collected gaseous effluents from all of the following tanks:

- 5,000-gal sodium storage tank

- 730-gal sodium day tanks

- 1,000 -gal caustic cooling tank

- 4,000-gal caustic storage tank

- 500-gal water holding tank.

Effluent from the 5,000-gal sodium storage tank included vacuum pump exhaust, normal operational venting, or effluent from the poppet check valve. Effluent from the 730 -gal sodium day tanks and 1,000-gal caustic cooling tank included normal operational venting or over-pressurization release from their respective poppet check valves. Effluent from the 500-gal water holding tank included normal operational venting through its own HEPA filter on top of the tank. These effluent streams vented to the caustic off-gas system upstream of the HEPA filters. 
In the sodium carbonate process area addition, the sources of effluents were the drum fill and capping station hoods. All vent piping in this area is made of stainless steel.

31.7.4 Steam and Condensate System. Steam was used for the following:

- Atomization of the $\mathrm{Na} / \mathrm{NaK}$

- Clearing of the injection nozzles in the reaction vessel in the sodium process area.

The 175-psig steam from the site steam supply was reduced in pressure to 30 to 50 psig for the injection process in the reaction. The steam system piping is made of carbon steel. Solenoid, ball, globe, and gate valves were used in the system. Relief valves provided overpressure protection.

3.1.7.5 Nitrogen System. Nitrogen gas was used in the sodium melting and draining room and sodium process area as follows:

1. Sodium Melting and Draining Room - Nitrogen was applied to the drums of $\mathrm{Na} / \mathrm{NaK}$ (while being heated) and flexible drain lines (when not in use). It was supplied at 3 to 5 in. $\mathrm{H}_{2} \mathrm{O}$.

2. Sodium Process Area - Nitrogen was used in the sodium process area to transfer sodium from the following:

a. $\quad 5,000$-gal sodium storage tank to the 730 -gal sodium day tanks (nitrogen was supplied at 15 psig)

b. $\quad 730$-gal sodium day tanks to the injection nozzles (nitrogen was supplied at 10 to $30 \mathrm{psig}$ ).

3.1.7.6 Support Systems. The support systems for operation of the Sodium Processing Facility are described in the following subsections.

3.1.7.6.1 Compressed Air System-The compressed air system was used to do the following:

- Operate the barrel tilting mechanism for the melting-draining operation

- Operate the pneumatically actuated valves in the $\mathrm{Na}$, caustic, and vacuum piping

- Operate the pneumatic tilting device to move drums of hydroxide to the drum palletizing area.

3.1.7.6.2 Heater System-The following five types of heaters were used throughout the process: drum strap-on heaters, disc heaters, strip heaters, mineral insulated wire, and heating tape.

3.1.7.6.3 Fire Suppression System-A fixed fire suppression system was provided in the sodium melting and draining room. Two ANSUL MET-L-X, Model 101-30, dry-powder fire extinguishers were provided to discharge through four modified ANSUL F-1 nozzles directly into each barrel container assembly. A single actuator was provided for each of these pairs of extinguishers. A fire hazard analysis of other Sodium Processing Facility areas determined that additional fire suppression systems were not required.

\subsubsection{Major Spills or Leaks}

There has been only one incident of a spill or leak that qualified for the filing of an Occurrence Report. It was a Na leak associated with a small crack at the root of the reducer connecting the 3/4-in. stainless steel piping to the $3 / 8$-in. nickel tubing for the sodium injection nozzle on the Sodium Reaction Vessel in MFC-799. Evaluation of the failed reducer by a materials characterization engineer confirmed the failure (crack) was fatigue induced by excessive movement in the piping runs from the sodium day tanks to the sodium reaction vessel. 
Approximately $4 \mathrm{oz}$ of sodium were leaked; the total amount was contained in the reaction vessel secondary containment. The sodium did not react and burn when exposed to air. The smoke appeared to come from the outside material of the pipe lagging. No hazardous material was released to the environment nor was the health and safety of personnel ever compromised.

Details of this occurrence may be found in Occurrence Report Number: NE-CH-AA-ANLW-EBR1999-0001, "Sodium Leak in the Sodium Process Facility."

There also was a small leak associated with the failure of the caustic pump. No Occurrence Report was filed as this failure happened during testing with clean caustic. The record of the leak is in the log book that will be turned over to CH2M-WG Idaho, LLC with the building.

\subsection{Caustic Storage Area Process Description}

The purpose of the Caustic Storage Area was to house the caustic storage tank, pump, and associated plumbing to transfer the caustic from the storage tank to MFC-799 for use in the sodium processing operation. The pad-mounted, exterior, caustic storage tank (A23-T-203) was intended to provide additional storage capacity, but it has never had any caustic or any other hazardous or radioactive material placed in it.

\subsubsection{Major Spills or Leaks}

There have been no spills or leaks associated with the Caustic Storage Area.

\subsection{Nuclear Calibration Laboratory Basic Process Description}

The laboratory was used to calibrate radiation detection/measurement instruments. The calibration equipment consists of a JL Sheperd Model 81-12 Beam Calibrator and Model 155 Attenuator System and a Cs-137 Source. This Cs- 137 source was validated to be $200 \mathrm{Ci}$ on August 19, 1975. Based on a 30.3 year half-life, the $\mathrm{Cs}-137$ source should be approximately $94 \mathrm{Ci}$ in strength.

\subsubsection{Major Spills or Leaks}

There have been no spills or leaks associated with the Nuclear Calibration Laboratory.

\section{EXISTING PHYSICAL CONDITIONS}

\subsection{Structures}

\subsubsection{Condition Assessments}

All facilities appear to be structurally sound and secure. There is no evidence of any damage or deterioration other than normal wear and tear incident to age and the normal effects of weather.

\subsubsection{Engineered Protective Barriers and Systems}

All installed equipment items (e.g., tanks and filters) used to process hazardous materials remain in place and appear to have maintained their integrity. There is no evidence of leakage and all openings are properly sealed or closed off and connections are sound. The pits appear clean with no evidence of cracking or deterioration that could lead to migration of contamination. 


\subsection{Required Follow-up Activities}

The MFC-799 and MFC-799A facilities are still covered under the MFC Hazardous Waste Management Act RCRA Storage and Treatment Permit, No. ID4890008952, dated August 16, 2004, and modified on October 2, 2008. Therefore, inspections related to these two facilities as specified in Appendix D of that permit will need to be complied with until such time as the facilities meet the RCRA Closure criteria. MFC-770C is not part of the RCRA permit.

The primary power line that supplies power to the Radioactive Waste Storage Facility will need to be rerouted prior to transition of ownership for the Sodium Processing Facility.

\section{EXISTING HAZARDOUS RADIOLOGICAL AND CHEMICAL CONTAMINATION}

MFC-799 and -799A both contain radiological and nonradiological hazardous materials and MFC-770C contains a sealed Cs-137 source. The hazardous materials in MFC-799 and MFC-799A are processing "heels" that are contained within enclosed tanks. The MFC-770C source is properly contained, and MFC-770C is a secure, controlled-entry building. The radiological hazards associated with MFC-799 and MFC-799A are less than Hazard Category-3 quantities per DOE-STD-1027-92, "Hazard Categorization and Accident Analysis Techniques for Compliance With DOE Order 5480.23, Nuclear Safety Analysis Reports," whereas the quantity of source material in MFC-770C designates that facility as Hazard Category-3. Inventories are provided in Section 7 of this report.

\section{$5.1 \quad$ MFC-799}

While radiological surveys indicate no external contamination of concern, past operational surveys have indicated significant counts (up to $40,000 \mathrm{cpm}$ ) on internal components, particularly the caustic recirculation pump at the bottom of the sodium reactor. The MFC-799 sodium tanks were drained as low as practical and have only "heels" remaining in the tanks. There is an estimated residual of approximately 200 to 240 gal of $50 \%$ by weight sodium hydroxide solution present in these tanks that will be transferred to EM with the facility.

\subsection{MFC-799A}

The 4,000-gal caustic storage tank within MFC-799A is estimated to contain a residual "heel" of approximately $50 \mathrm{gal}$ of $50 \%$ by weight solution of sodium hydroxide that will be transferred to EM with the facility.

\section{$5.3 \quad$ MFC-770C}

MFC-770C has no contamination.

\section{SPECIAL NUCLEAR AND FISSIONABLE MATERIALS INVENTORY}

The only special nuclear material associated with these facilities is the Cs- 137 source material in the Nuclear Calibration Laboratory (MFC-770C). Currently, the following four disposition options are available:

3. Relocate source "as is" to another INL laboratory

4. Ship source back to supplier for refurbishment and return to service within the DOE complex

5. Ship source back to supplier for disposition 
6. Ship source to the Off-site Source Recovery Project at the Los Alamos National Laboratory, New Mexico, for disposition.

NE will make the appropriate determination of which option is most cost effective and complete this action prior to facility transfer.

\section{HAZARDOUS MATERIALS, WASTE, AND CHEMICAL INVENTORIES}

Table 3 summarizes the hazardous materials, waste, and chemical inventories for the facilities being transferred. Note that some materials have been exempted from further consideration due to the relatively small quantities remaining.

Table 3. Hazardous material, waste, and chemical inventory.

\begin{tabular}{|c|c|c|c|c|c|}
\hline Location & Material & $\begin{array}{c}\text { Maximum } \\
\text { Quantity }\end{array}$ & $\begin{array}{l}\text { Threshold } \\
\text { Quantity }\end{array}$ & $\begin{array}{c}\text { Threshold } \\
\text { Quantity Reference }\end{array}$ & $\begin{array}{l}\text { Basis for Exemption } \\
\text { from Further } \\
\text { Consideration } \\
\end{array}$ \\
\hline $\begin{array}{l}\text { MFC-799 } \\
\text { and } \\
\text { MFC-799A }\end{array}$ & Radiological & $\begin{array}{l}\text { Less than } \\
\text { Hazard } \\
\text { Category-3 }\end{array}$ & $\mathrm{NA}$ & DOE-STD-1027.92 & $\begin{array}{l}\text { MFC-799 and } \\
\text { MFC-799A are less than } \\
\text { Hazard Category-3 } \\
\text { facilities }\end{array}$ \\
\hline MFC-770C & Radiological & $100 \mathrm{Ci}$ & $\begin{array}{l}60 \mathrm{Ci} \text { for } \\
\text { Hazard } \\
\text { Category-3 }\end{array}$ & DOE-STD-1027.92 & Not exempted \\
\hline $\begin{array}{l}\text { MFC-799 } \\
\text { and } \\
\text { MFC-799A }\end{array}$ & Sodium & NA & $\mathrm{NA}$ & NA & $\begin{array}{l}\text { The MFC- } 799 \text { sodium } \\
\text { tanks have been drained } \\
\text { to an "as low as } \\
\text { practical" level; this is } \\
\text { judged to be reasonable } \\
\text { to exempt the sodium } \\
\text { from further evaluation }\end{array}$ \\
\hline MFC-799 & $\begin{array}{l}\text { Sodium } \\
\text { hydroxide }\end{array}$ & $1,522 \mathrm{lb}$ & $\begin{array}{l}5,000 \mathrm{lb} \\
(5 \times 1,000)\end{array}$ & $\begin{array}{l}\text { Less than five times the } \\
\text { reportable quantity of the } \\
\text { screening threshold in } \\
40 \text { CFR } 302.4 \text {, } \\
\text { Table } 302.4 \text {; however, } \\
\text { material has a National } \\
\text { Fire Protection } \\
\text { Association Health Hazard } \\
\text { Rating of } 3 \text { with a quantity } \\
\text { greater than laboratory } \\
\text { quantity (approximately } \\
5 \text { gal or } 40 \text { lb) }\end{array}$ & NA \\
\hline
\end{tabular}


Table 3. (continued).

\begin{tabular}{|c|c|c|c|c|c|}
\hline Location & Material & $\begin{array}{l}\text { Maximum } \\
\text { Quantity }\end{array}$ & $\begin{array}{l}\text { Threshold } \\
\text { Quantity }\end{array}$ & $\begin{array}{c}\text { Threshold } \\
\text { Quantity Reference }\end{array}$ & $\begin{array}{c}\text { Basis for Exemption } \\
\text { from Further } \\
\text { Consideration } \\
\end{array}$ \\
\hline MFC-799A & $\begin{array}{l}\text { Sodium } \\
\text { hydroxide }\end{array}$ & $317 \mathrm{lb}$ & $\begin{array}{l}5,000 \mathrm{lb} \\
(5 \times 1,000)\end{array}$ & $\begin{array}{l}\text { Less than five times the } \\
\text { reportable quantity of the } \\
\text { screening threshold in } \\
40 \text { CFR } 302.4 \text {, } \\
\text { Table } 302.4 \text {; however, } \\
\text { material has a National } \\
\text { Fire Protection } \\
\text { Association Health Hazard } \\
\text { Rating of } 3 \text { with a quantity } \\
\text { greater than laboratory } \\
\text { quantity (approximately } \\
5 \text { gal or } 40 \text { lb) }\end{array}$ & NA \\
\hline
\end{tabular}

\section{FIXED OCCUPATIONAL HAZARDS}

The only occupational hazards noted on the walk-down were two uncaged ladders and miscellaneous tripping hazards due to clutter in some areas. The first ladder is on the north exterior wall of MFC-799 and the second is located inside MFC-799 on the west side of the mezzanine. The tripping hazards will be eliminated as excess equipment is removed from the facility prior to transfer.

\section{TRANSFER CONSIDERATIONS}

\subsection{Documents}

\subsubsection{Permits, Licenses, and Agreements}

MFC-799 and MFC-799A are included in the following permits:

- MFC Hazardous Waste Management Area RCRA Storage and Treatment Permit, No. ID4890008952, dated August 16, 2004, and modified on October 2, 2008

- Air Quality Tier I Operating Permit, No T1-030520, Facility ID Nos. 023-0001, 011-00022.

\subsubsection{Outstanding Commitments}

There are no outstanding commitments related to MFC-799, MFC-799A, and MFC-770C.

\subsubsection{Excess Equipment and Material}

Excess equipment associated with MFC-799 and 799A includes the following:

- Daewoo BC30S electric forklift and charger

- Spacemaster II 5-ton single beam overhead electric hoist

- P\&H Beta HEVI-LIFT 500-lb overhead gantry crane

- $\mathrm{P} \& H$ Spectrum 1,000-1b pedestal crane.

Excess equipment associated with MFC-770C includes the following:

- JL Sheperd Model 81-12 beam calibrator (Serial No. 540) 
- JL Sheperd Model 155 attenuator system (Serial No. 783) (with Cs-137 source).

\subsection{Stabilization and Other Required Actions Required for Transfer}

The criteria/end points that must be met prior to facility transfer, the current status of each, and the actions that remain to be completed are listed as follows.

1. Facility Structure/Personnel Safety - Structural integrity is such that (1) inspection personnel are safe, and (2) engineered protective barriers and containment systems (for example, but not limited to, safety class systems) are sufficient to prevent the release of radiological or hazardous chemical substances.

Status: Facilities have been walked down and determined to be structurally sound. Hazardous materials are safely and effectively contained and present minimal risk as long as enclosures (tanks in the case of MFC-799 and 799A and sealed source in the case of MFC-770C) are not breached.

Actions to be Completed: None.

2. Process Systems and Equipment - Process systems and equipment are systematically shut down, isolated, sealed off, or removed (if there is a compelling reason to do so) to establish a stable and known condition.

Status: MFC-799 and 799A process systems and equipment were systematically shut down when these facilities were placed in standby in March 2001. The source contained in MFC-770C is secure. The systems and equipment for all three facilities are in stable and known conditions.

Actions to be Completed: None.

3. Service and Utility Systems and Equipment - Only systems required to support disposition and surveillance and maintenance and maintain the stable condition (such as lighting, exhaust ventilation, and sump pumps) are operational. Equipment that has been judged to be valuable for future decommissioning is left available for future use. Other utility systems are isolated or sealed off for safety of future personnel or removed (if there is a compelling reason to do so).

Status: All three facilities are in stable condition and necessary support systems remain operational. Actions to be Completed:

- Modification of electrical service for the Radioactive Storage Waste Facility(MFC-771)

- Electrical engineering and design

- Install new underground power duct bank for power to MFC-771

- Install new power panel and disconnects

- Outage - disconnect old power/reconnect new power systems and re-energize new power supply system

- Final burial of manholes and final cleanup of site areas

- As built drawings/final report

- Disposition of equipment and property

- Delisting of excess property - disposition of equipment to other programs

- Removal of applicable excess equipment

- Removal of stored materials and equipment - interior of MFC-799, 799A and 770C

- Removal of stored materials and equipment - exterior of MFC-799 and 799A. 
4. Radiation Protection - Barriers and so forth are established in accordance with standard procedure per the site/DOE radiological control manual. Radioactive contamination remaining in the facility is contained in limited areas or has been stabilized against release.

Status: Radioactive contamination in MFC-799 and 799A is internal to tanks and systems, is properly placarded, and is considered stabilized against release. There is no radioactive contamination at MFC-770C.

Actions to be Completed: None.

5. Radioactive Materials - Radioactive materials are removed.

Status: There are no radioactive materials in MFC-799 or 799A. MFC $770 \mathrm{C}$ contains a sealed Cs-137 source.

Actions to be Completed: Removal and disposition of the Cs-137 source (assuming the source will be excessed).

6. Hazardous Materials and Waste - Hazardous materials and chemicals are removed in accordance with environmental regulations. The only liquids remaining are minor quantities that cannot be readily removed with installed equipment. Where feasible, RCRA closure has been achieved for listed materials. Hazardous materials remaining in the facility are contained in limited areas or have been stabilized against release. Documentation of the amount and location of remaining hazardous material is complete.

Status: The hazardous materials and chemicals remaining are residuals (i.e., heels) within the processing and storage vessels in MFC-799 and 799A. These are minor quantities that cannot be readily removed, are in a stabilized condition, and will be transferred to EM with the facilities. Estimated quantities are documented and are presented in this report. RCRA closure activities will be performed by EM post-transfer.

\section{Actions to be Completed:}

- Limited characterization plan development

- Verification of caustic and sodium levels in tanks/vessels

- Transfer MFC-799 and 799A out of the PER 116 MFC RCRA Permit.

7. Housekeeping and Miscellaneous Materials - Classified and valuable materials are removed. Remove all classified documents, materials, and tools and downgrade security requirements.

Status: There are no classified materials in any of these facilities. Other housekeeping activities will be completed as part of the disposition of equipment and property activities associated with Item 3 in the list above.

Actions to be Completed: Prepare end state condition report.

\subsection{Cost Estimates}

Cost estimates prepared for actions to be completed before transition of MFC-799, MFC-799A, and MFC-770C are provided in Appendix E. The estimates support project execution of facility transition prerequisite work scope and are classified as AACEI Class 3 cost estimates. The duration for completing the pre-requisite work scope is approximately 22 weeks. The total estimated cost for completing the work scope, excluding management reserve, is $\$ 535,000$. 


\section{SUMMARY, CONCLUSIONS, AND RECOMMENDATIONS}

MFC-799, 799A, and $770 \mathrm{C}$ are excess to future $\mathrm{NE}$ mission requirements. These facilities are in good overall physical condition, and associated hazardous or potentially hazardous conditions are well defined and well understood. Transfer of these facilities from NE to EM and an associated schedule for doing so have been agreed upon by the two offices. The prerequisites for this transfer are the removal of nonexcess materials and chemical inventory, deinventory of the calibration source in MFC-770C, and the rerouting or isolation of utility and service systems.

Based on the available information/documentation reviewed and overall conditions observed during the facilities walk-down, it is concluded that these facilities may be disposed of at minimal risk to human health and safety or the environment.

Therefore, the following is recommended:

1. NE proceed with stabilization activities that will ensure the identified pre-transfer end states are met

2. Upon completion of these pre-transfer requirements, NE and EM perform a joint pre-transfer review, which will include a joint facility walk-down

3. NE and EM execute a final transfer memo documenting date of transfer and any other information pertinent to the transfer of management responsibility.

\section{REFERENCES}

40 CFR 270, "EPA Administered Permit Programs: the Hazardous Waste Permit Program," Code of Federal Regulations, Office of the Federal Register, 2000.

IDAPA 58.01.05, July 2000, "Rules and Standards for Hazardous Waste," Idaho Administrative Code, Idaho Administrative Procedures Act, Idaho Department of Environmental Quality.

MFC Hazardous Waste Management Act RCRA Storage and Treatment Permit, No. ID4890008952, dated August 16, 2004, and modified on October 2, 2008.

Air Quality Tier I Operating Permit, No T1-030520, Facility ID Nos. 023-0001, 011-00022 (Section 3.4).

EHA-70, Appendix R, "Emergency Management Hazards Assessment for MFC-799, Sodium Process Facility, and MFC-799A, Caustic Storage Tank Building," Rev 0, Effective Date July 05, 2006.

DOE-STD-1027-92, "Hazard Categorization and Accident Analysis Techniques for Compliance with DOE Order 5480.23, Nuclear Safety Analysis Reports," U.S. Department of Energy,

December 1992. 


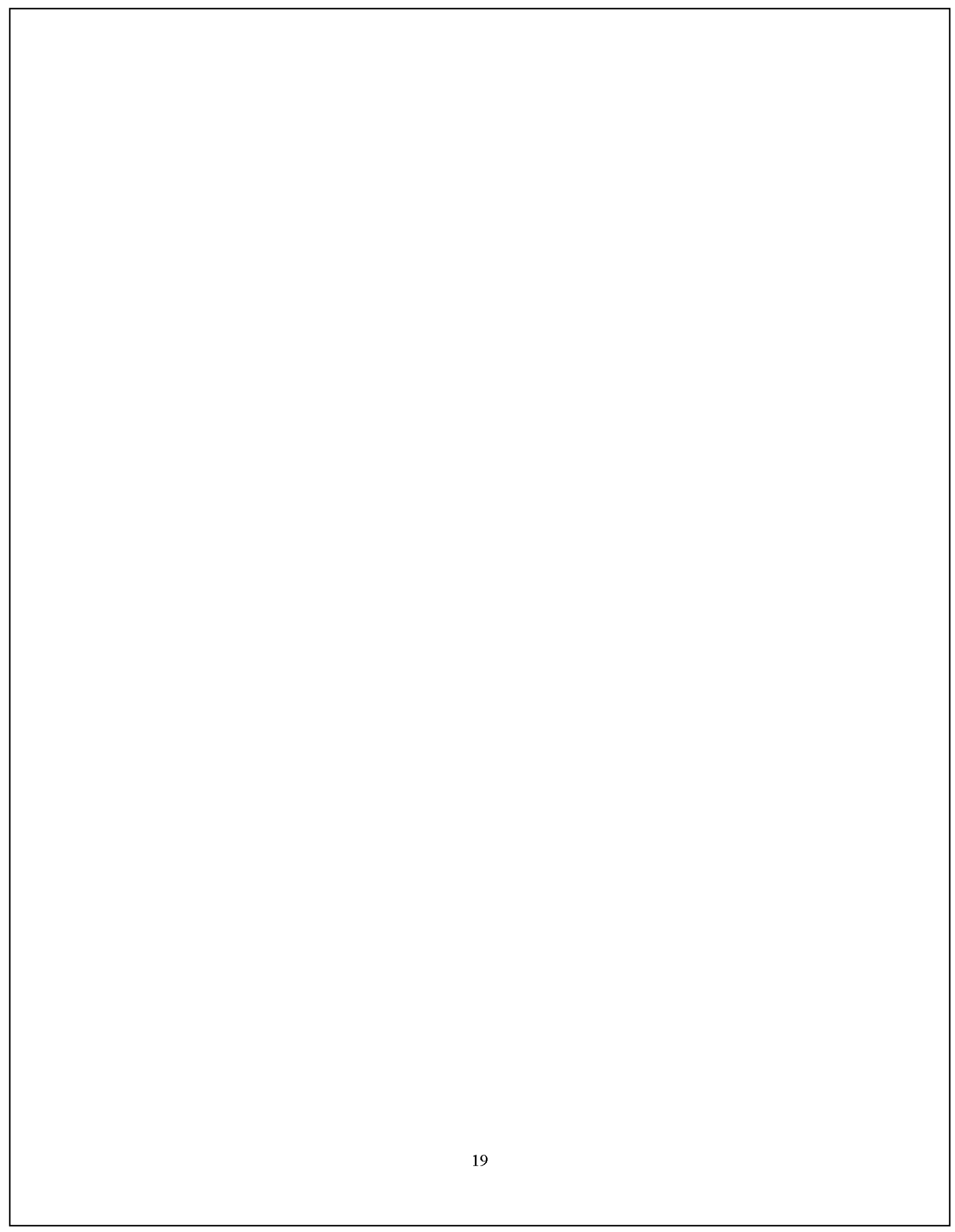

A-29 
Appendix A

Facilities Walk-Down Checklist 


\begin{tabular}{|c|c|c|}
\hline \multicolumn{3}{|c|}{$\begin{array}{l}\text { DOE Guide } 430.1-5==>\text { Facility Checklist } \\
\text { Projected Cost for DD\&D of MFC-770C, }-799,-799 \mathrm{~A} \text { - Transition Plan Cost } \\
\text { Prepared by DJ Kenoyer, Revision 0,30-04-09 }\end{array}$} \\
\hline & & $\begin{array}{l}\text { Based upen Observations by DJ Kenoyer / G Mechan during Facility Wallk-down } \\
\text { Wednesday, 28-Oct-09 }\end{array}$ \\
\hline \multicolumn{2}{|r|}{ Subject of Survey } & Notes \\
\hline & Exterior Structure & \\
\hline 1,01 & Roof Condition (Integrity) & Exterior Not avatiable for Observation \\
\hline 1.02 & Roof Leakage & 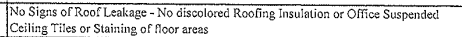 \\
\hline 1.03 & Foundation (cracks, crumbling) & Not Visible \\
\hline 1.04 & Walls (air and water tight) & Walls were all air and water tight las observed \\
\hline 1.05 & Doors & 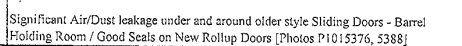 \\
\hline 1.06 & Iratithes & None Oosserved \\
\hline 1.07 & Windows & $\begin{array}{l}\text { Oolly windows were Personnel Door Litcs and linterior Office / Observation Windows - } \\
\text { All in good condition }\end{array}$ \\
\hline 1.08 & Loading Docks & None Observed \\
\hline 1.09 & Ladders and Stairs & 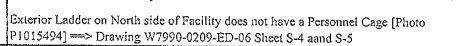 \\
\hline 1.1 & Piping Supports & None Observed \\
\hline 1.11 & Power Poles & 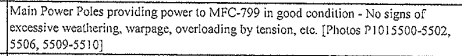 \\
\hline 1.12 & Transmission lines & 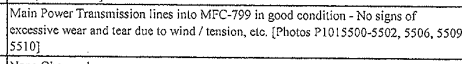 \\
\hline 1.13 & Transfer piping & None Observed \\
\hline 1.14 & Walkways and Roadways & 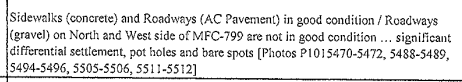 \\
\hline 1.15 & Tanks and piping & $\begin{array}{l}\text { Abandoned Caustic Storage Tank (A23-T-203) in good condition / above ground tank } \\
\text { winh no Secondtary Containment [Photos P1015471-5473, 5481] }\end{array}$ \\
\hline 1.16 & Piping insulation & None Observed. \\
\hline 1.17 & Valve boxes or pits & Norie Observed \\
\hline 1.18 & Manholes and Drains & Drain - Grate on NW orner of Barrel Washing Pad (concrete) (Plioto P1015480] \\
\hline 1.19 & Cribs, ditches and trenches & 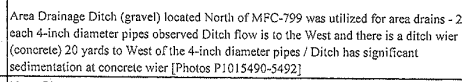 \\
\hline 1.2 & Waste sites & None Observed \\
\hline & Animal Nesting & None Observed \\
\hline 1.21 & Paint chipping & None Observed \\
\hline 1.22 & Paved or Painted Contamination & None Observed \\
\hline & Interior Structure & \\
\hline 2.01 & Ceilings & 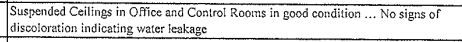 \\
\hline 2.02 & Floors & Concretete Roors in good condition - No Craking ard/or Spalling of surfaces \\
\hline 2.03 & Walls (load bearing) & $\begin{array}{l}\text { All CMU walls were observed to be in Good Condilition - No visibie signs of cracking } \\
\text { andior spalling }\end{array}$ \\
\hline 2.04 & Foundations & Not Visible \\
\hline 2.05 & Mezzanines & 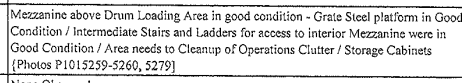 \\
\hline 2.06 & Cat Walks & None Observed \\
\hline 2.07 & Ladders and Stairs & 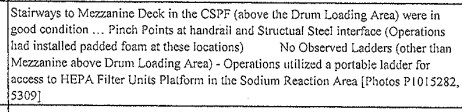 \\
\hline 2.08 & Doors & 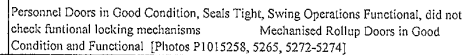 \\
\hline 2.09 & Fire Doors \& Air Locks & None Observed - - - \\
\hline & Vaults. & None Observed \\
\hline 2.11 & Cells & None Observed \\
\hline 2.12 & Hot Cells & None Observed \\
\hline 2.13 & Pits and Crawl spaces & 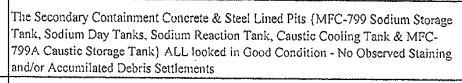 \\
\hline 2.14 & Sumps & 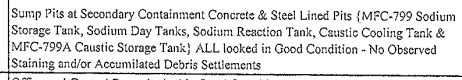 \\
\hline 2.15 & Office and Maintenance Shops & offfice and Control Room locked in Good Condition \\
\hline 2.16 & Elevators & None Observed \\
\hline & General App & \\
\hline
\end{tabular}




\begin{tabular}{|c|c|c|}
\hline 2.17 & Housekeeping & 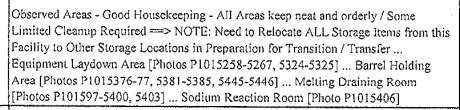 \\
\hline 2.18 & Maintenance & Dobserved Areas - Gooc SeM becing Maintzinned \\
\hline 2.19 & Lighting & $\begin{array}{l}\text { Observed Areas - Good Lighting / Ail Lighting Fix xures working properly - No } \\
\text { Observed burned out ballasts, elc. }\end{array}$ \\
\hline 2.2 & Signage & Observed Signage Seemed up to date and a deguate \\
\hline 2.21 & Access Control & Access to Favility is Limiled by Lockied and Controlled Access \\
\hline 3 & Environmental Compliance & a \\
\hline & Liquid Effluents & \\
\hline 3.01 & Liquid Discharge Points & $\sec 1.19$ \\
\hline 3.02 & Cribs, Ditches, Ponds & $\sec 1.19$ \\
\hline 3.03 & Sampling and monitoring & None Observed \\
\hline 3.04 & Abandoned systems & None Observed \\
\hline 3.05 & Marking and Mapping & Not Know a This Time \\
\hline 3.06 & Characterization info & Not Know a This Time \\
\hline 3.07 & Storm water Management & Not Know a This Time \\
\hline 3.08 & Records Retention & Not Know a This Tinine \\
\hline & Gaseous Effluents & \\
\hline 3.09 & Discharge Points (stacks) & 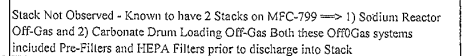 \\
\hline 3.1 & Fugitive Emission sources & Not Know a This Time \\
\hline 3.11 & Sampling and monitoring & 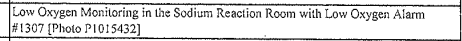 \\
\hline 3.12 & Abandoned systems & 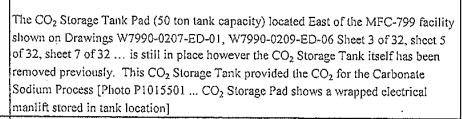 \\
\hline 3.13 & Records Retention & Not Know a This Time \\
\hline 3.14 & Characterization info & Not Know a This Time \\
\hline 3.15 & Filter calibration & Not Know a This Time \\
\hline 3.16 & $\begin{array}{l}\text { Filter loading info } \\
\end{array}$ & Not Know a This Time \\
\hline & Chemical Management & \\
\hline 3.17 & Spills and Releases & 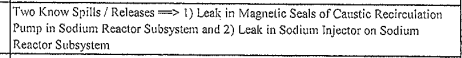 \\
\hline 3.18 & Chemical Storage & None Observed \\
\hline 3.19 & Underground Tanks & None Observed \\
\hline & Records Retention & Not Know a This Time \\
\hline & Regulatory & \\
\hline 3.21 & Permitted Area boundary & MFC-799/MFC-799A-All Physical Boundarics in Placec \\
\hline 3.22 & TSCA-PCB Labeis & None Observed \\
\hline 3.23 & Hazard Labels & Caustic and Sodium Hazards L.abeis throughout the MPC- 799, MFC. $-799 \mathrm{~A}$ \\
\hline$\frac{3.24}{4}$ & $\begin{array}{l}\text { Calibration records/stickers } \\
\text { Process Systems } \\
\end{array}$ & Oouserved Calibration Stickers - Facility in Operational Layup Status \\
\hline 4.01 & Process Control Room & 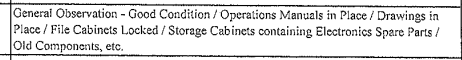 \\
\hline 4.02 & Exhaust Systems & 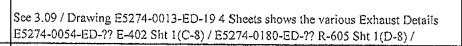 \\
\hline 4.03 & Fans & Did NOT Check These \\
\hline 4.04 & Motors & Did NOT Chesk These \\
\hline 4.05 & Stacks & see $3.09-1-2$ \\
\hline 4.06 & Ductwork & $\begin{array}{l}\text { Bulilding HVAC Duct work in Good Condition - Ducc Insustration is in place and in } \\
\text { Good Condition }\end{array}$ \\
\hline 4.07 & HEPA Filters & 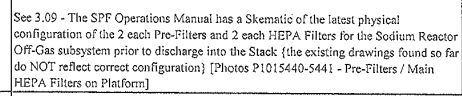 \\
\hline 4.08 & Off Gas Scrubber & None Observed \\
\hline 4.09 & Stack Monitoring & None Observed \\
\hline 4.1 & Glove Boxes & 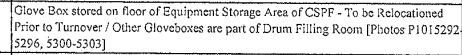 \\
\hline 4.11 & Lab Hoods & Nonc Observed \\
\hline 4.12 & Fume Hoods & None Observed \\
\hline 4.13 & Vactum Pumps & 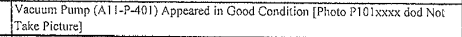 \\
\hline 4.14 & Vessels or tanks & 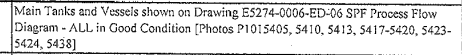 \\
\hline 4.15 & Pumps & $\begin{array}{l}\text { Main Pumps shown on Drawing ES274-0006-ED-06 SPF Procoss Flaw Diagram - ALL } \\
\text { in Oood Condition }\end{array}$ \\
\hline 4.16 & Motors & 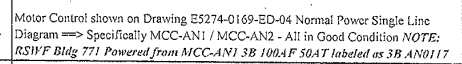 \\
\hline 4.17 & Piping & Causlic Piping has High Nickel content/ Sodium Piping \\
\hline 4.18 & Level Detection & 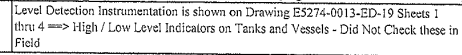 \\
\hline
\end{tabular}




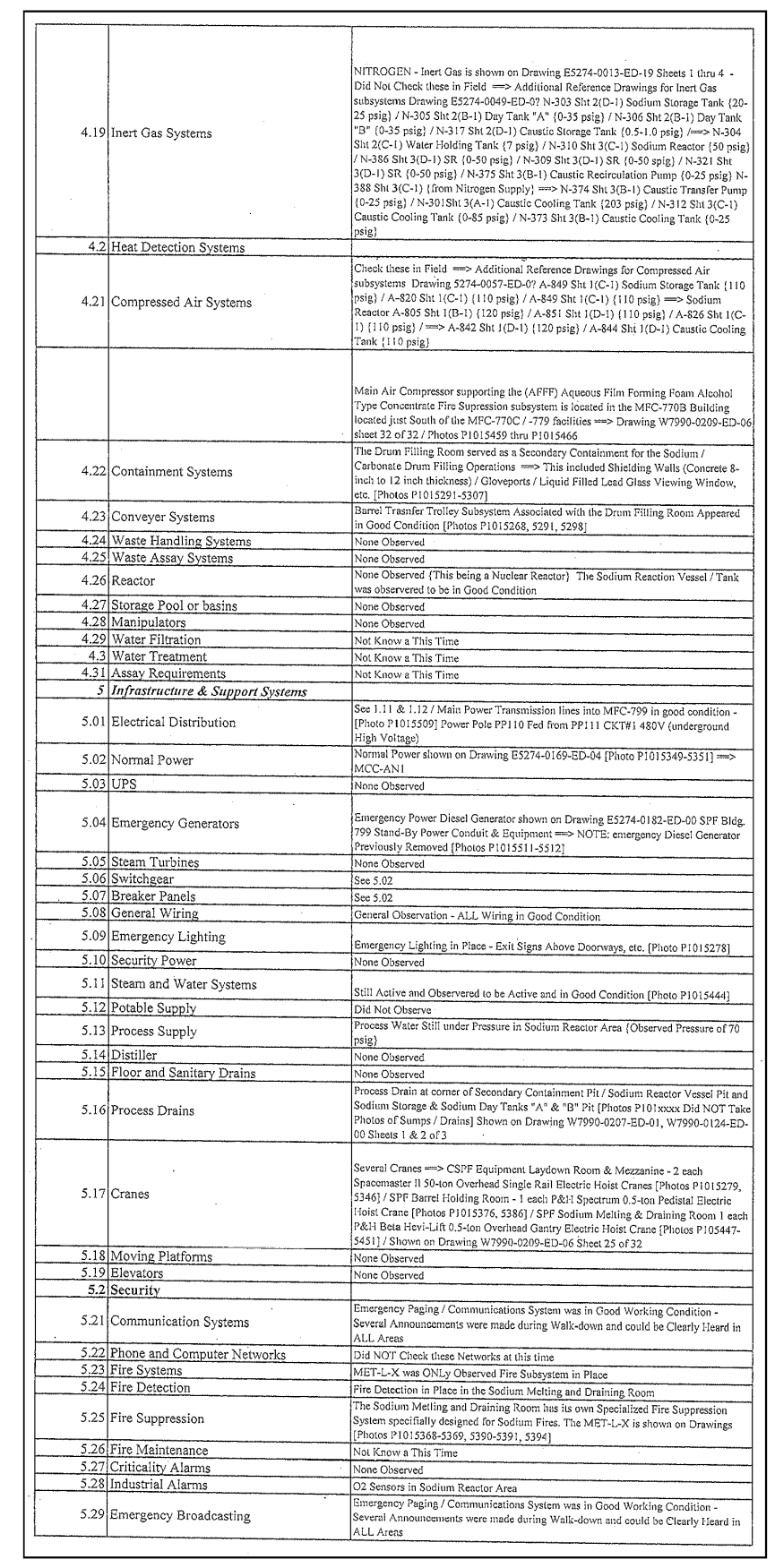




\begin{tabular}{|c|c|c|}
\hline 5.3 & HVAC Supply & 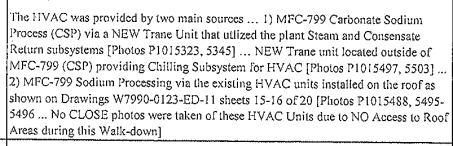 \\
\hline 5.31 & Air filtering & 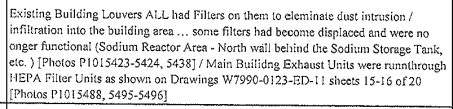 \\
\hline 5.32 & Building Heat & 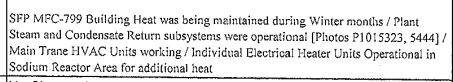 \\
\hline$\frac{5.33}{5.34}$ & $\begin{array}{l}\text { Building } A / C \\
\text { Freon Systems }\end{array}$ & 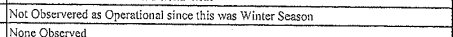 \\
\hline 5.35 & Shop systems & 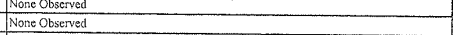 \\
\hline 5.36 & Supply Storage & 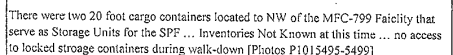 \\
\hline 5.37 & Change Rooms & None Observed \\
\hline 5.38 & Emergency Response Org & Nol Know a This Time \\
\hline 5.39 & Temporary Structures & None Observed \\
\hline 5.4 & Site Services/Support i.e. Rigging & None Observed \\
\hline 6 & Nuclear Safery \& . Materials & \\
\hline & Plutonium & \\
\hline & Material in Storage & None Observed - Platonitum NA \\
\hline 6.02 & In Solution & None Observed-Platonium N/A \\
\hline 6.03 & In Equipment & None Observed - Plutoniem N/A \\
\hline 6.04 & In Glove Boxes & None Observed - Plutonium N/A \\
\hline 6.05 & In Hot Cells & None Observed-Plintonitum N/A \\
\hline 6.06 & In Cells, Sumps & None Observed - Plutonitum N/A \\
\hline 6.07 & In Ducts & None Observed - Plutronizum N/A \\
\hline 6.08 & In HEPA Filters & Nonc Observed - Plutonitun N/A \\
\hline & Sump or Pool Sludge & None Observed - Plutonium N/A \\
\hline & Uranium or Thorium & \\
\hline & Material in Storage & None Observed - Uranium or Thorium N/A \\
\hline 6.11 & In Solution & None Observed - Uranium or Thorium N/A \\
\hline 6.12 & In Equipment & None Observed - Uranium or Thoritum N/A \\
\hline 6.13 & In Glove Boxes & None Observed - Uranium of Thiorium N/A \\
\hline 6.14 & In Hot Cells & None Observect - Uranitum of Troorium $N / A$ \\
\hline 6.15 & in Cells, Sumps & None Observed - Utanium of Thorrium N/A \\
\hline 6.15 & In Ducts & None Observert - Uranium or Thorium N/A \\
\hline 6.16 & In HEPA Fitters & None Observed - Uranium or Thortum N/A \\
\hline 6.17 & Sump or Pool Sludge & None Observed - Uratiunun or Thorium N/A \\
\hline & Nuclear Fuel & \\
\hline 6.18 & New in Storage & None Observed-Nuclear Fuel N/A \\
\hline 6.19 & In Reactor & None Observed-Nuclear Fuel $N / A$ \\
\hline & In Wet Storage & None Observed -Nuelear Fuel N/A \\
\hline & In Dry Storage & None Oosserved-Nuclear Fuel N/A \\
\hline & $\mathrm{TRU}-(\mathrm{am}, \mathrm{cm}, \mathrm{bk}, \mathrm{cf})$ & 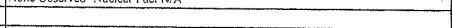 \\
\hline & Material in Storage & None Observed - TRU N/A \\
\hline 6.23 & In Solution & None Observed - TRU N/A \\
\hline 6.24 & In Equipment & None Observed - TRU N/A \\
\hline 6.25 & In Glove Boxes & None Observed-TRU N/A \\
\hline 6.26 & In Hot Cells & None Observed-TRU N/A \\
\hline 6.27 & In Cells, Sumps & None Obseived - [RU N/A \\
\hline 6.28 & In Ducts & None Observed - TRU N/A \\
\hline & In HEPA Filters & None Observed -TRU N/A \\
\hline & Sump or Pool Sludge & None Observed - TRU N/A \\
\hline & Other Nuclear Materials & D \\
\hline & Deuterium, Tritium, Lithium 6 & Nonc Observed \\
\hline 6.32 & Sealed Sources & MFC-770C - Nuclear Calibration Laboratory \\
\hline 6.33 & Source Accountability & Noc Known at this Time \\
\hline 6.34 & Neutron Monitors & None Observed \\
\hline 6.35 & Neutron Absorbers & Nonc Observed \\
\hline & In line Neutton Source & None Observed \\
\hline & Hazardous Material & \\
\hline & Process Chemicals & \\
\hline 7.01 & Acids & None Observed \\
\hline 7.02 & Caustics & 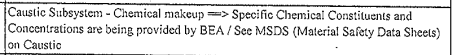 \\
\hline 7.03 & Sodium & 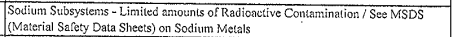 \\
\hline 7.04 & Hydrazine & None Observed \\
\hline 7.05 & Lab Reagents & None Observed \\
\hline & Misc. Chemicals or Explosives & None Observed \\
\hline & Environmental Hazards & \\
\hline 7.07 & Lead, Heavy Metals & None Observed \\
\hline & Potassium Chromate & None Observed \\
\hline 7.09 & PCBS & Noire Observed \\
\hline 7.1 & Solvents and thinners & None Observed \\
\hline 7.11 & Freon, CFC's & None Observed \\
\hline & Paints, Sealants, Adhesives & Nane Observed \\
\hline
\end{tabular}

24 


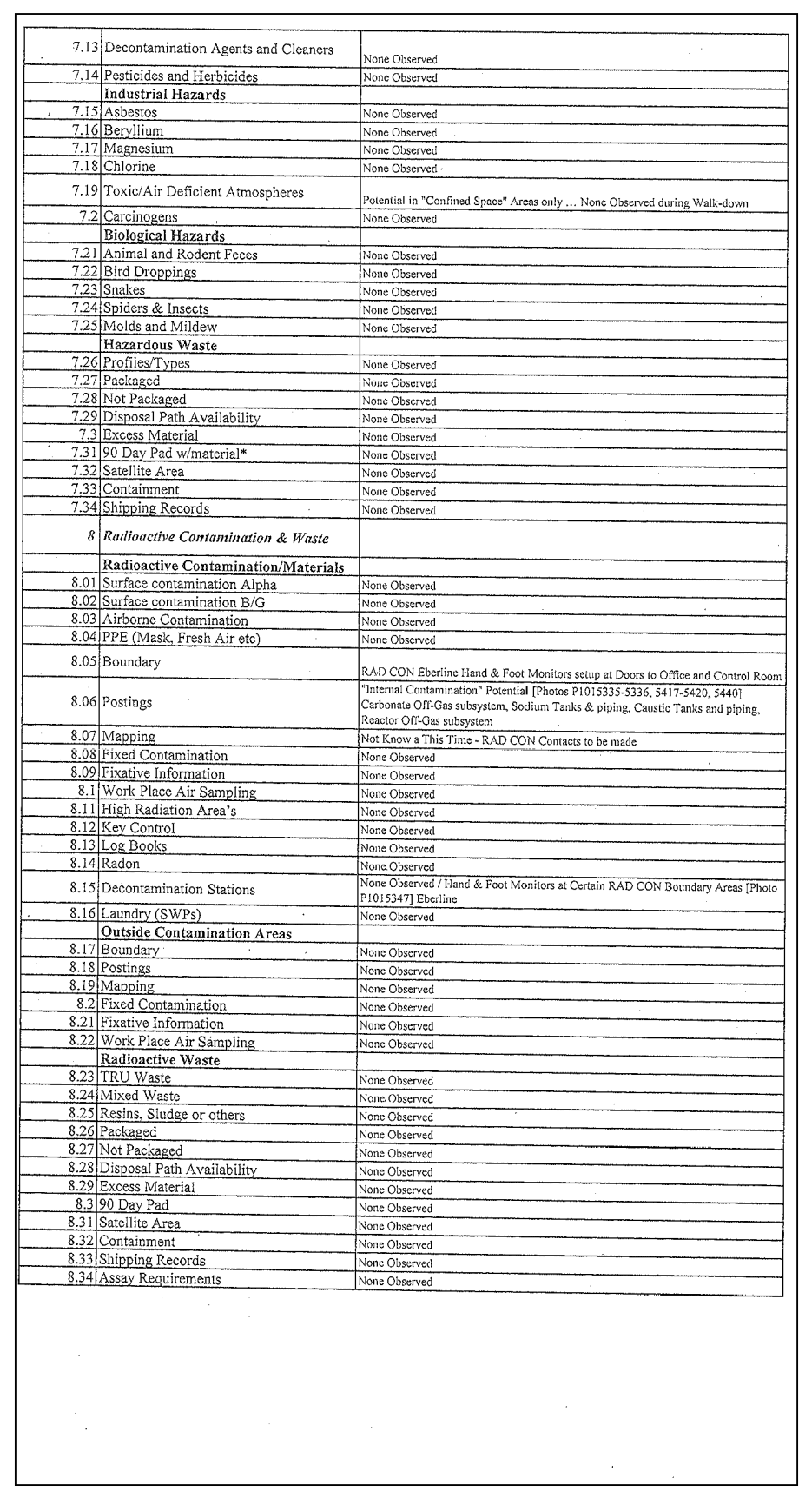


Appendix B

Drawings

26 

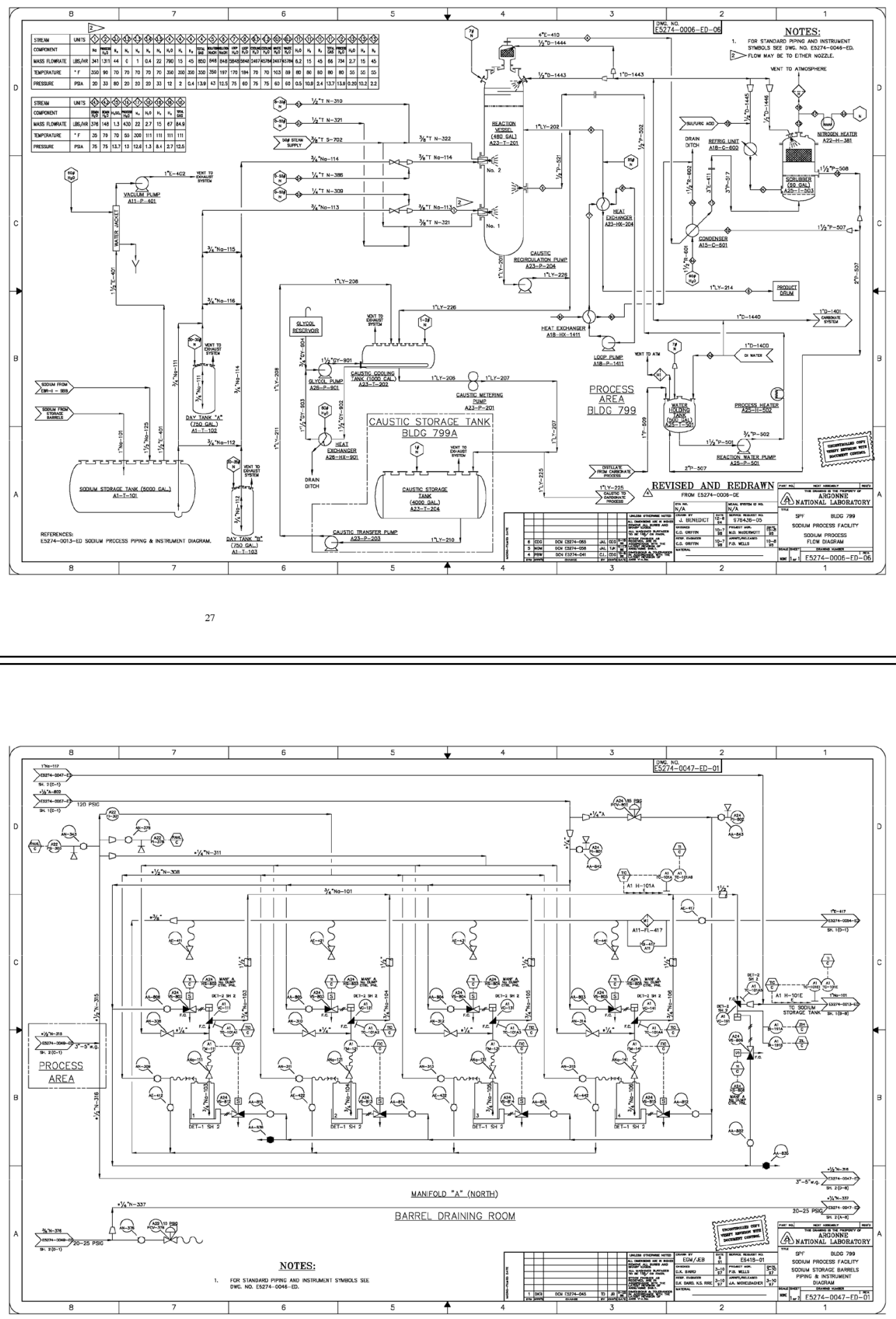


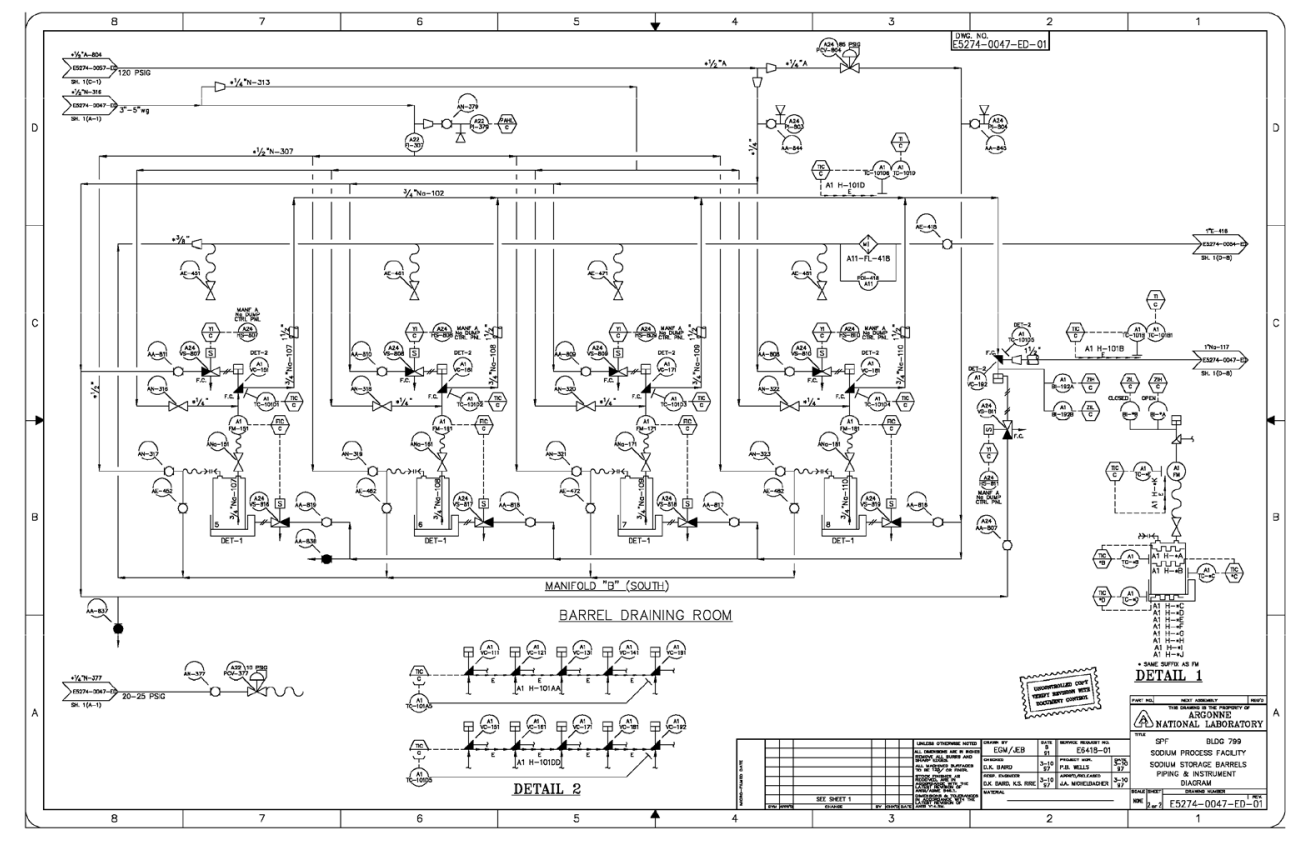

29

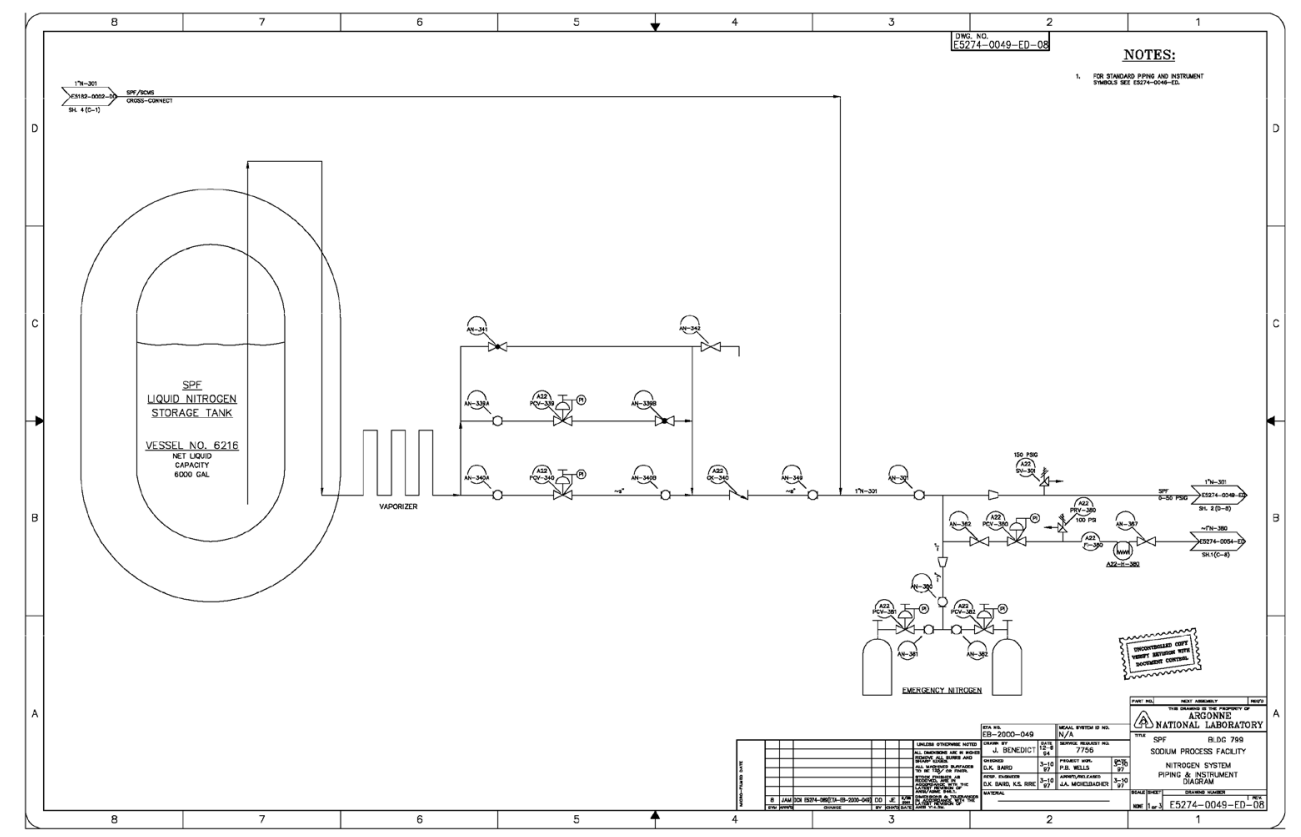



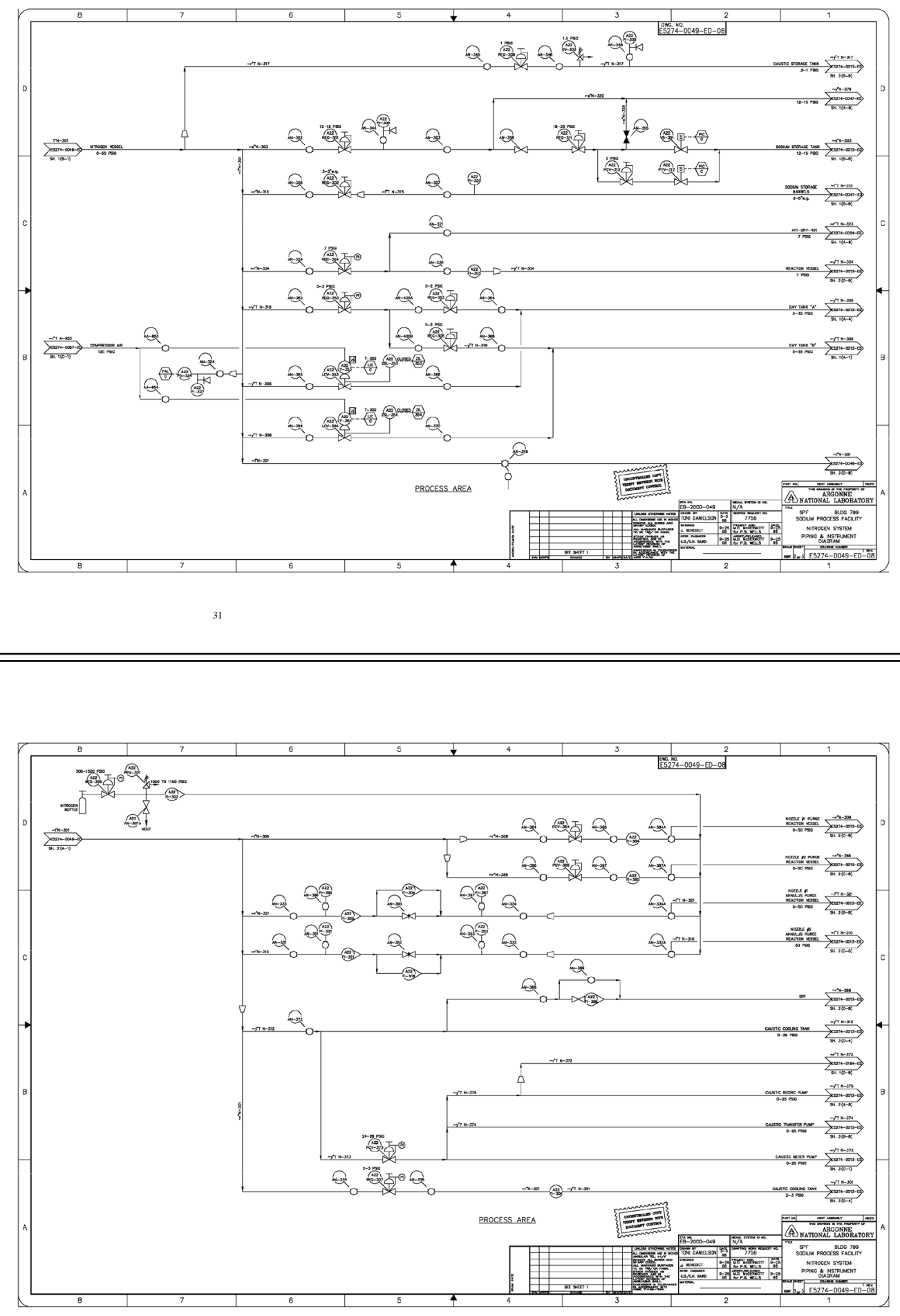


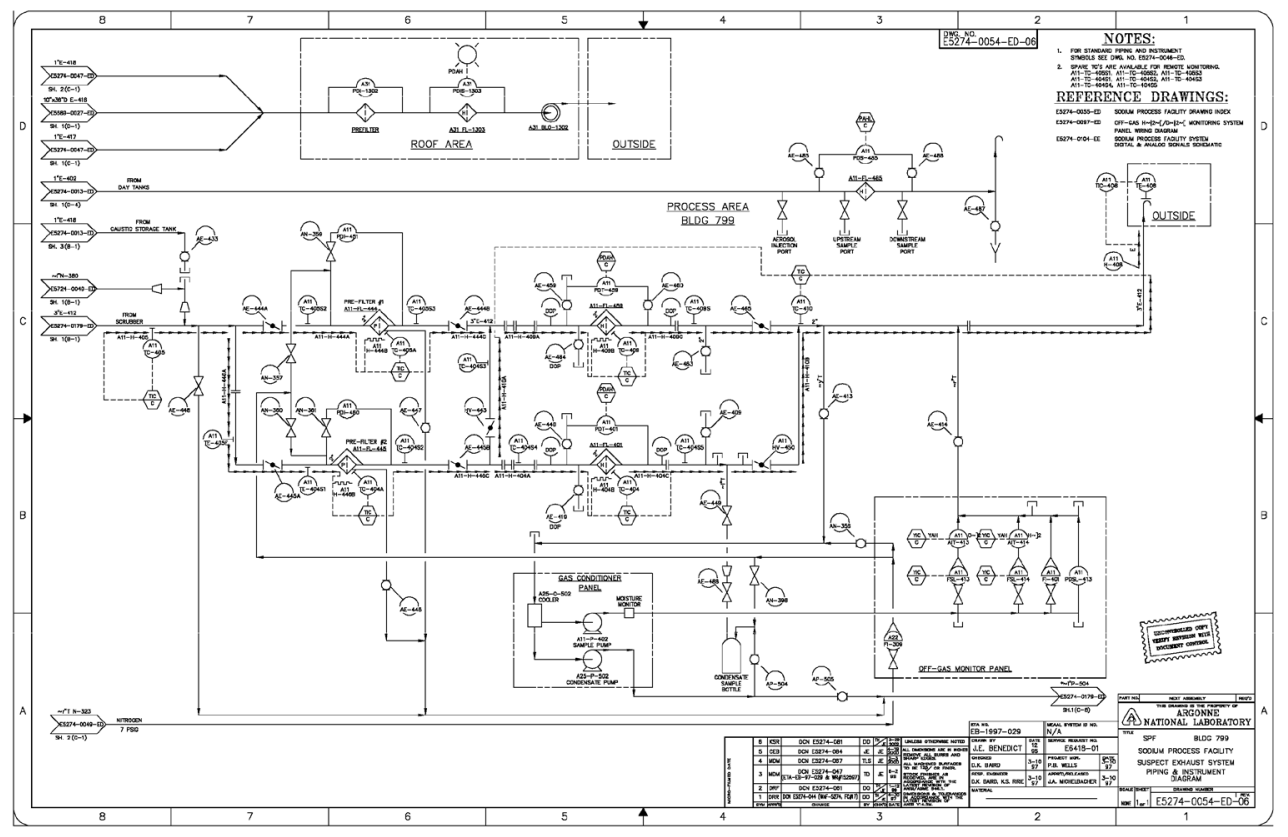

33

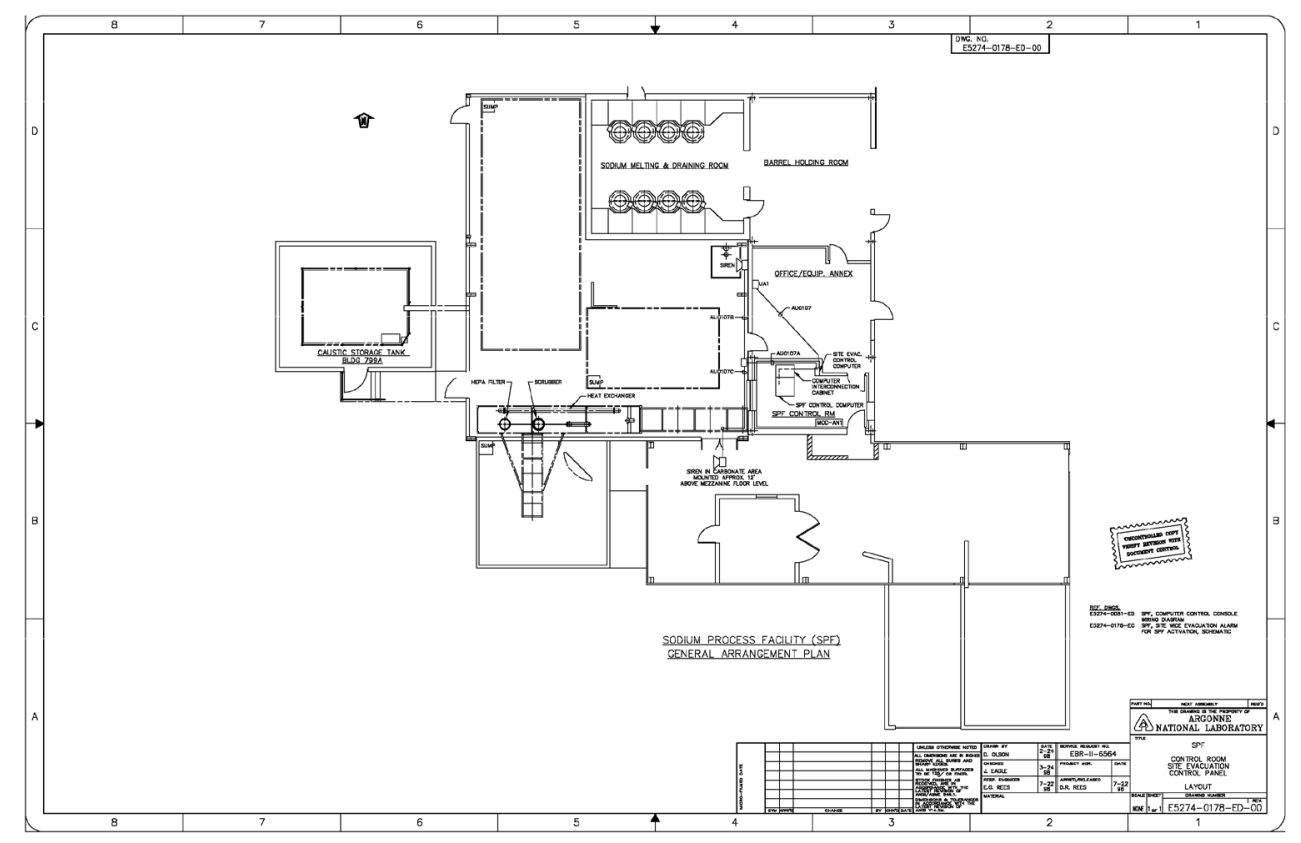




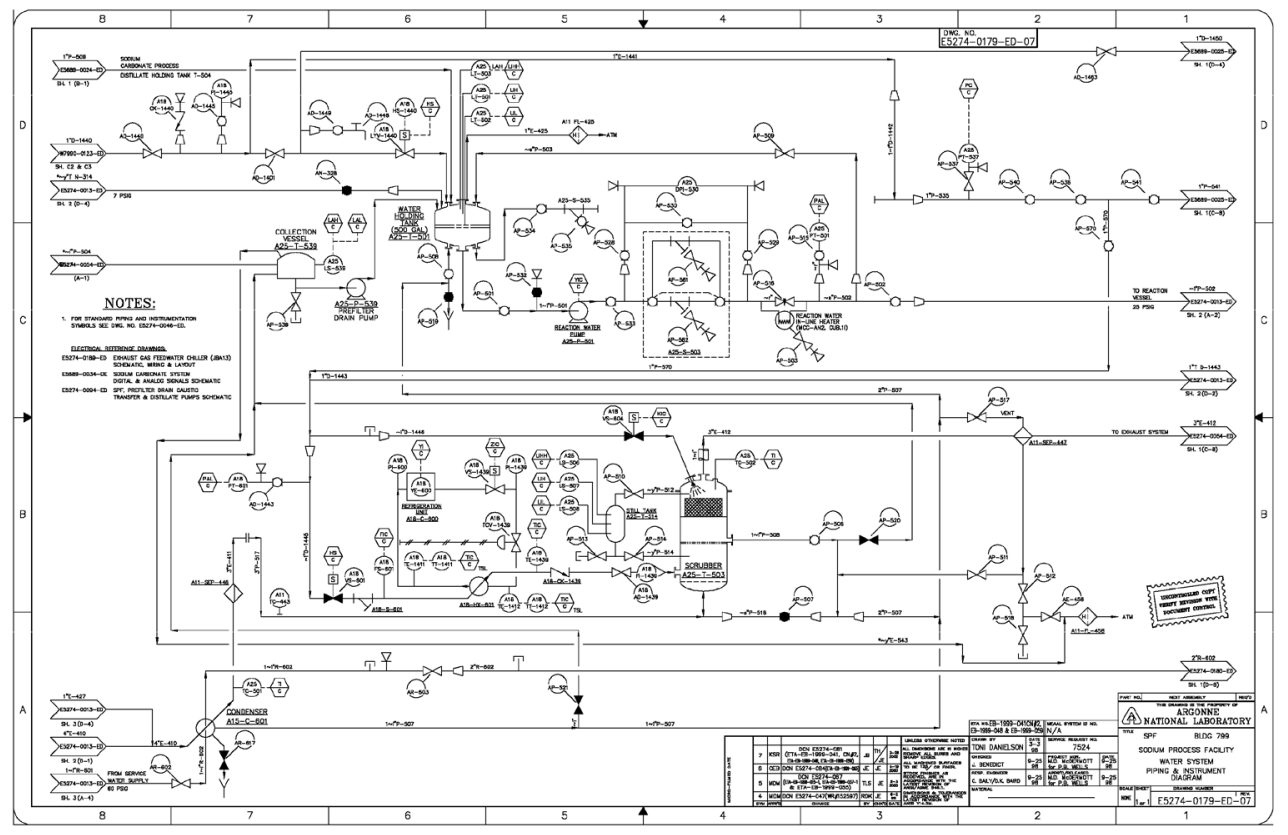

35

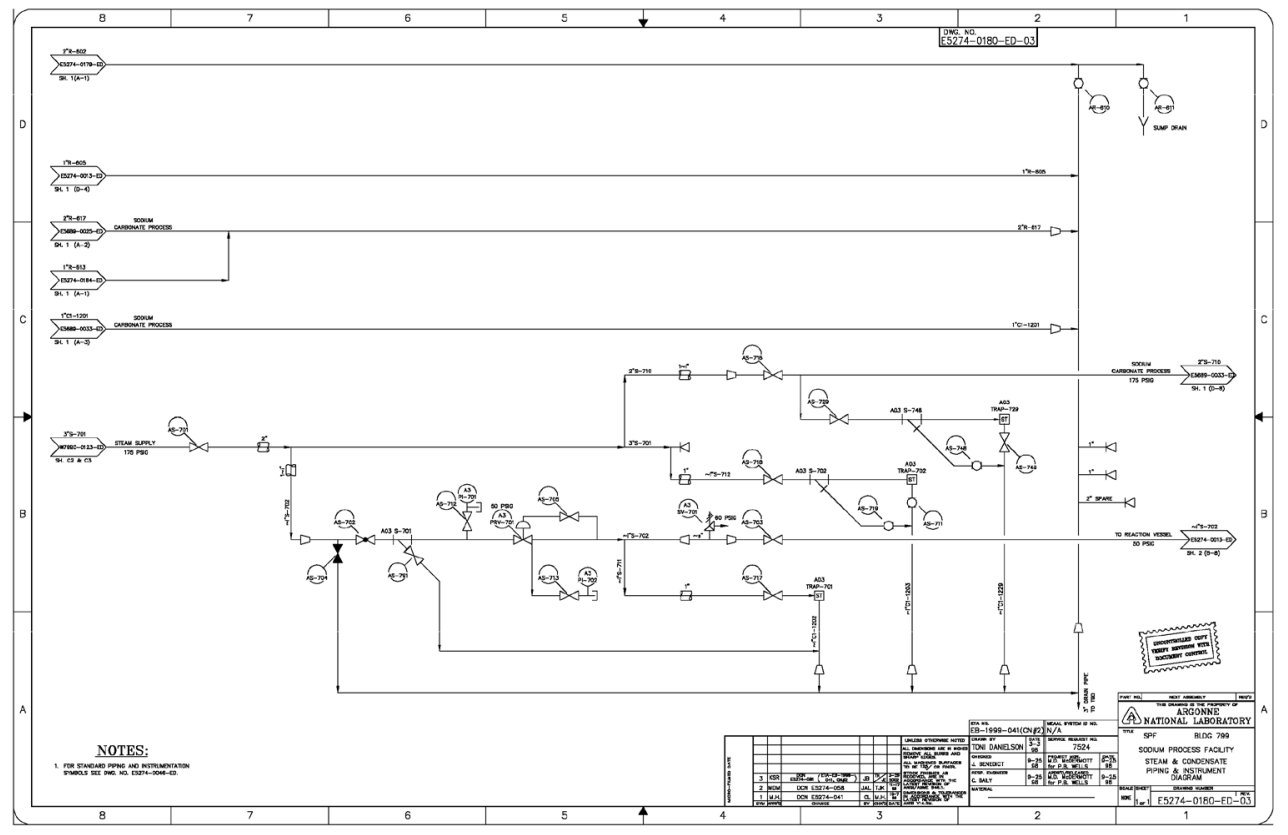



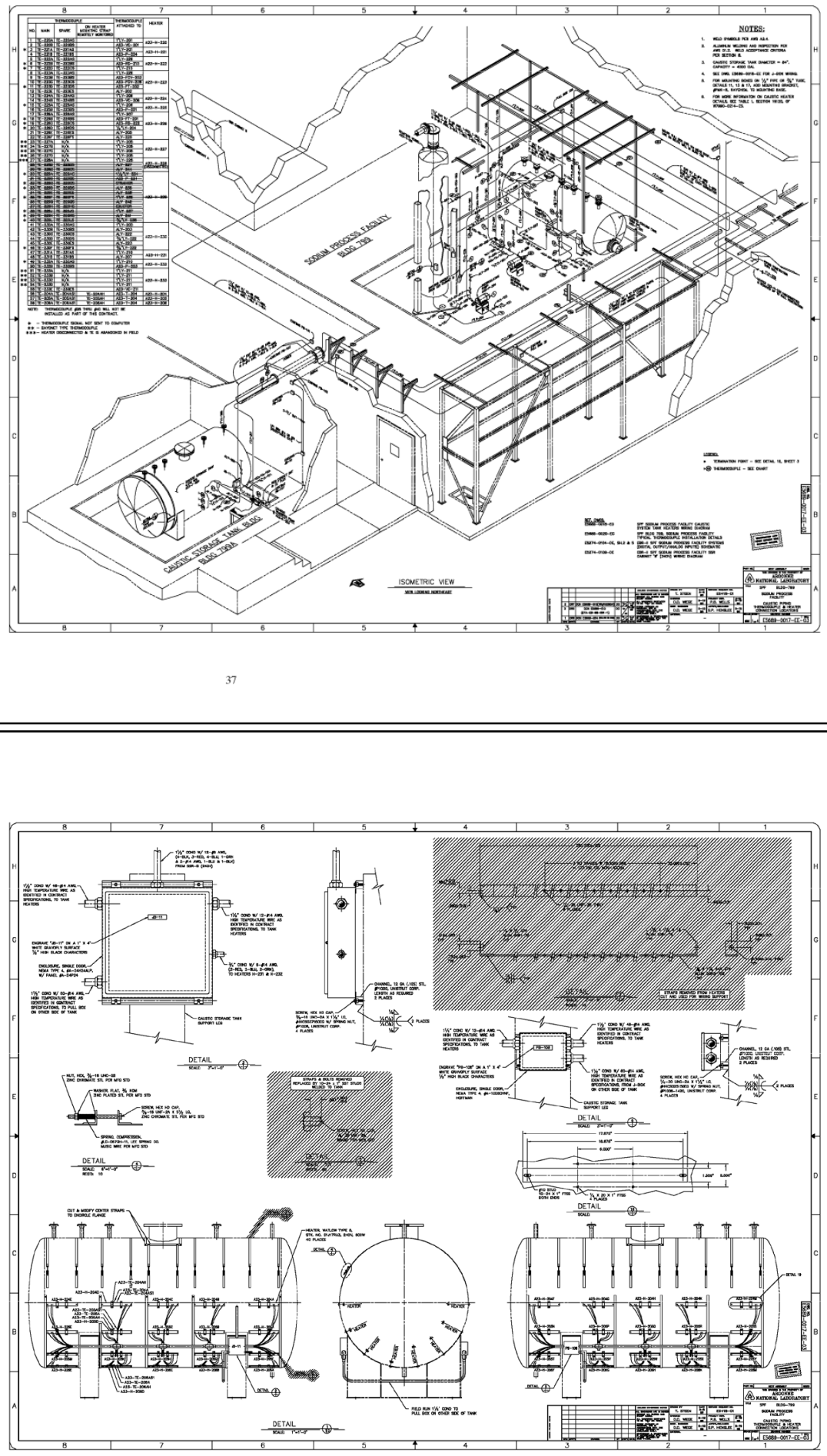

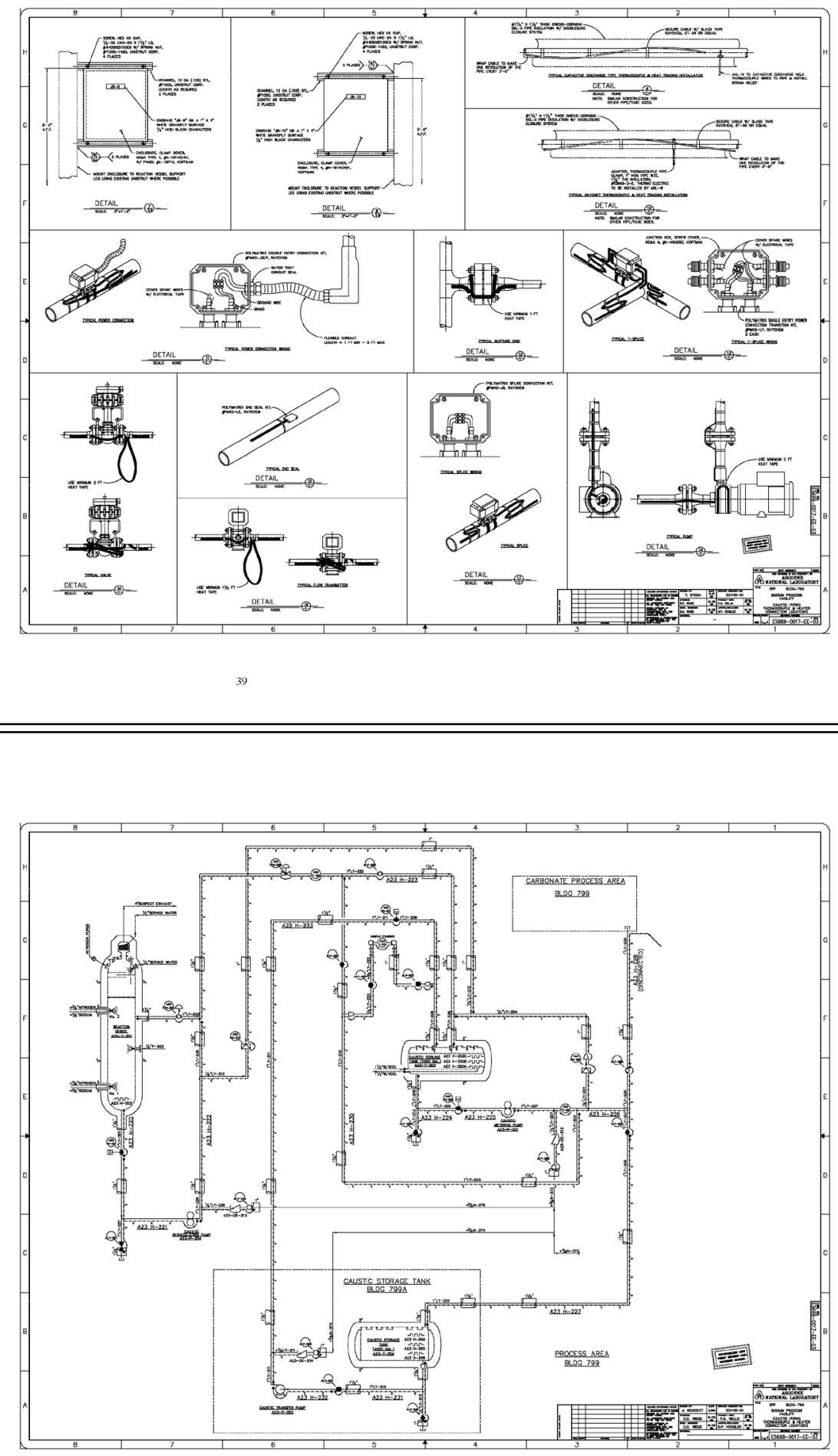

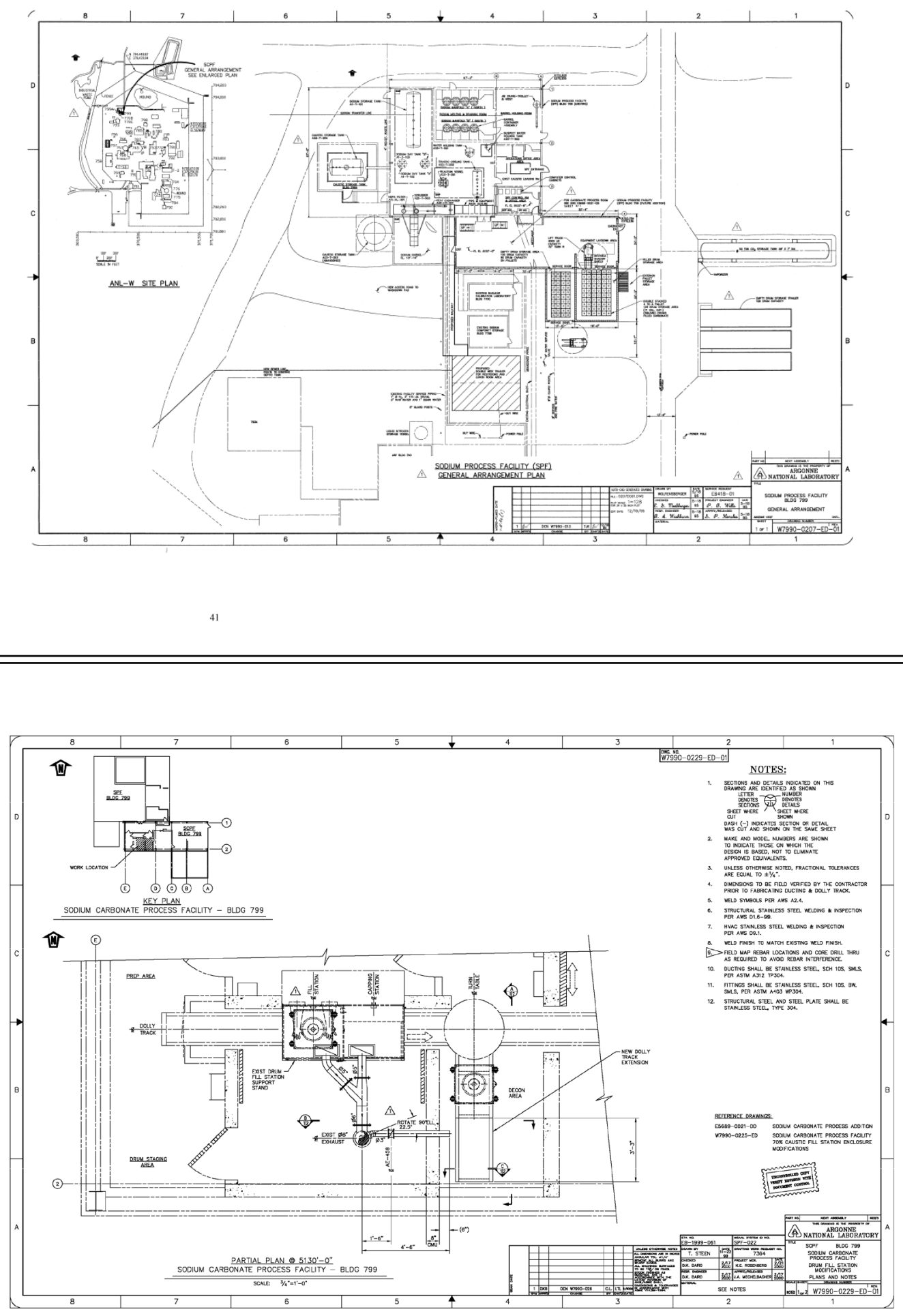

42 


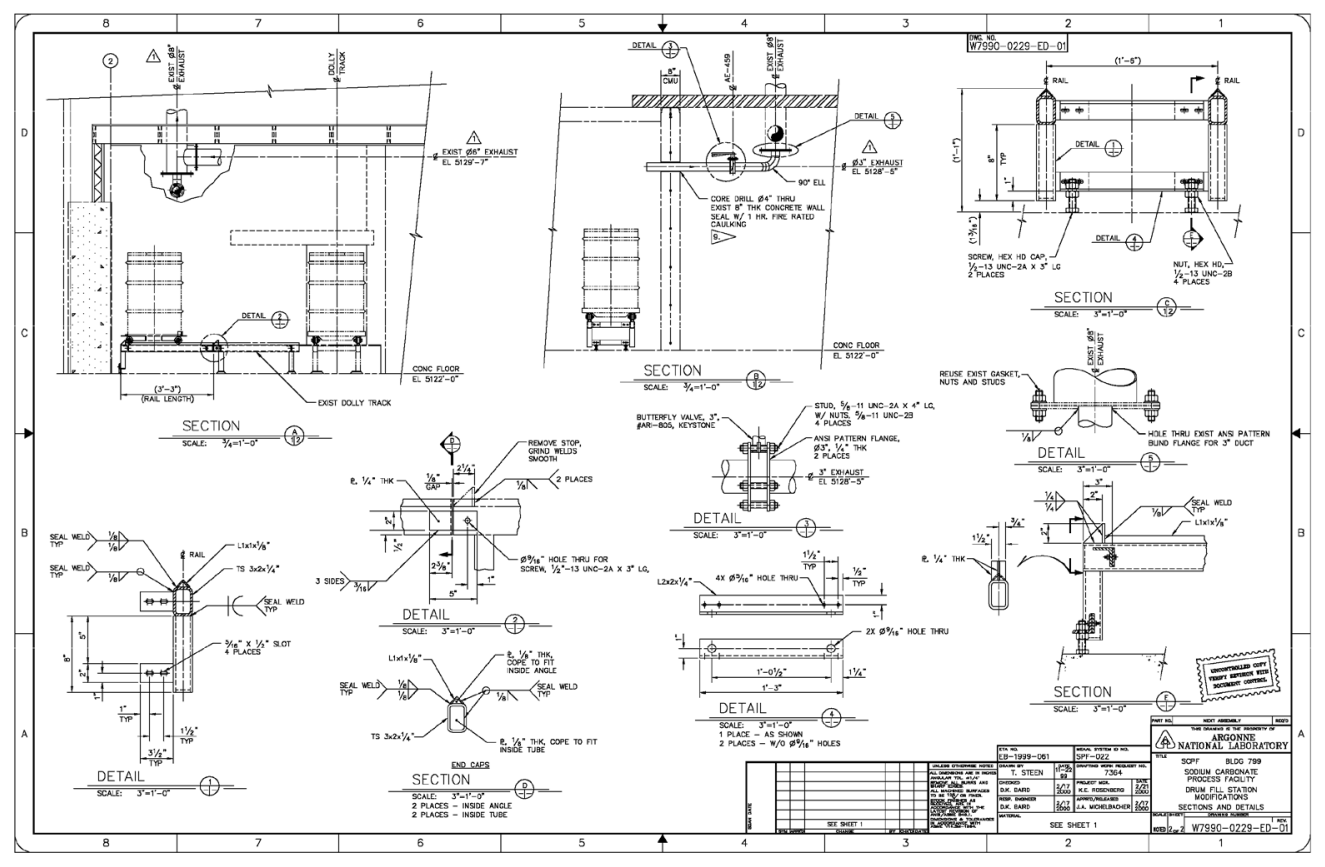


Appendix C

Photographs

44 
MFC-799, 799A, 770B, and 770C Photo Description Log

Sodium Processing Facility MFC-799 - Equipment Laydown Area

P1015258

Filled Drum Room (looking south)

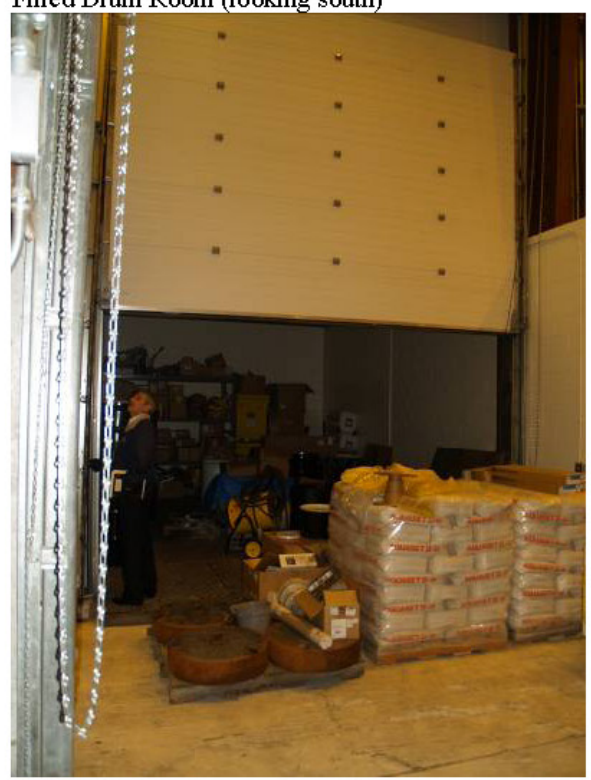


P1015259

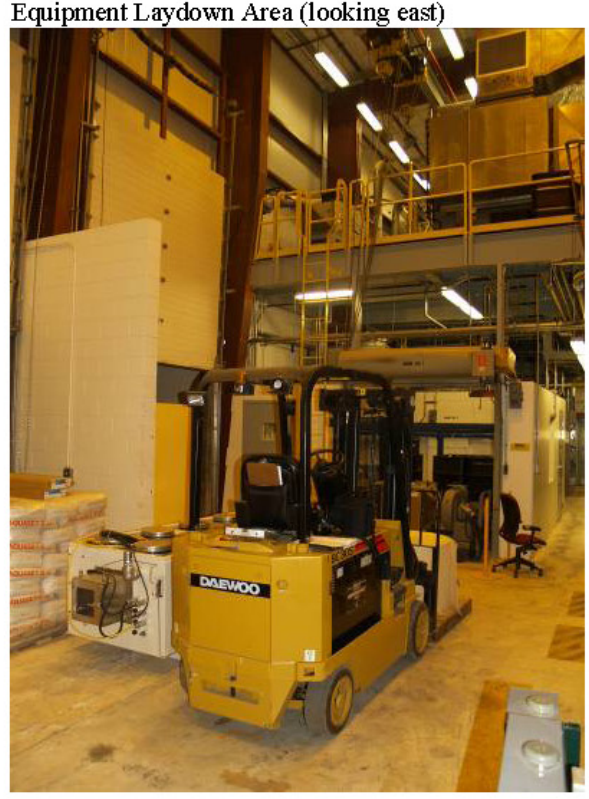

P1015260

Equipment Laydown Area (looking east)

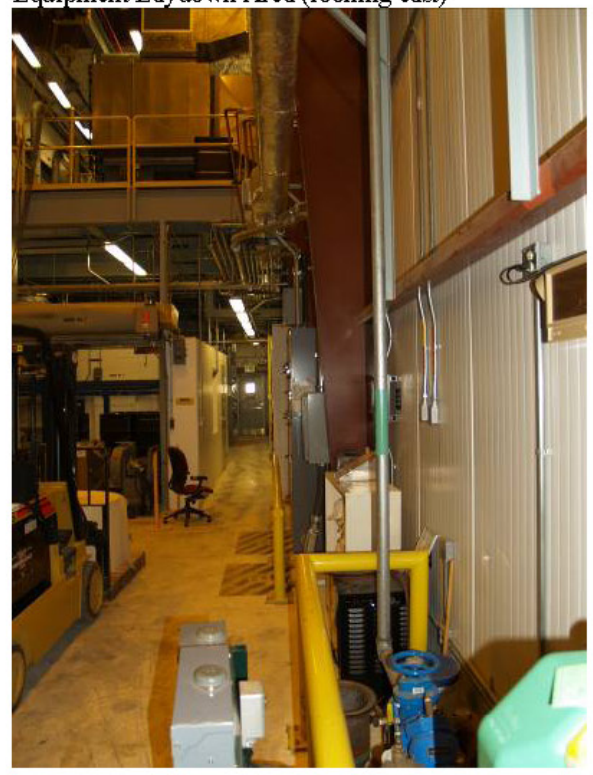




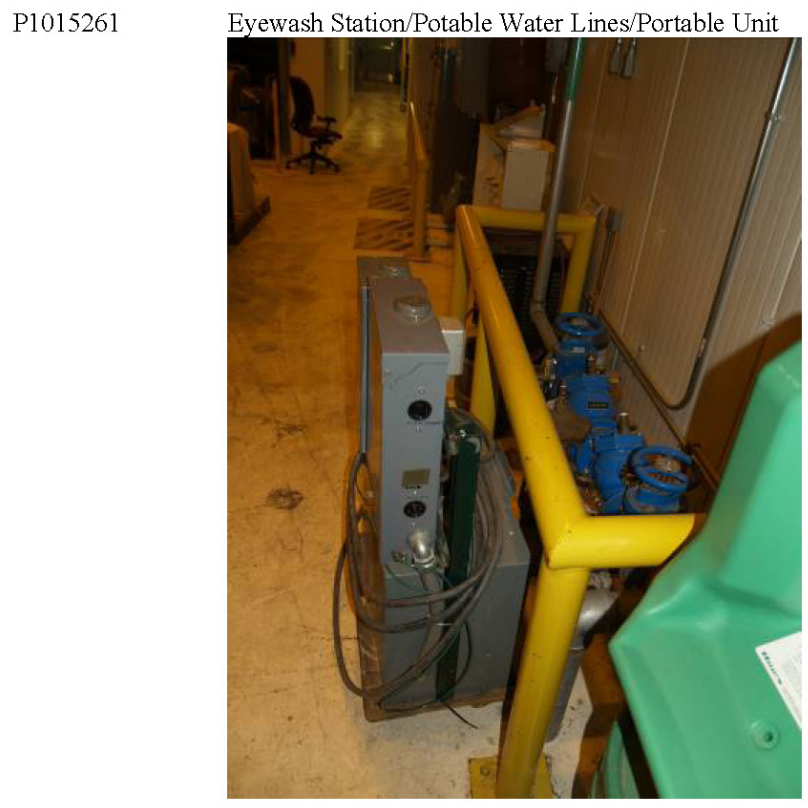

P1015262 Filled Drum Room/Excess Storage

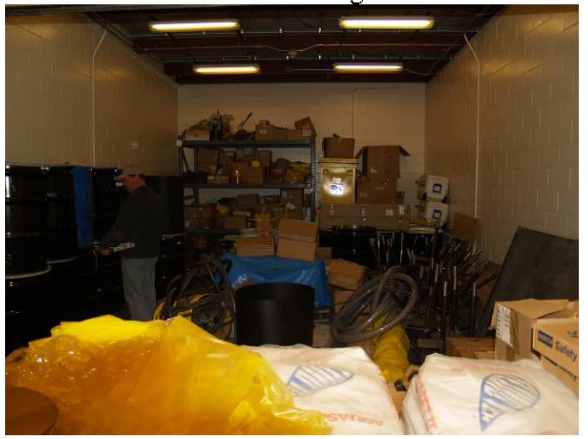


P1015263

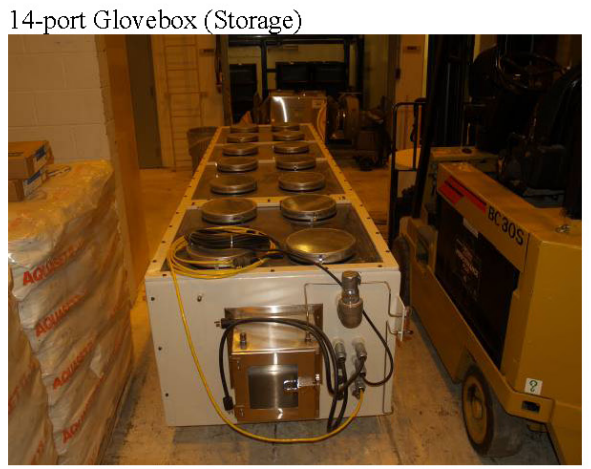

P1015264

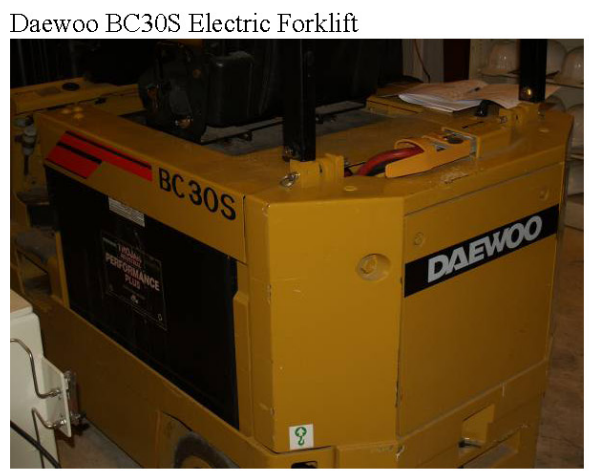

P1015265

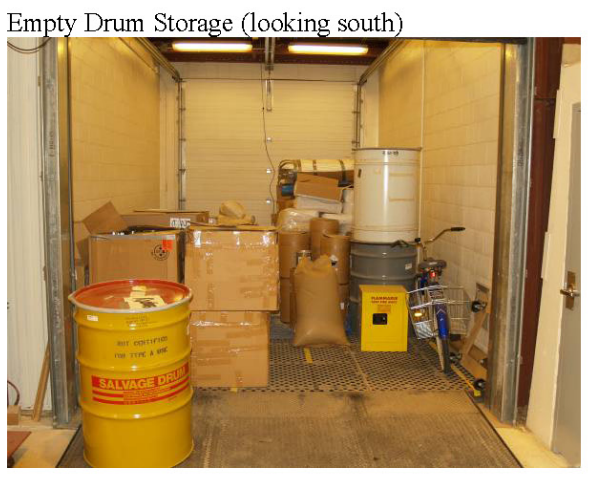


P1015266

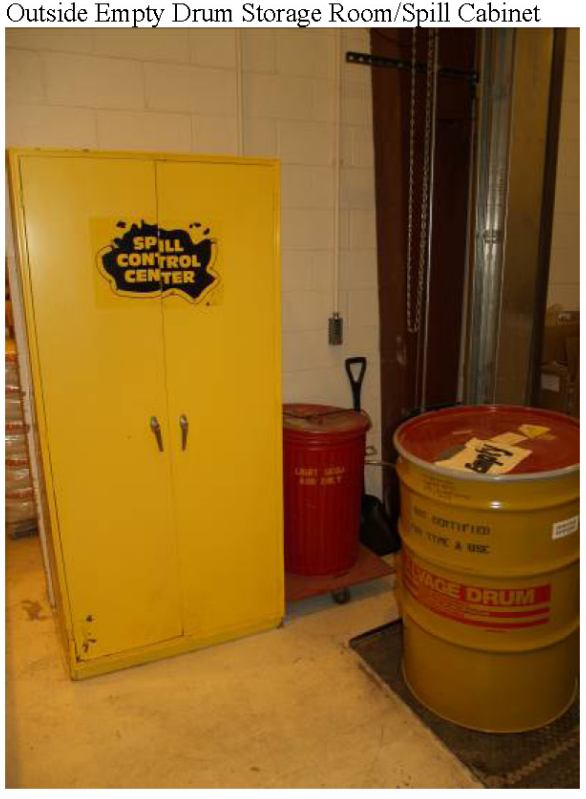

P1015267

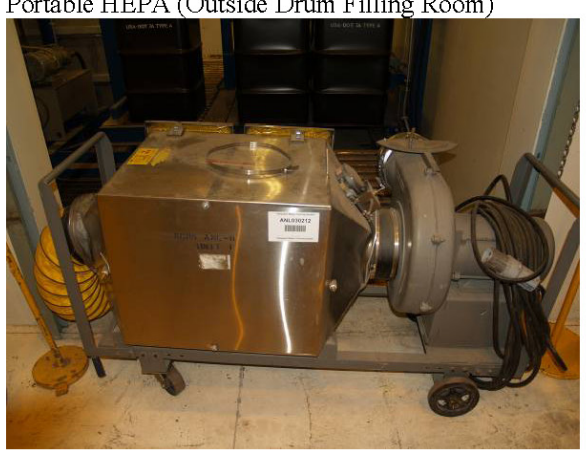


P1015268

Drum Filling Room (looking west)

P1015269 MCC-AE1 (north wall, Equipment Laydown Area)
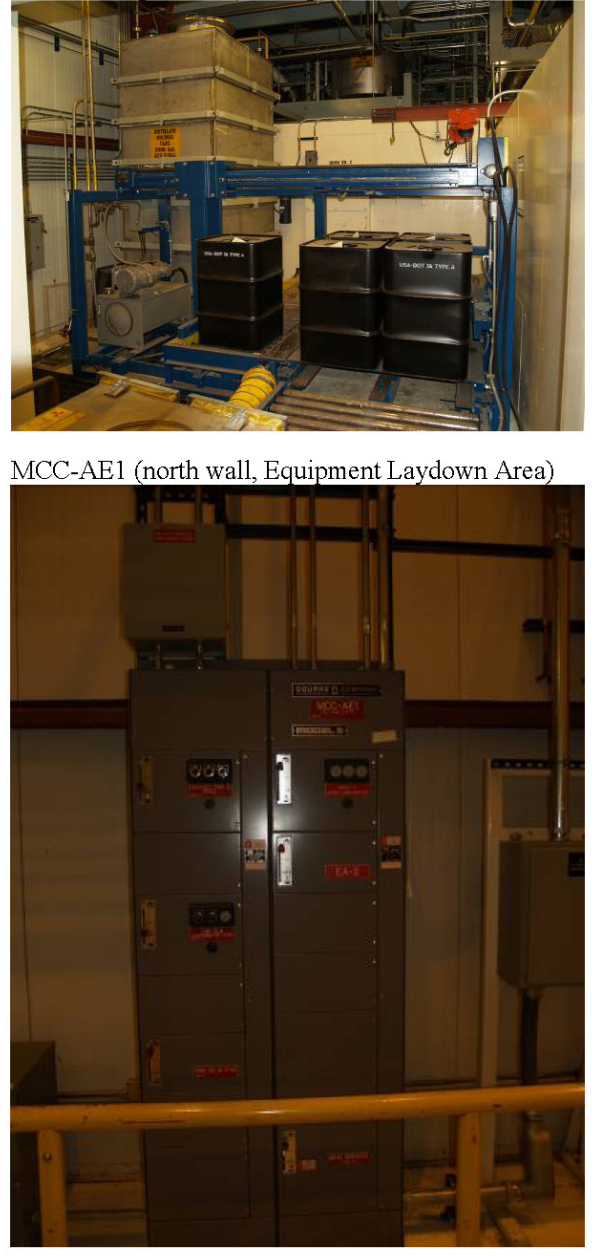
P1015270

Junction Box JB-200/Forklift Battery Disconnect (north wall, Equipment Laydown Area)

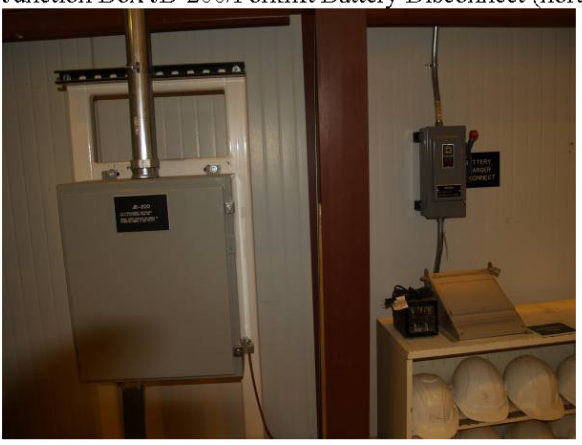

P1015271

Transformer TF-AE1 (north wall, Equipment Laydown Area)

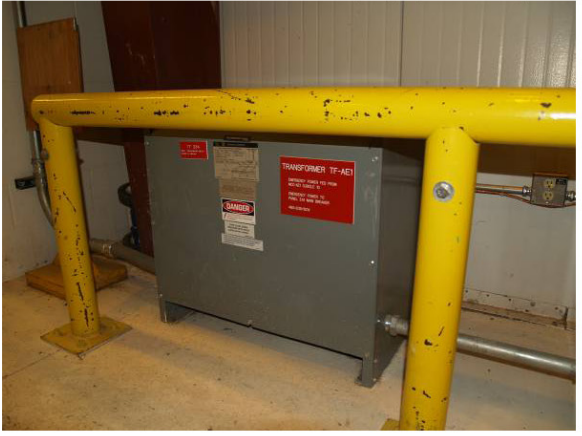




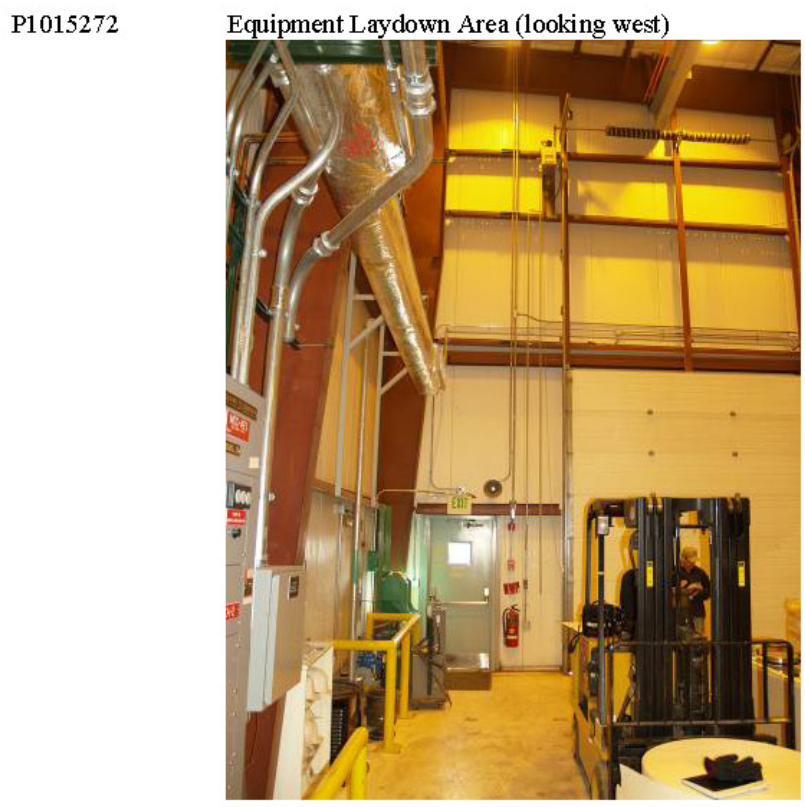

P1015273 Equipment Laydown Area (looking southwest)

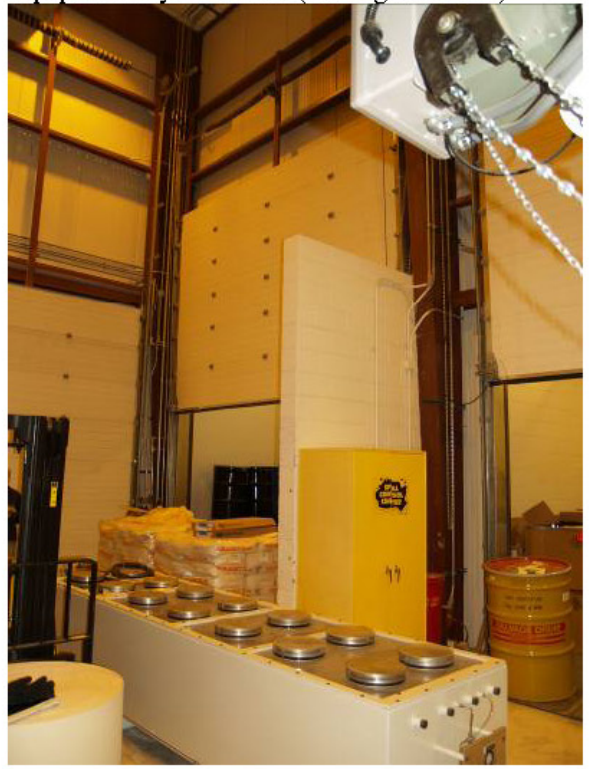




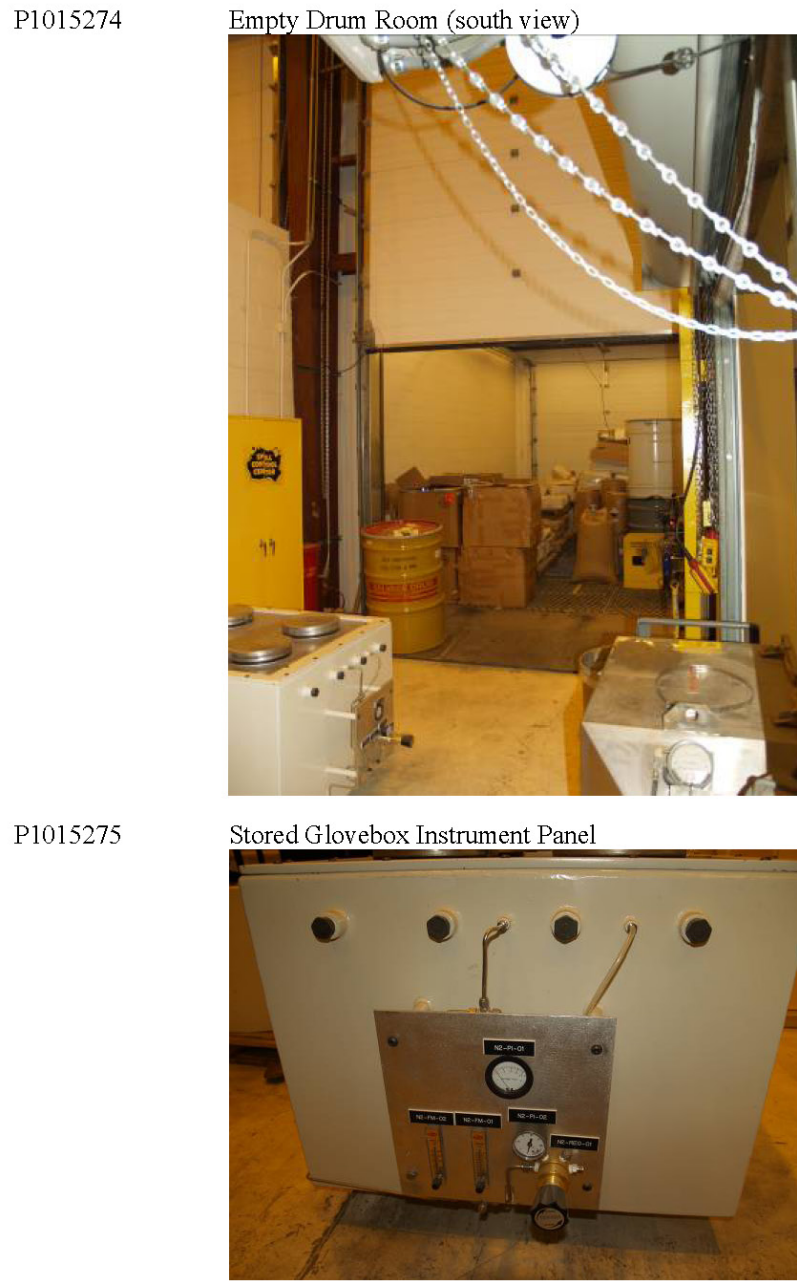


P1015276

Forklift Battery Charger (Trojan II)

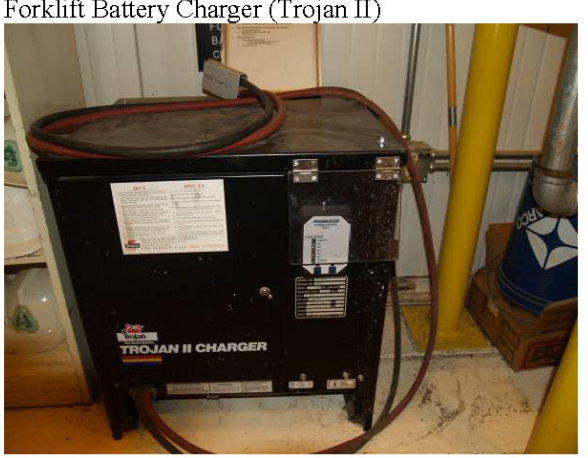

P1015277

Eyewash Station (northwest man door, Equipment Laydown Area)

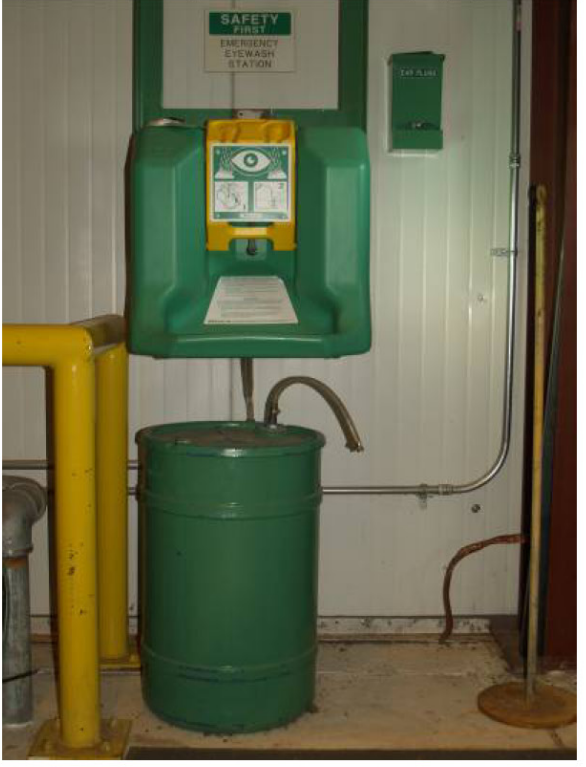


P1015278

Exit/Fire Alarm/Extinguisher (northwest man door, Equipment Laydown Area)

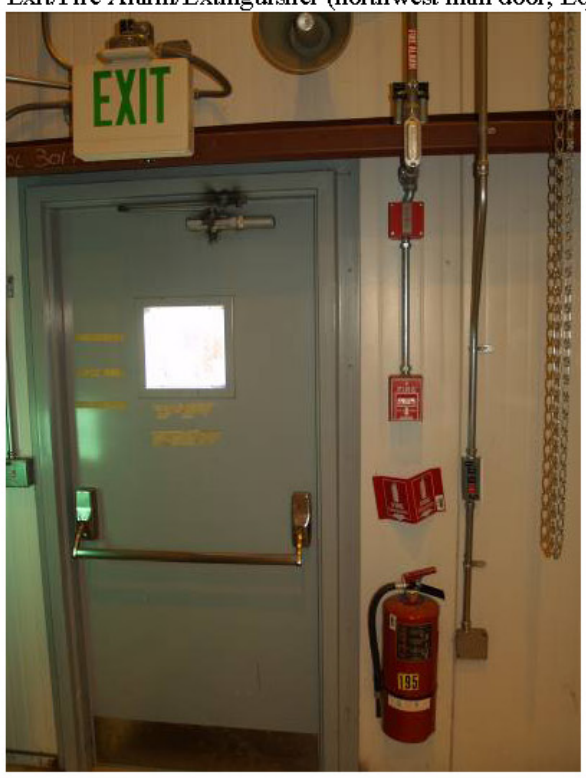

P1015324

Mezzanine View - Equipment Laydown Area

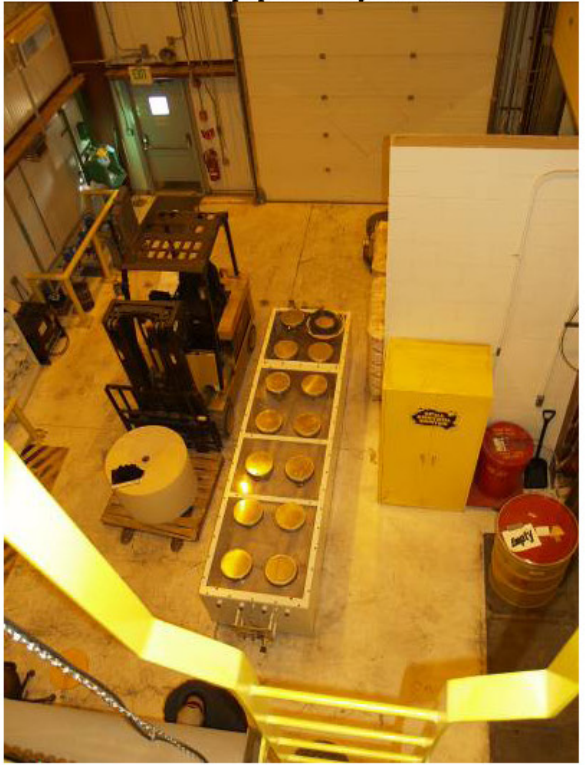




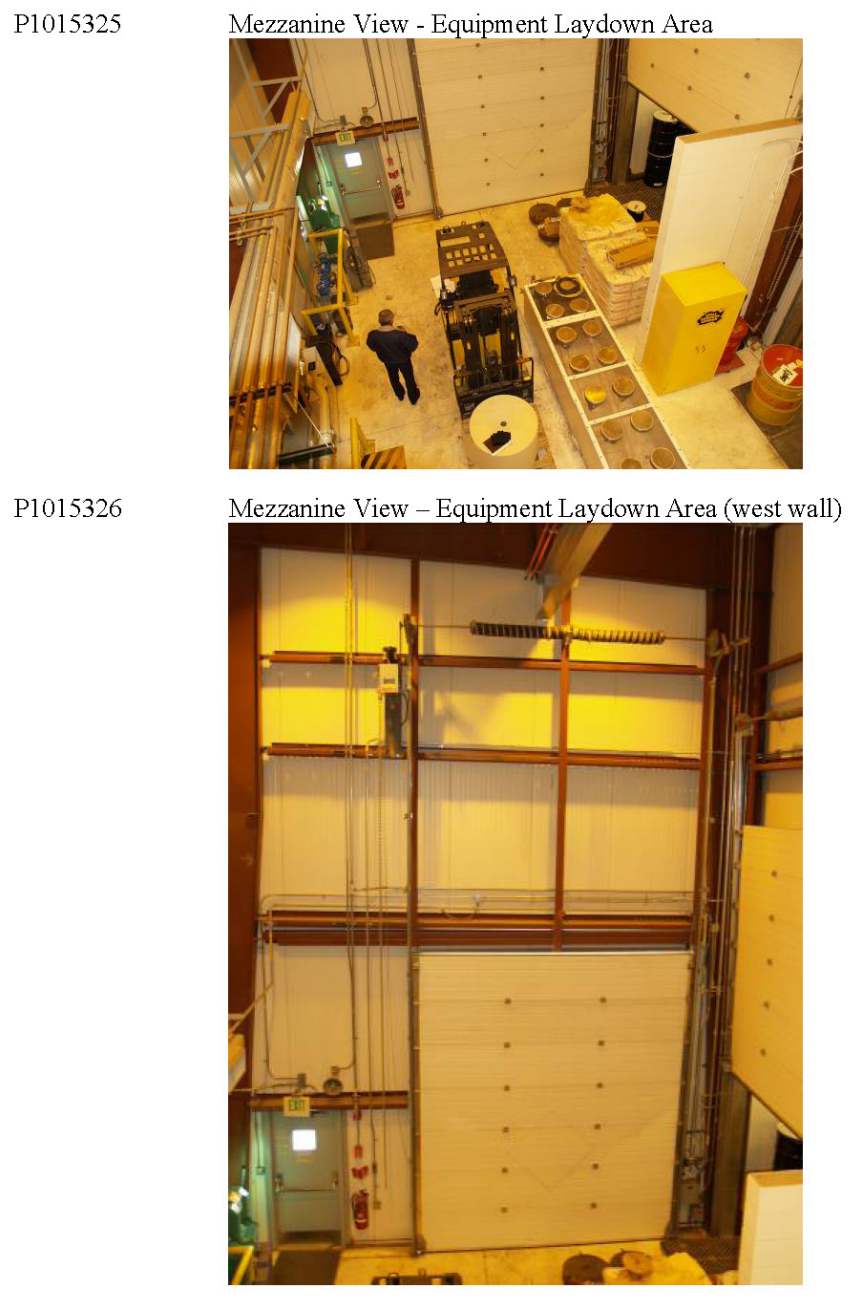

56 


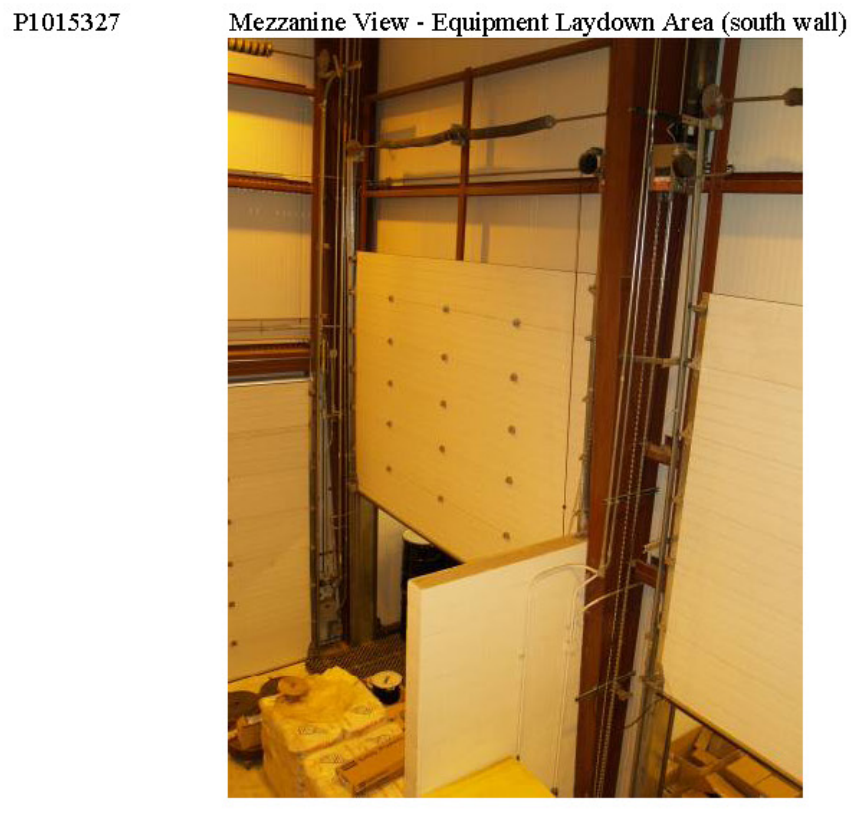

P1015328

Mezzanine View - Equipment Laydown Area (south wall)

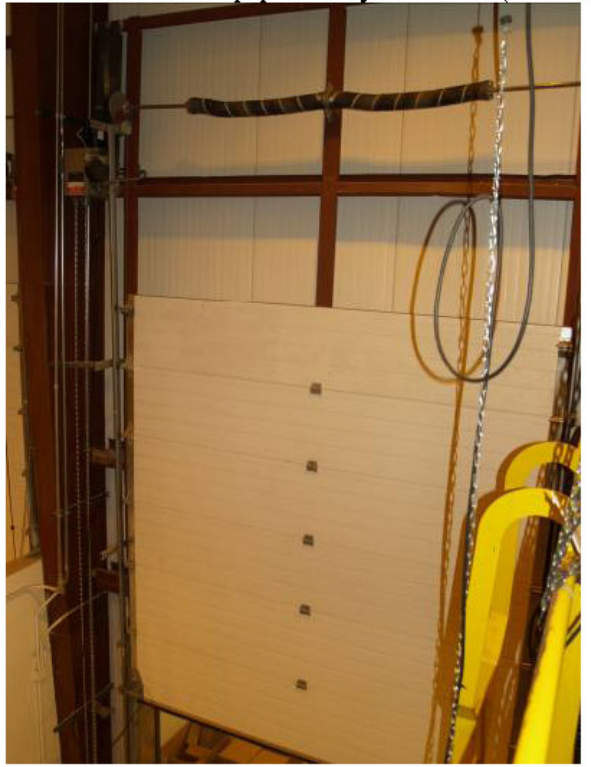


Sodium Processing Facility MFC-799 - Carbonate Sodium Processing Facility

P1015279 Mezzanine/TRANE Unit/2 to 5-Ton Rail Crane (looking south)

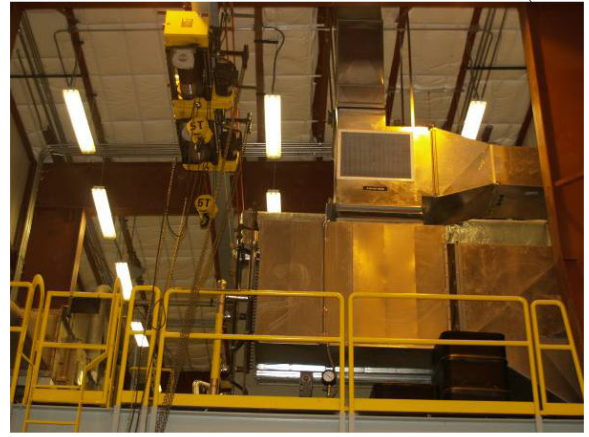

P1015280

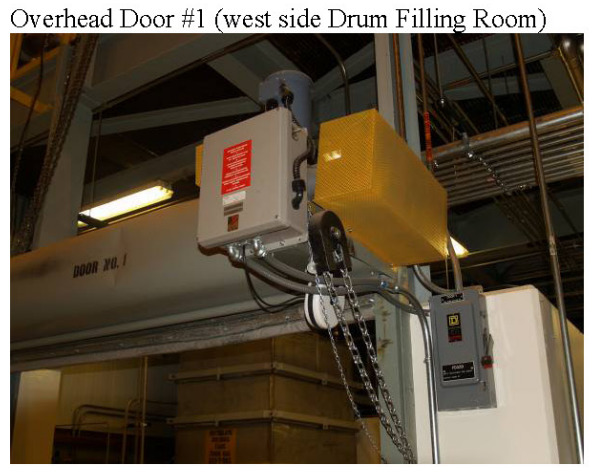


P1015281

Leaded Window looking into Drum Filling Area/Palletizer Control Station

P1015282

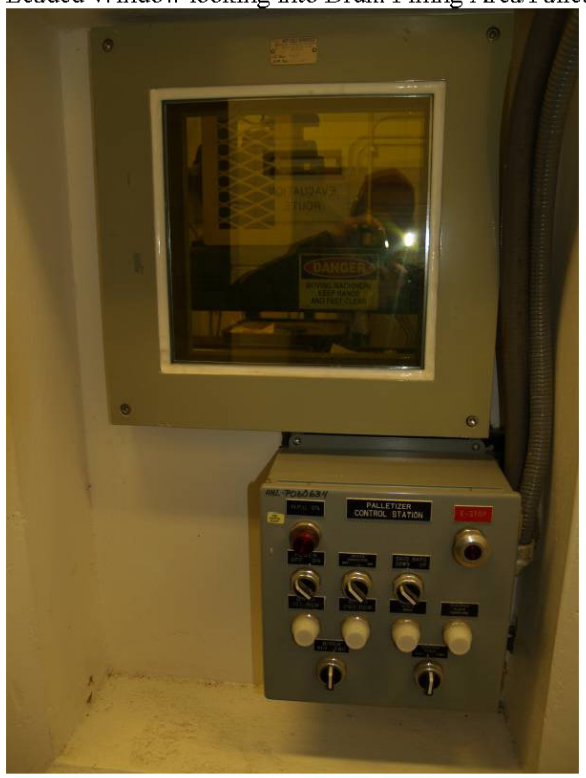

Stairway to Mezzanine (looking east)/Main MCC's for Drum Filling Area

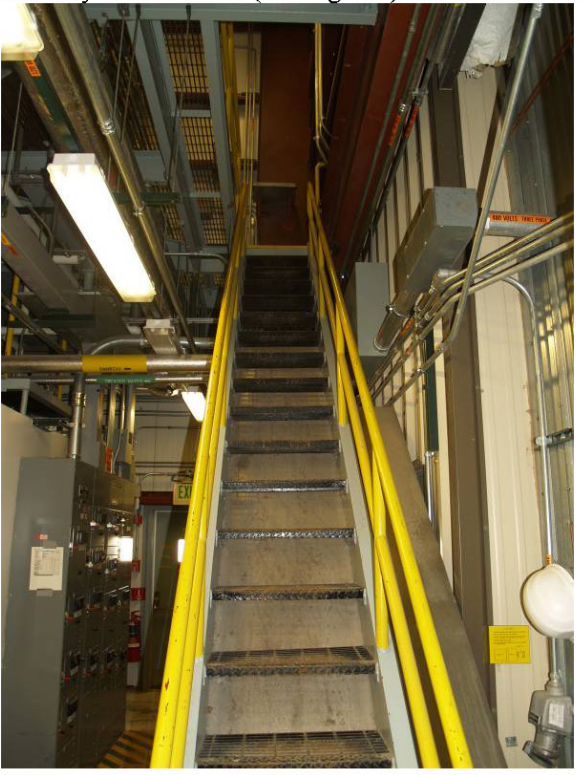




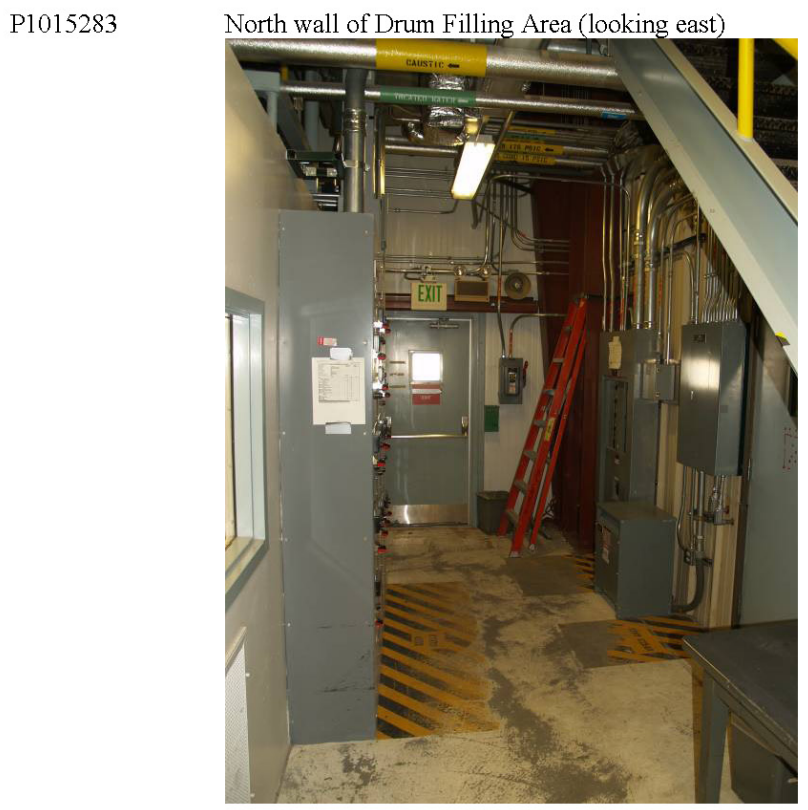

P1015284

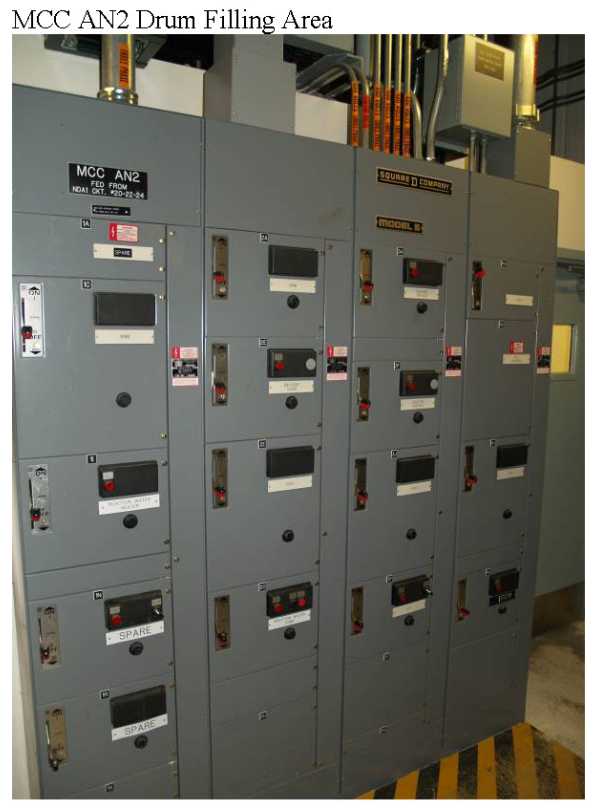




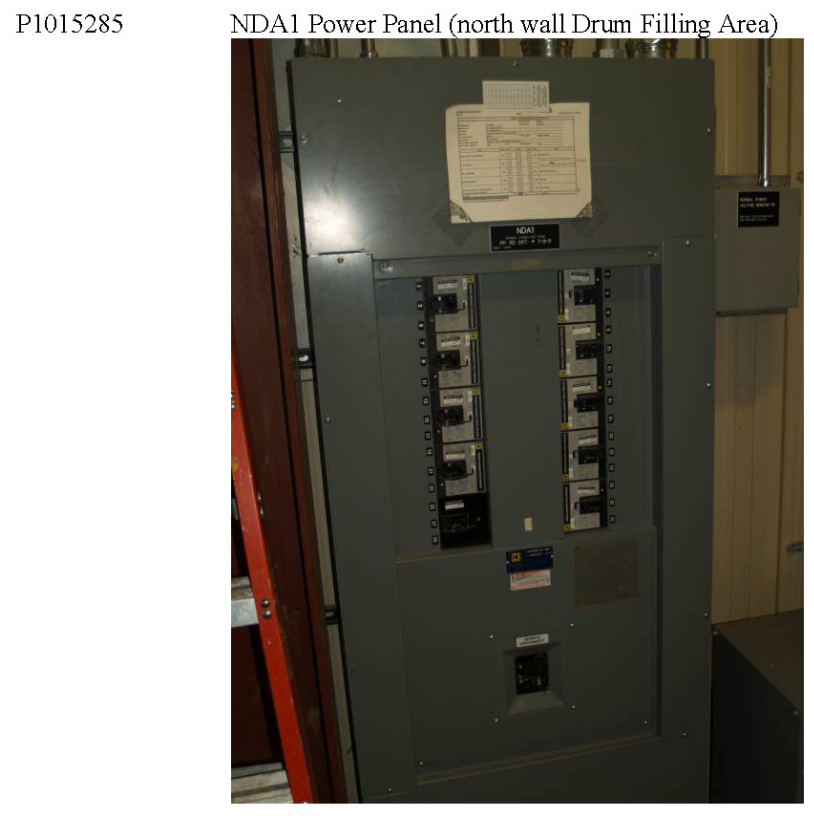

P1015286

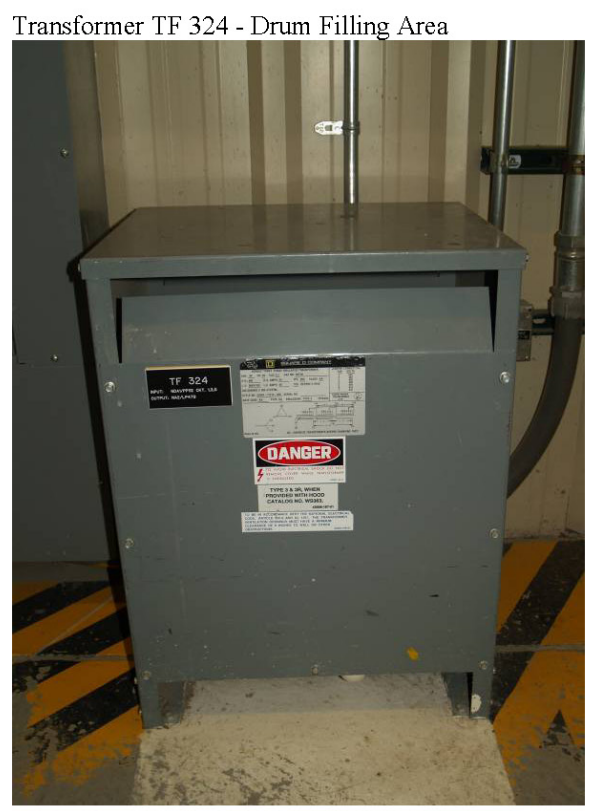


P1015287

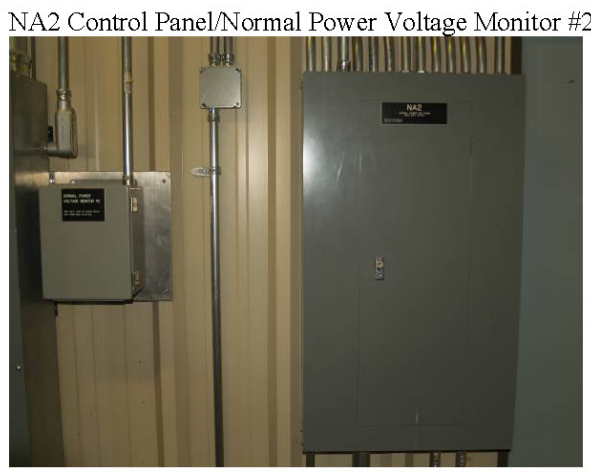

P1015288

Bulk Solids Cooler Power Monitor Cabinet A30-JT-1002 - Drum Filling Area

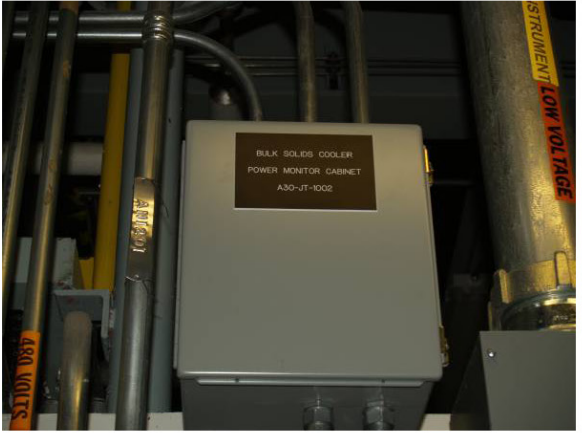

P1015289

480 and 120 Volt Leads into MCC AN2

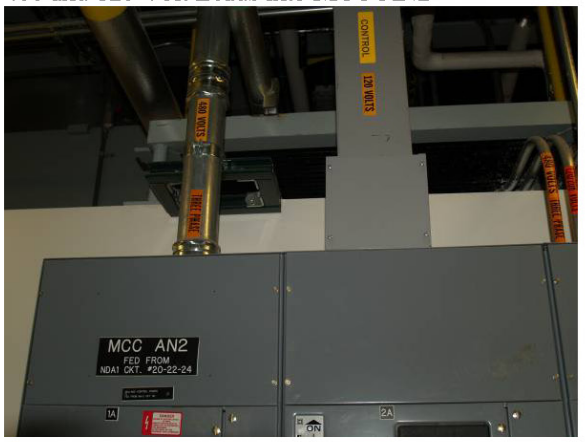


P1015290

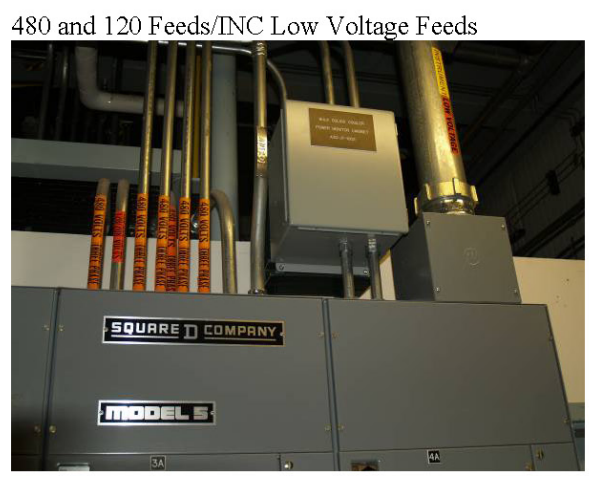

P1015291

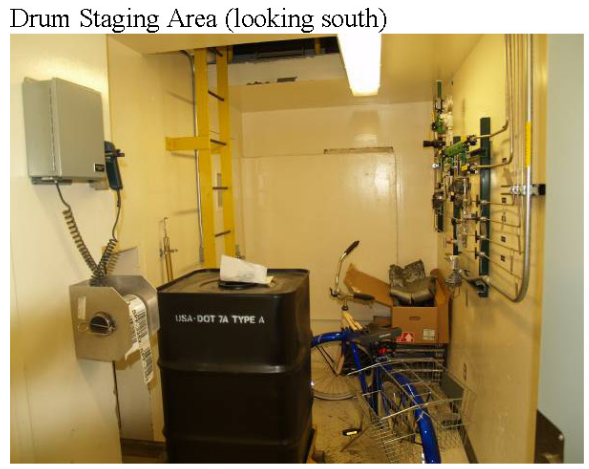


P1015292

Control Panel Control Box for Drum Filling Room (looking west)

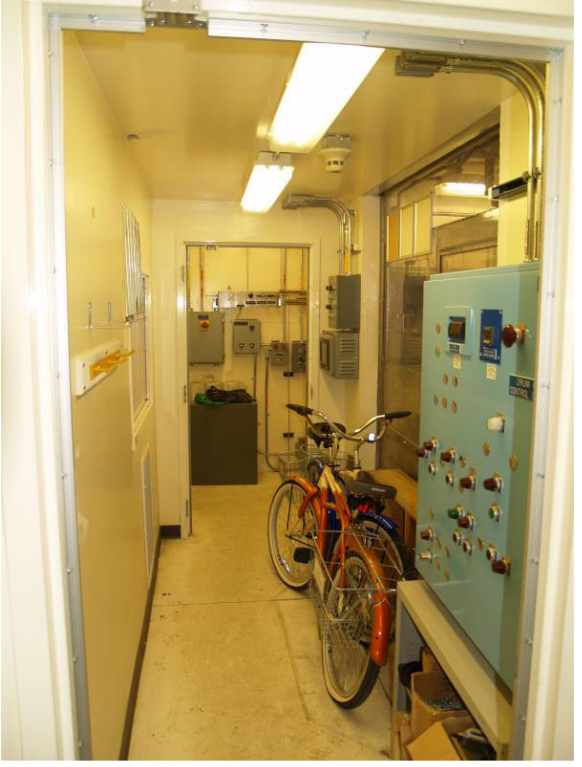

P1015293

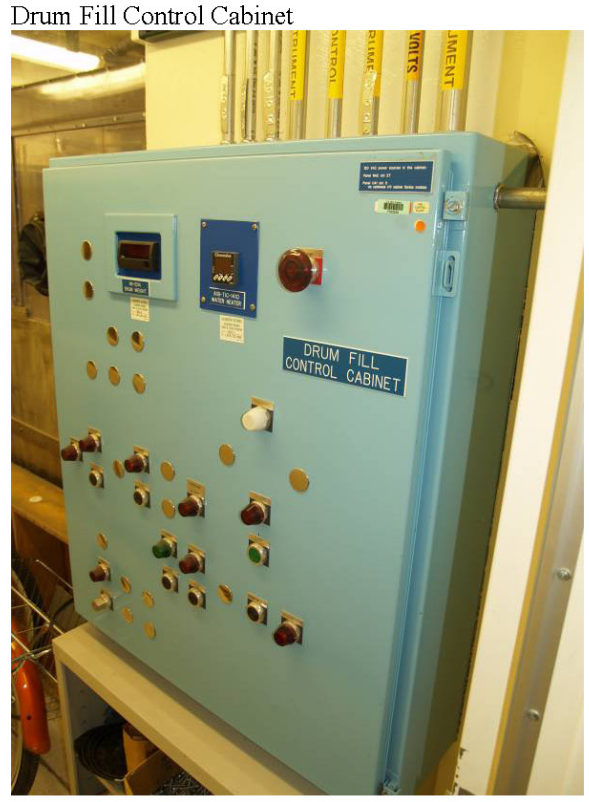


P1015294

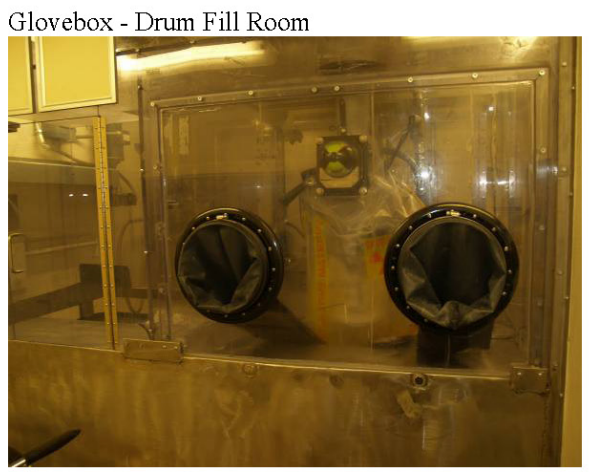

P1015295

Controls for Drum Filling Station

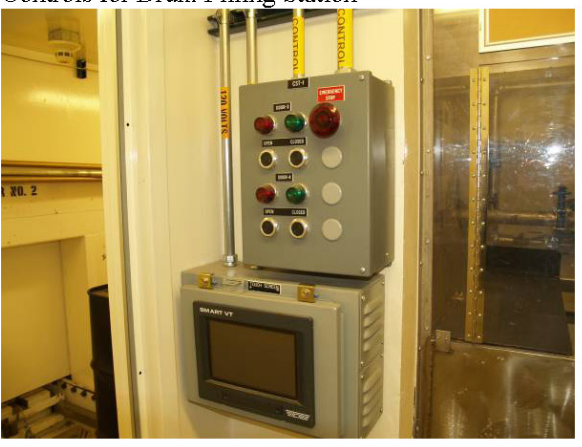

P1015296

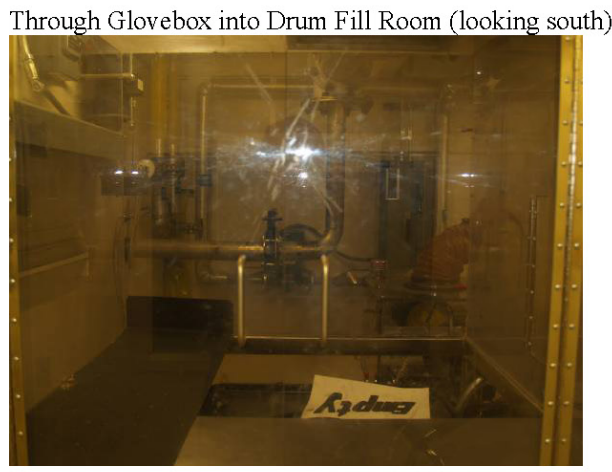


P1015297

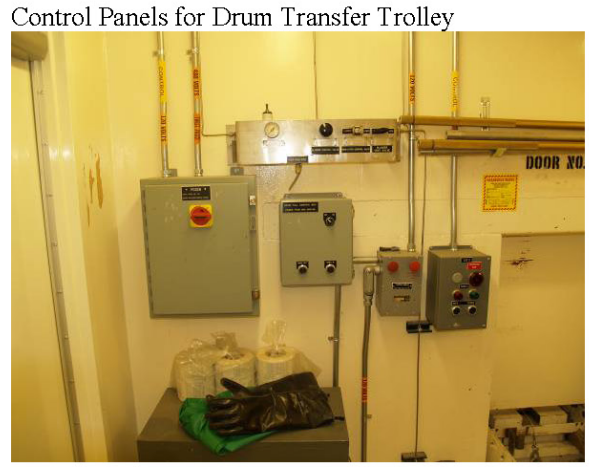

P1015298

Drum Transfer Trolley Weigh Station

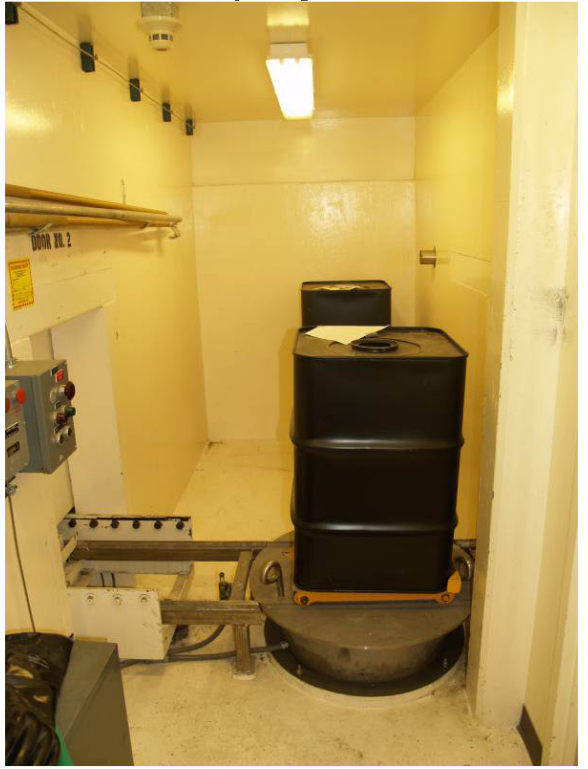


P1015299

Through Man Door into Drum Fill Room (looking west)

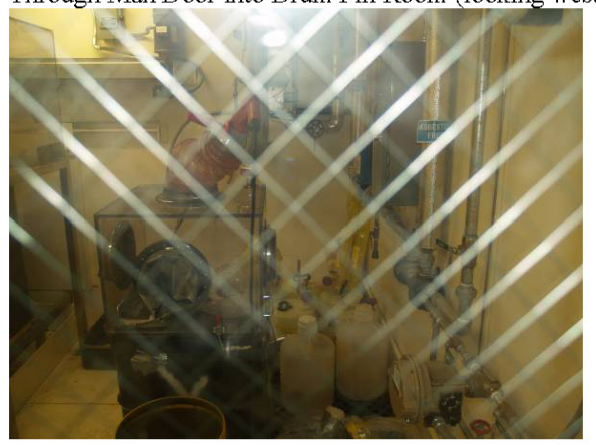

P1015300

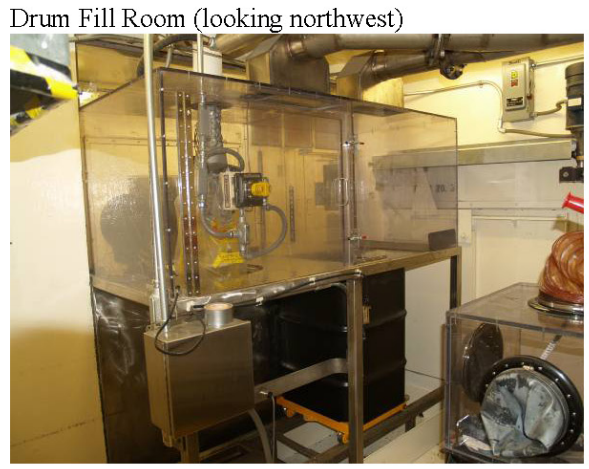




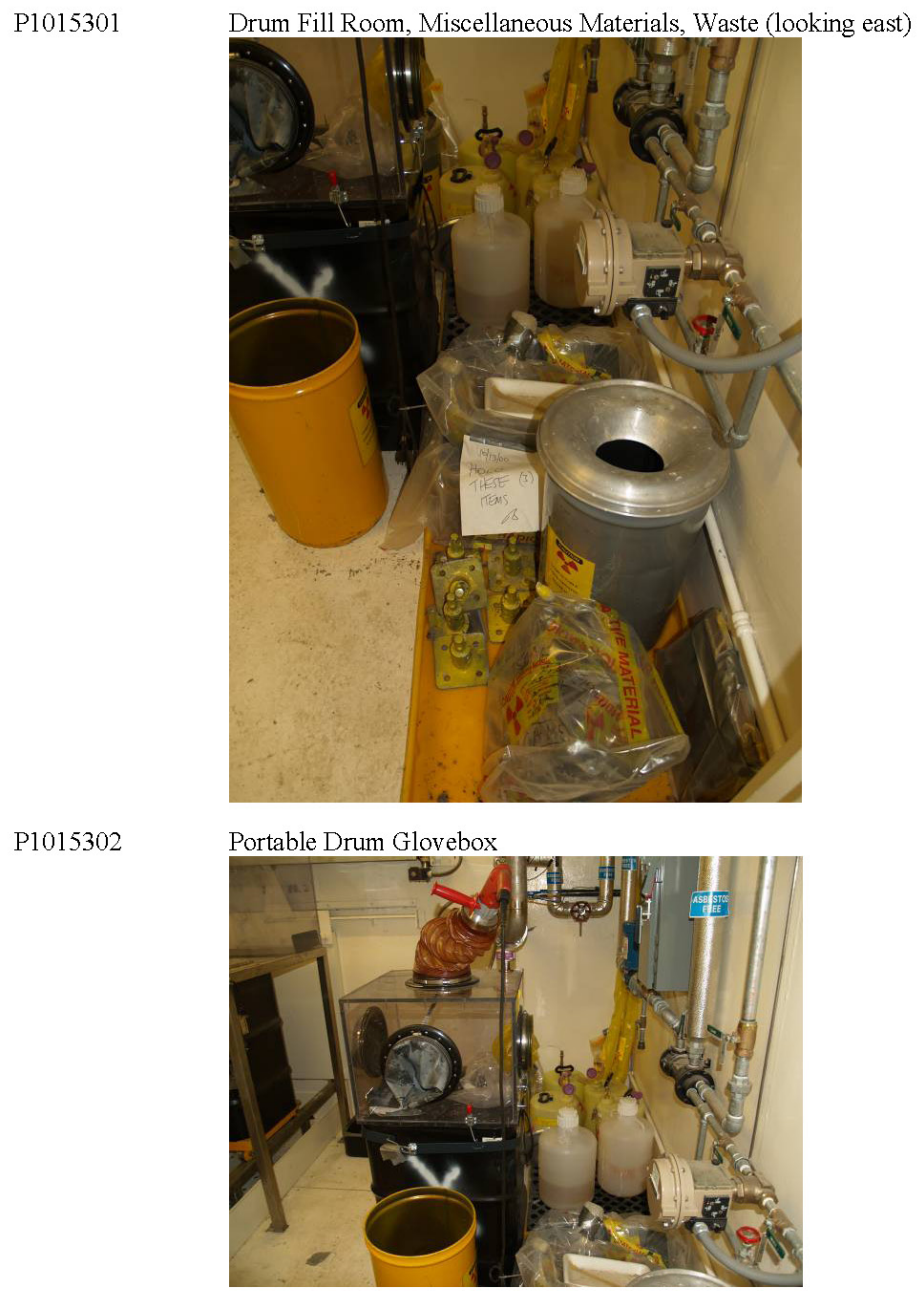


P1015303

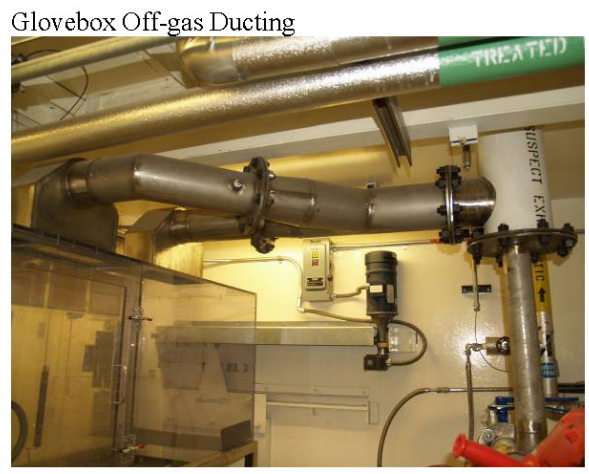

P1015304

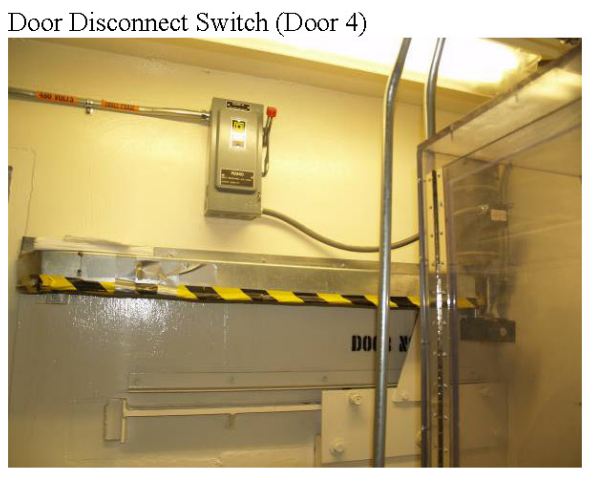

P1015305

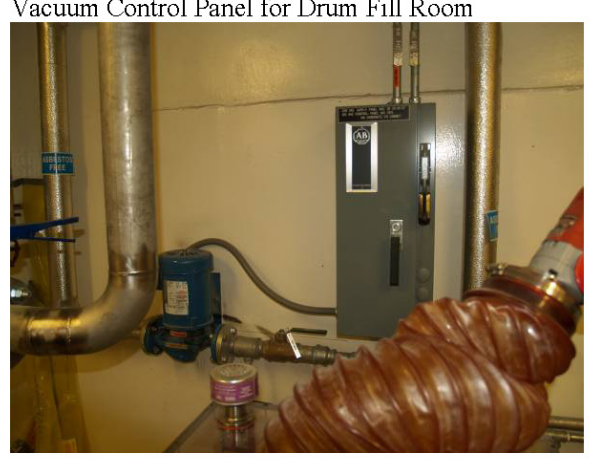


P1015306

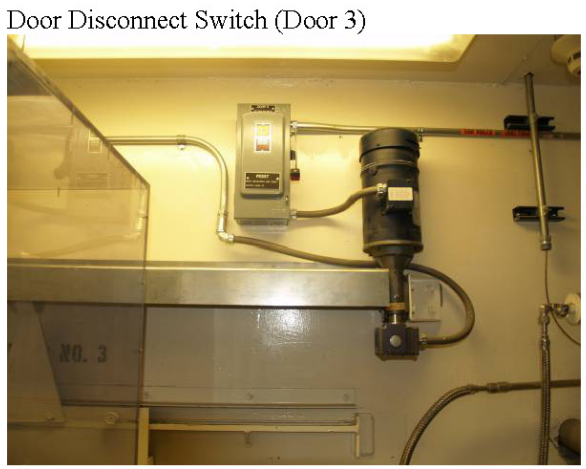

P1015307

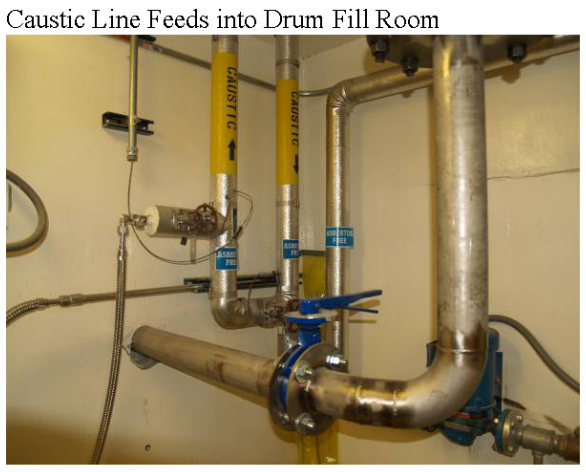

P1015308

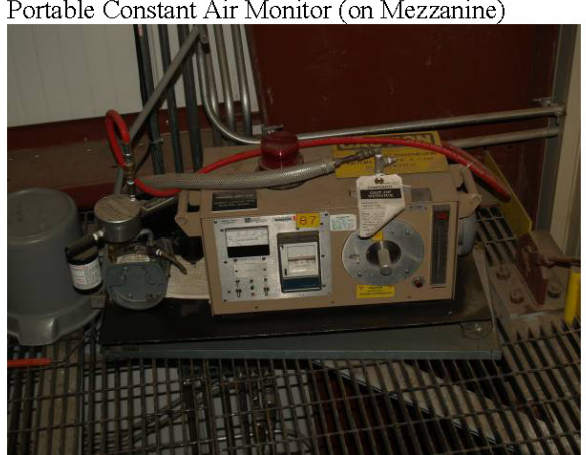




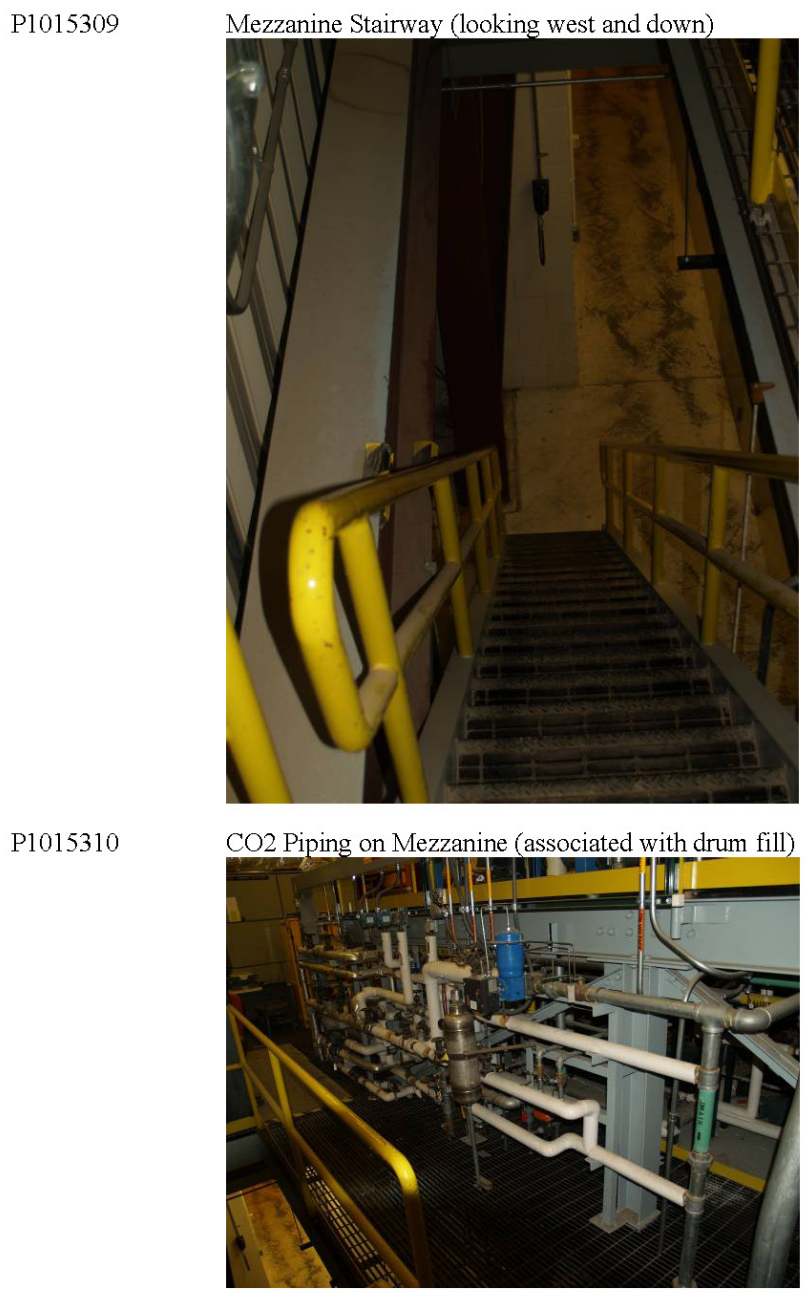


P1015311

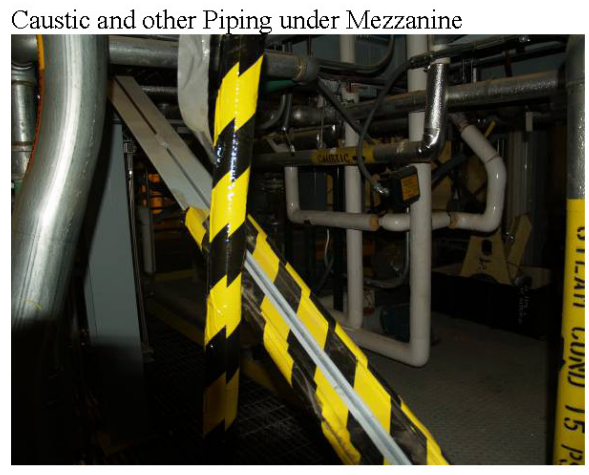

P1015312

Steam and Condensate Piping under Mezzanine

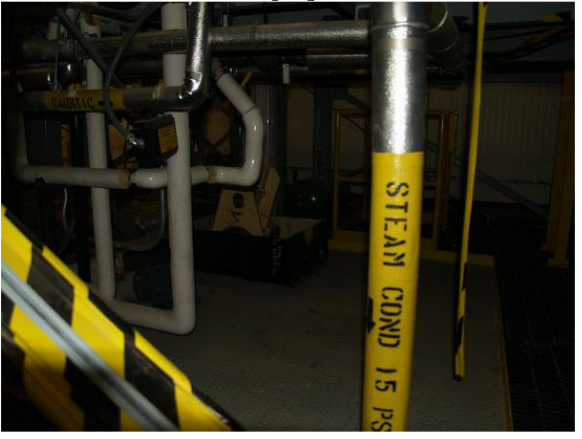

P1015313

Thin Film Evaporator Subsystem (never functioned properly - abandoned in place)

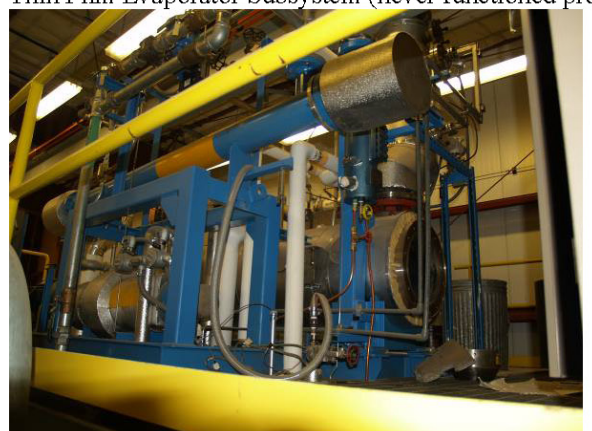




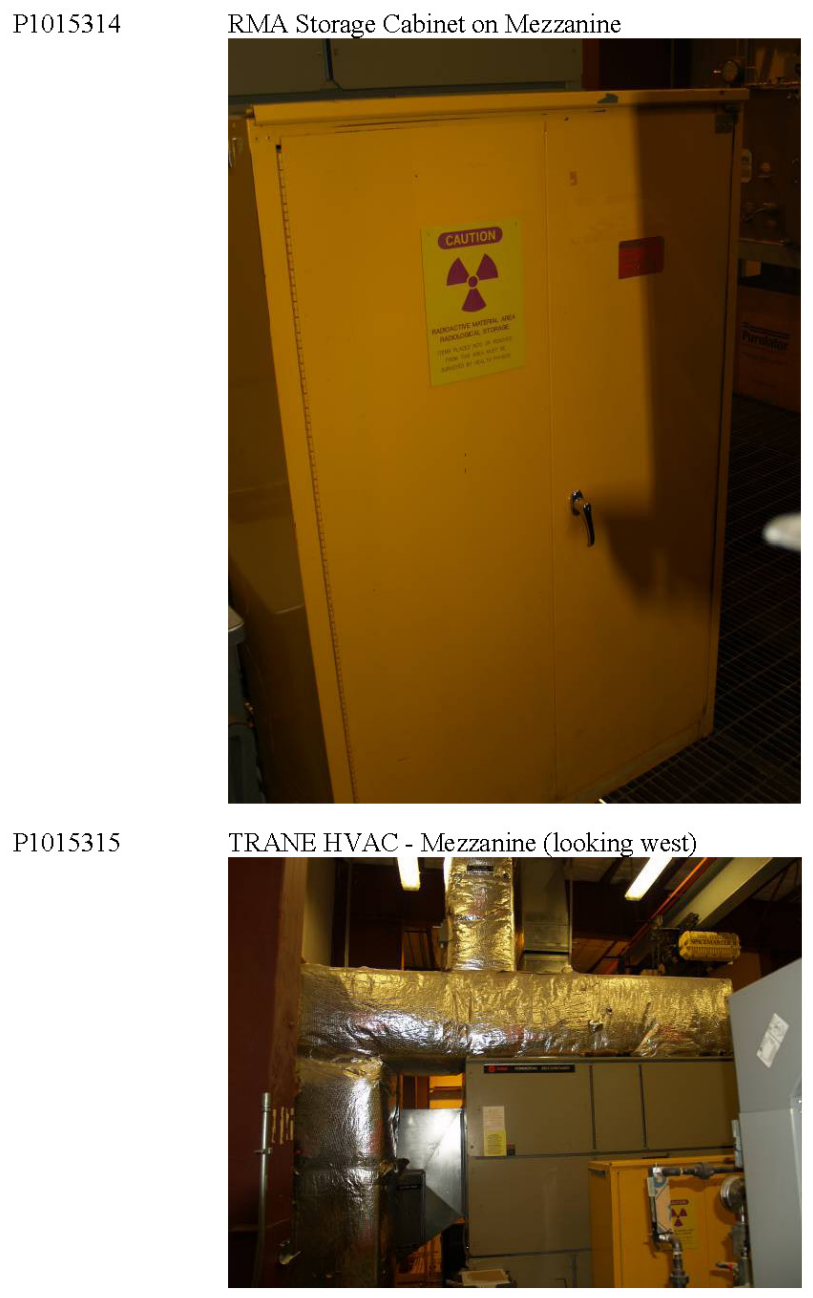


HVAC Control Panel A31-AHU-1301 - north wall of Mezzanine

P1015317
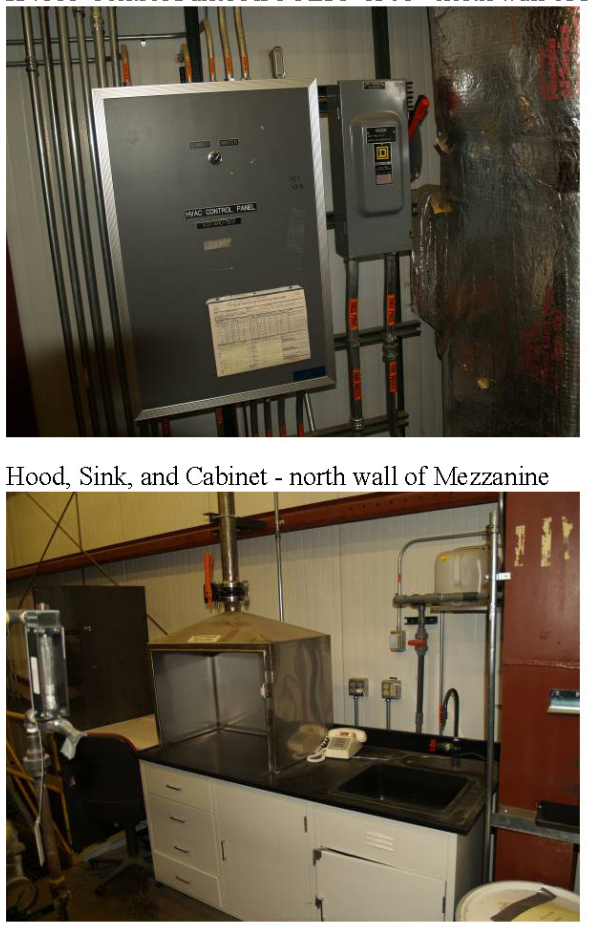

P1015318

Flanders HEPA for Carbonate System Off-gas (looking south)

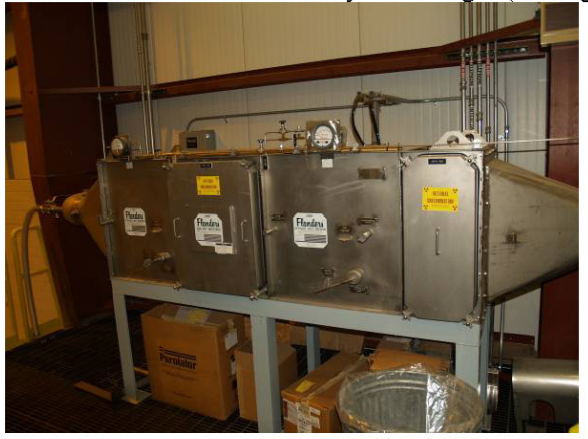




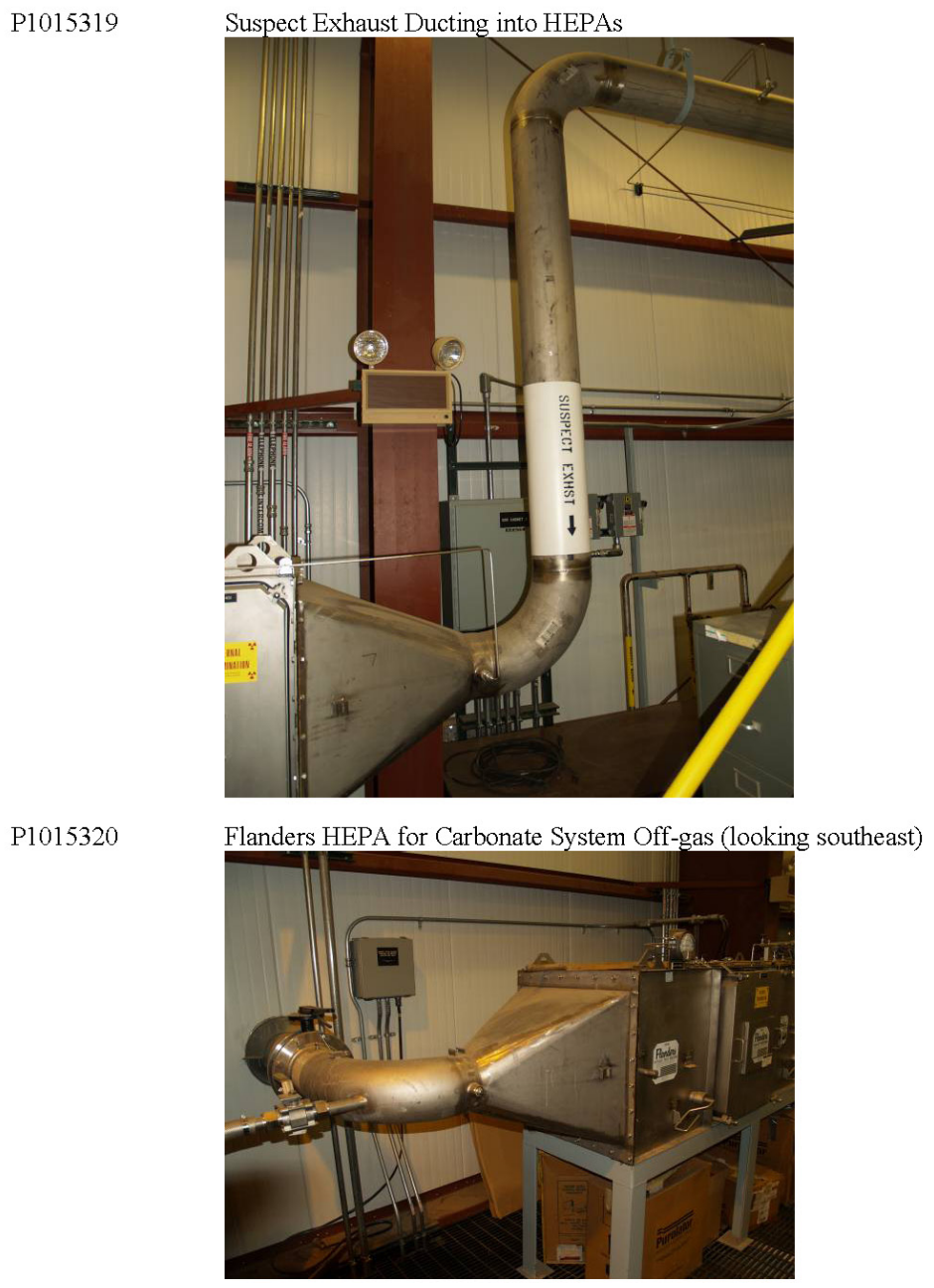




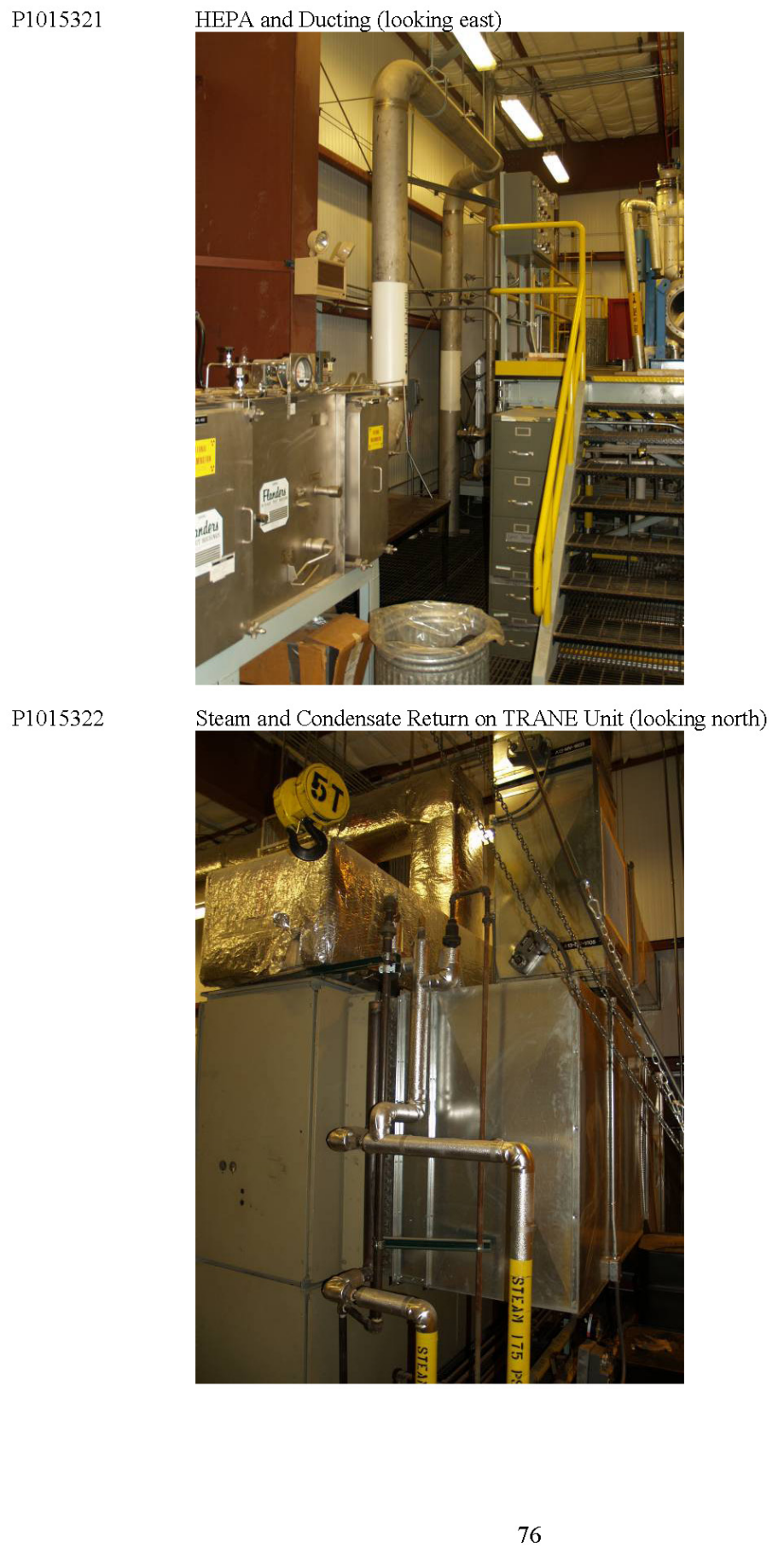


P1015323

Steam and Condensate Return on TRANE Unit (looking north)

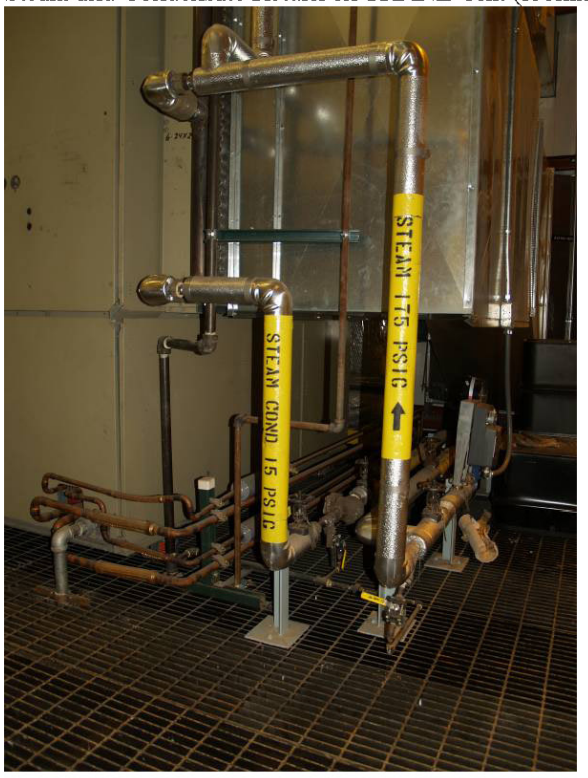

P1015329

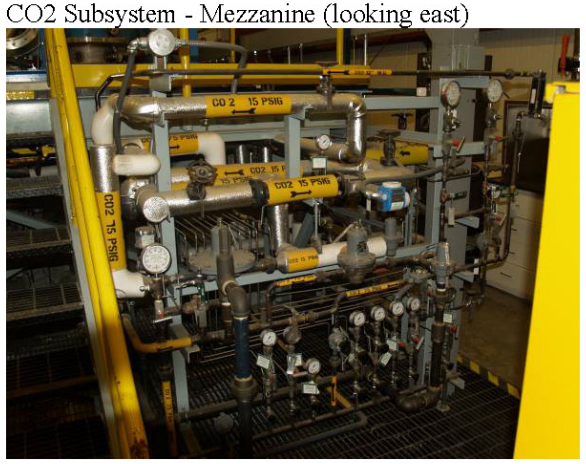


P1015330

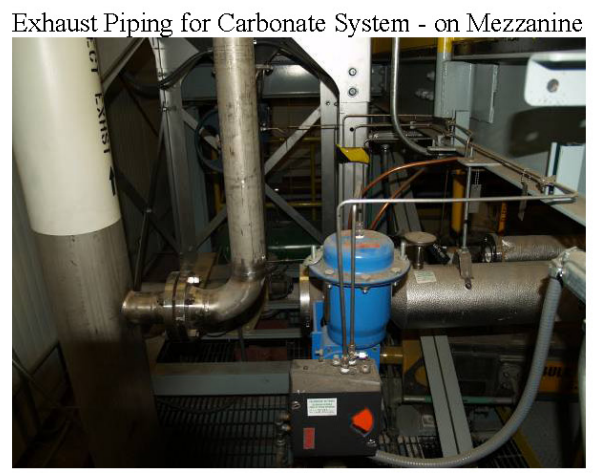

P1015331

Fan for Exhaust Blower

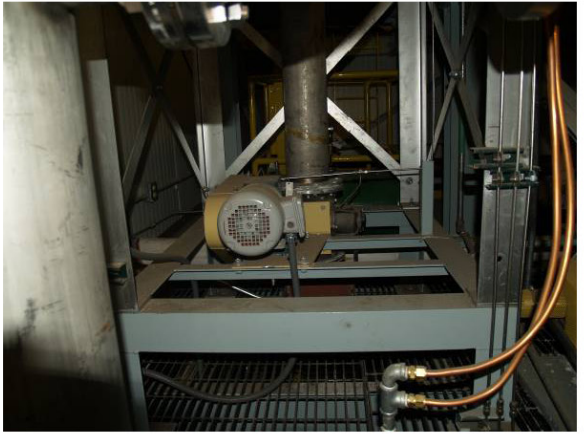

P1015332

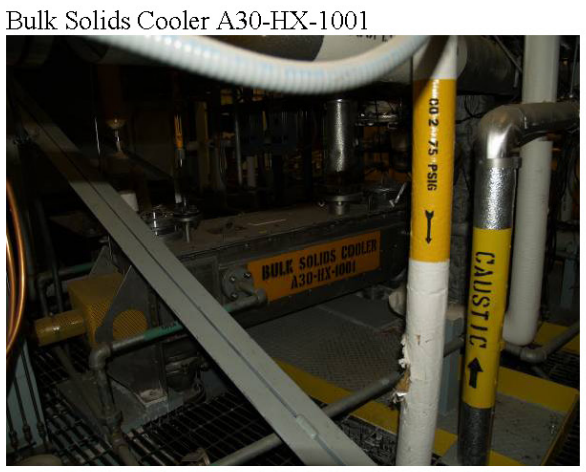


P1015333

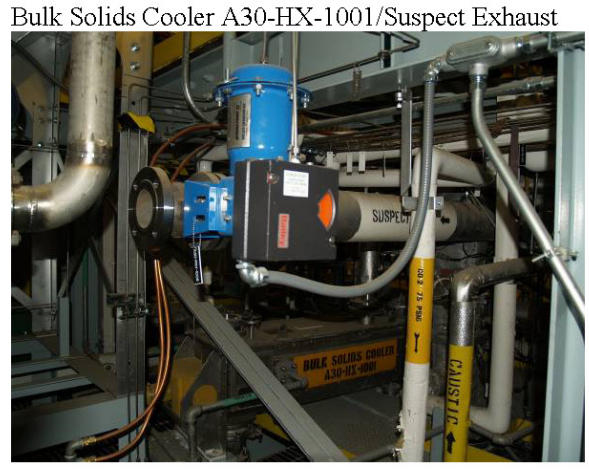

P1015334

Thin Film Evaporator Subsystem (never functioned properly - abandoned in place)

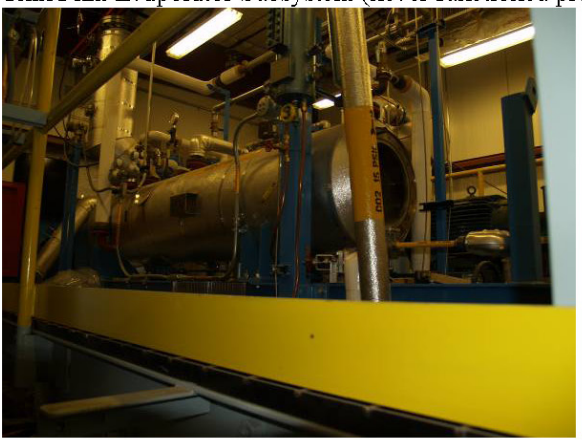

P1015335

Internal Contamination Placard, Flanders HEPA A11-FL-452

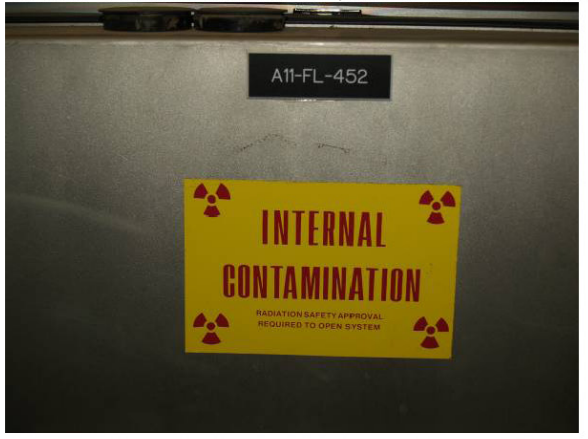


P1015336

Internal Contamination Placard, Flanders HEPA A11-FL-451

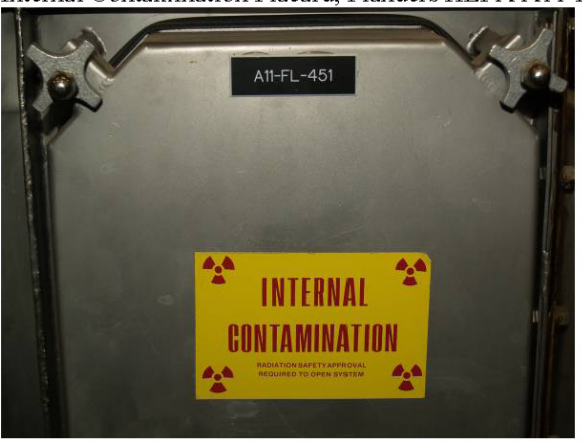

P1015337

Control Panel CST-4 for Carbonate Process

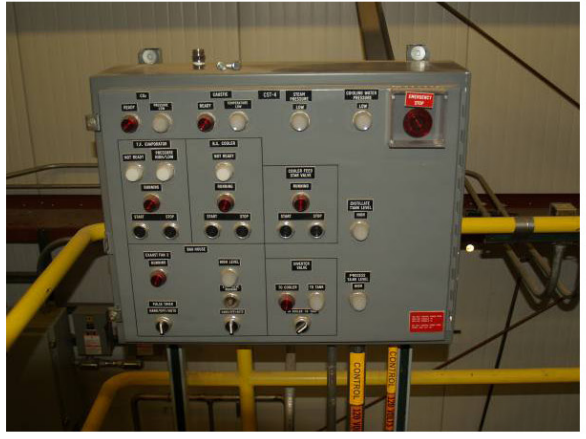

P1015338

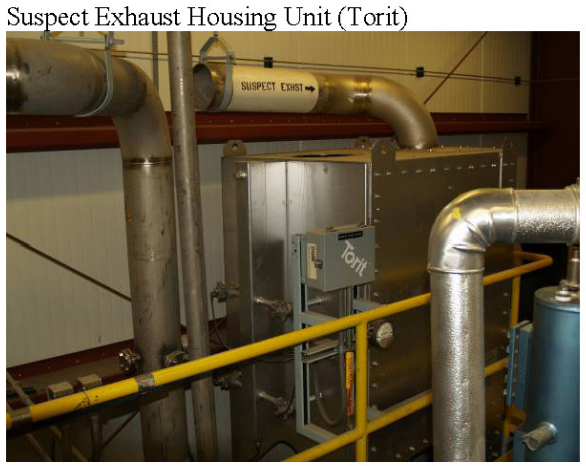


P1015339

Thin Film Evaporator Subsystem (never functioned properly - abandoned in place)

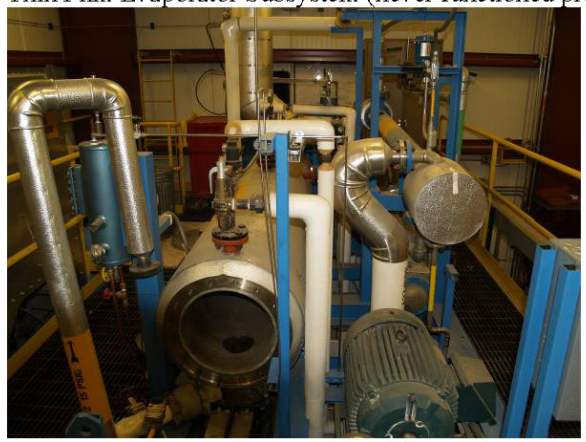

P1015340

Thin Film Evaporator Subsystem (never functioned properly - abandoned in place) (looking north)

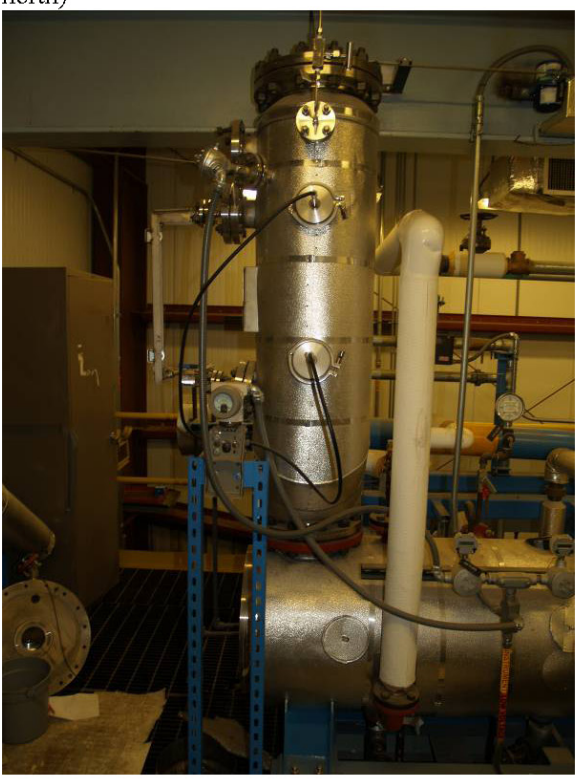


P1015341

Thin Film Evaporator Subsystem -Additional Instrumentation (never functioned properly abandoned in place) (looking north)

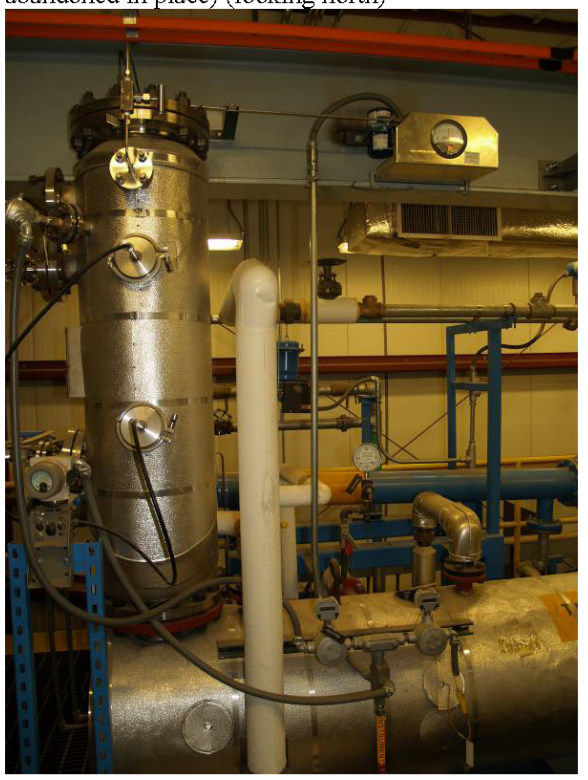

P1015342

Thin Film Evaporator Subsystem A30-EV-1001 (never functioned properly - abandoned in place)

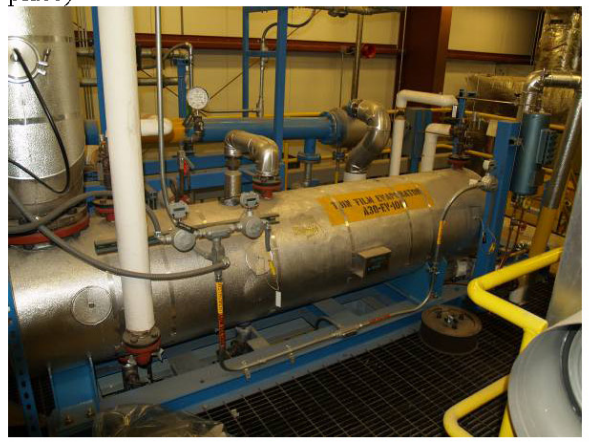




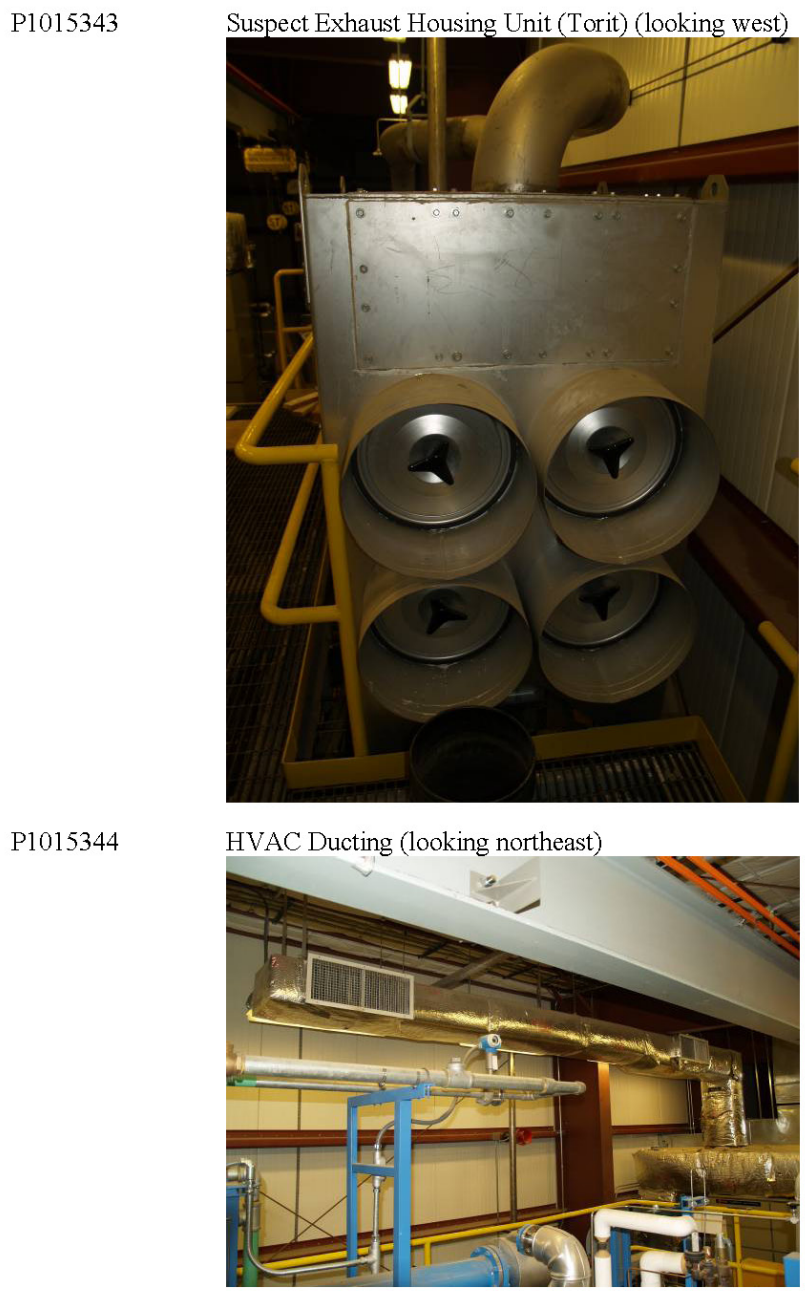


P1015345

TRANE/SpaceMaster II 5-ton Electric Hoist (looking northeast)

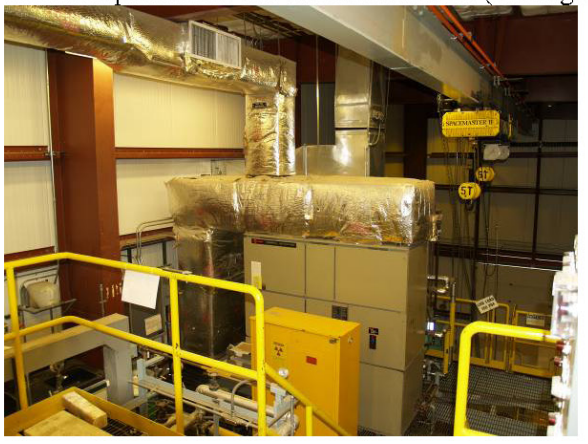

P1015346

Closeup of SpaceMaster II 5-ton Electric Hoist (two units)

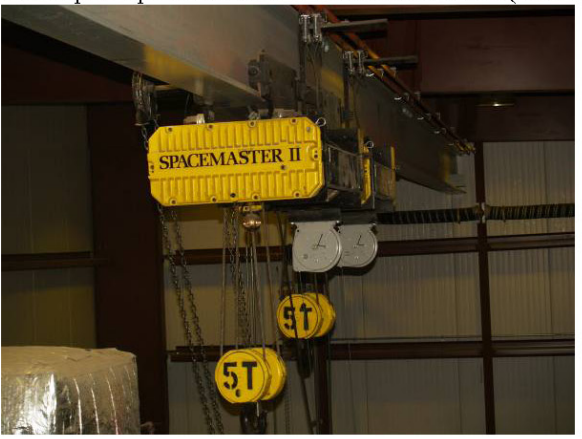


Sodium Processing Facility MFC-799 - Sodium Processing Facility Control Room

P1015347 Eberline Hand and Foot Monitor - south door, Control Room

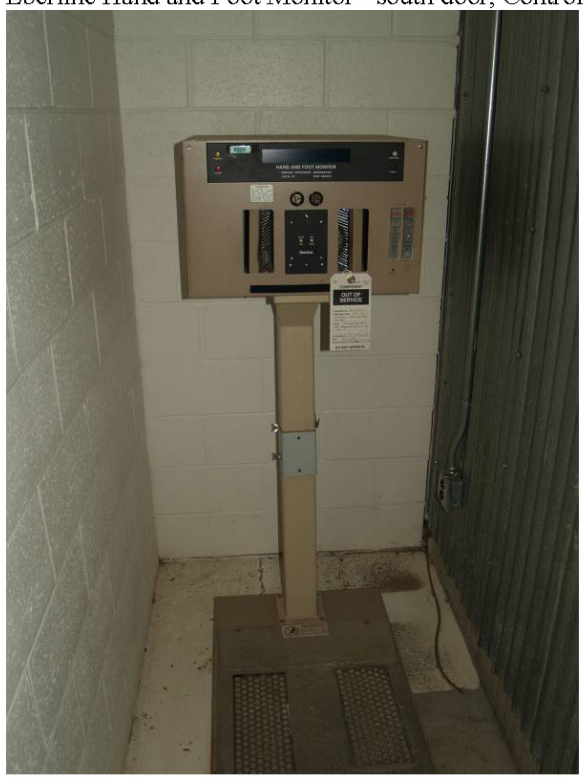

P1015348

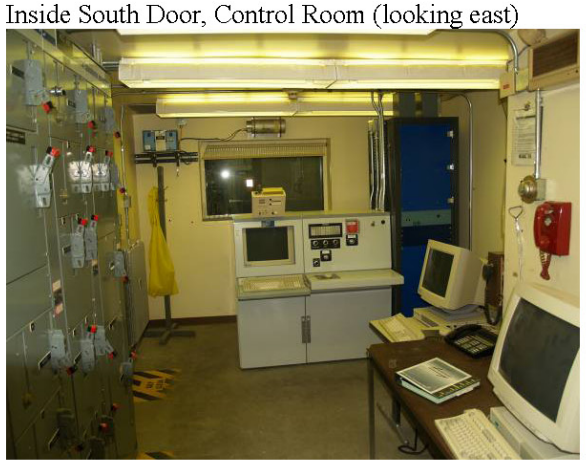




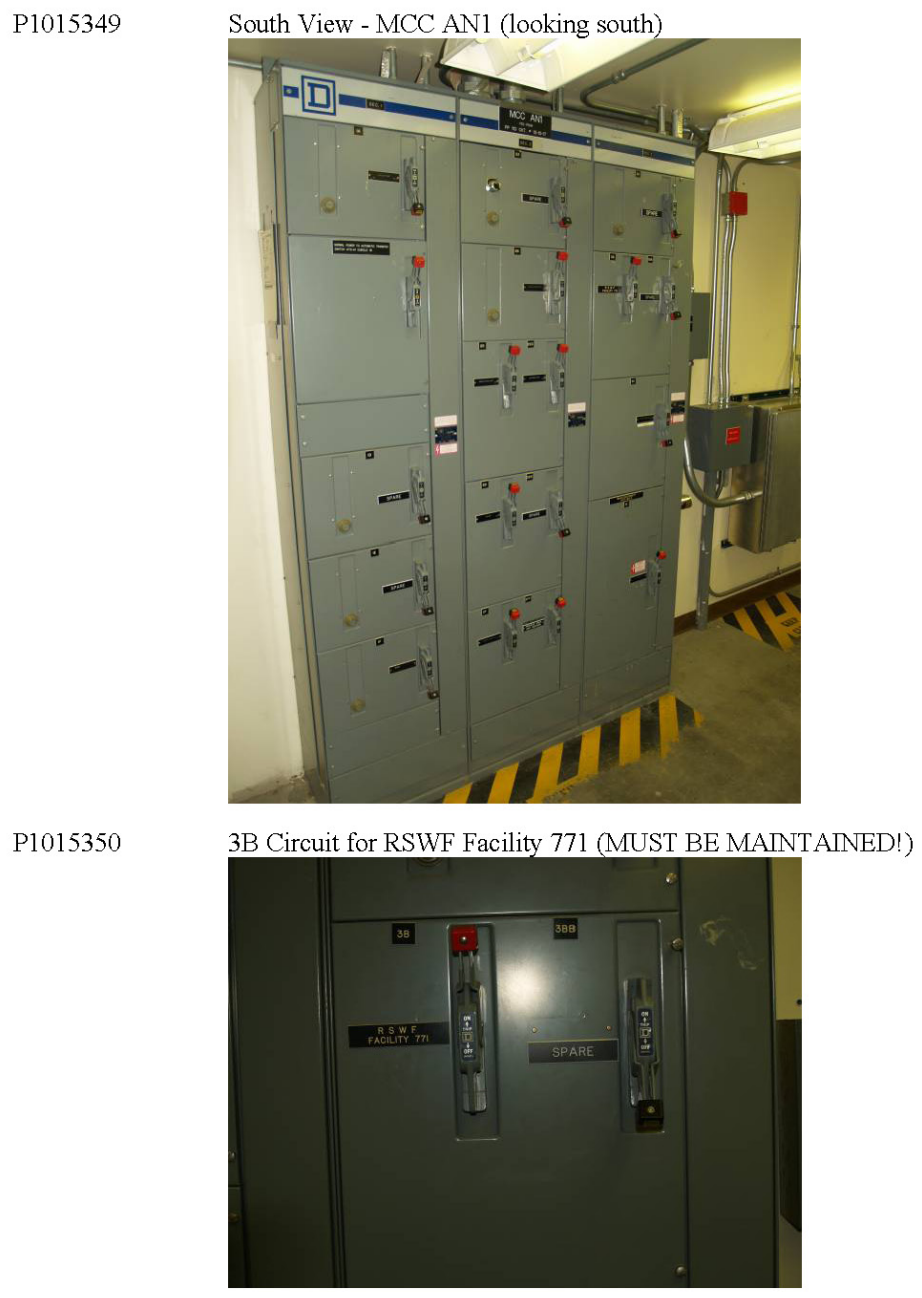

86 
P1015351

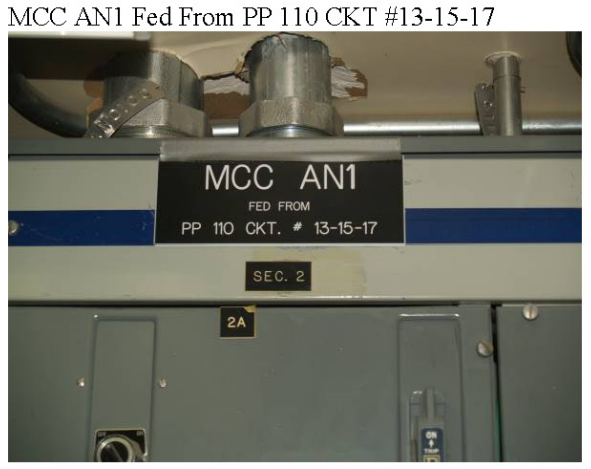

P1015352

Fire Alarm Terminal Box and Communication Boxes (looking north)

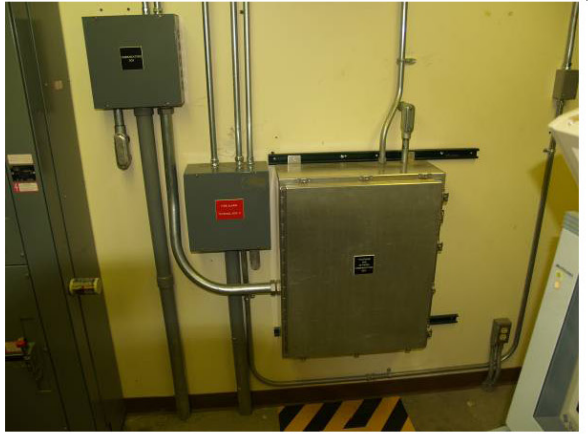

P1015353

RAM Station 1 - Southeast Wall

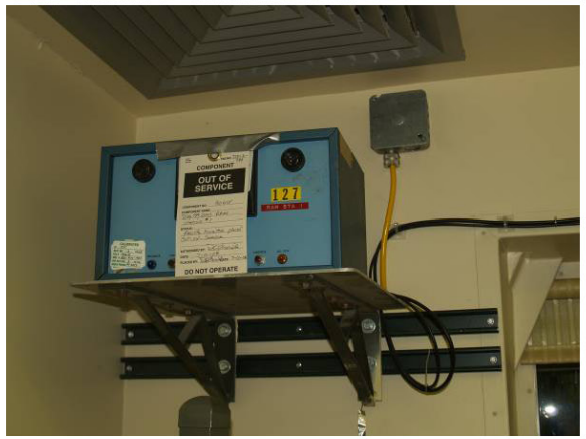

87 


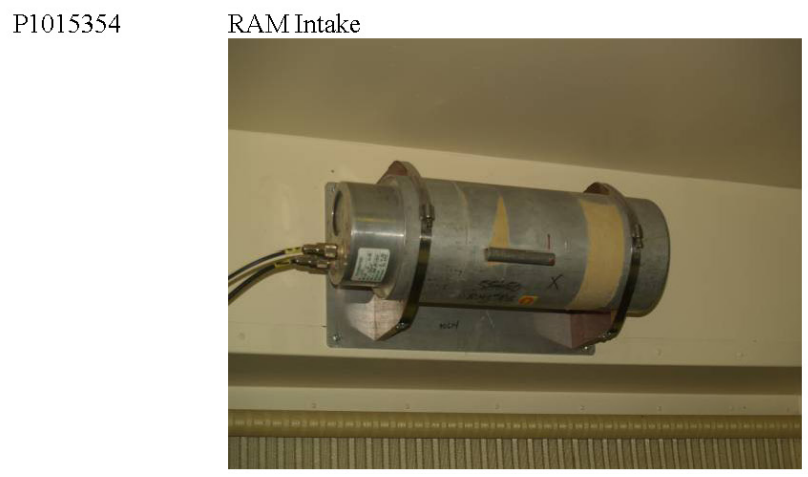

P1015355

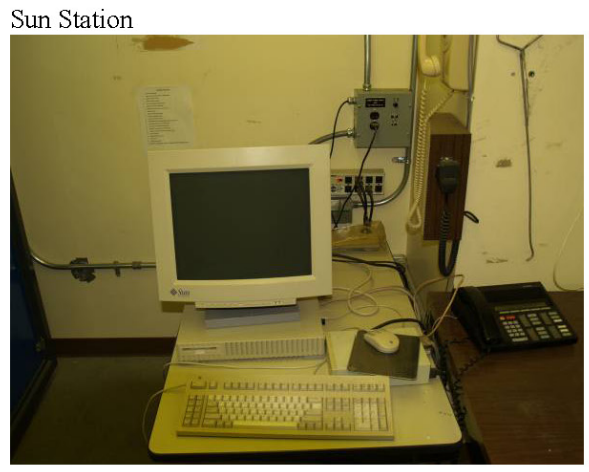

P1015356

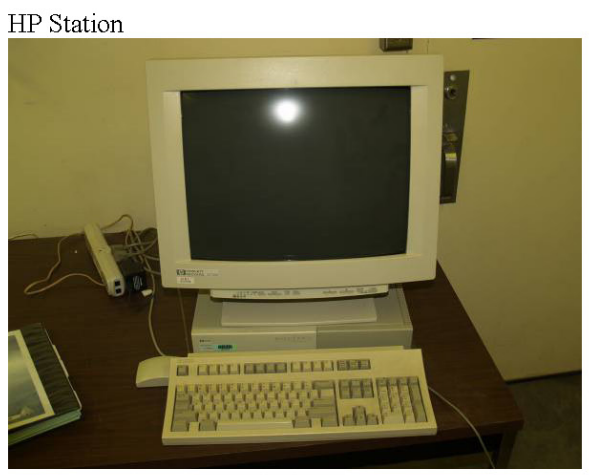


P1015357

Sodium Reactor Control Panel

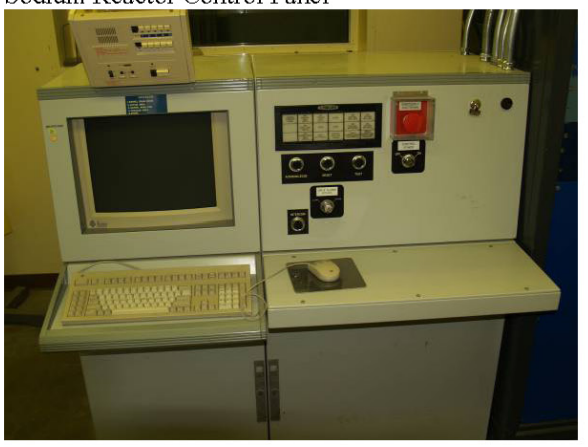

P1015358

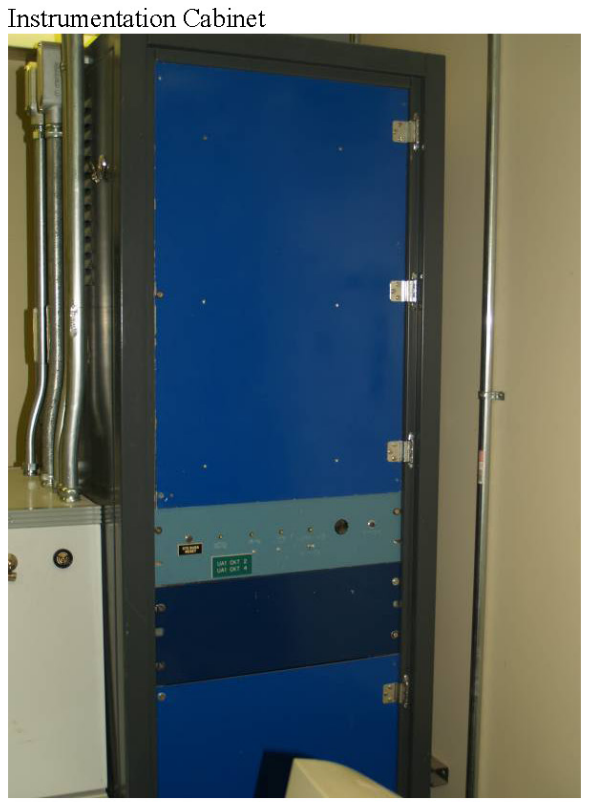


Sodium Processing Facility MFC-799 - Sodium Processing Facility Operations Office P1015359 Inside South Door (looking northeast)

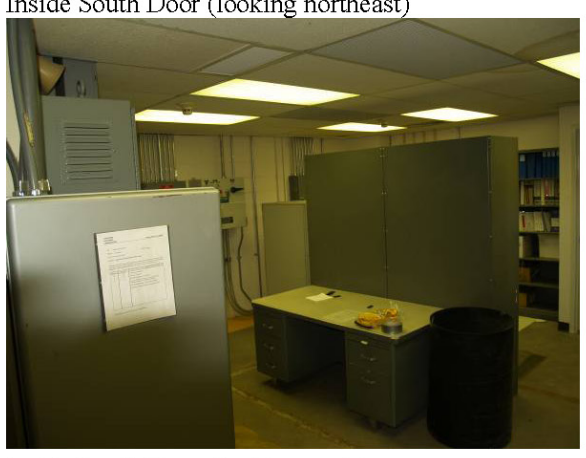

P1015360 Inside South Door (looking north)

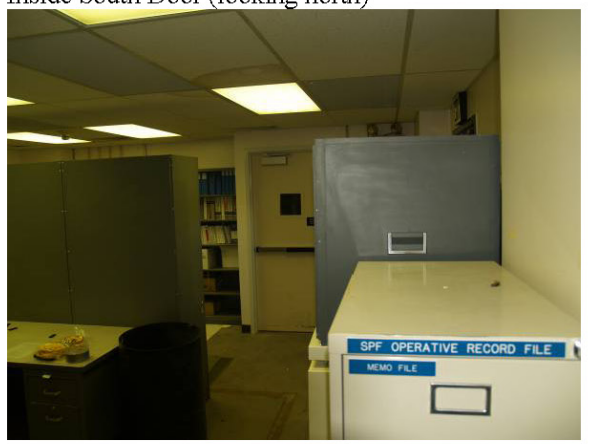


P1015361

Sodium Processing Facility Operating Record File Cabinet

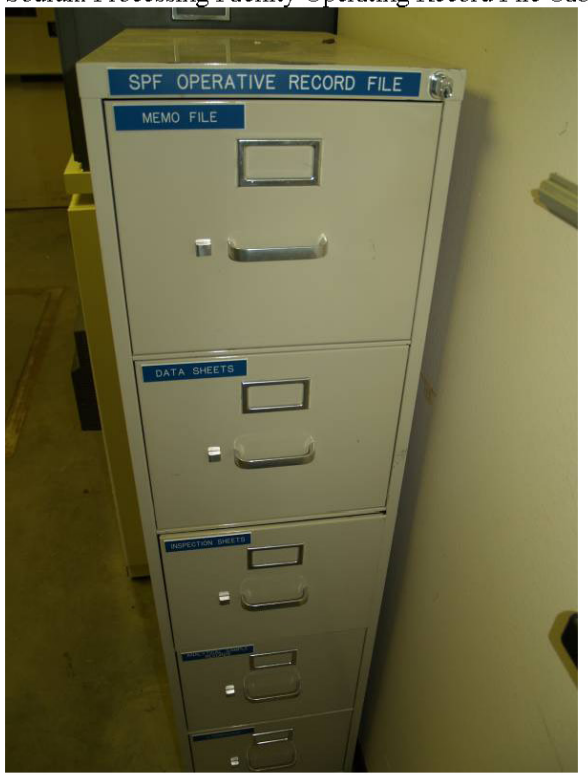

P1015362

Sodium Process Facility Hydrogen - Oxygen Area Monitors

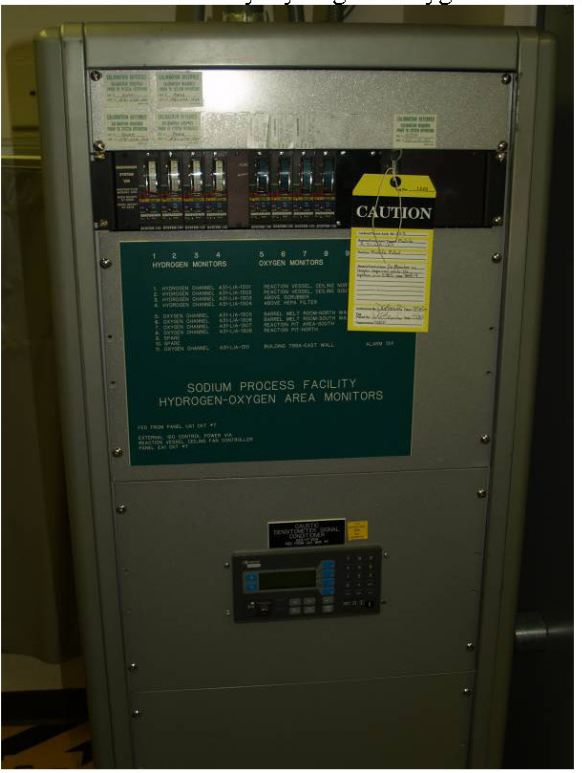




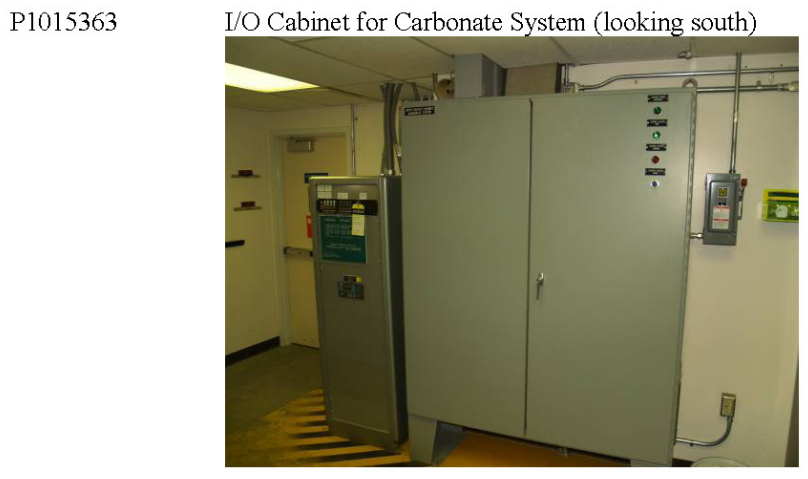

P1015364

Storage Cabinet by Southeast Door

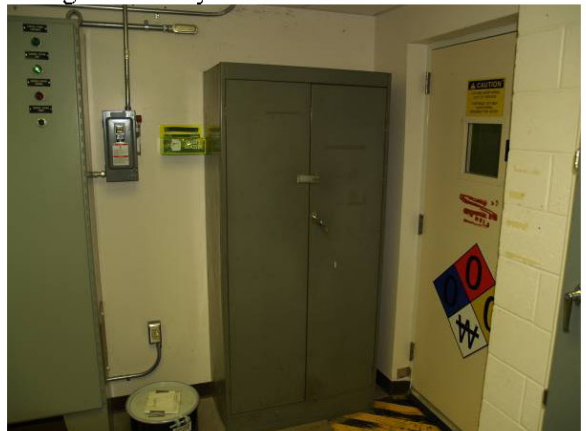

P1015365

EA1 Emergency Power fed from MCC-AE1 Cabinet/UPS Maintenance Bypass Cabinet

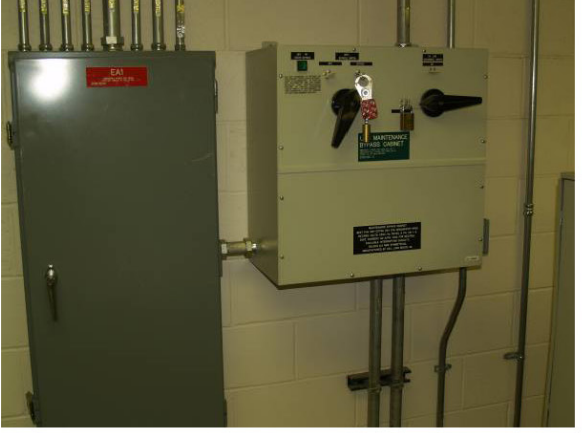

92 
P1015367

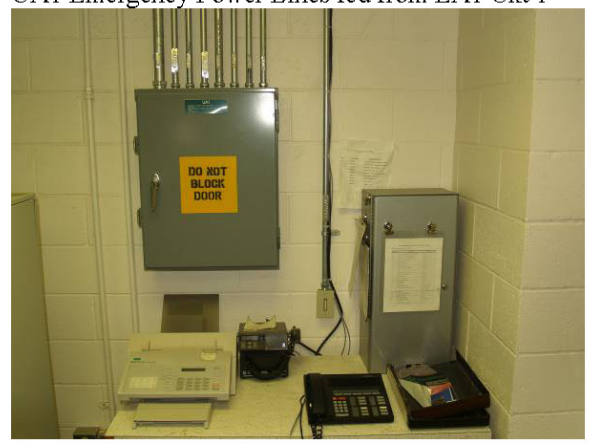

UPS A1 Cabinet

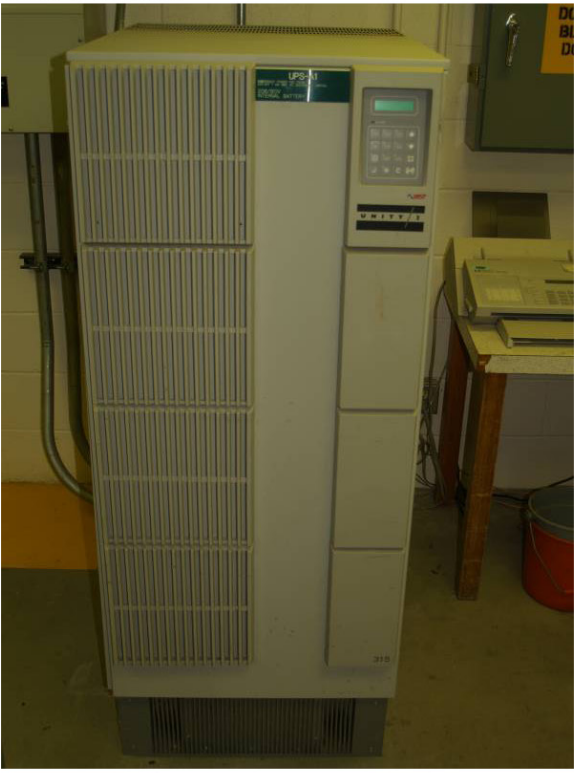




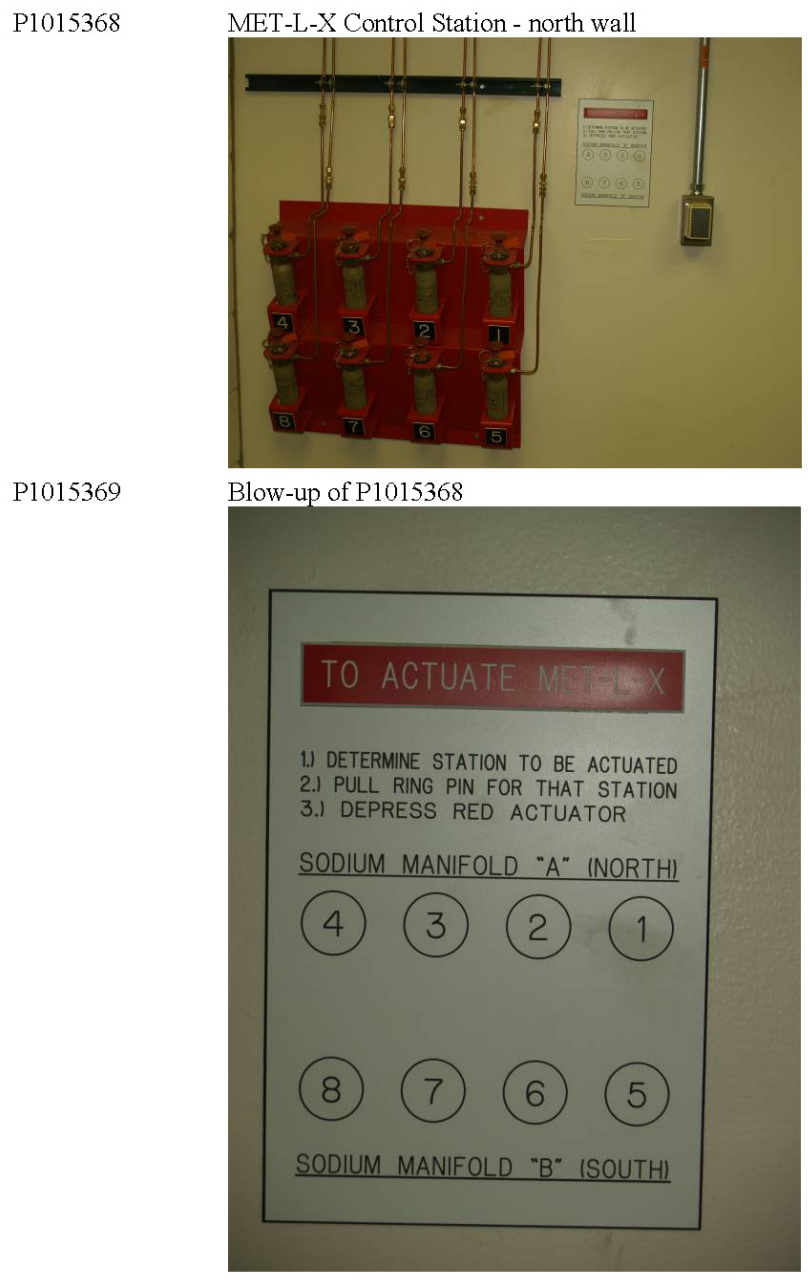


P1015370

Reference Materials/Control Units (looking west)

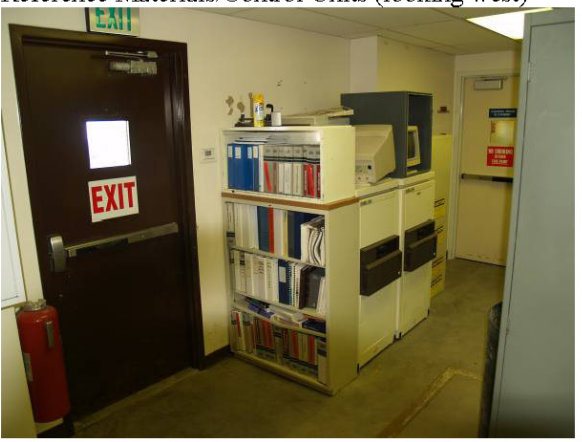

P1015371

Storage Cabinets (looking west)

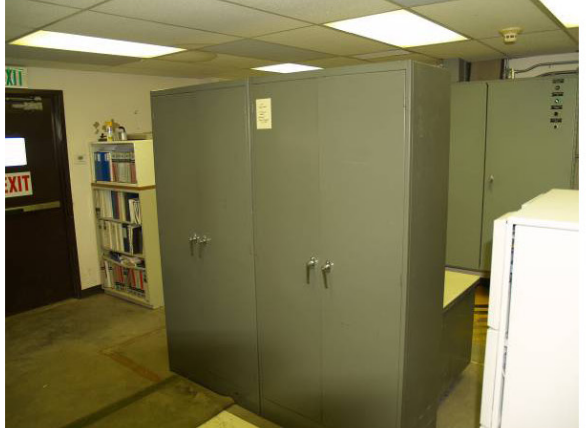

P1015372

North Door - Spill Control Station/Reference Materials/Fire Blanket, Extinguisher

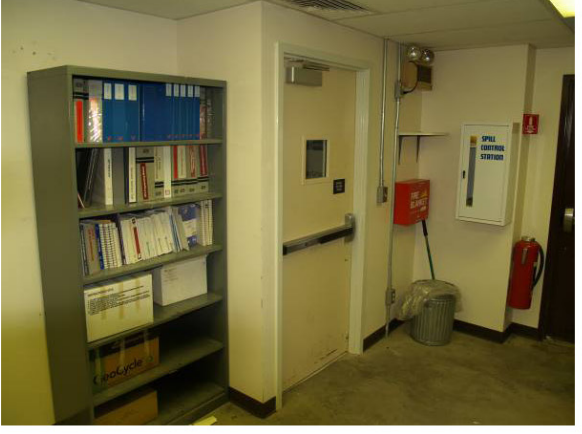




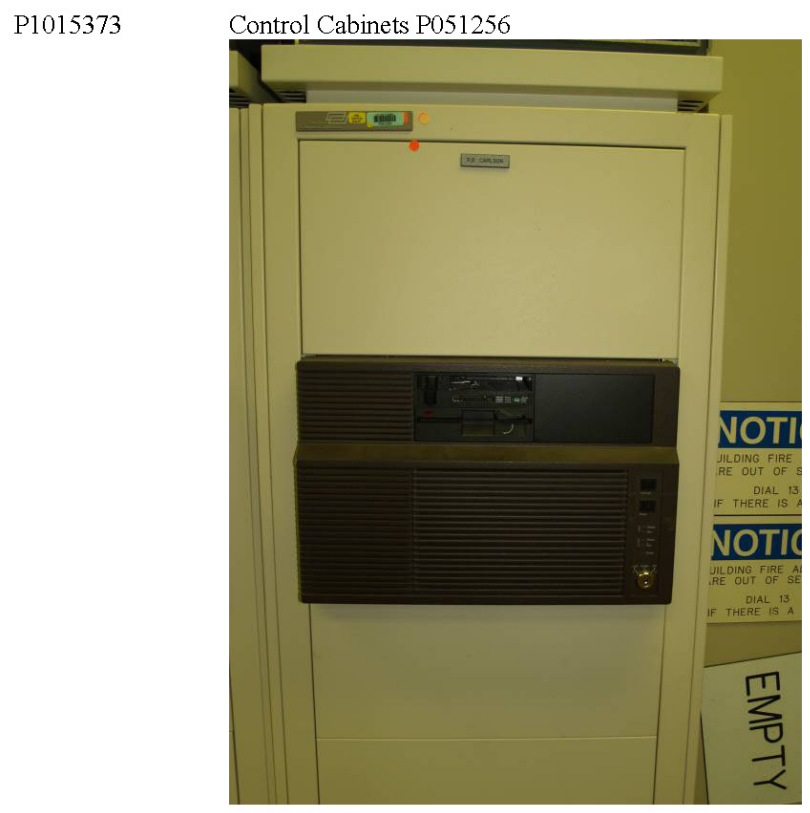

P1015374 Control Cabinets P051256

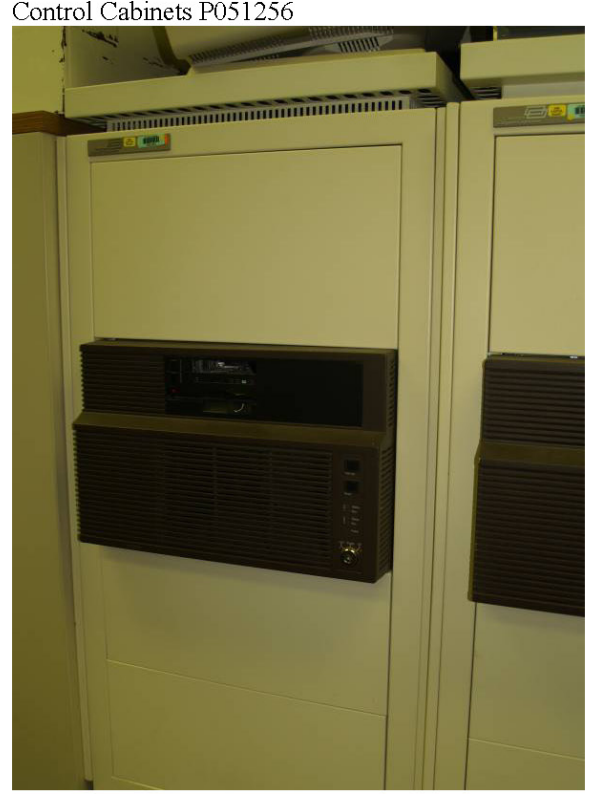

96 


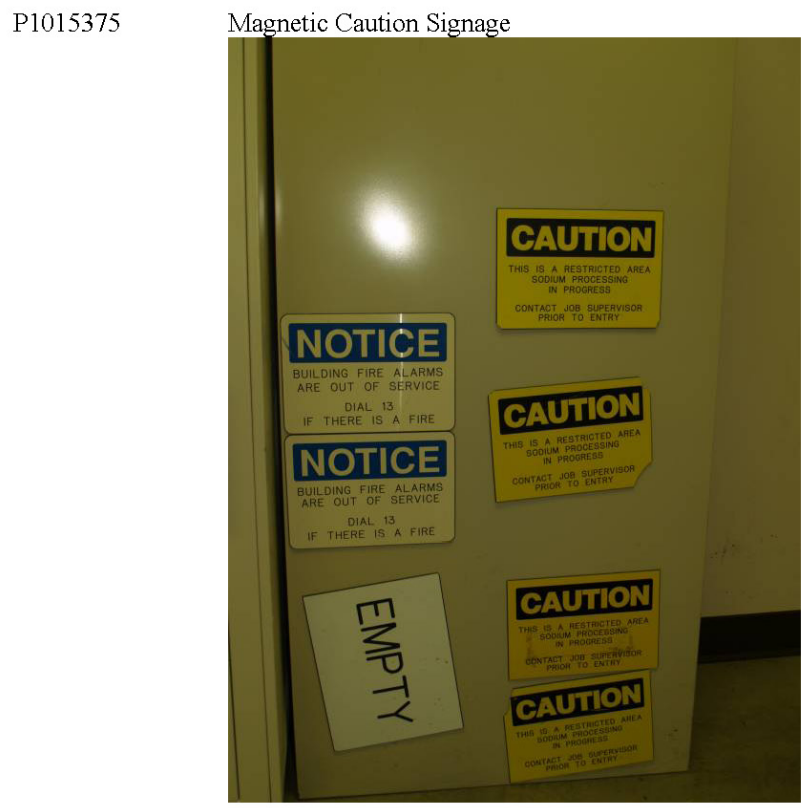

Sodium Processing Facility MFC-799 - Sodium Processing Facility Barrel Holding Room P1015376 P\&H Spectrum 1,000-lb Pedestral Crane 


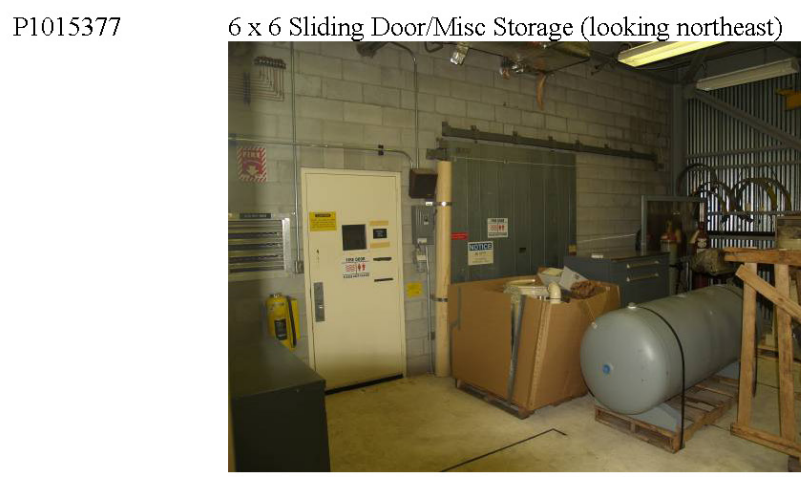

P1015378 Eberline Hand and Foot Monitor (looking south at north door of Operations Office

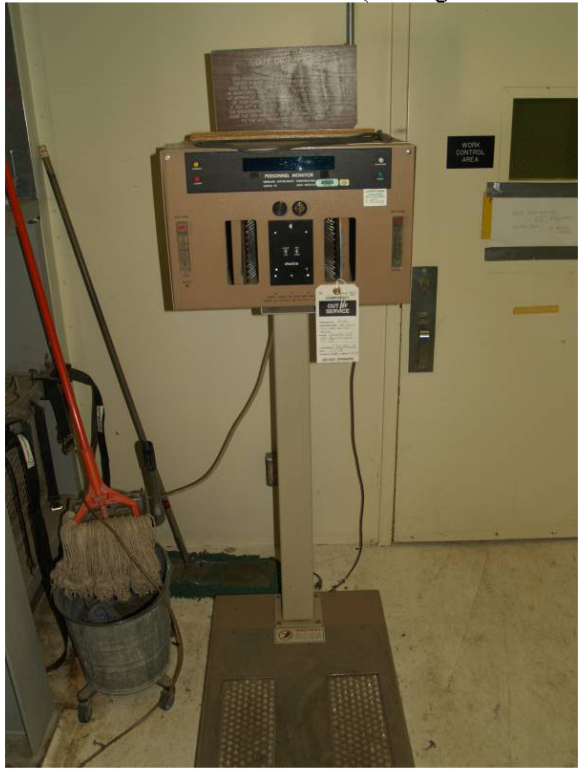


P1015379

Transformers/Control Panels for Sodium Melting Draining Room - South Wall

P1015380

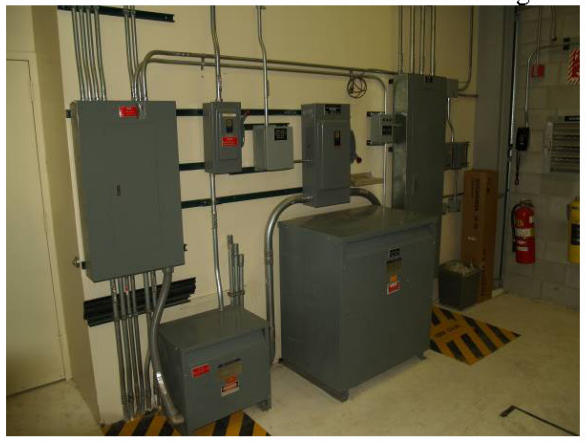

PD080 Heater Transformer Disconnect

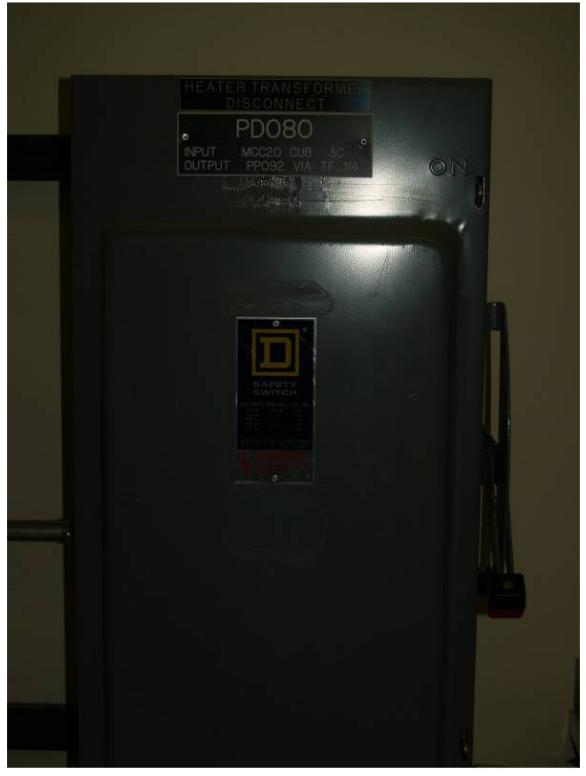


P1015381

P1015382

P1015383

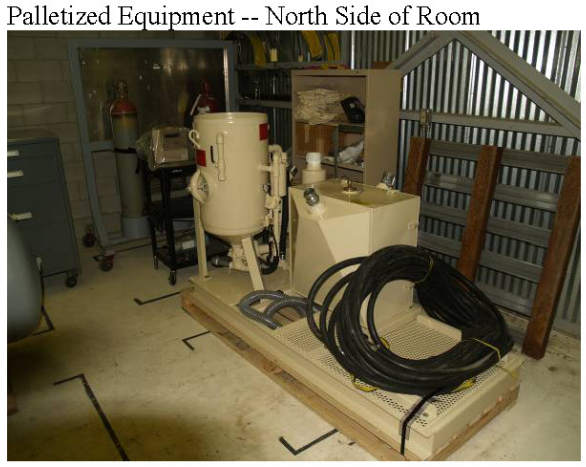

RAM Equipment (on wheeled cart)

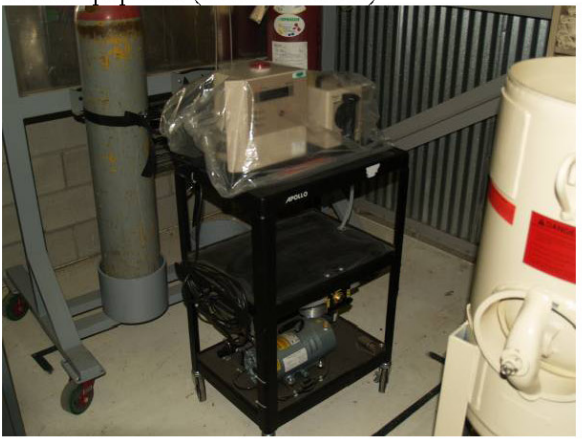

Rolling Storage Cabinet (RAD Supplies)

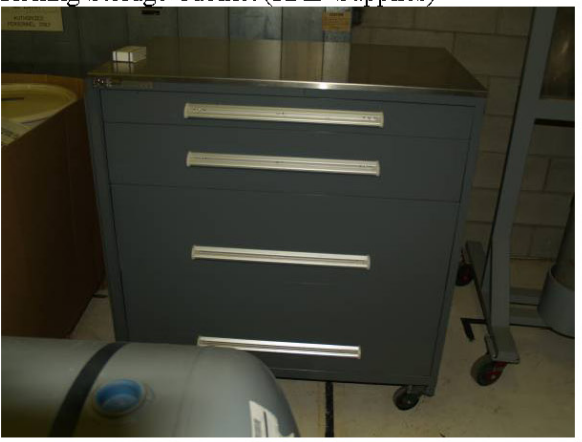




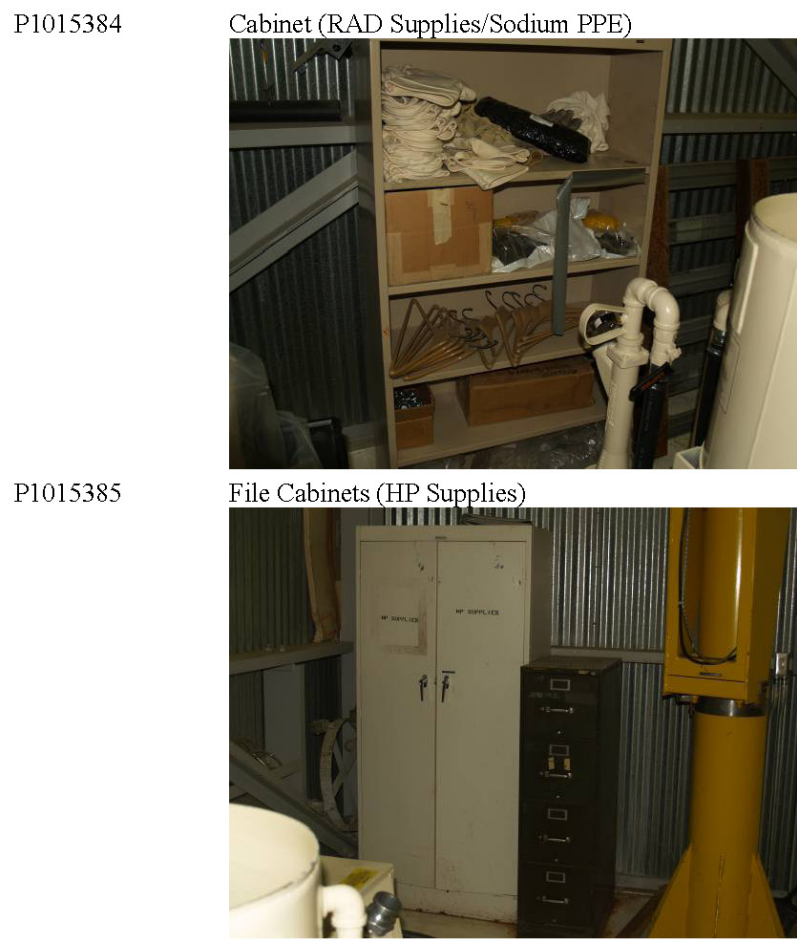




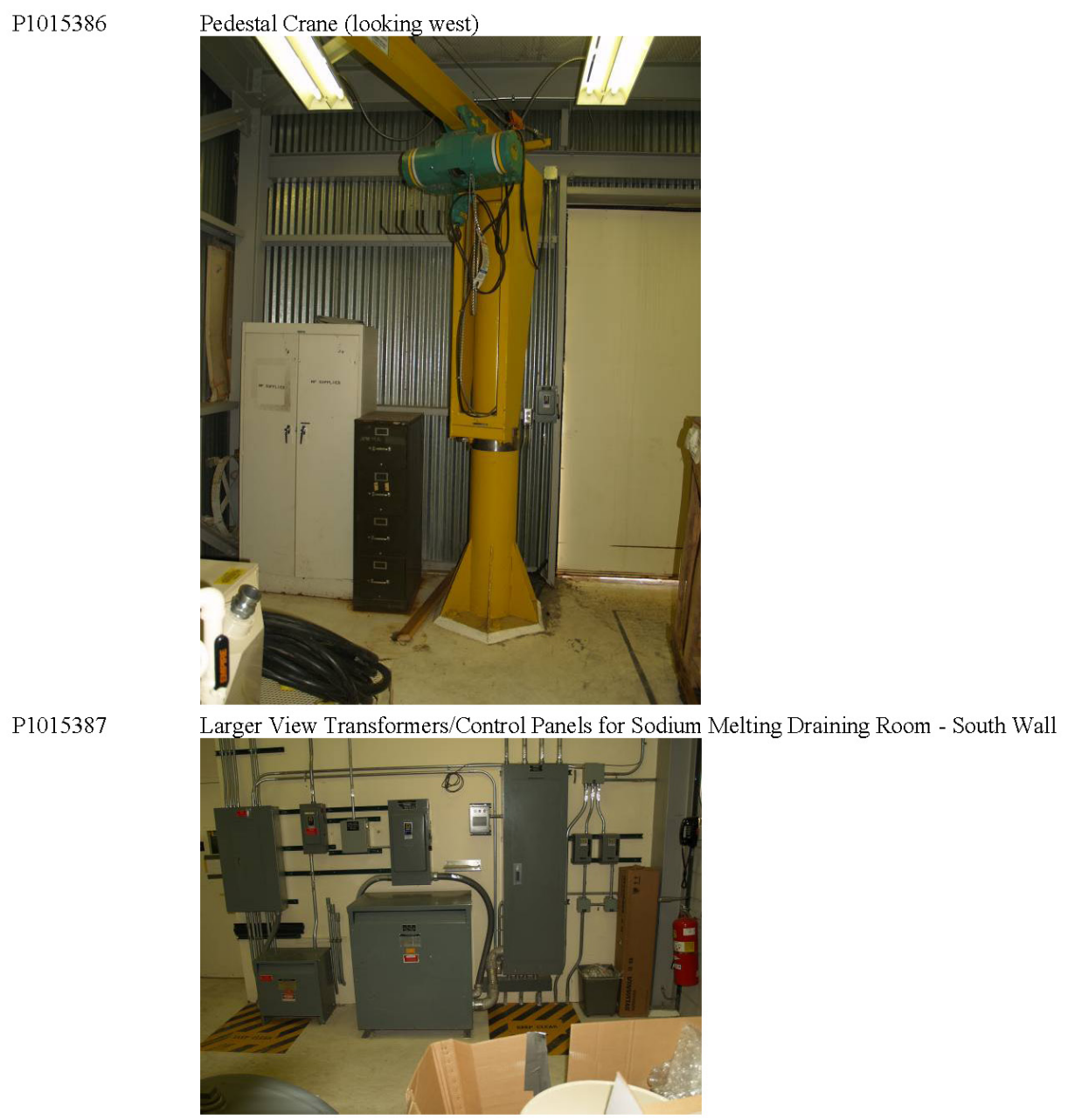




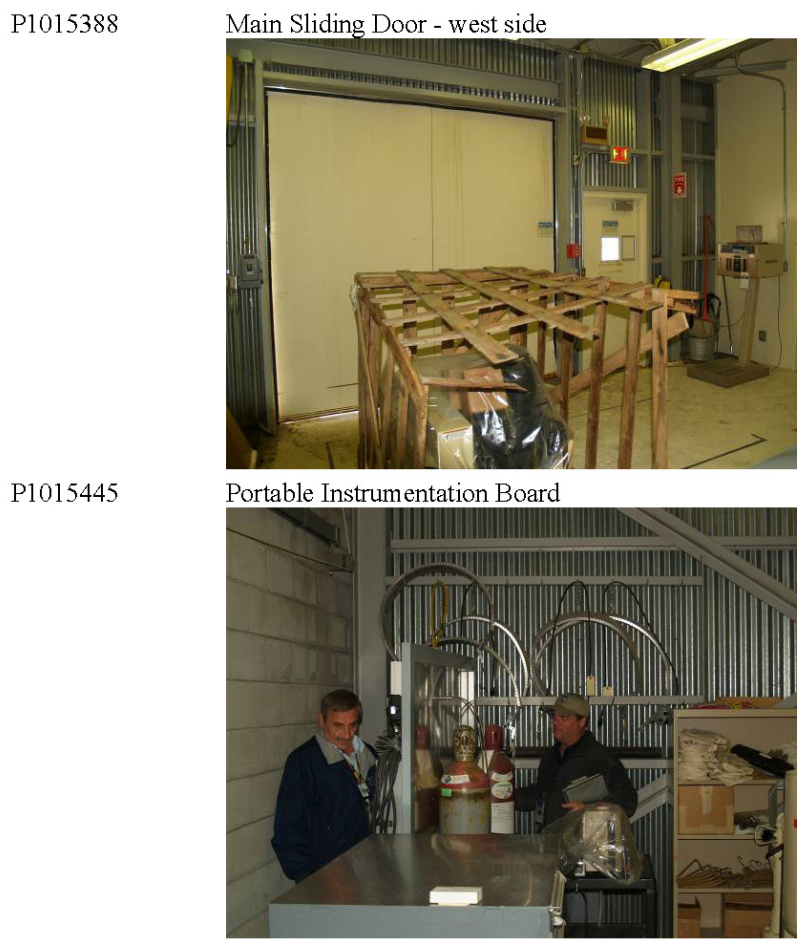

P1015446 Barrel Holding Room (looking northwest) (NOTE PALLET MARKINGS ON FLOOR)

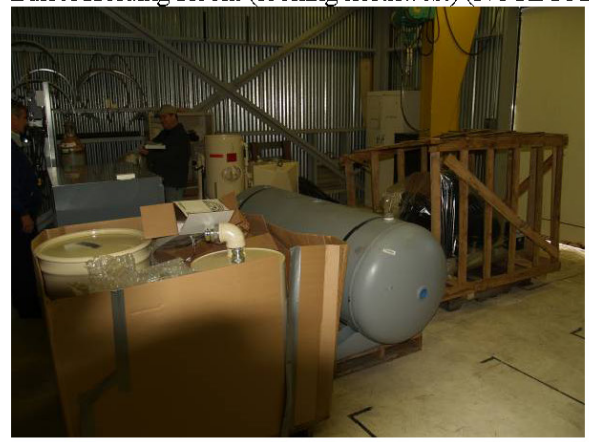


Sodium Processing Facility MFC-799 - Sodium Melting Draining Room

P1015389 Inside Personnel Door, Manifold B (Looking East)

P1015390

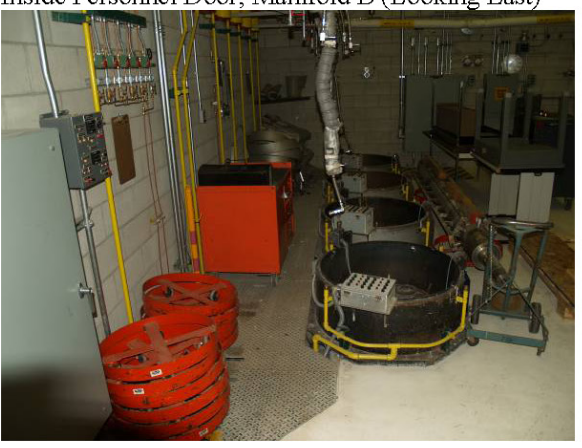

MET-L-X Fire Suppression Bottles

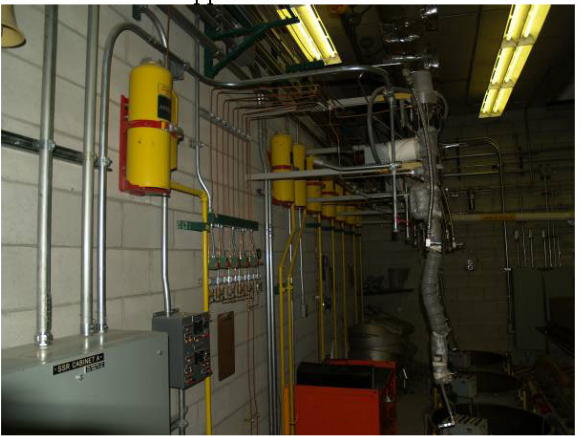


P1015391

Closeup of Inductive Heating System/Fire Suppression Nozzles (4 per station), Manifold B

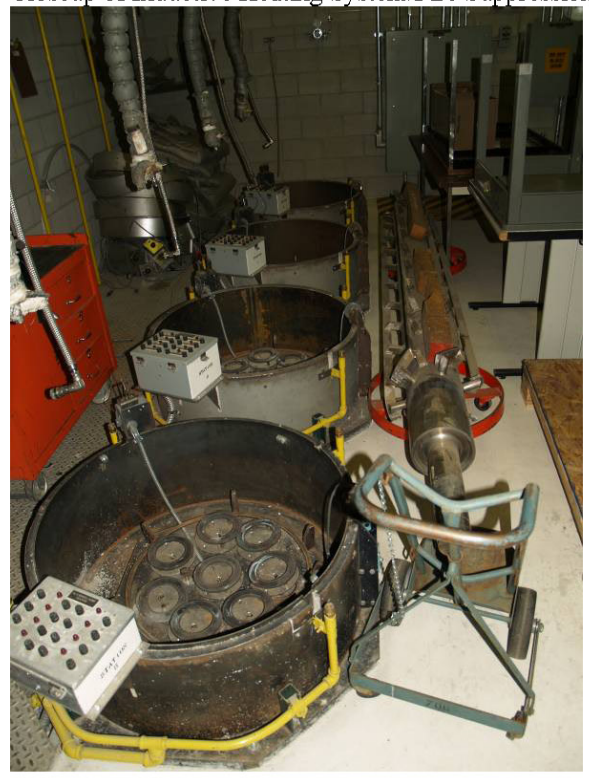

P1015392

Manifold B Piping for Nitrogen Vacuum Systems

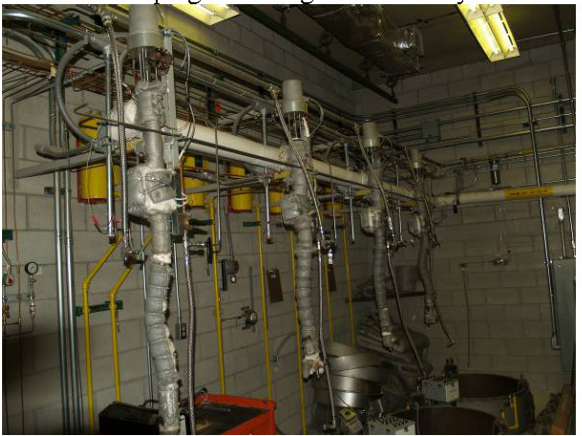


P1015393

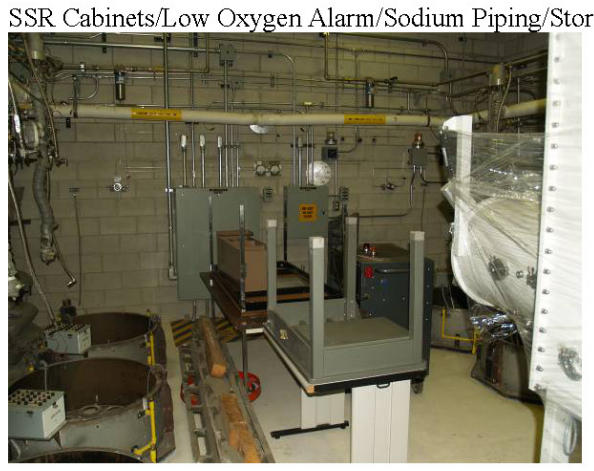

P1015394

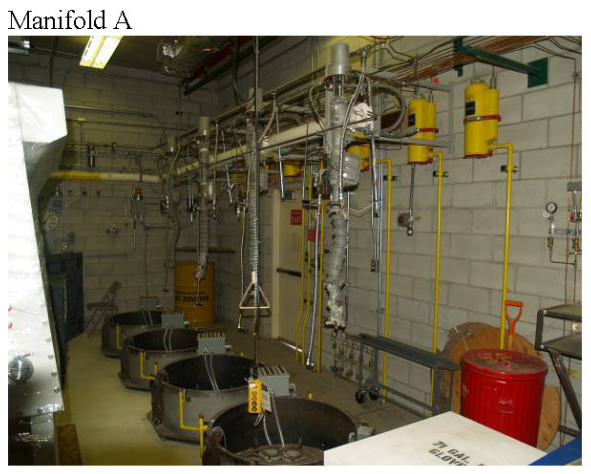

P1015395
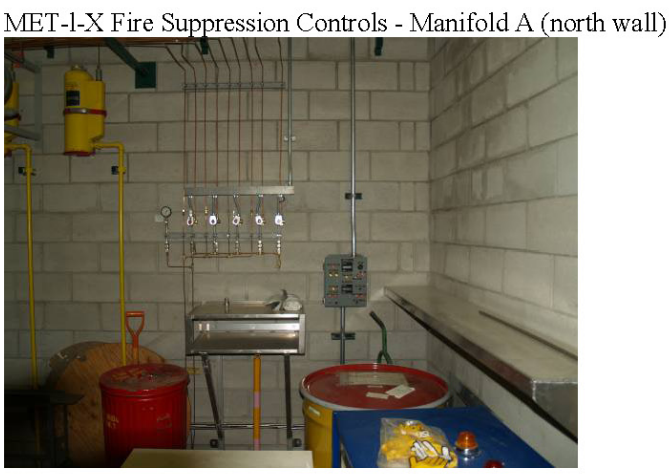
MET-1-X Fire Suppression Controls - Manifold B (south wall)

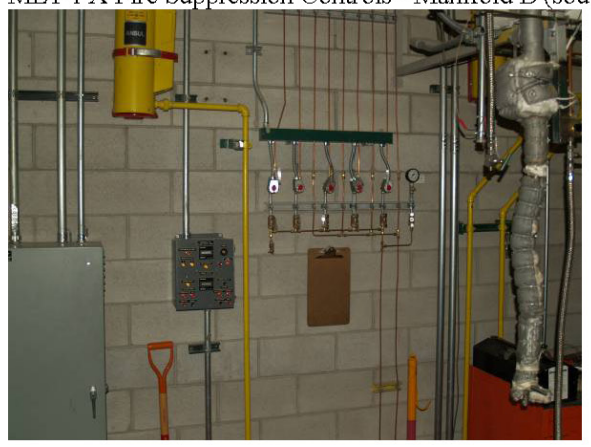

P1015397

New Glove Box for MFC 781 (Being Stored)

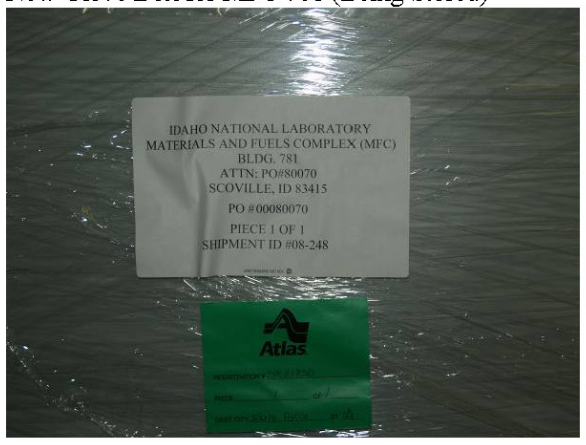

P1015398

Portable Instrumentation - Counting Ratemeter Model CRM-51M (Manufactured by NMC)

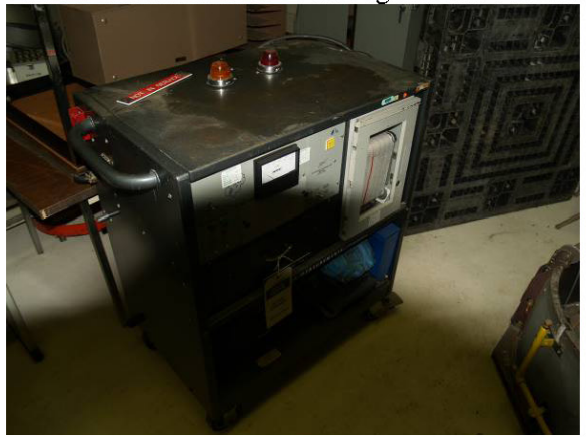


P1015399

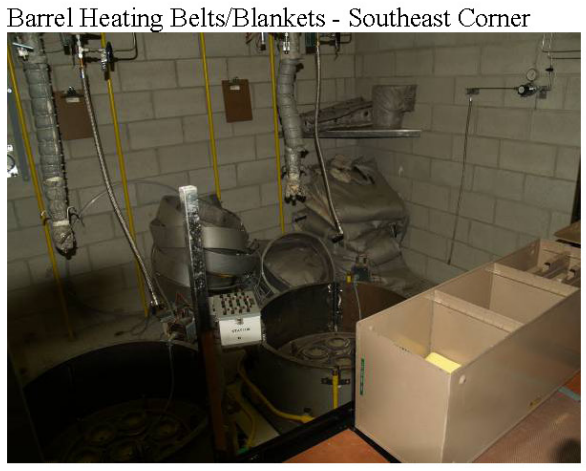

P1015400

Portable Instrum entation - Counting Ratemeter Model CRM-51M (Manufactured by NMC) on west wall

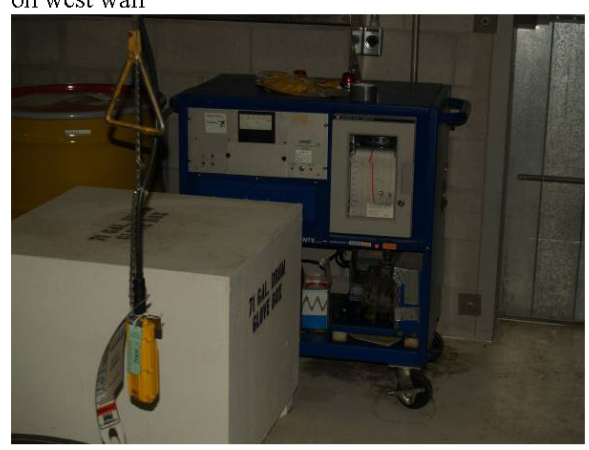


P1015401

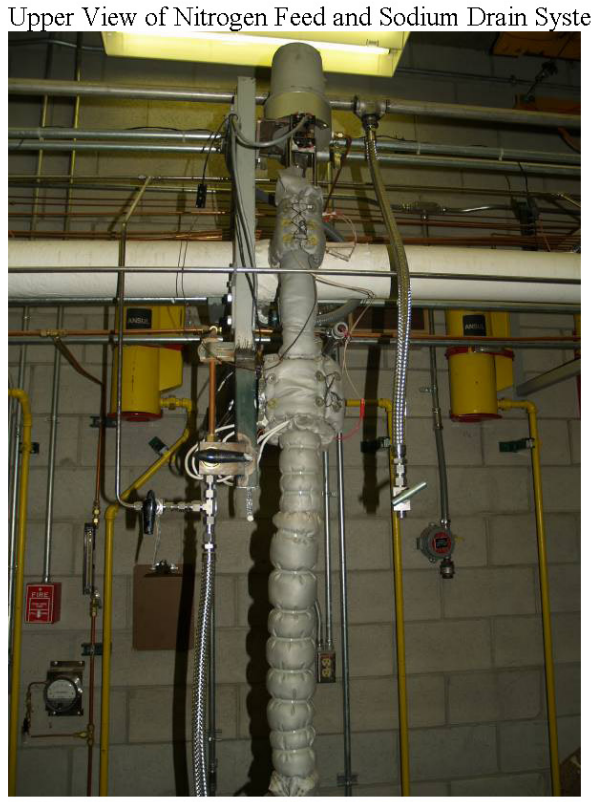

P1015402

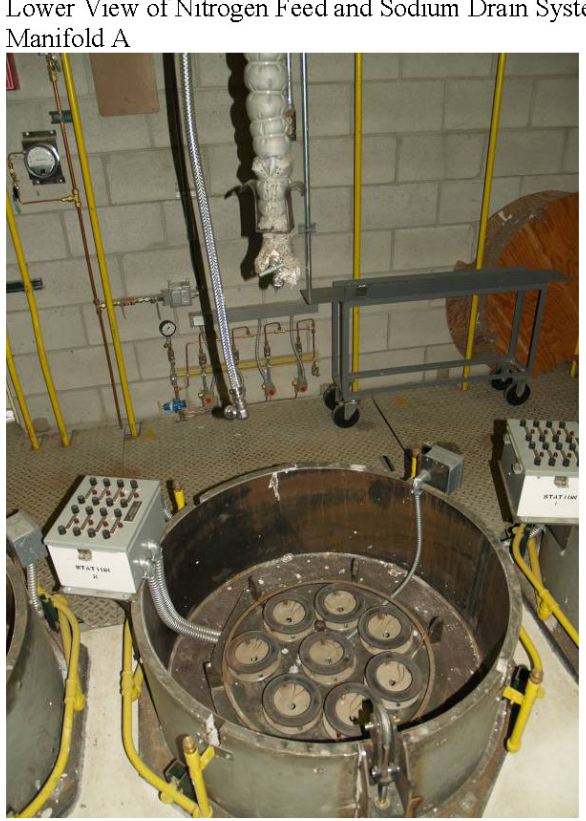




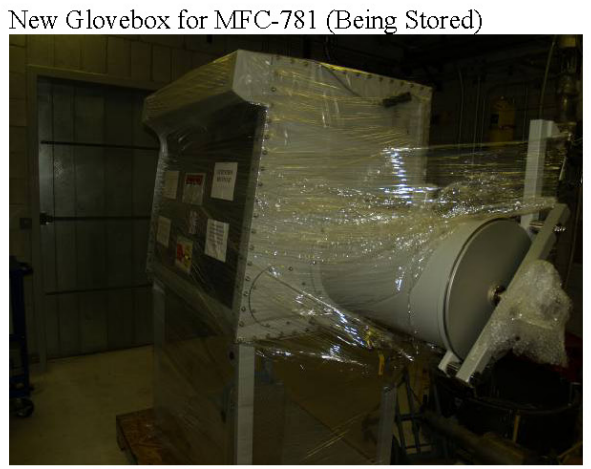

P1015447

P\&H Beta HEVI-LIFT 1/2-Ton Overhead Gantry Crane System

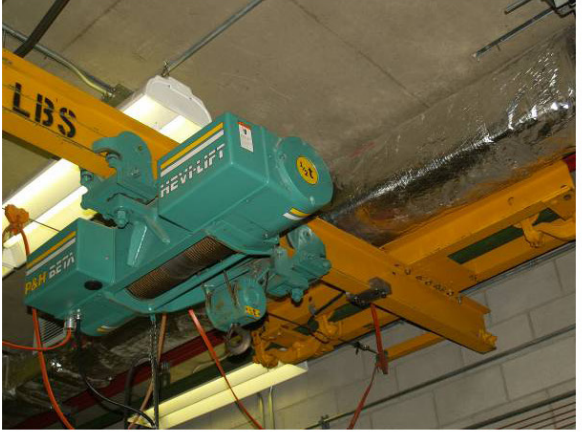

$\mathrm{P} 1015448$

P\&H Beta HEVI-LIFT 1/2-Ton Overhead Gantry Crane System

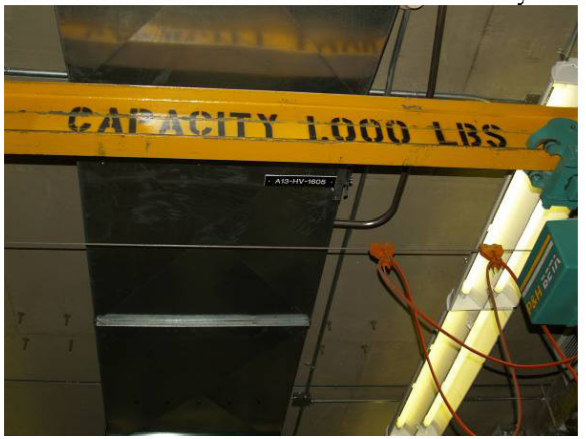


P1015449

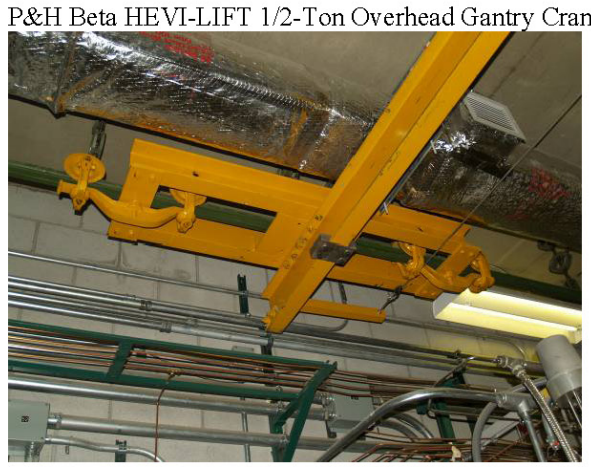

P1015450

Larger View P\&H Beta HEVI-LIFT 1/2-Ton Overhead Gantry Crane System/HVAC Ducting

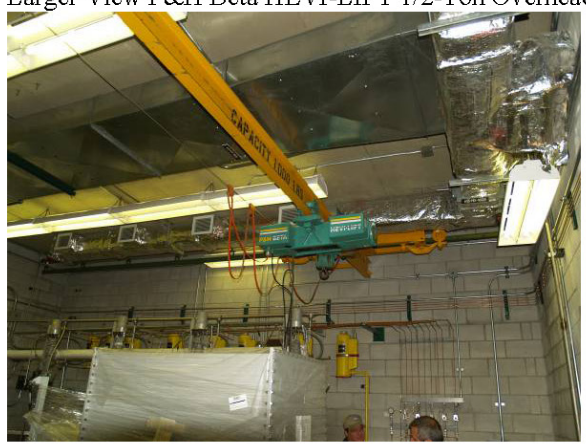

P1015451

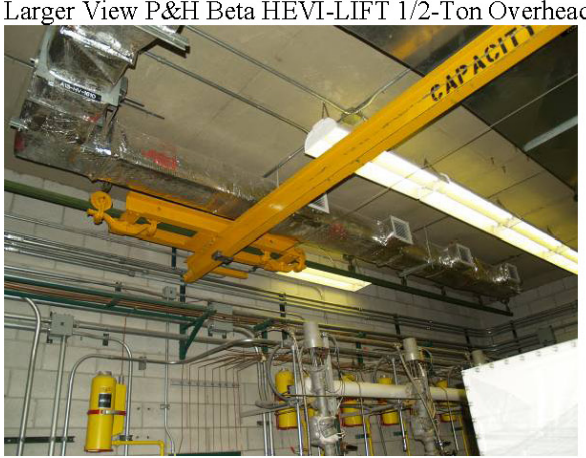


Sodium Processing Facility MFC-799 - Sodium Reaction Area

P1015404 Emergency Safety Shower/In-floor Pit and Drain - Inside West Door, North Wall

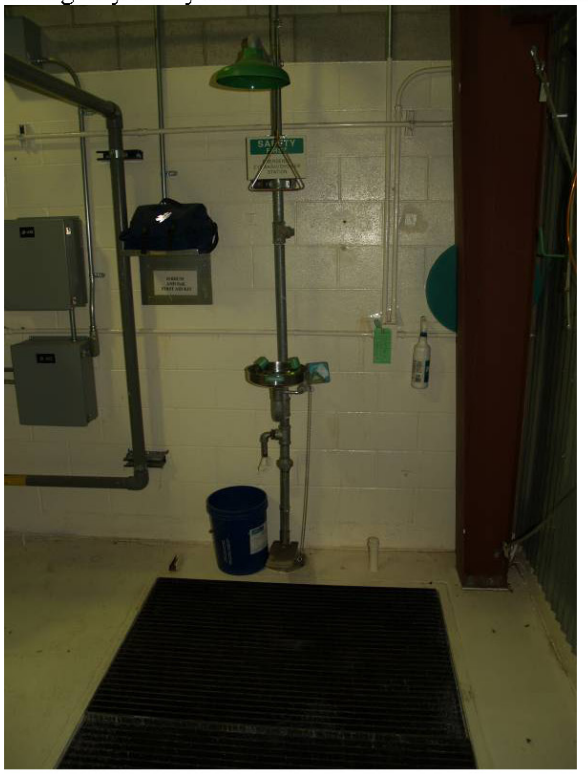

P1015405

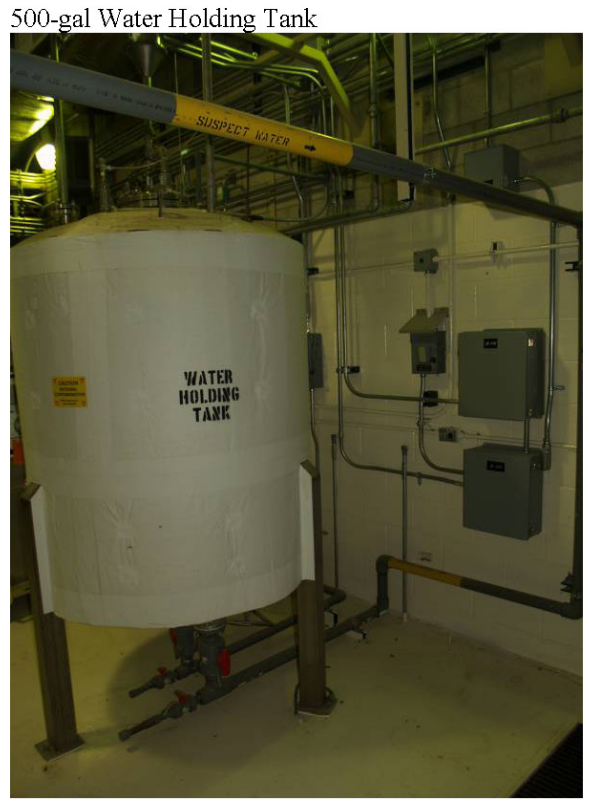

112 


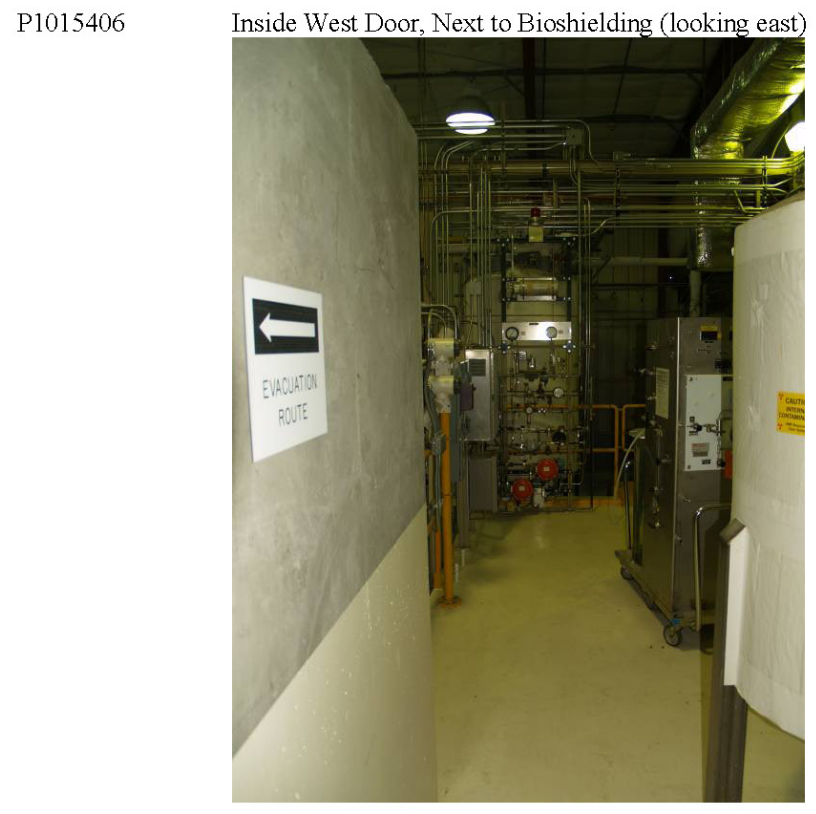

P1015407 Sodium Reactor Vessel (looking southeast)

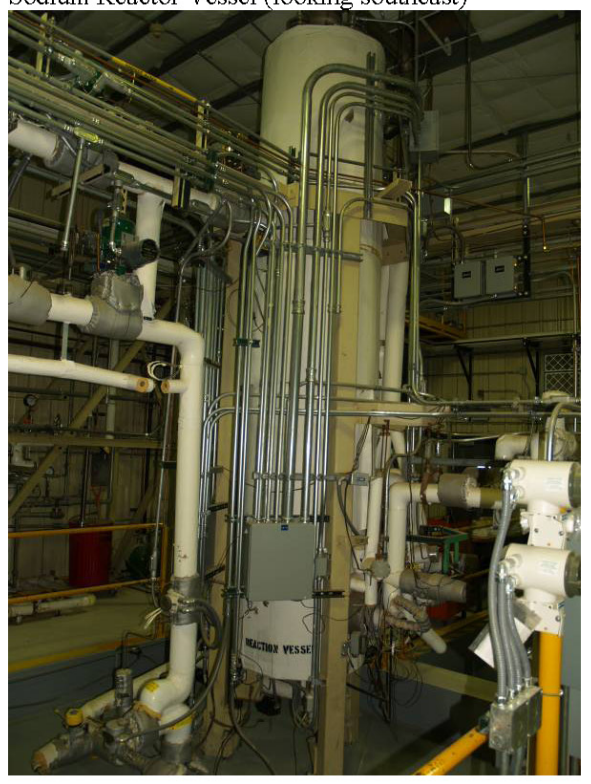


P1015408

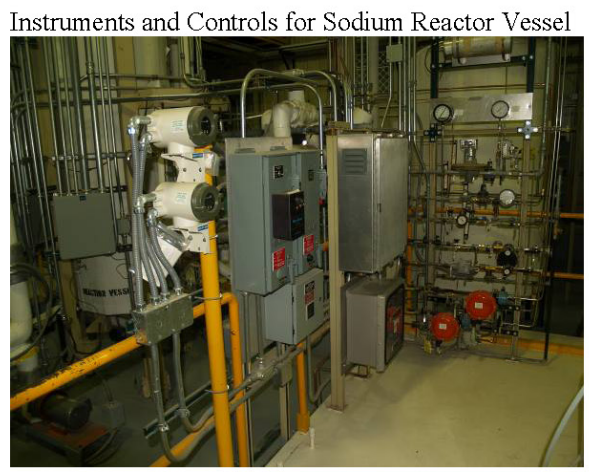

P1015409

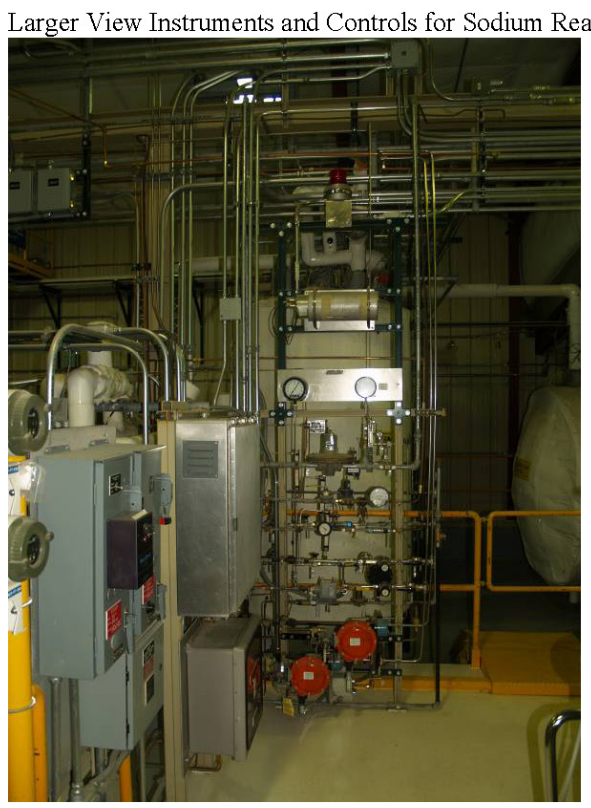


P1015410

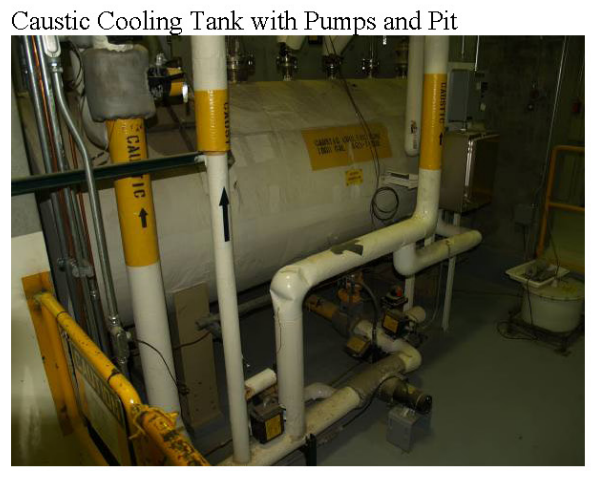

P1015411

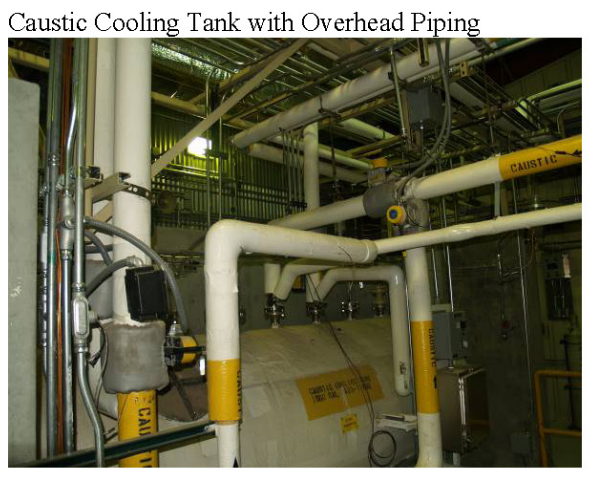

P1015412

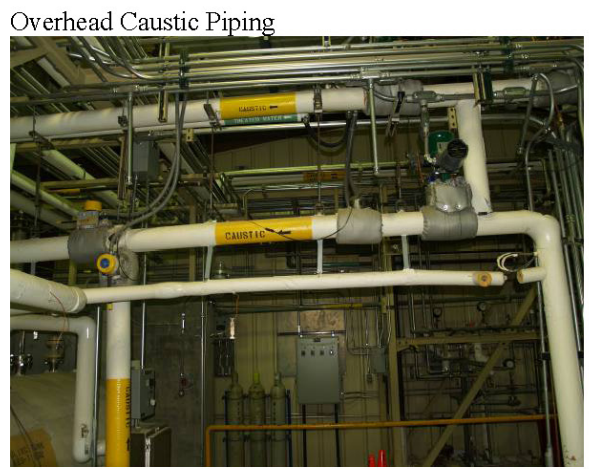

115 
P1015413

Sodium Reactor Vessel/Piping/Instrumentation

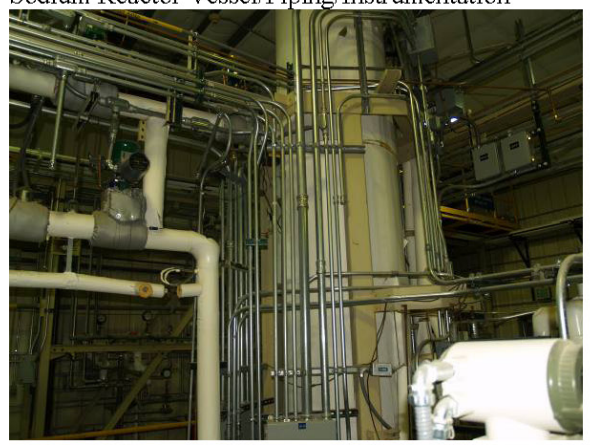

P1015414

Nitrogen Bottles/Control System

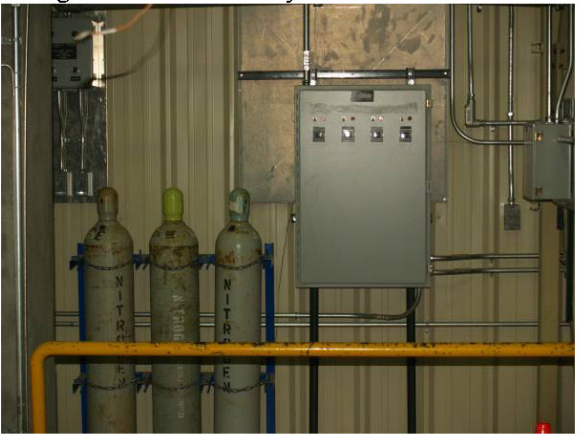

P1015415

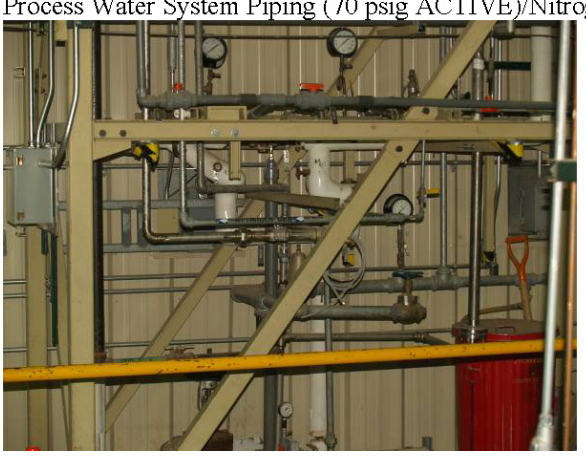


Caustic Recirculation Pump for Sodium Reactor Vessel

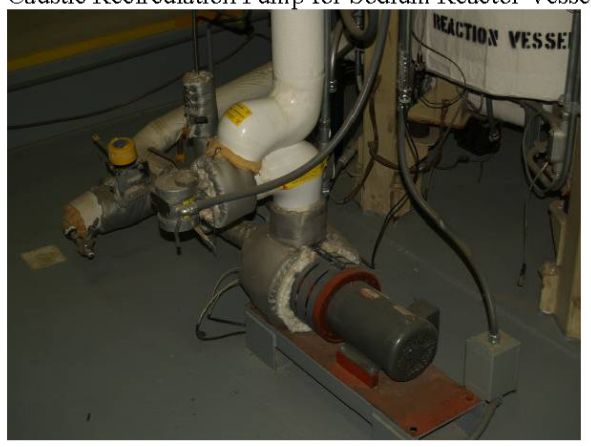

P1015417

Sodium Day Tanks B and A

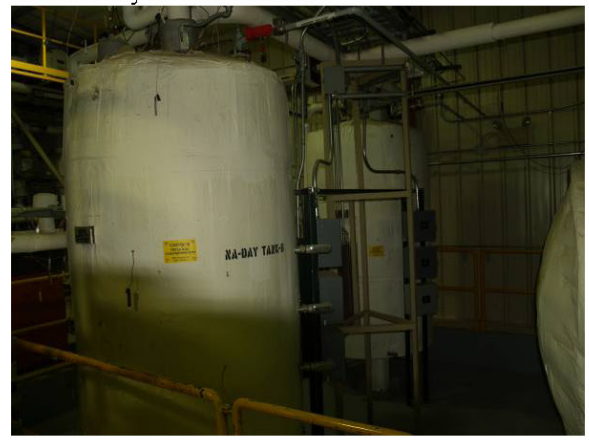

P1015418

Sodium Storage Tank A1-T-101

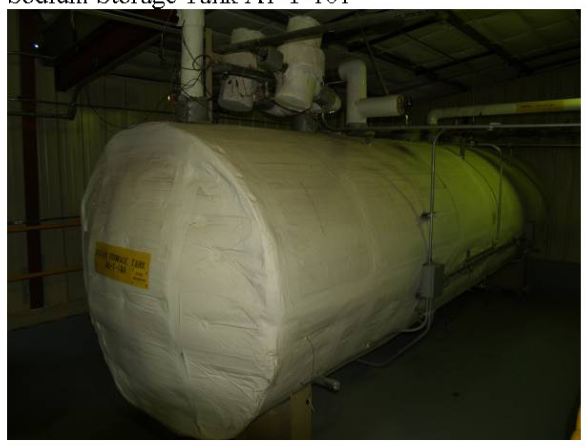


P1015419

Sodium Day Tanks Contamination Placard

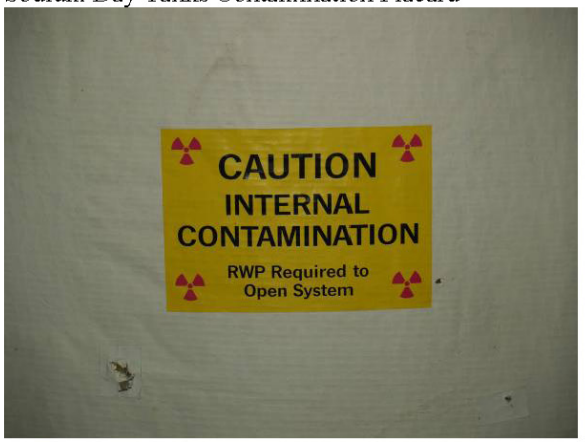

P1015420

Sodium Storage Tank A1-T-101 Contamination Placard

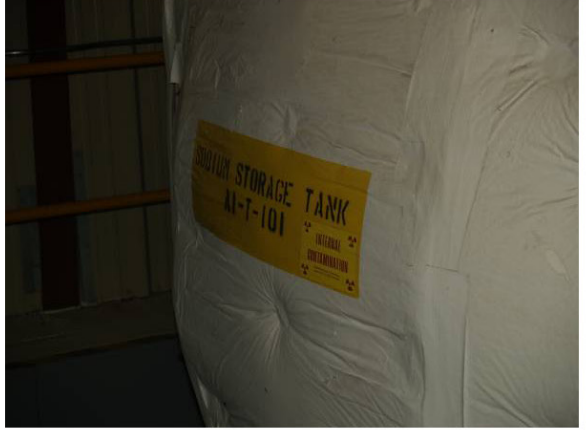




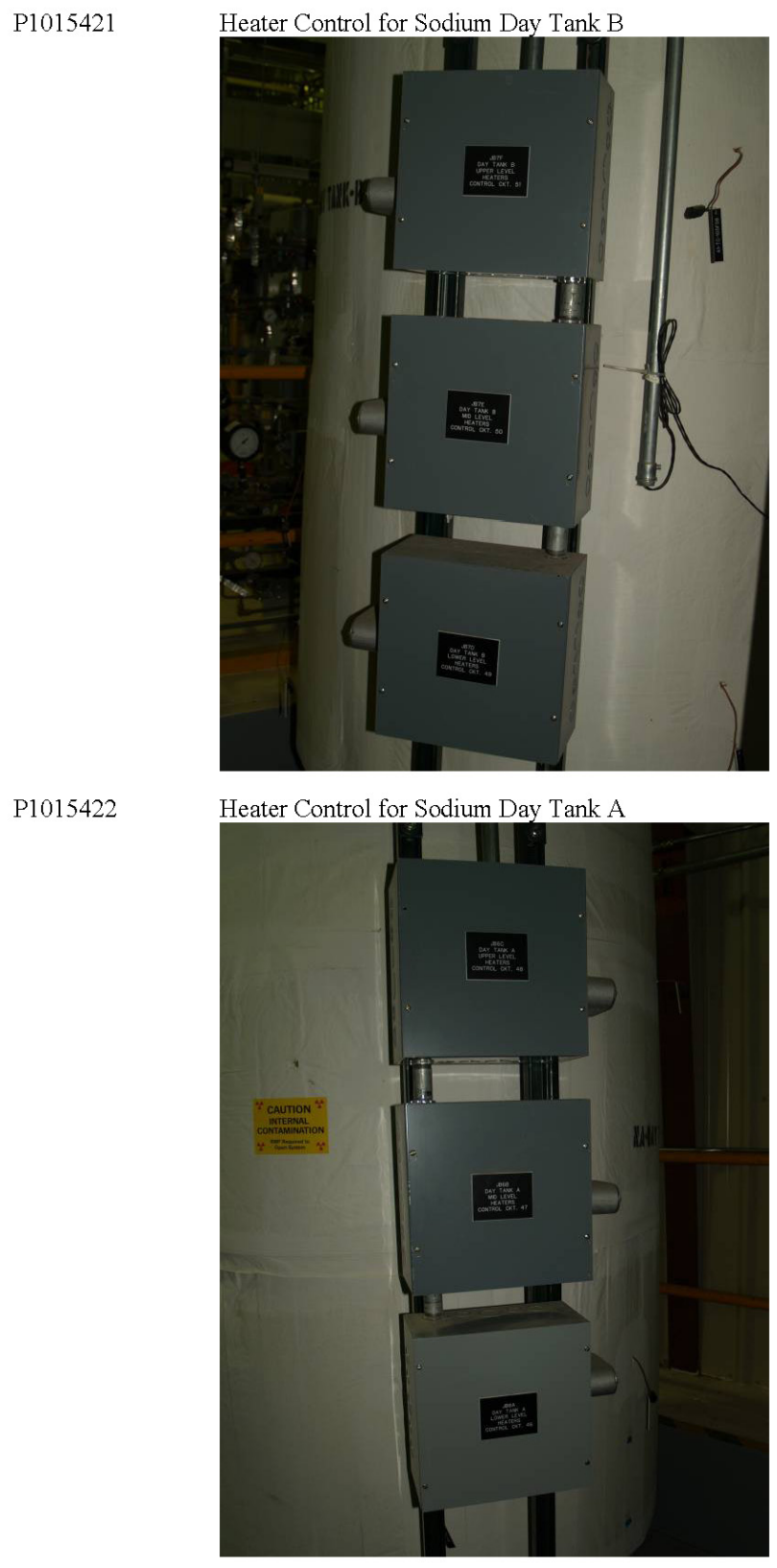


P1015423

Sodium Storage Tank A1-T-101, East Side (looking north)

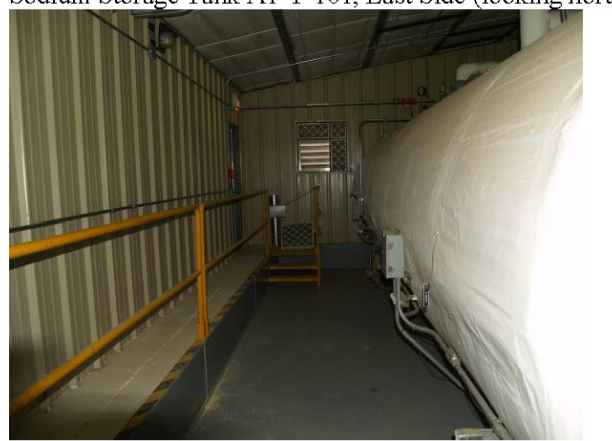

P1015424

Sodium Storage Tank A1-T-101, West Side (looking north)

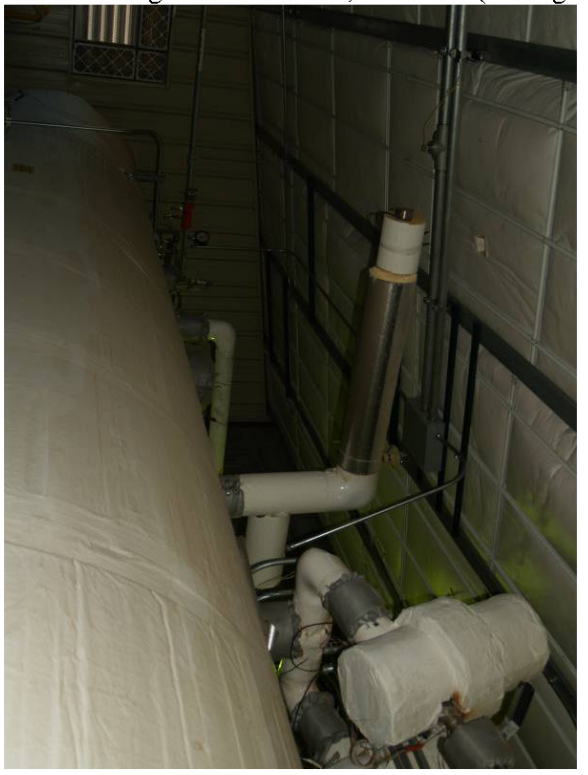




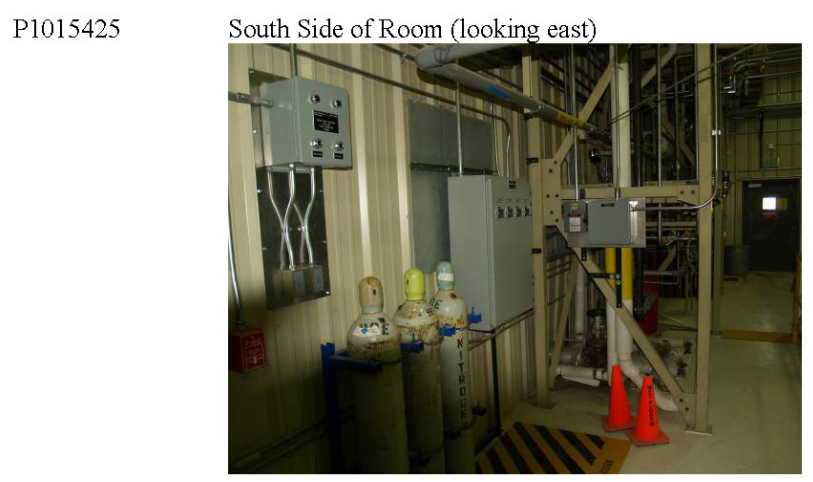

P1015426 Overhead Utility Piping - south wall

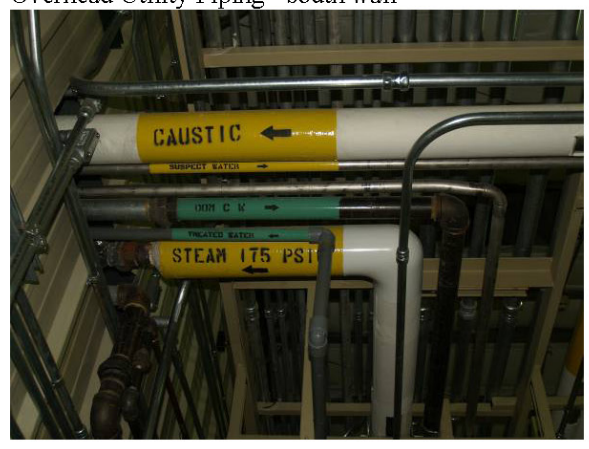




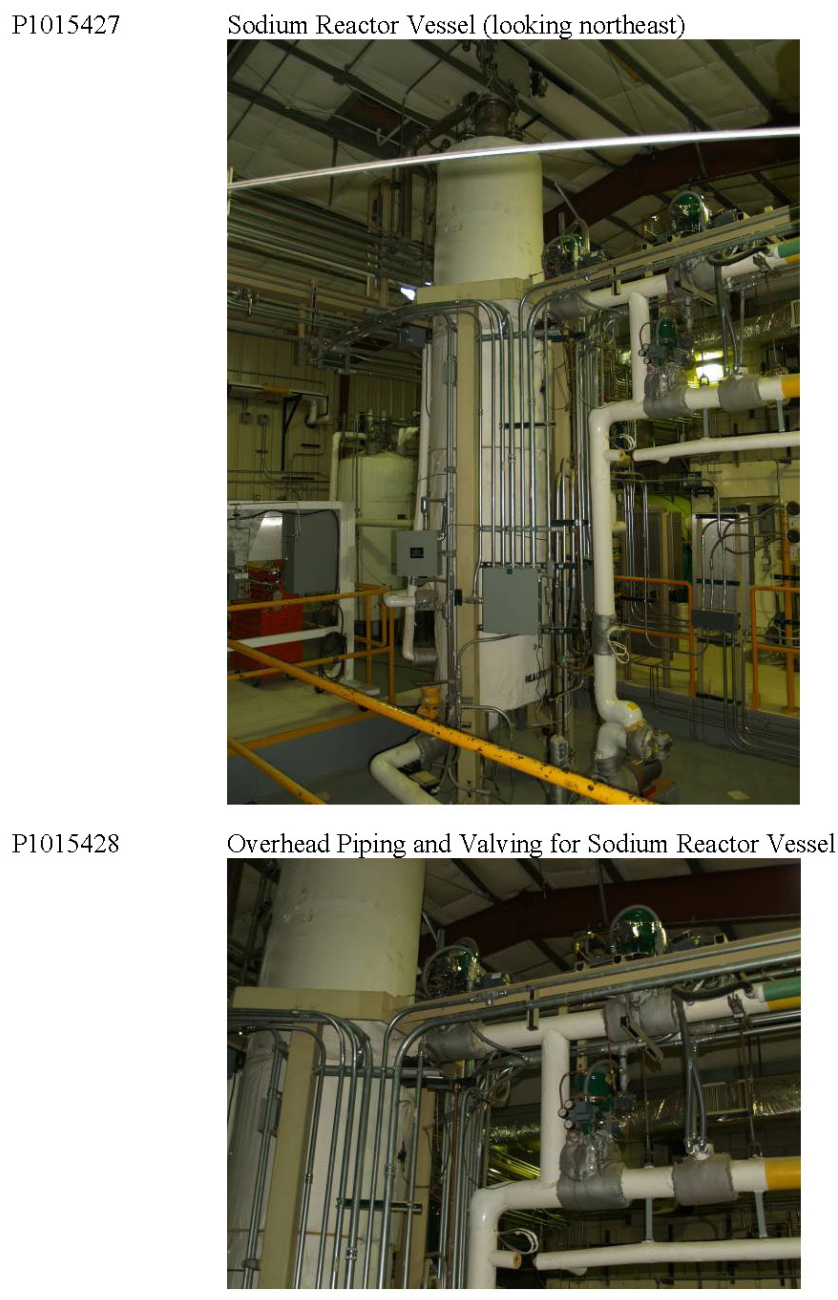


P1015429

Caustic Recirculation Pump for Sodium Reactor Vessel

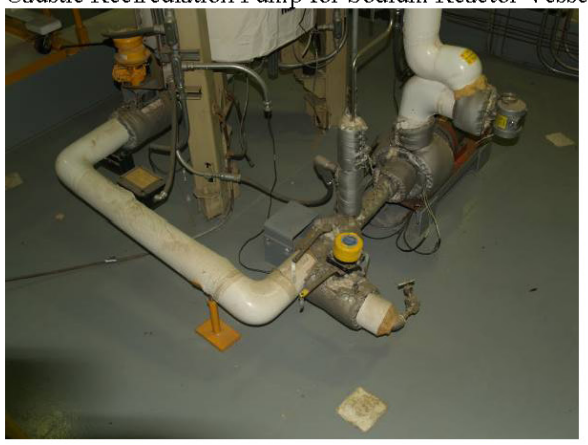

P1015430

Caustic Cooling Tank Pump

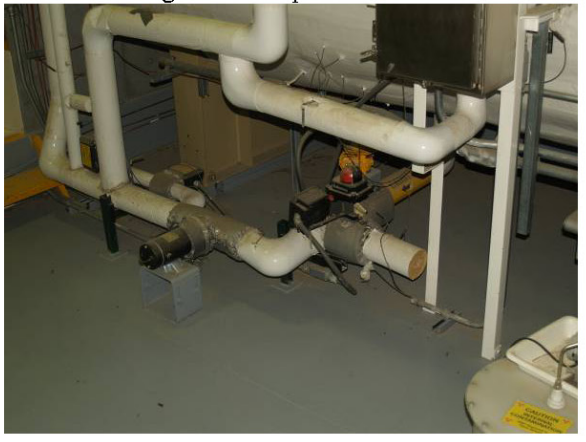

P1015431

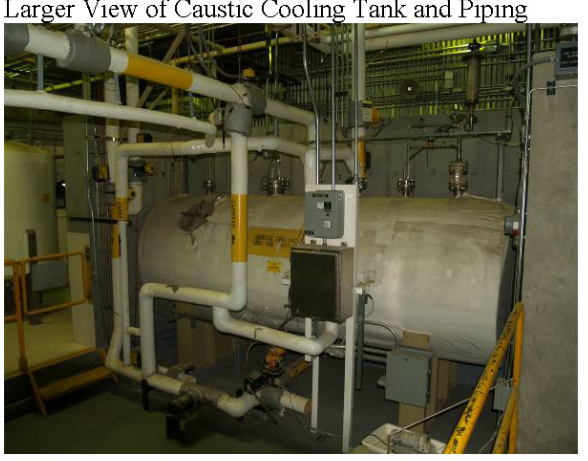

123 
P1015432

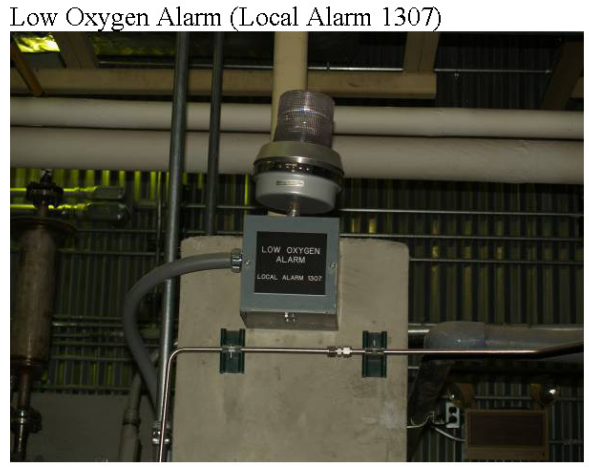

P1015433

Portable Sodium Treatment Instrument and Control Cabinet

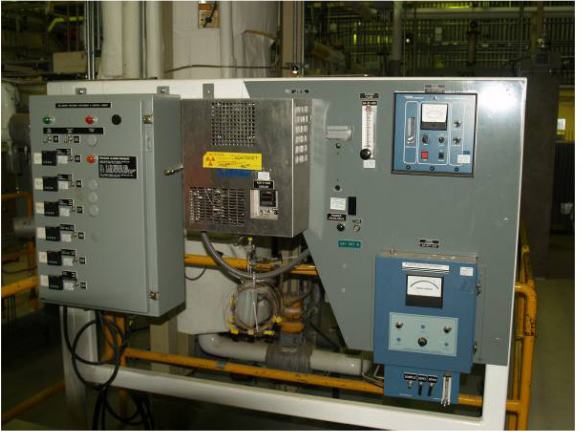

P1015434

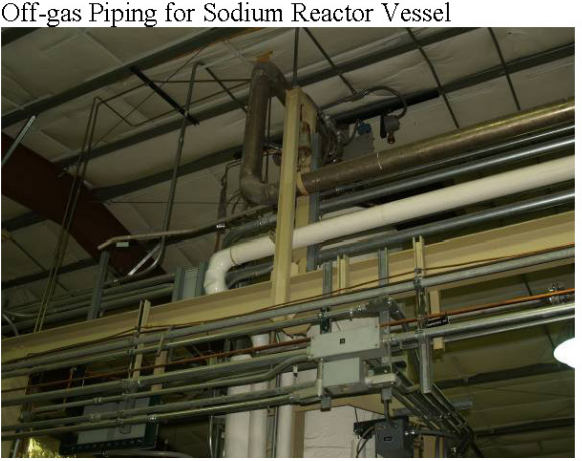


P1015435

Overhead Instrumentation/Power Conduits for Day Tanks

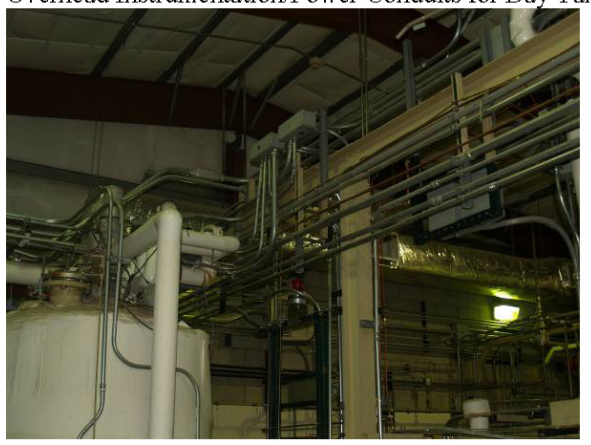

P1015436

Overhead Instrumentation/Power Conduits for Day Tank B

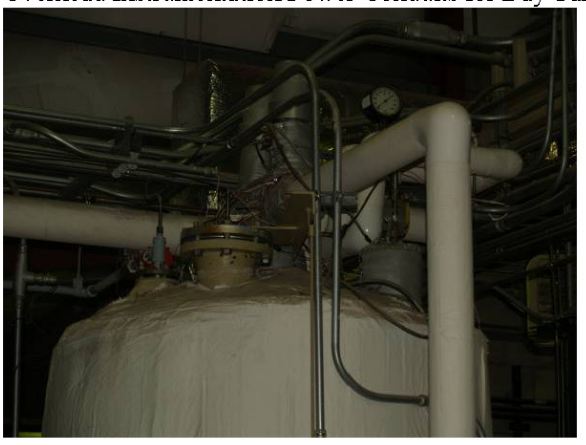

P1015437

Overhead Instrumentation/Power Conduits for Day Tank A

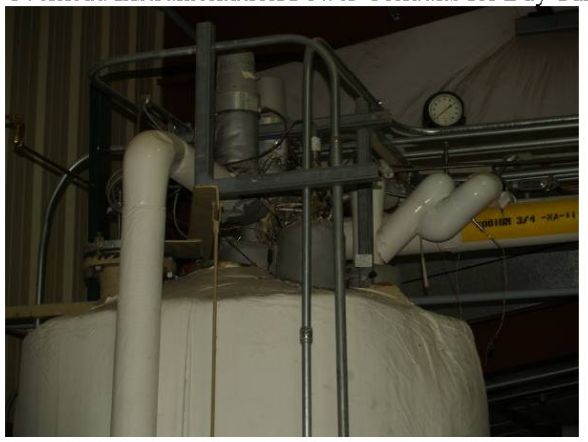


P1015438

Expanded View of Day Tanks A and B and Sodium Storage Tank

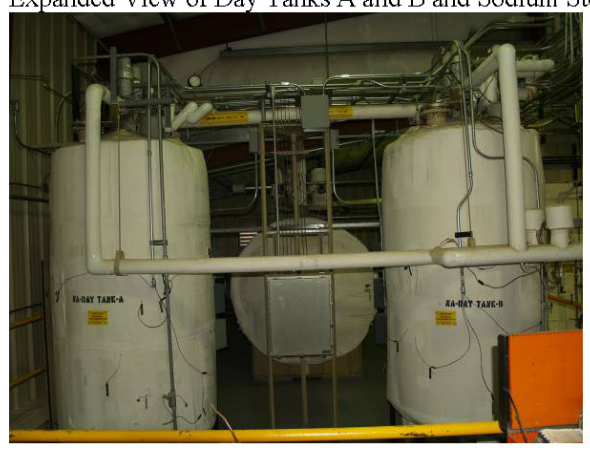

P1015439

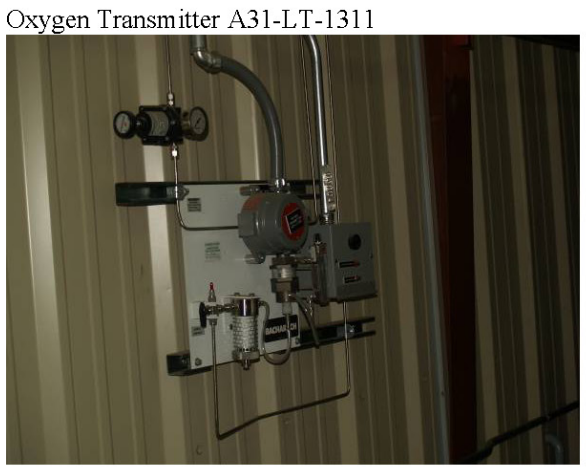

P1015440

Flanders Pre-Filters for Sodium Reactor Off-gas System (looking south) (Flanders HEPA Filters Directly Above)

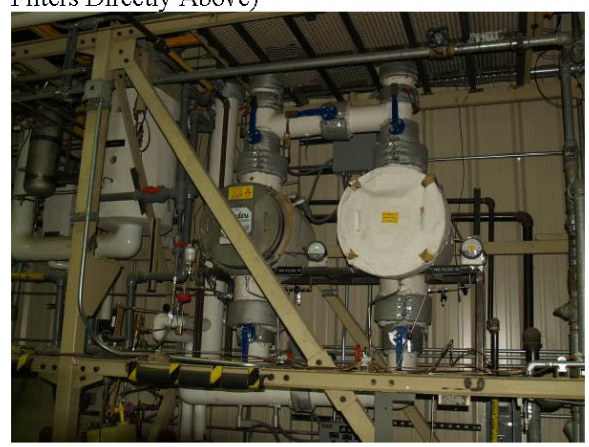


P1015441

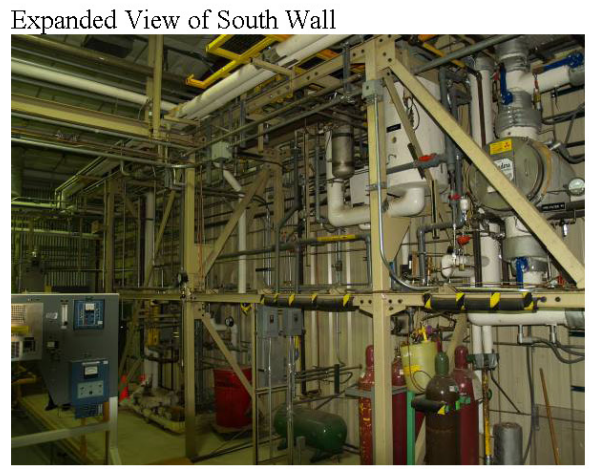

P1015442 Scrubber and Condenser for Sodium Reactor Off-gas System

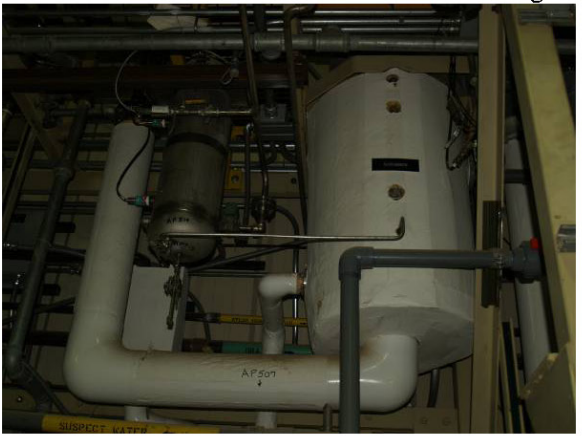

P1015443

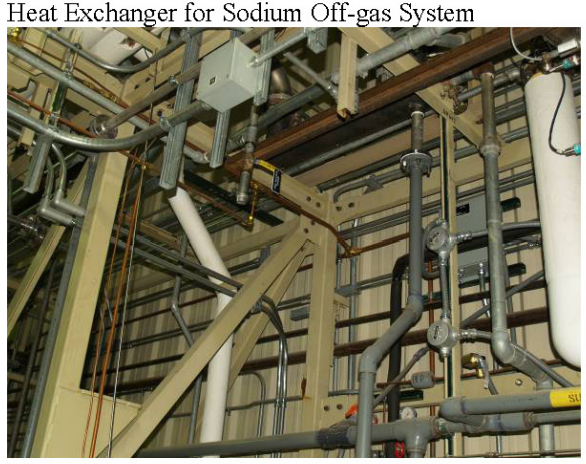


P1015444

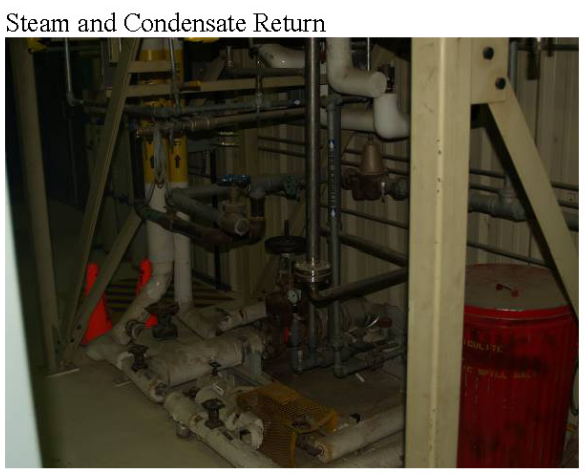


MFC-770C

P1015452

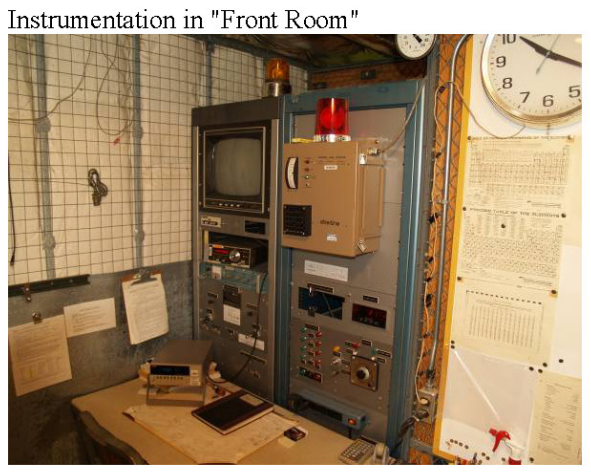

P1015453

Source and Auto Attenuation Device

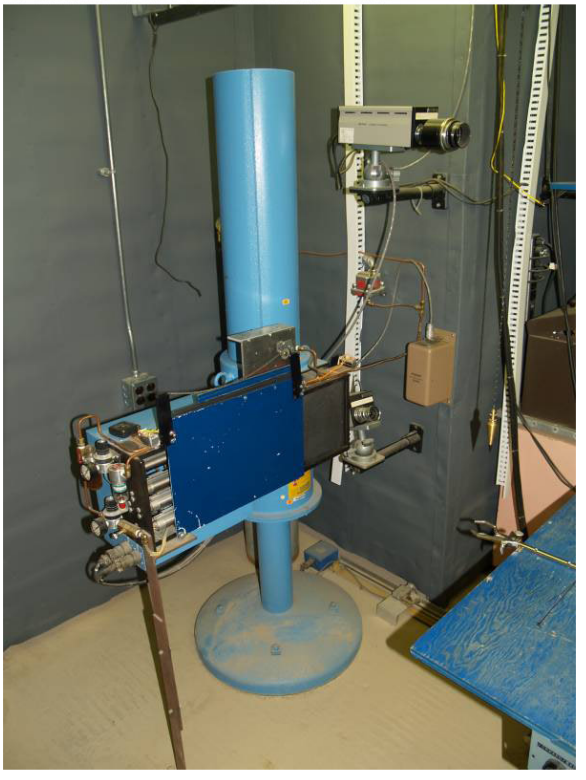


P1015454

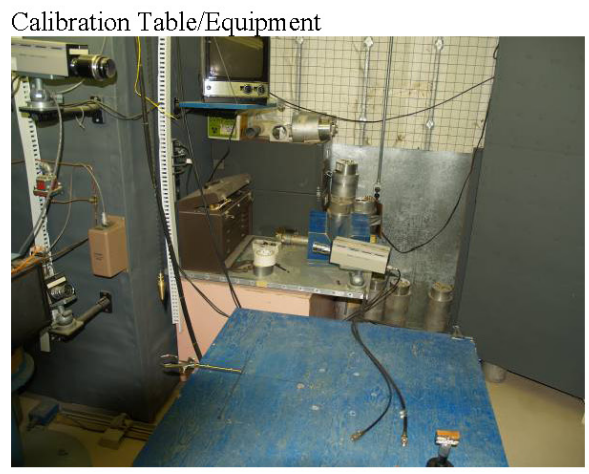

P1015455

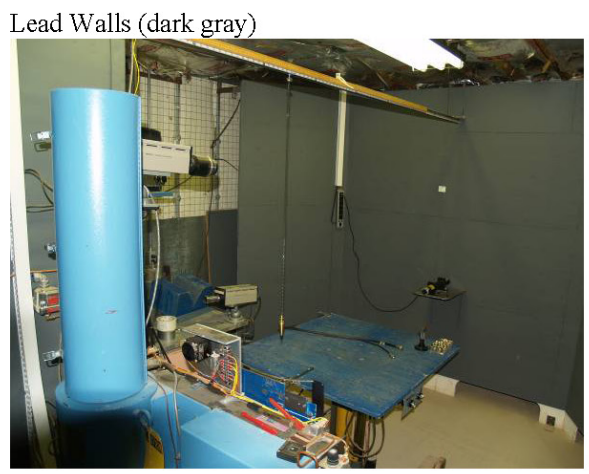




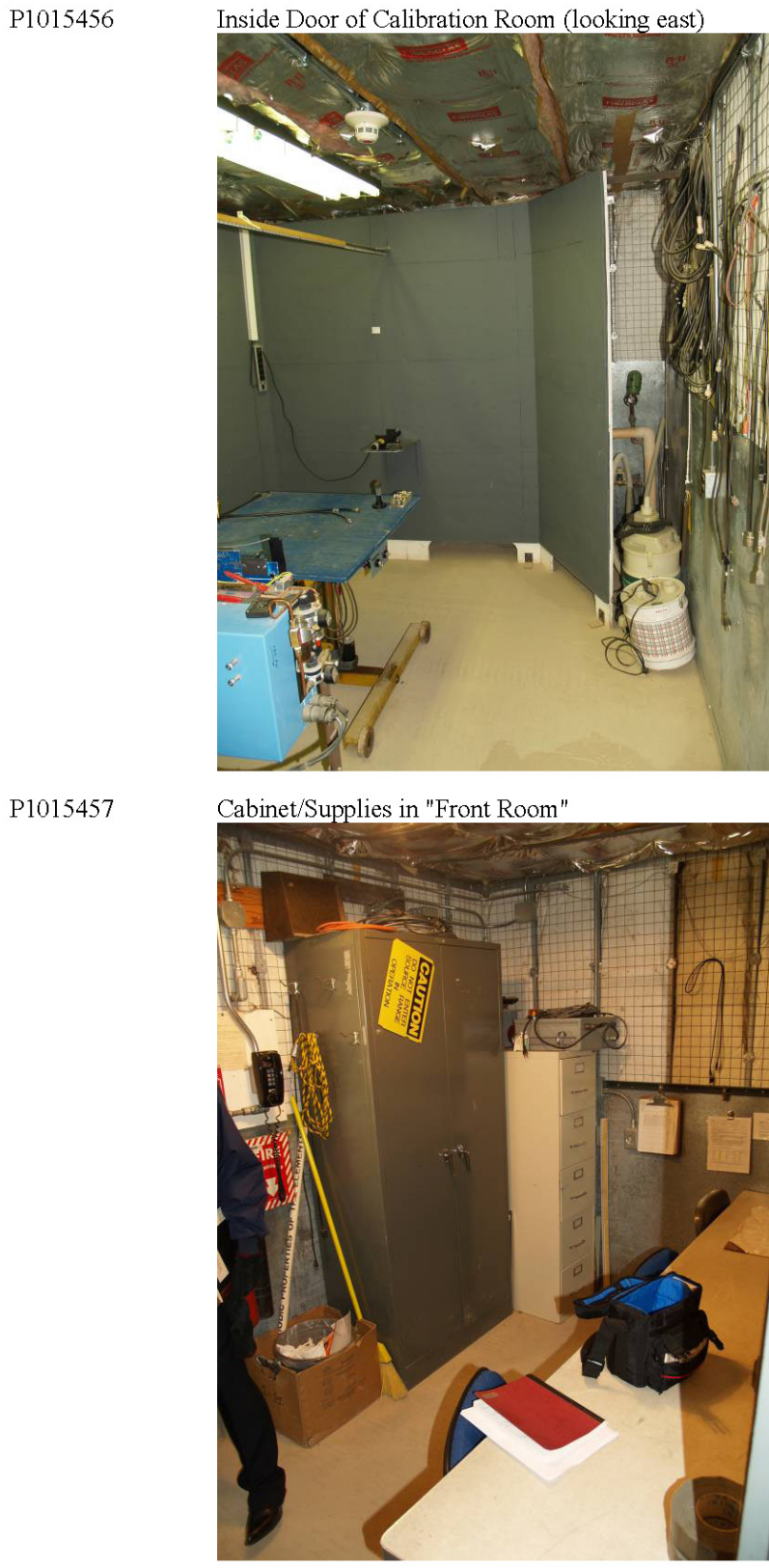

131 
P1015458 Л Sheperd Source and Auto Attenuation Device

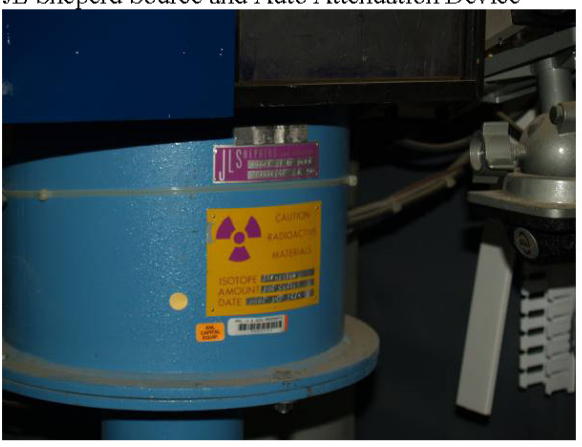


MFC-770B

P1015459

Ingersol Rand Air Compressor Placard

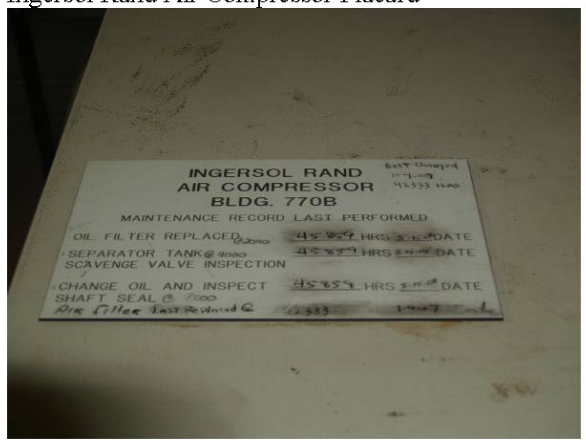

P1015460

Interior Compressed Air Piping (looking northeast)

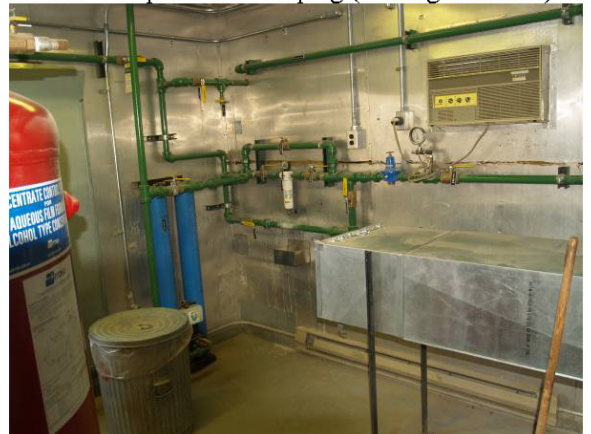

P1015461

Compressor/Pressure Tank/Ducting/Power/Controls (looking west)

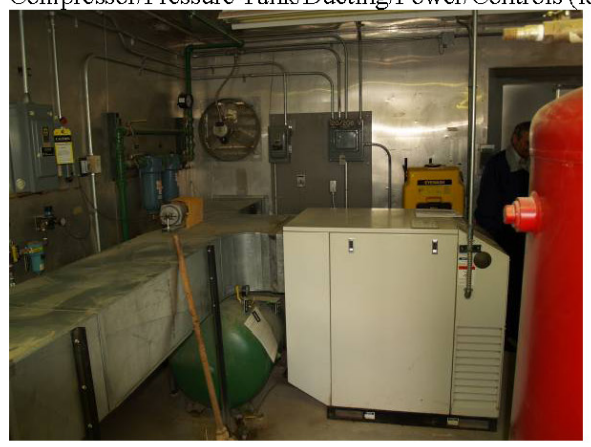

133 
P1015462

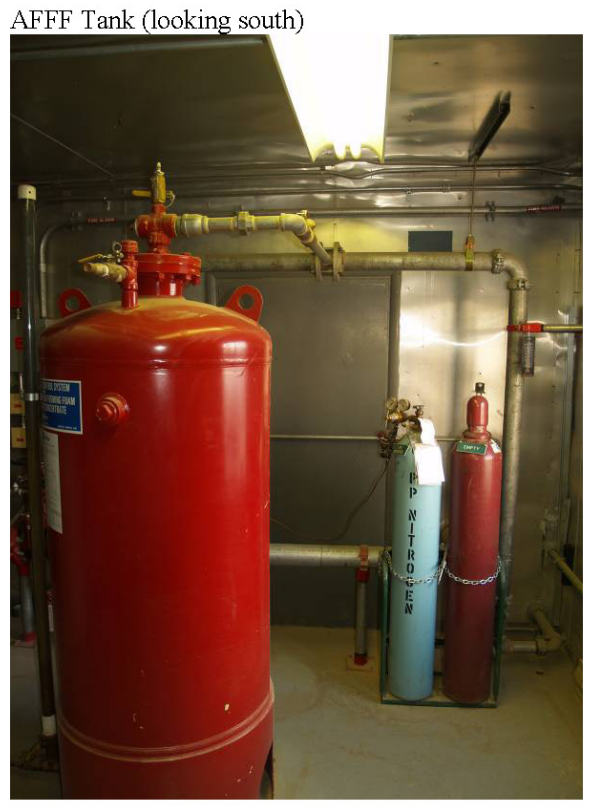

P1015463

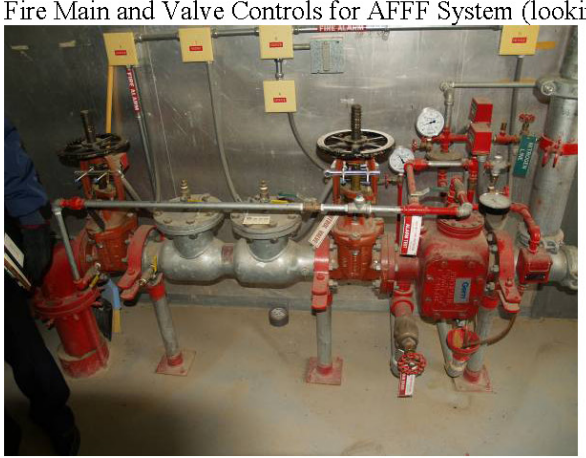




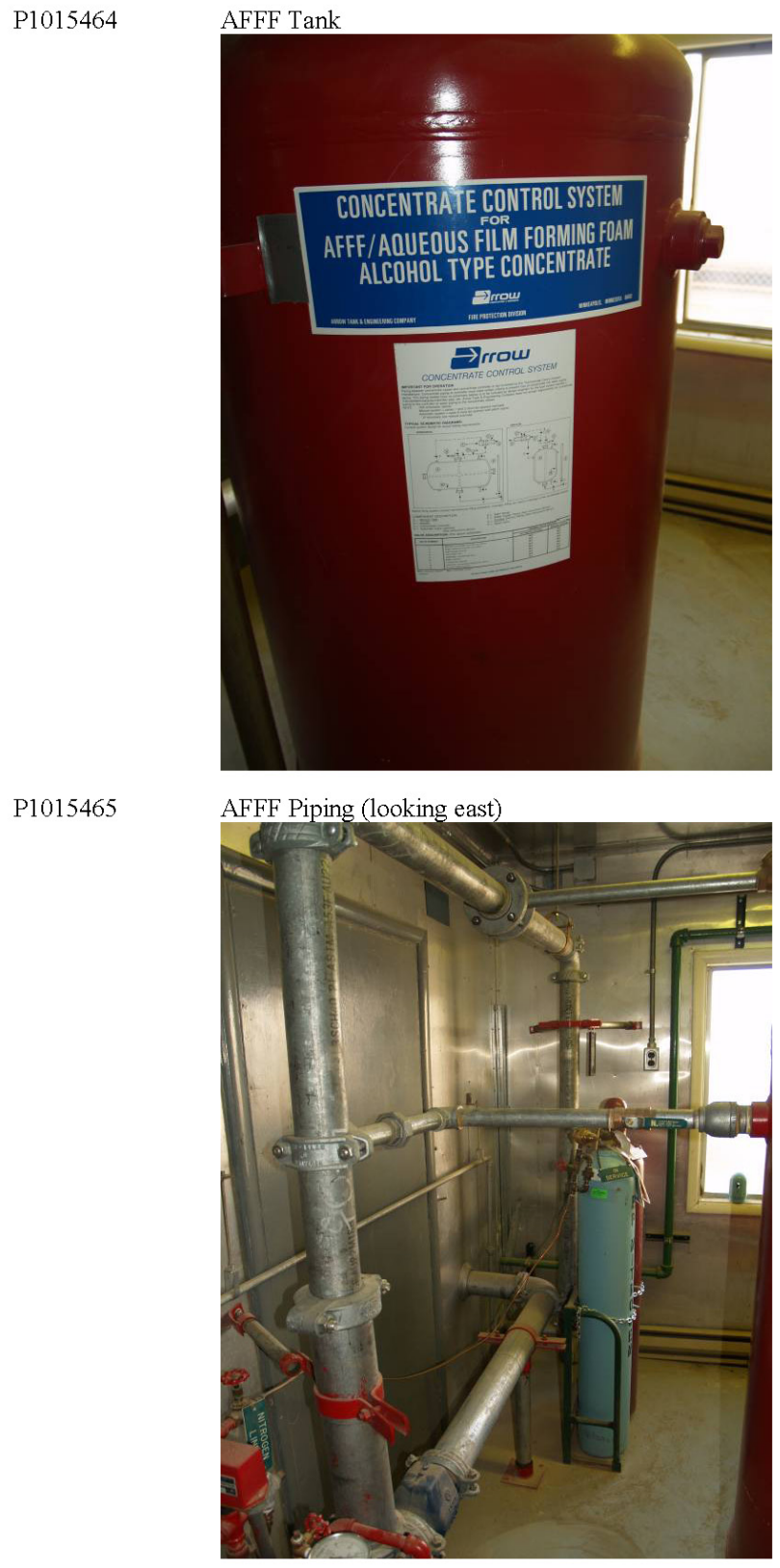


P1015466

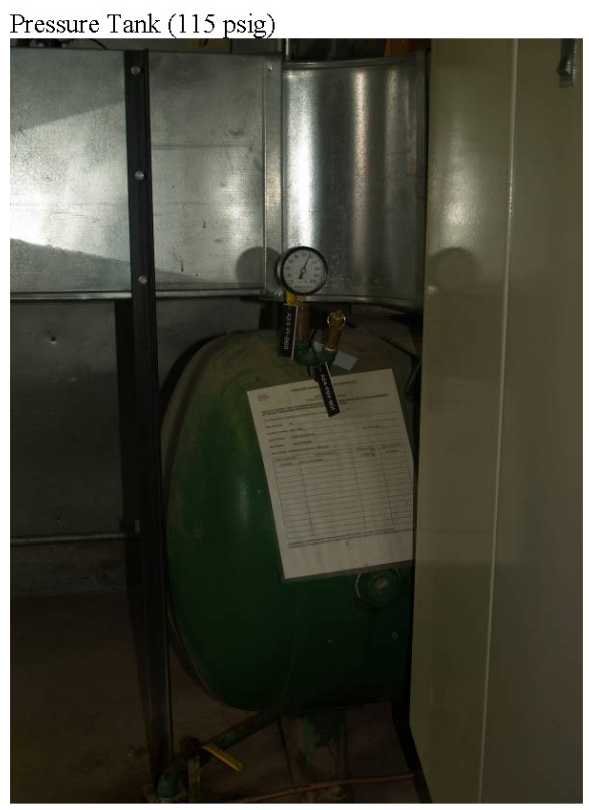




\section{Site Photos}

P1015467

East Side of MFC-770B and MFC-770C (looking north)

P1015468

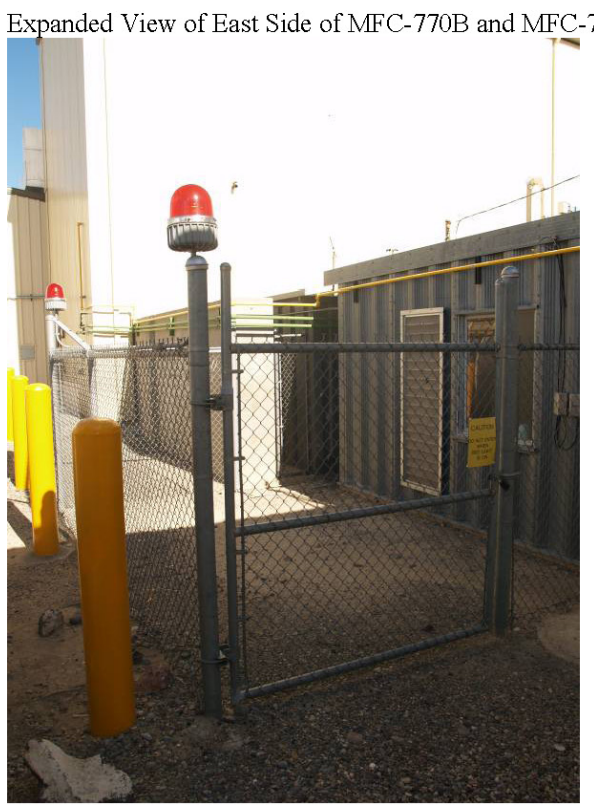

137

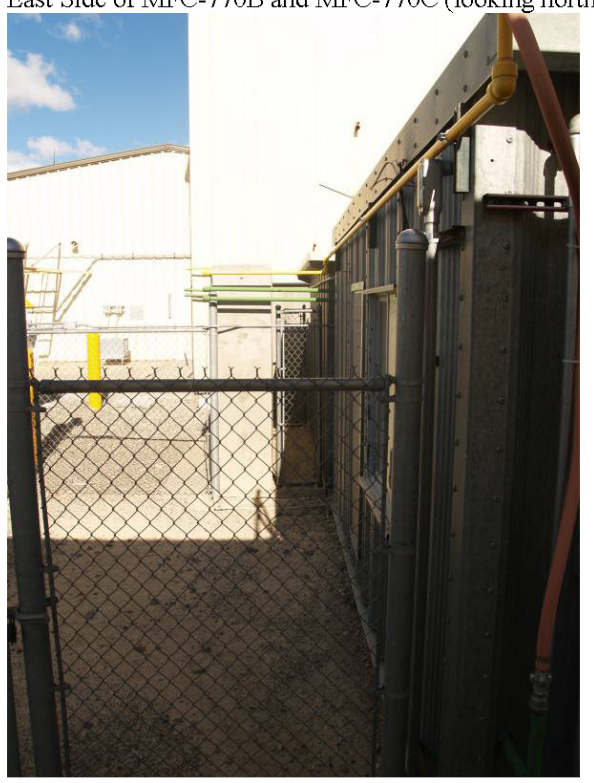

Expanded View of East Side of MFC-770B and MFC-770C (looking north) 


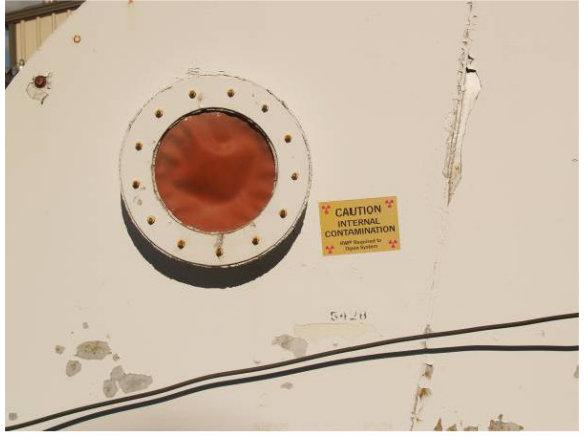

P1015470

Expanded View of Internal Contamination Placard on Vessel Stored on East Side of MFC-770B and MFC-770C/Portable Storage Shed (looking northwest)

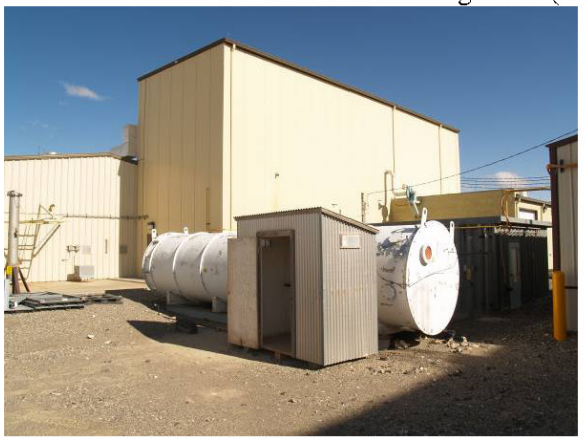

P1015471

Cargo Container/Abandoned Caustic Storage Tank (looking north)

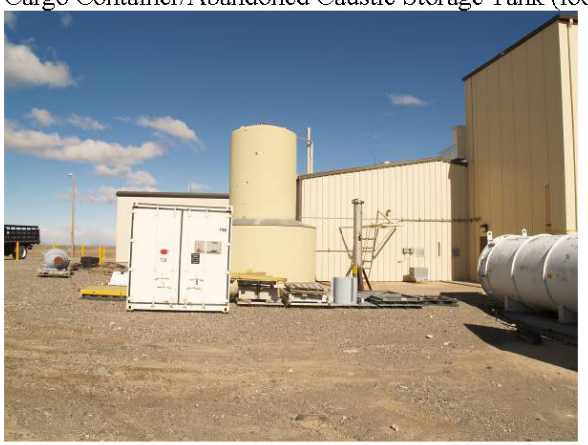


P1015472 MFC-799A (Caustic Storage Tank Building) and Abandoned Caustic Storage Tank (looking northwest)

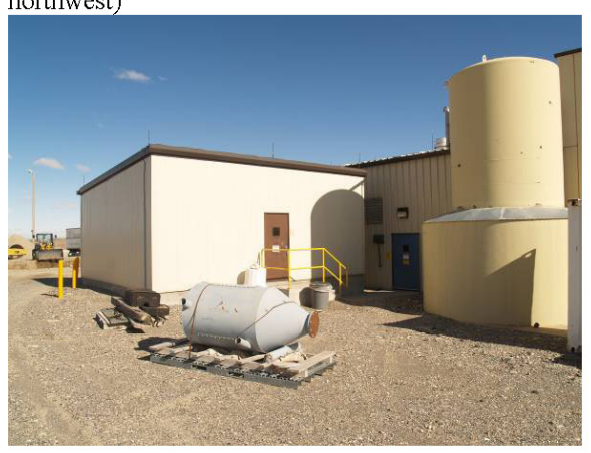

P1015473

Abandoned Caustic Storage Tank (looking west)

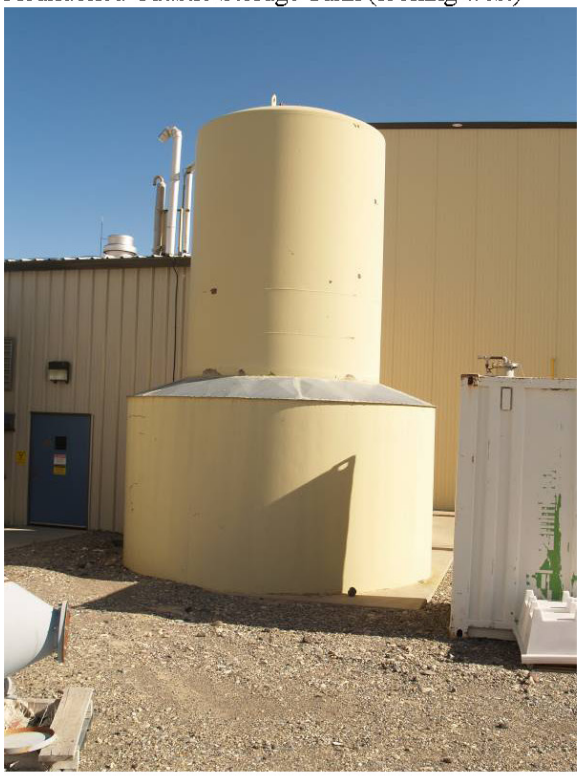


P1015474

Barrel Washing Pad with Vessel with Internal Rad Contamination (looking west)

P1015475

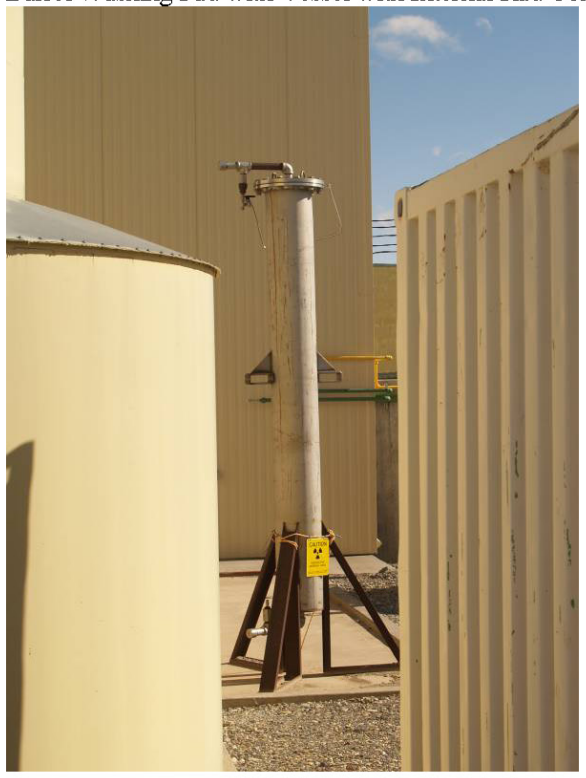

Building 793 (looking south)

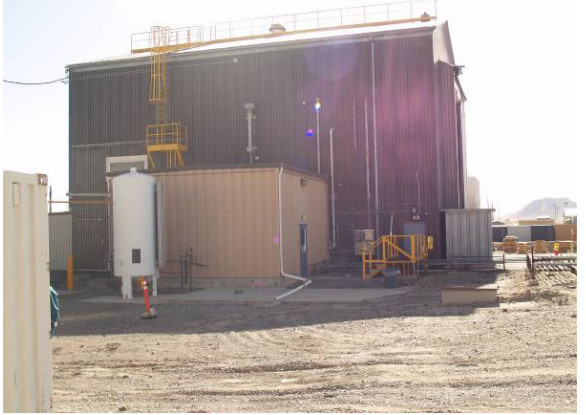


P1015476

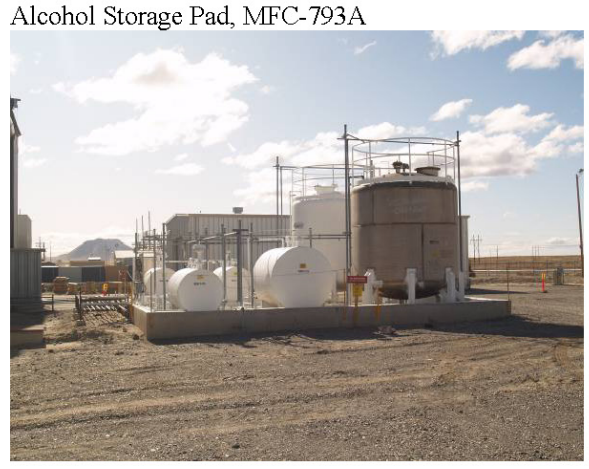

P1015477

Barrel Washing Pad with Vessel with Internal Rad Contamination (looking west)

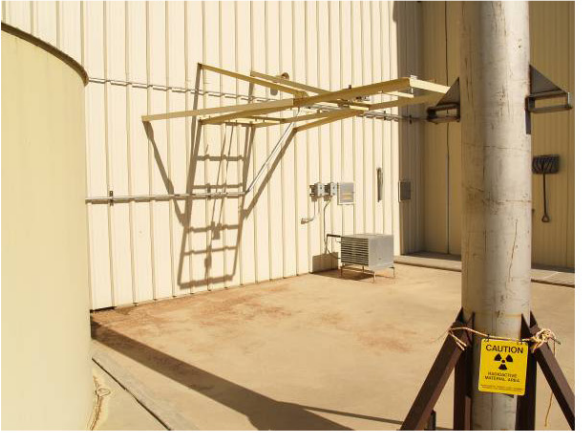

P1015478 MFC-770C

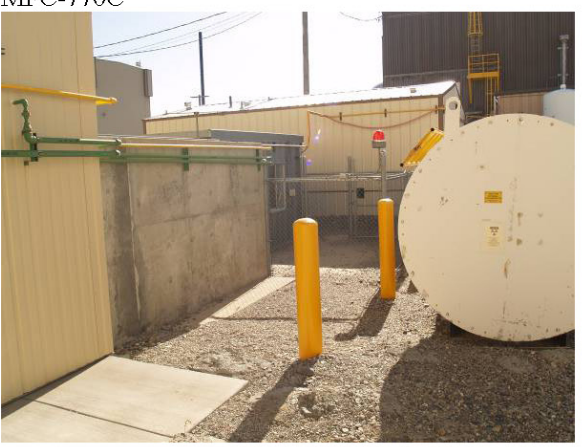


Expanded View of Internal Contamination Placard on Vessel Stored on East Side of MFC-770B and MFC-770C/Portable Storage Shed (looking south from Barrel Washing Pad)

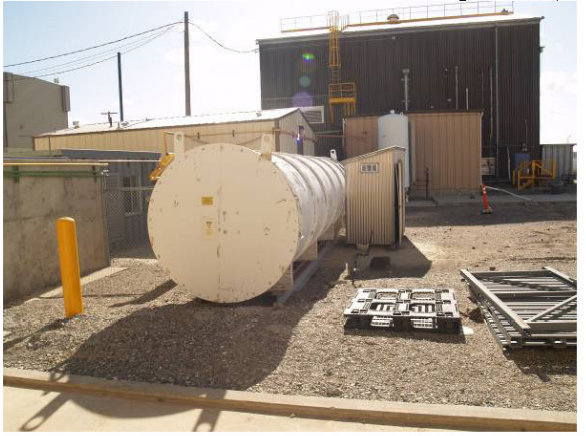

P1015480

Barrel Washing Pad Drain - located in northeast corner

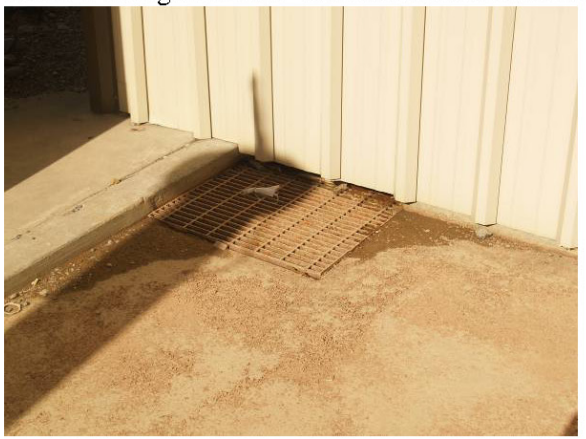

P1015481

Confined Space Placard on Abandoned Caustic Storage Tank

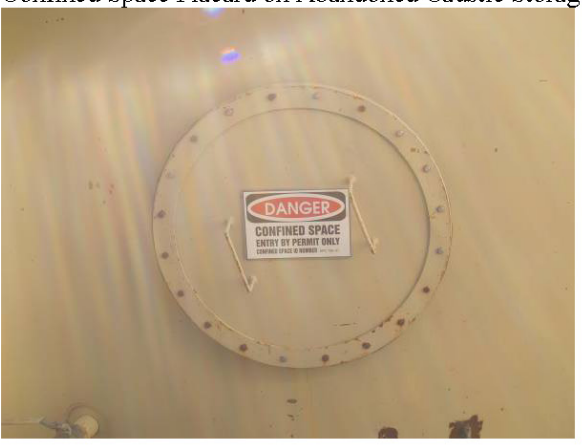




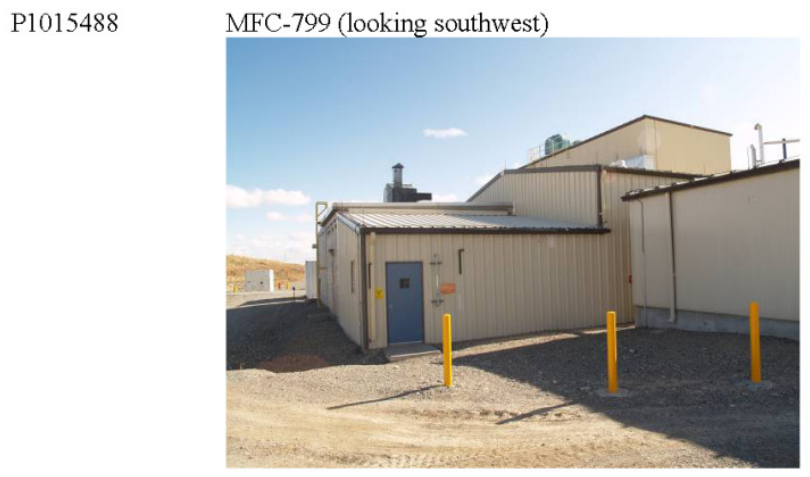

P1015489

MFC-799A (looking southwest)

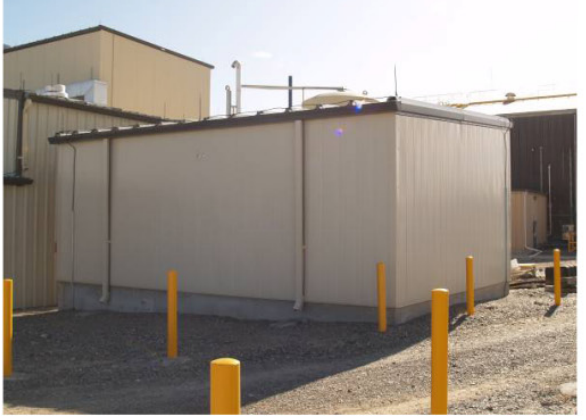

P1015490

Two 4-in Diameter Drain Pipes from MFC-799 and Barrel Washing Pad (Drains to North Area Drainage Ditch)

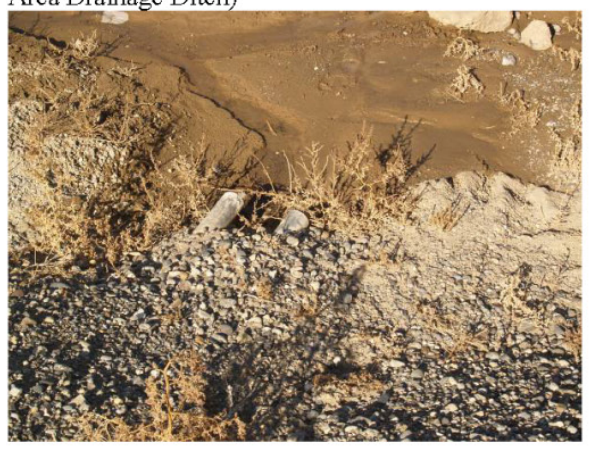


P1015491

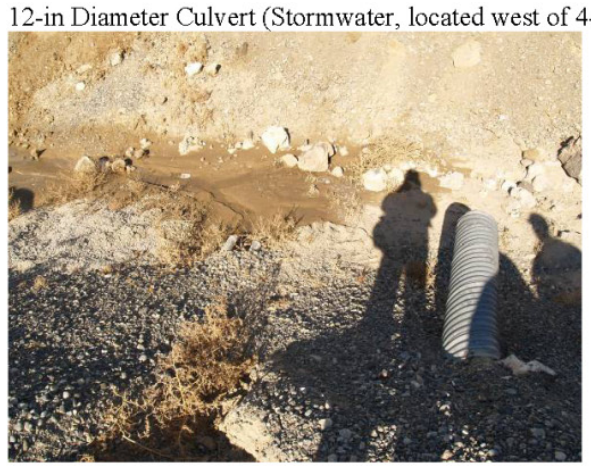

P1015492

Drainage Ditch/Concrete Weir Structure approximately 20 yards downstream (looking east)

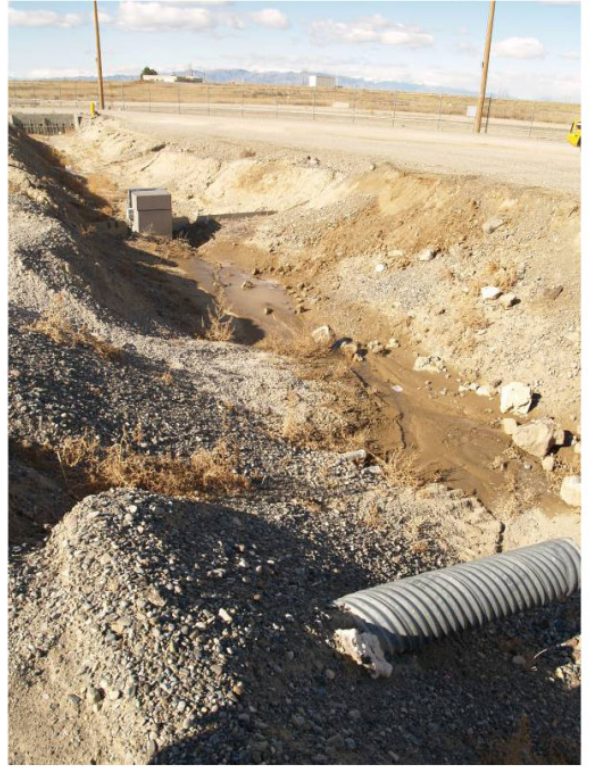


P1015493

Northeast Exterior Corner of Barrel Holding Room

P1015494

P1015495

North Side of MFC-799

20-ft Cargo Storage Container RSU-1765
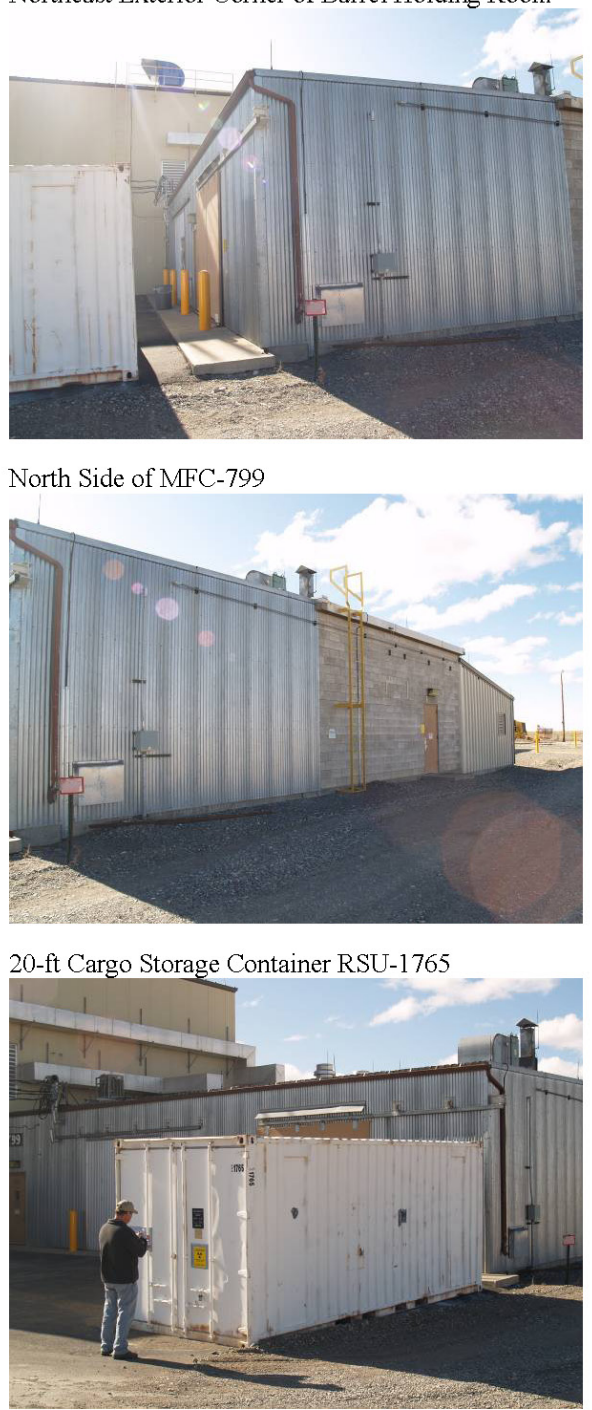
P1015496

Expanded View of 20-ft Cargo Storage Container RSU-1765 (looking southeast)

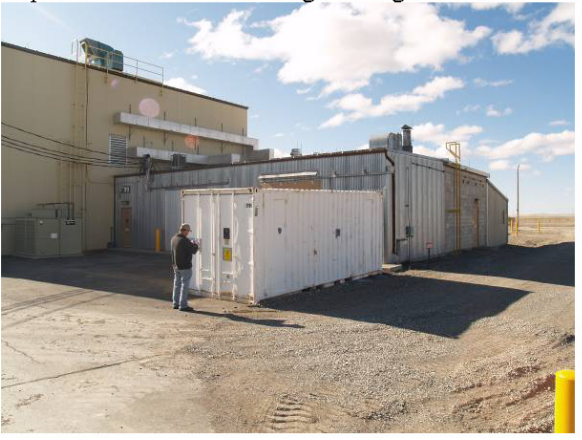

P1015497

MFC-799 with Carbonate Sodium Process Facility Addition (looking southeast)

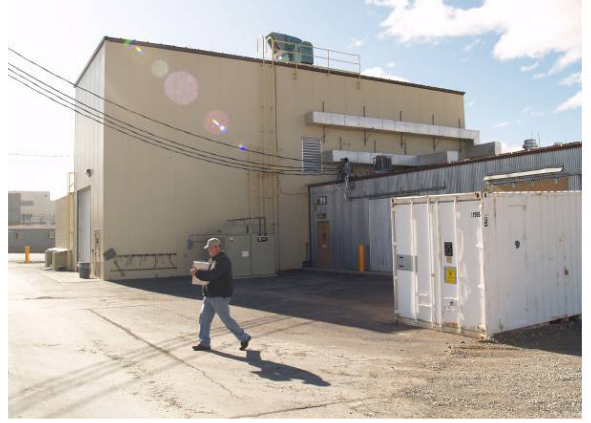

P1015498 1765

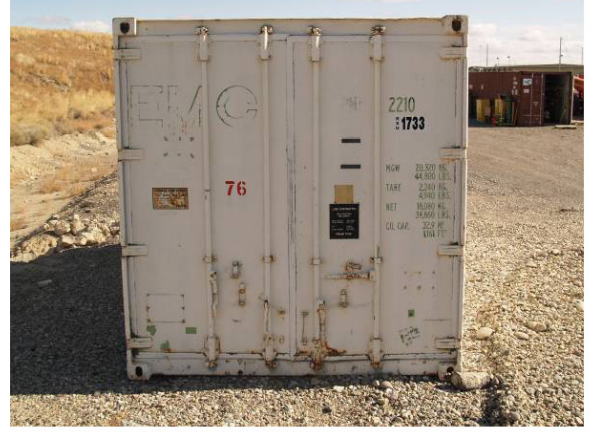


P1015499

20-ft Cargo Storage Container RSU-1765 (looking east)

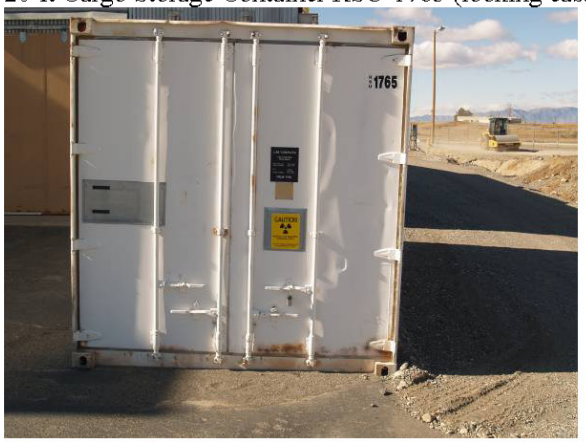

P1015500

Power Pole for Main Power Feed to MFC-799 (looking southwest)

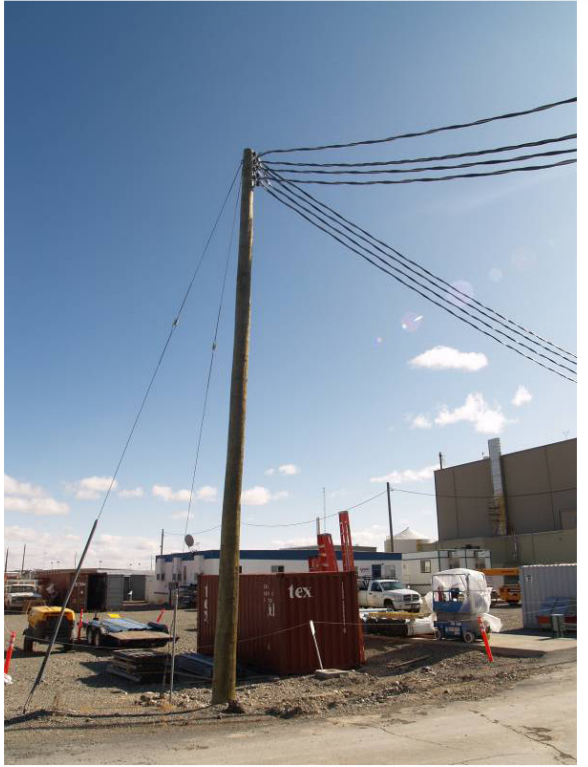


P1015501

Power Transmission Lines and Pole $/ \mathrm{CO}_{2}$ Storage Tank Pad

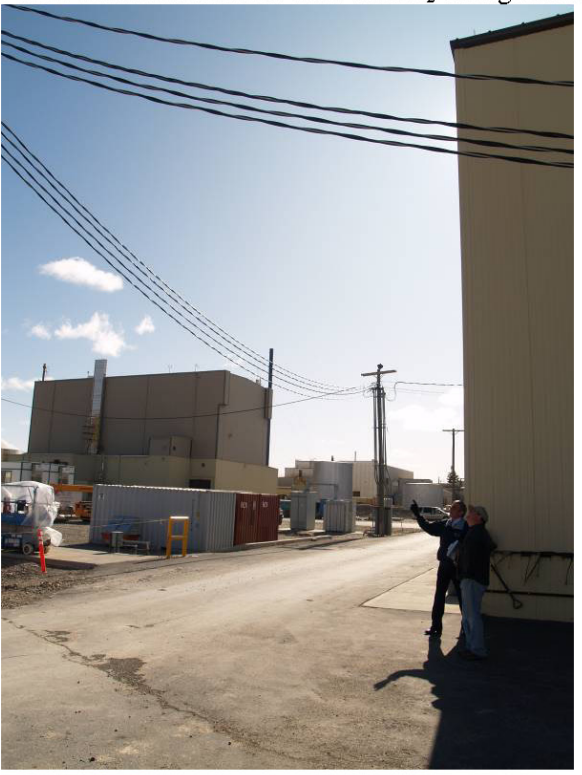

P1015502

Main Power Weatherhead Feed into MFC-799

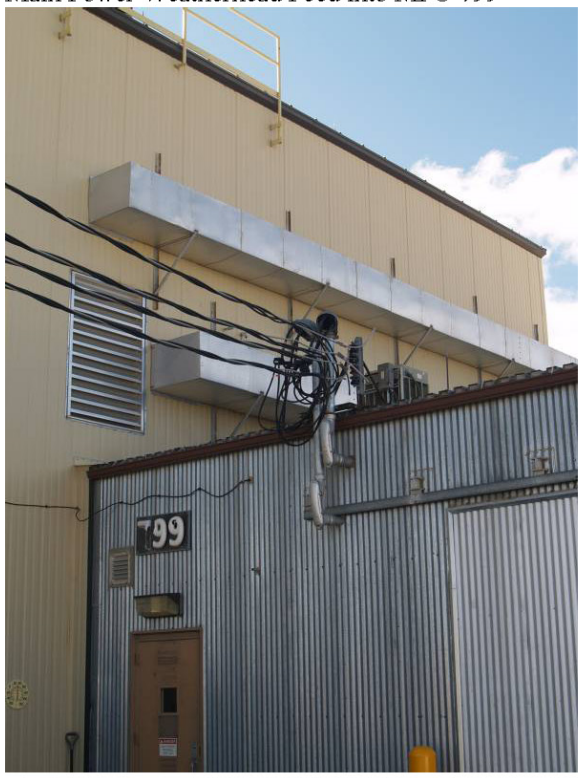


P1015503

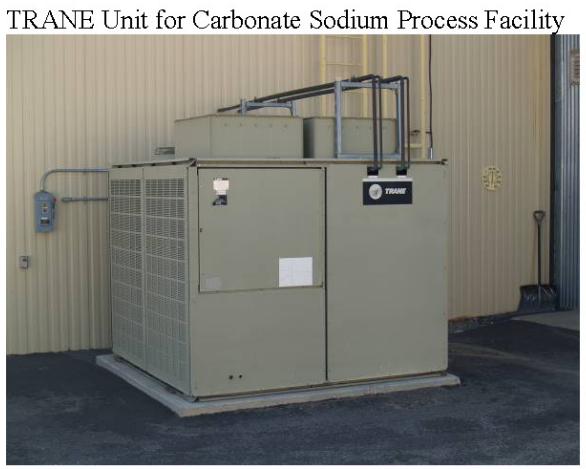

P1015504

External View of MFC-770B (looking northeast)

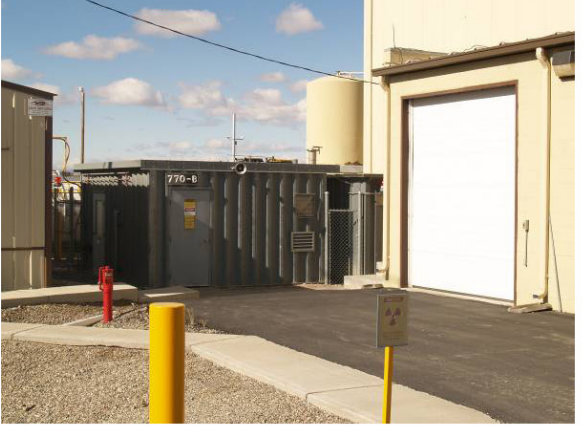

P1015505

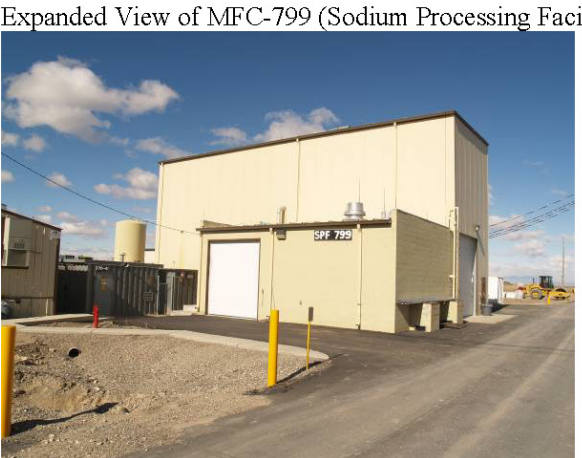


P1015506

Expanded View of MFC-799 (Sodium Processing Facility) (looking northeast)

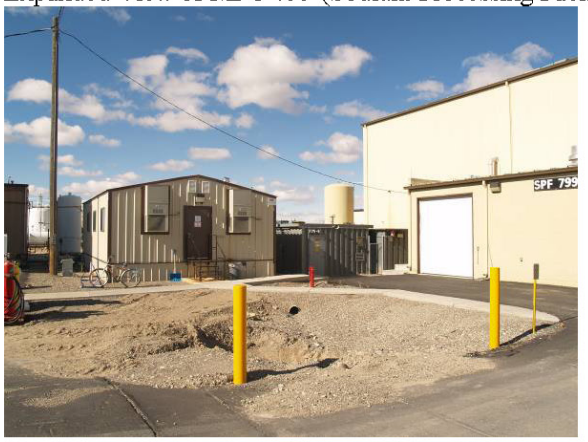

P1015507

MFC-793 (looking east)

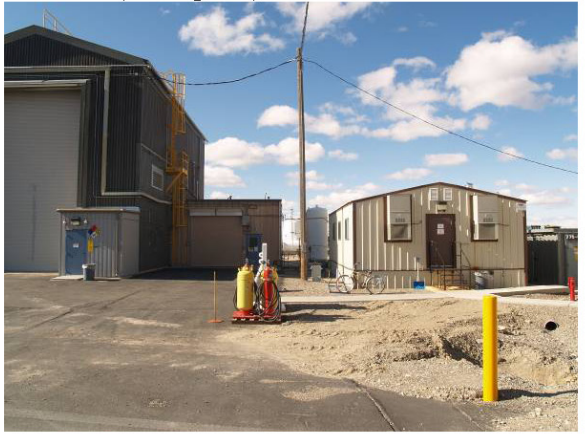

P1015508

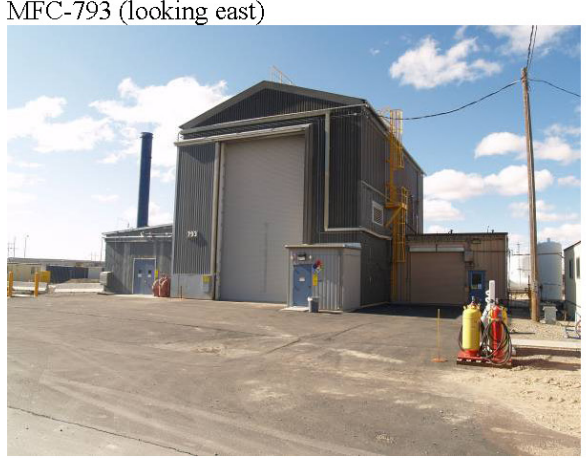


Main Power Distribution Pole PP1 10, Input is PP111 Ckt \#1 480 Volt

$\mathrm{P} 1015510$

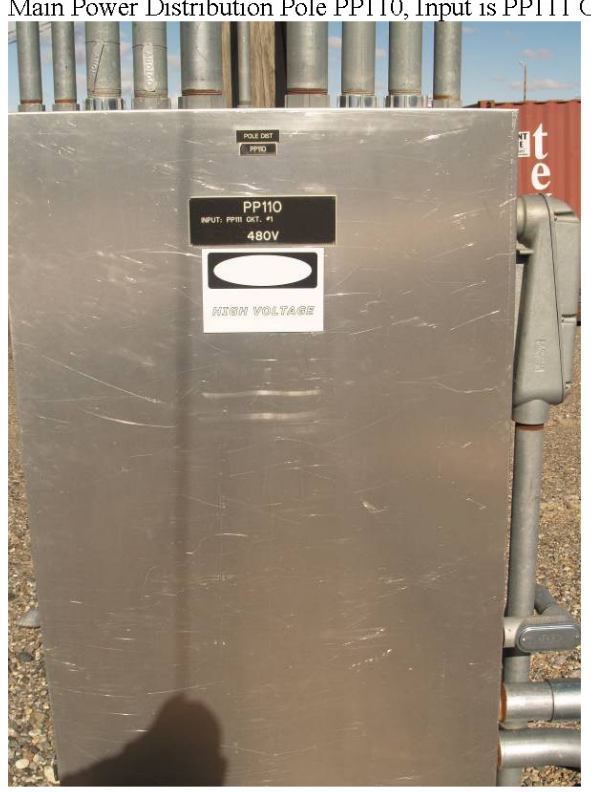

Power Pole Weatherhead (PP1 10)

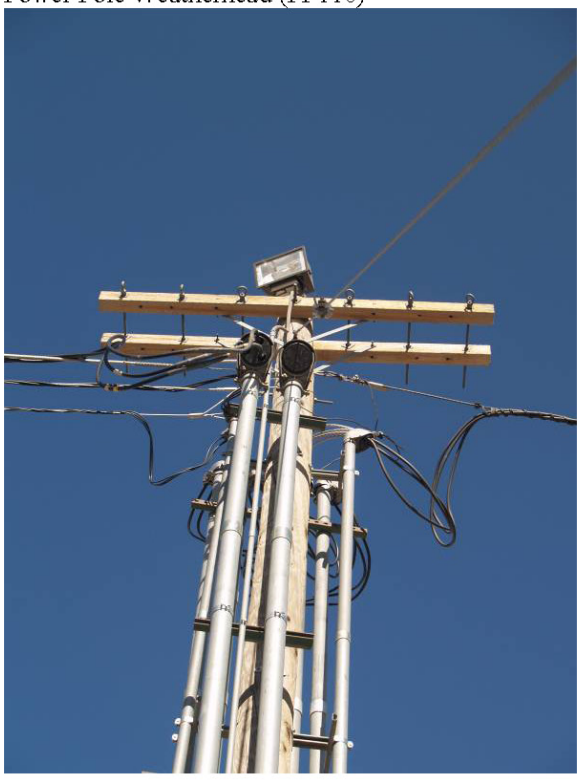

151 
P1015511

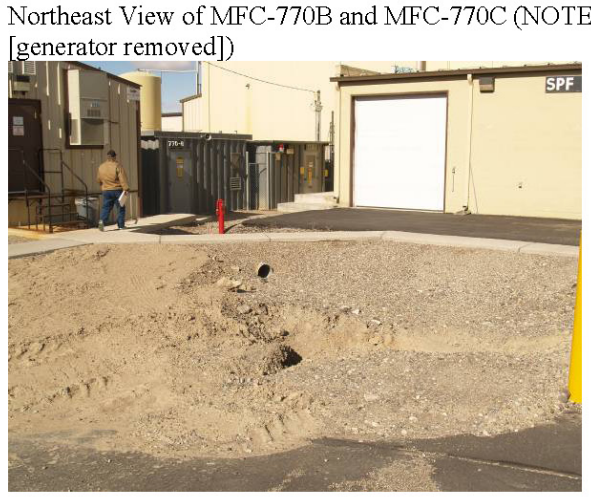

P1015512

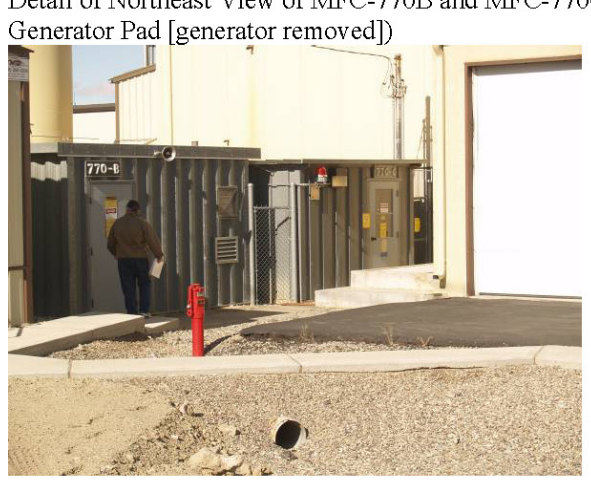


MFC-799A

P1015482

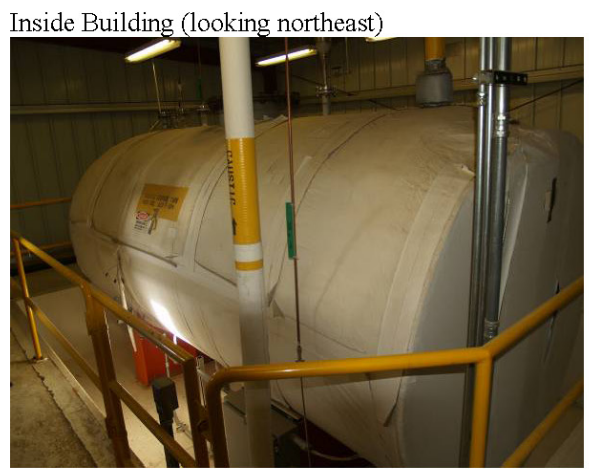

P1015483

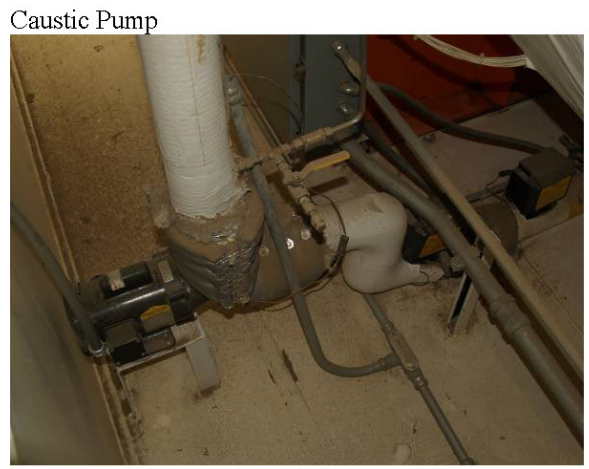

P1015484

Caustic Storage Tank and Pit (looking southwest)

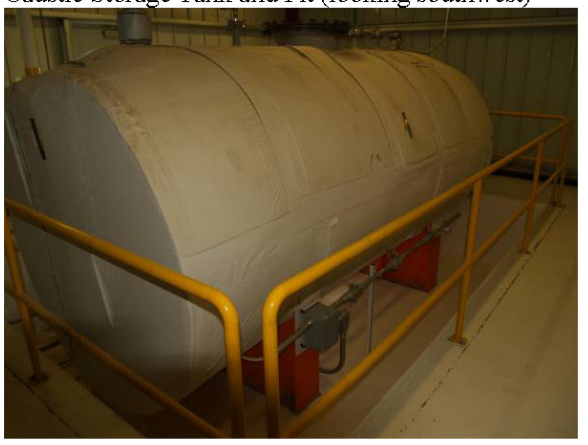

153 


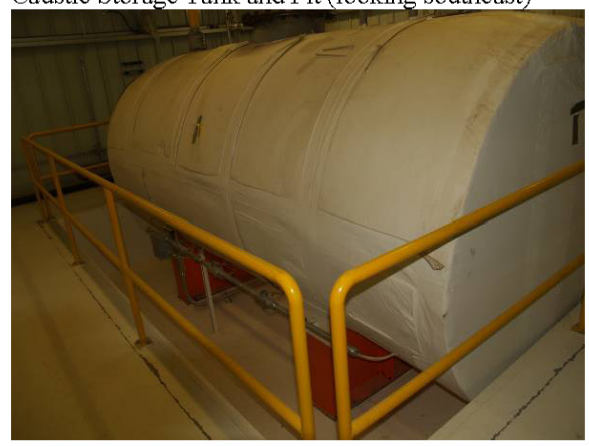

P1015486

Caustic Storage Tank and Pit (looking northwest)

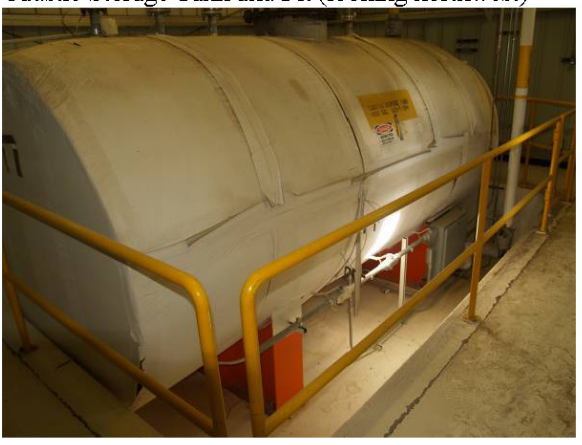

P1015487

Overhead Caustic Piping (looking northwest)

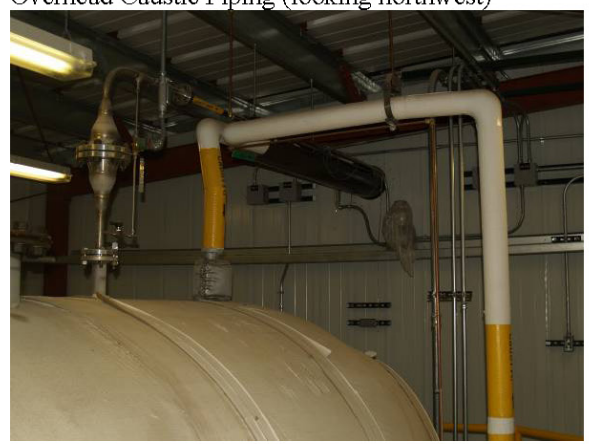




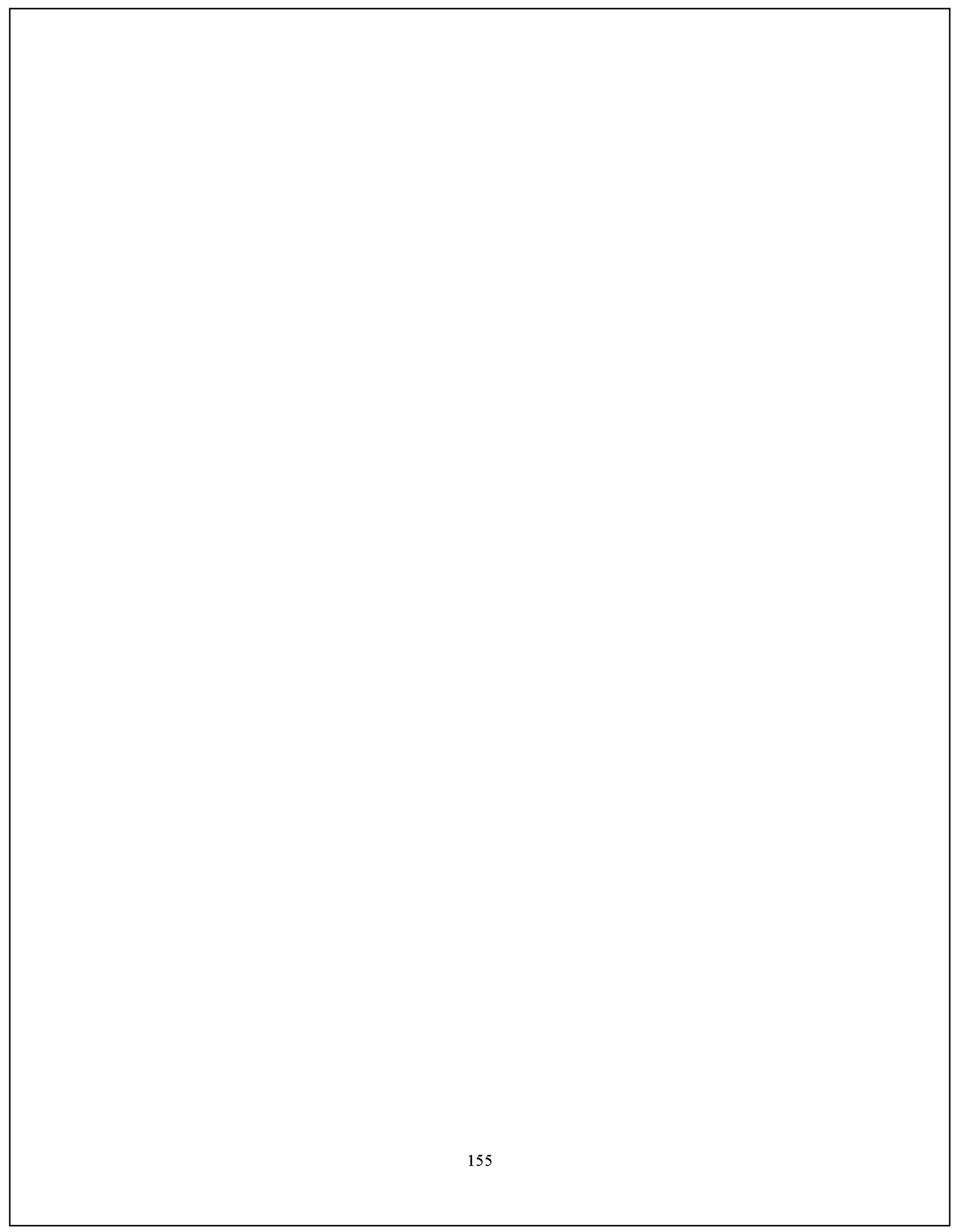

A-157 
Appendix D

Radiological Control Survey Maps 


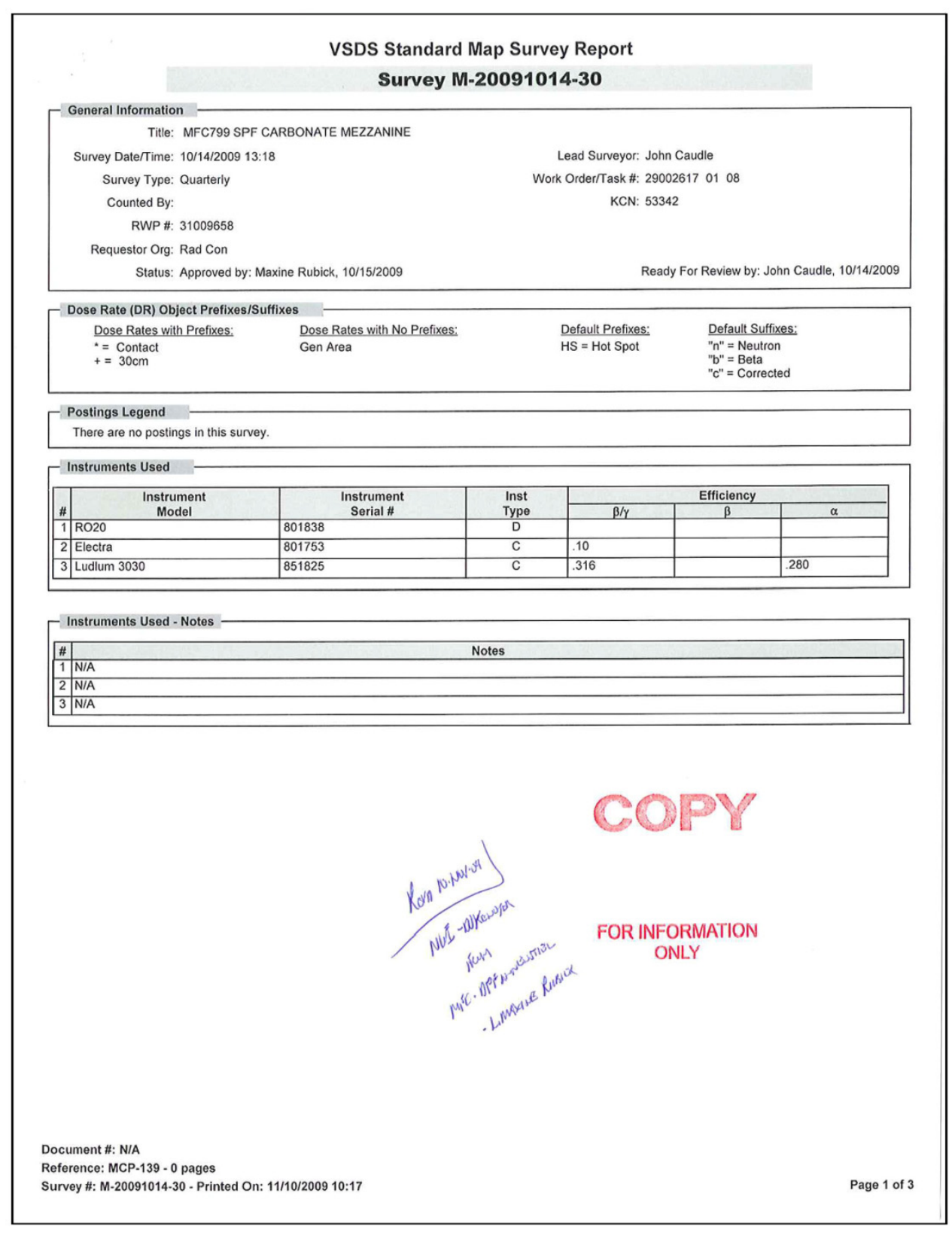

157 


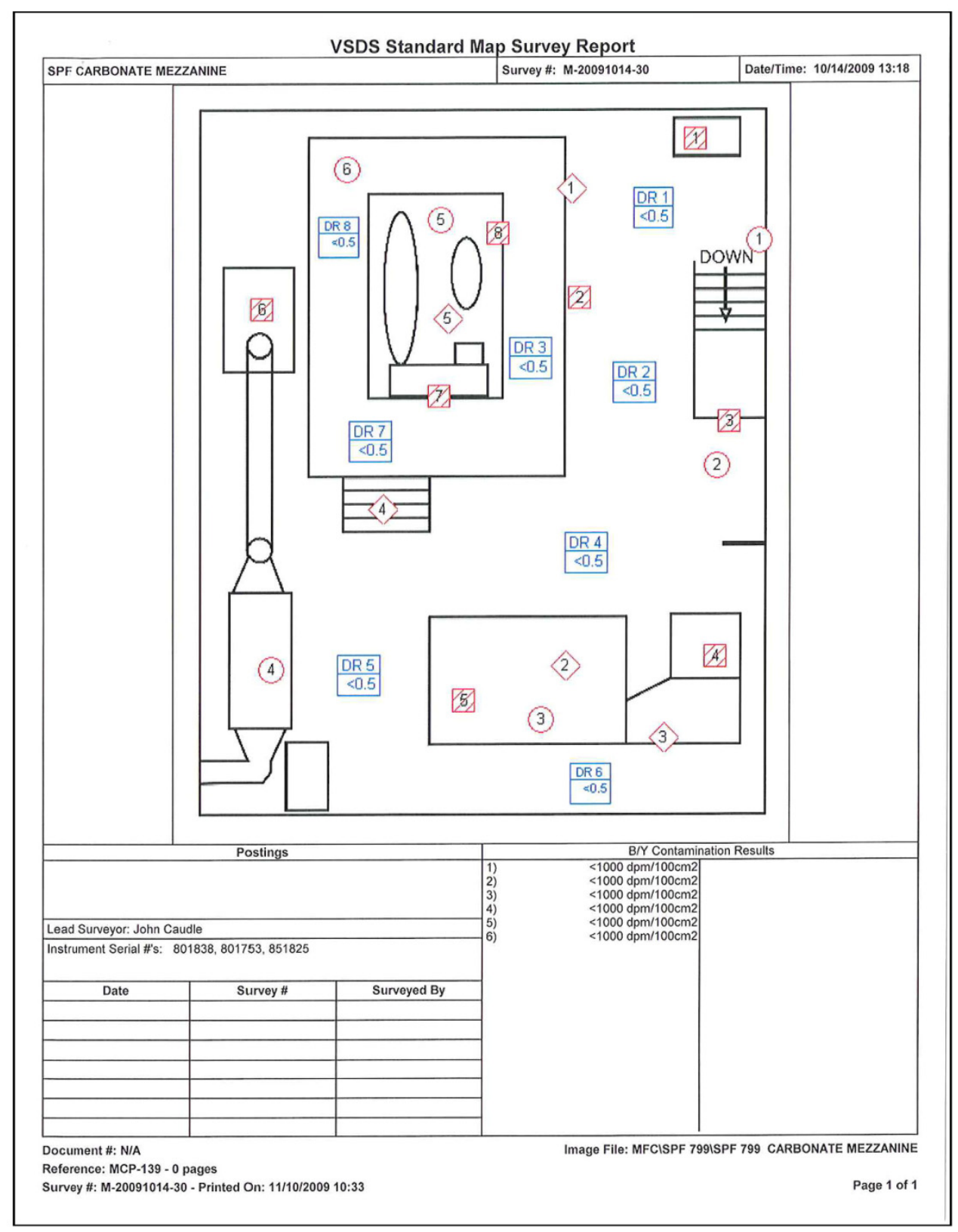

158 


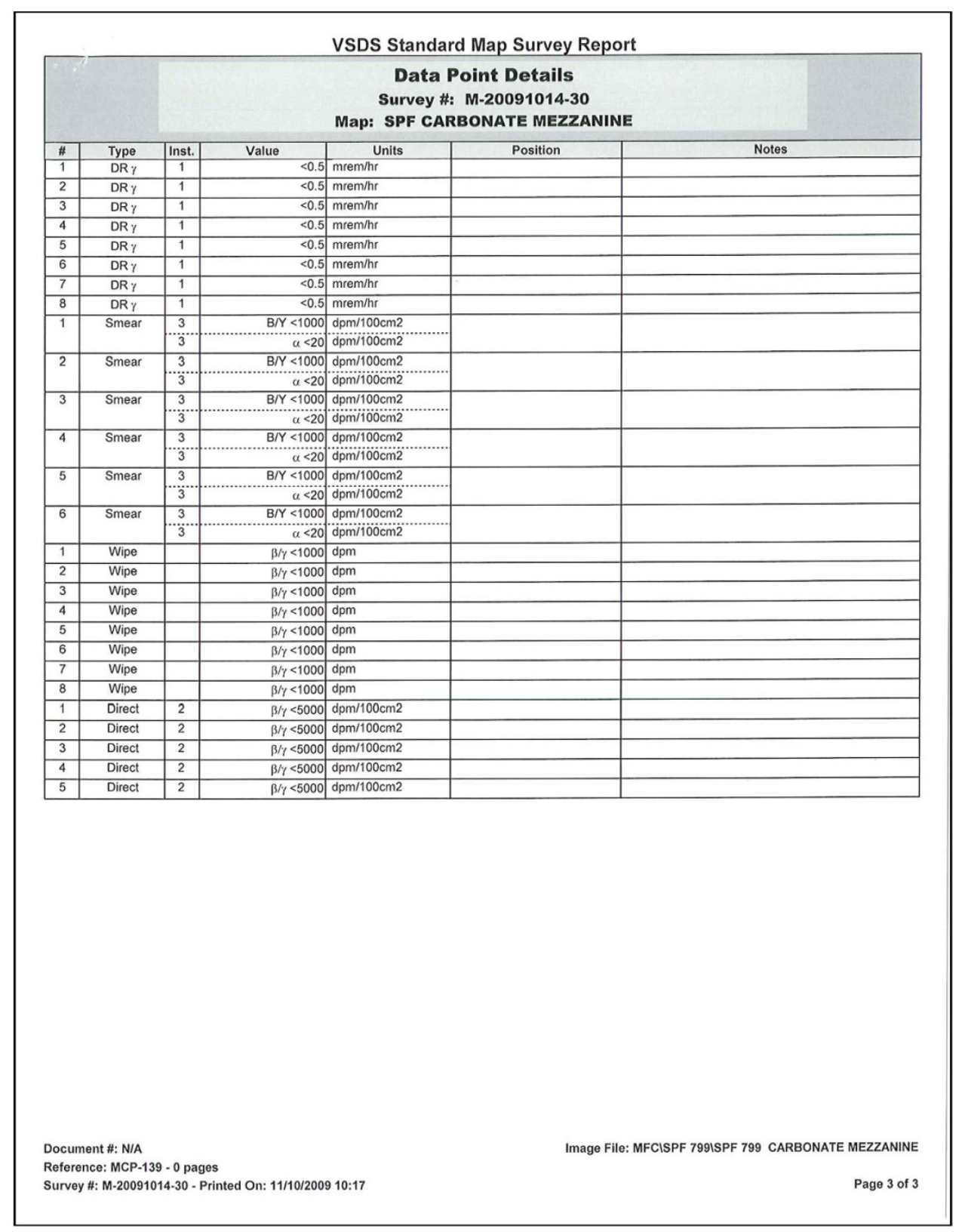




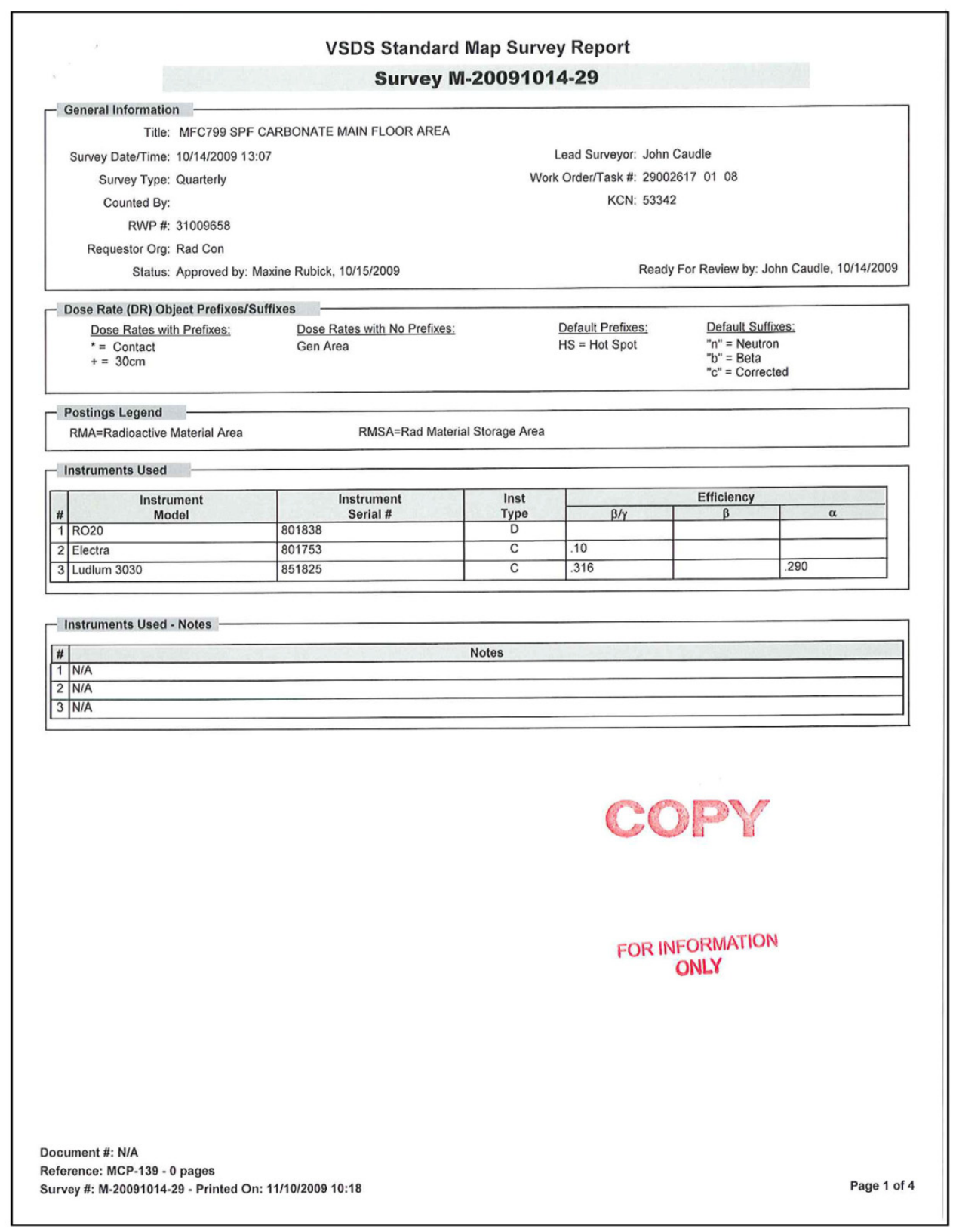




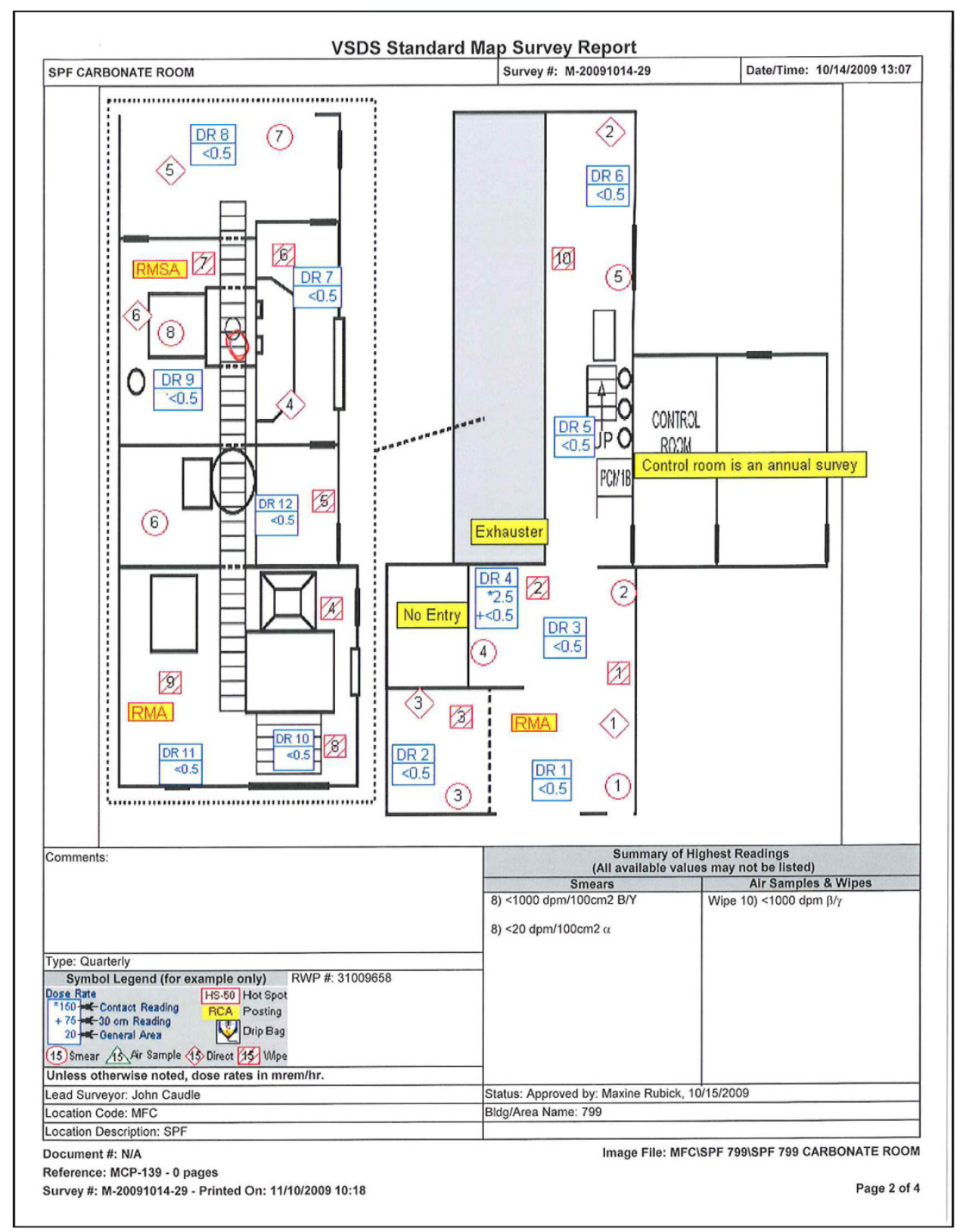

161 


\begin{tabular}{|c|c|c|c|c|c|c|}
\hline \multicolumn{7}{|c|}{ VSDS Standard Map Survey Report } \\
\hline \multicolumn{7}{|c|}{$\begin{array}{c}\text { Data Point Details } \\
\text { Survey \#: M-20091014-29 } \\
\text { Map: SPF CARBONATE ROOM }\end{array}$} \\
\hline$\#$ & Type & Inst. & Value & Units & Position & Notes \\
\hline 1 & DRy & 1 & $<0.5$ & $\mathrm{mrem} / \mathrm{hr}$ & & \\
\hline 2 & $\mathrm{DR}_{\gamma}$ & 1 & $<0.5$ & $\mathrm{mrem} / \mathrm{hr}$ & & \\
\hline 3 & DRy & 1 & $<0.5$ & $\mathrm{mrem} / \mathrm{hr}$ & & \\
\hline \multirow[t]{2}{*}{4} & \multirow[t]{2}{*}{$\mathrm{DR} \gamma$} & 1 & $\cdot 2.5$ & $\mathrm{mrem} / \mathrm{hr}$ & & \\
\hline & & 1 & $+<0.5$ & mrem $/ \mathrm{hr}$ & & \\
\hline 5 & DRy & 1 & $<0.5$ & $\mathrm{mrem} / \mathrm{hr}$ & & \\
\hline 6 & $\mathrm{DR}_{\gamma}$ & 1 & $<0.5$ & $\mathrm{mrem} / \mathrm{hr}$ & & \\
\hline 7 & $\mathrm{DR}_{\gamma}$ & 1 & $<0.5$ & $\mathrm{mrem} / \mathrm{hr}$ & & \\
\hline 8 & DRy & 1 & $<0.5$ & $\mathrm{mrem} / \mathrm{hr}$ & & \\
\hline 9 & DRy & 1 & $<0.5$ & mrem/hr & & \\
\hline 10 & DRy & 1 & $<0.5$ & mrem/hr & & \\
\hline 11 & DRy & 1 & $<0.5$ & $\mathrm{mrem} / \mathrm{hr}$ & & \\
\hline 12 & $\mathrm{DR}_{\gamma}$ & 1 & $<0.5$ & mrem/hr & & \\
\hline \multirow[t]{2}{*}{1} & \multirow[t]{2}{*}{ Smear } & 3 & $B / Y<1000$ & $\mathrm{dpm} / 100 \mathrm{~cm} 2$ & & \\
\hline & & 3 & $\alpha<20$ & $\mathrm{dpm} / 100 \mathrm{~cm} 2$ & & \\
\hline \multirow[t]{2}{*}{2} & \multirow[t]{2}{*}{ Smear } & 3 & $B / Y<1000$ & $\mathrm{dpm} / 100 \mathrm{~cm} 2$ & & \\
\hline & & 3 & $a<20$ & $\mathrm{dpm} / 100 \mathrm{~cm} 2$ & & \\
\hline \multirow[t]{2}{*}{3} & \multirow[t]{2}{*}{ Smear } & 3 & $\mathrm{~B} / \mathrm{Y}<1000$ & $\mathrm{dpm} / 100 \mathrm{~cm} 2$ & & \\
\hline & & 3 & $\alpha<20$ & $\mathrm{dpm} / 100 \mathrm{~cm} 2$ & & \\
\hline \multirow[t]{2}{*}{4} & \multirow[t]{2}{*}{ Smear } & 3 & $\mathrm{~B} / \mathrm{Y}<1000$ & $\mathrm{dpm} / 100 \mathrm{~cm} 2$ & & \\
\hline & & 3 & $\alpha<20$ & $\mathrm{dpm} / 100 \mathrm{~cm} 2$ & & \\
\hline \multirow[t]{2}{*}{5} & \multirow[t]{2}{*}{ Smear } & 3 & $\mathrm{~B} / \mathrm{Y}<1000$ & $\mathrm{dpm} / 100 \mathrm{~cm} 2$ & & \\
\hline & & 3 & $\alpha<20$ & $\mathrm{dpm} / 100 \mathrm{~cm} 2$ & & \\
\hline \multirow[t]{2}{*}{6} & \multirow[t]{2}{*}{ Smear } & 3 & $\mathrm{~B} / \mathrm{Y}<1000$ & $\mathrm{dpm} / 100 \mathrm{~cm} 2$ & & \\
\hline & & 3 & $a<20$ & $\mathrm{dpm} / 100 \mathrm{~cm} 2$ & & \\
\hline \multirow[t]{2}{*}{7} & \multirow[t]{2}{*}{ Smear } & 3 & $B / Y<1000$ & $\mathrm{dpm} / 100 \mathrm{~cm} 2$ & & \\
\hline & & 3 & $\alpha<20$ & dpm/100 cm2 & & \\
\hline 8 & Smear & 3 & $B / Y<1000$ & $\mathrm{dpm} / 100 \mathrm{~cm} 2$ & & \\
\hline & & 3 & $a<20$ & $\mathrm{dpm} / 100 \mathrm{~cm} 2$ & & \\
\hline 1 & Wipe & & $\beta / \gamma<1000$ & dpm & & \\
\hline 2 & Wipe & & $\beta / \gamma<1000$ & $d p m$ & & \\
\hline 3 & Wipe & & $\beta / \gamma<1000$ & dpm & & \\
\hline 4 & Wipe & & $\beta / \gamma<1000$ & dpm & & \\
\hline 5 & Wipe & & $\beta / \gamma<1000$ & $\mathrm{dpm}$ & & \\
\hline 6 & Wipe & & $\beta / \gamma<1000$ & $\mathrm{dpm}$ & & \\
\hline 7 & Wipe & & $\beta / \gamma<1000$ & $\mathrm{dpm}$ & & \\
\hline 8 & Wipe & & $\beta / \gamma<1000$ & $\mathrm{dpm}$ & & \\
\hline 9 & Wipe & & $\beta / \gamma<1000$ & dpm & & \\
\hline 10 & Wipe & & $\beta / \gamma<1000$ & $\mathrm{dpm}$ & & \\
\hline 1 & Direct & 2 & $\beta / \gamma<5000$ & $\mathrm{dpm} / 100 \mathrm{~cm} 2$ & & \\
\hline 2 & Direct & 2 & $\beta / \gamma<5000$ & $\mathrm{dpm} / 100 \mathrm{~cm} 2$ & & \\
\hline 3 & Direct & 2 & $\beta / \gamma<5000$ & $\mathrm{dpm} / 100 \mathrm{~cm} 2$ & & \\
\hline 4 & Direct & 2 & $\beta / \gamma<5000$ & $\mathrm{dpm} / 100 \mathrm{~cm} 2$ & & \\
\hline 5 & Direct & 2 & $\beta / \gamma<5000$ & $\mathrm{dpm} / 100 \mathrm{~cm} 2$ & & \\
\hline 6 & Direct & 2 & $\beta / \gamma<5000$ & $\mathrm{dpm} / 100 \mathrm{~cm} 2$ & & \\
\hline & Text & & $\begin{array}{l}\text { Control room is an } \\
\text { annual survey }\end{array}$ & & & \\
\hline & Text & & Exhauster & & & \\
\hline & Text & & No Entry & & & \\
\hline & Posting & & RMA & & & \\
\hline Docu & $n t \#: N / A$ & & & & & ge File: MFCISPF $7991 S P F 799$ CARBONATE ROOM \\
\hline Refer & Ce: MCP-1 & 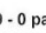 & & & & \\
\hline Surve & : -20091 & 14-29. & Printed On: 11/10/2009 & $910: 18$ & & Page 3 of 4 \\
\hline
\end{tabular}




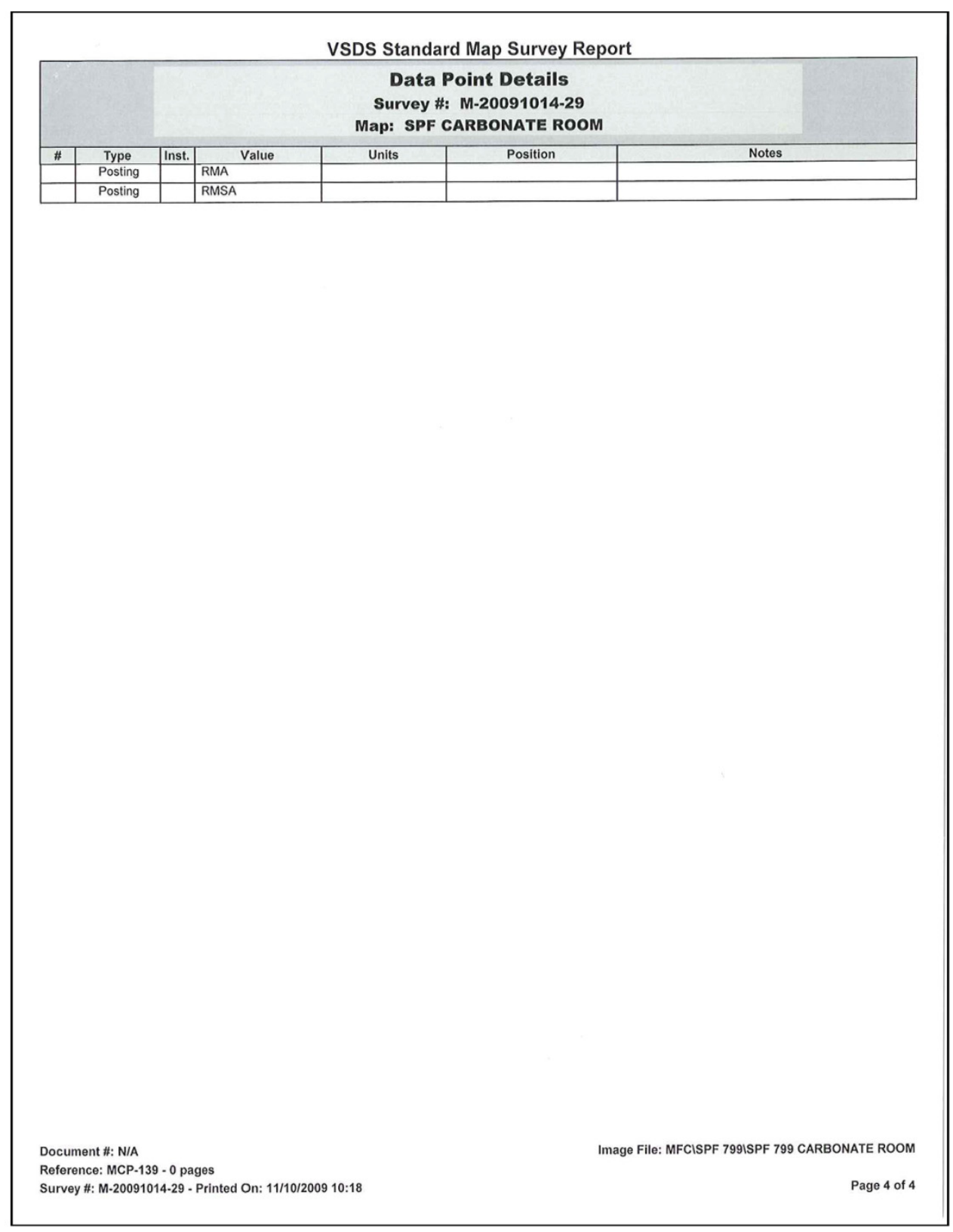

163 


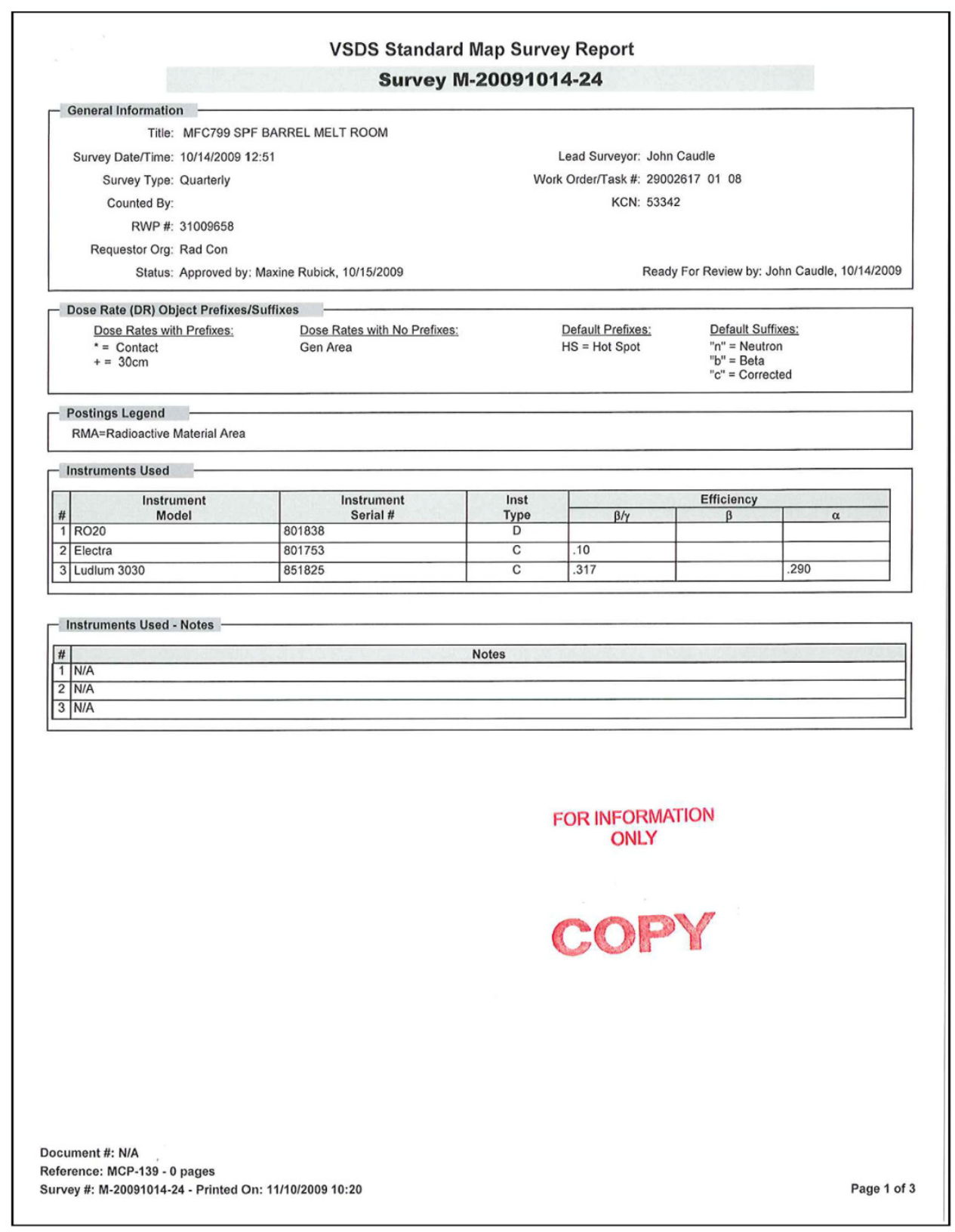




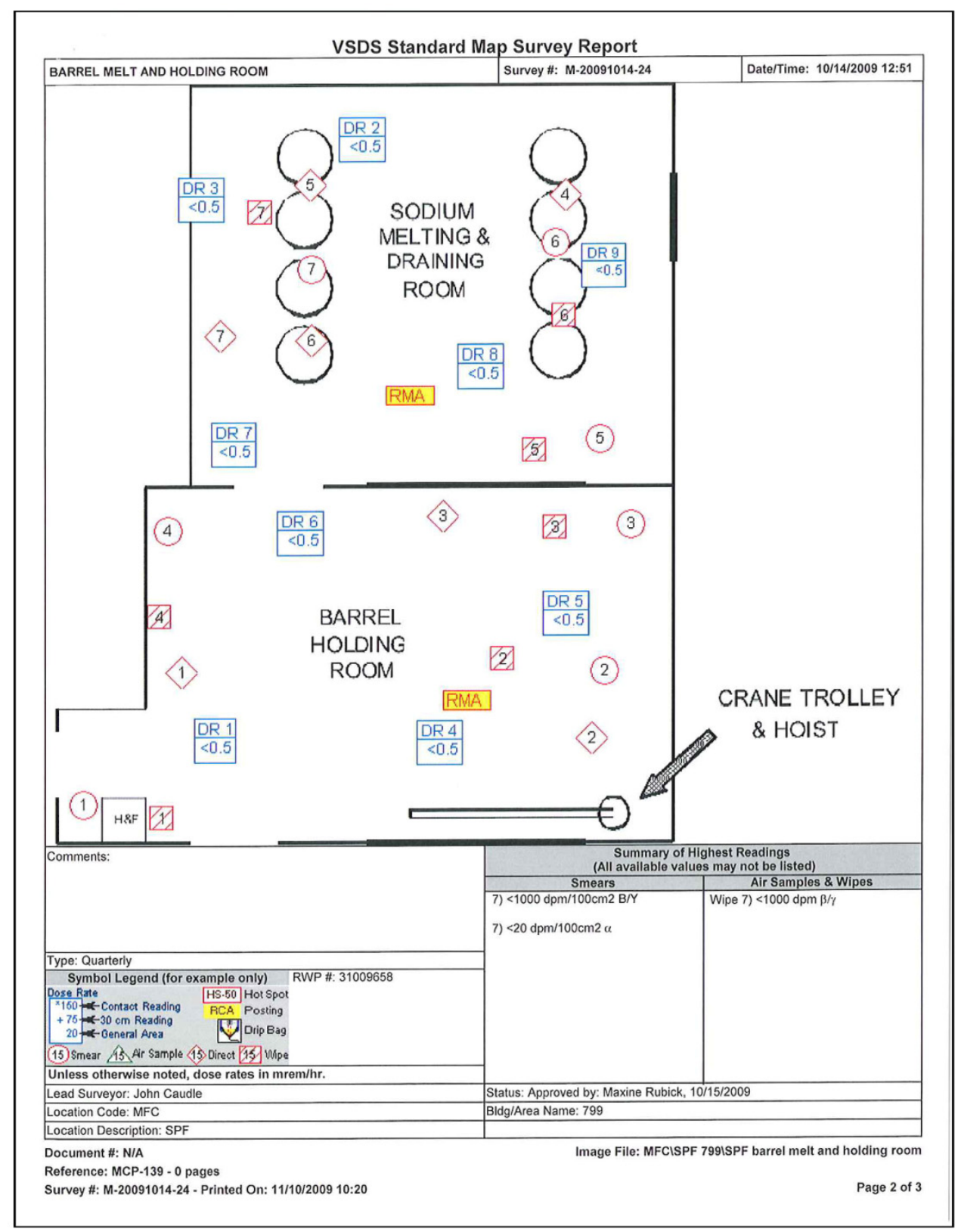

165 


\begin{tabular}{|c|c|c|c|c|c|c|c|}
\hline \multicolumn{8}{|c|}{ VSDS Standard Map Survey Report } \\
\hline \multicolumn{8}{|c|}{$\begin{array}{c}\text { Data Point Details } \\
\text { Survey \#: M-20091014-24 } \\
\text { Map: BARREL MELT AND HOLDING ROOM }\end{array}$} \\
\hline$\#$ & Type & Inst. & Value & \begin{tabular}{|l|} 
Units \\
\end{tabular} & Position & & Notes \\
\hline 1 & DRy & 1 & $<0.5$ & $\mathrm{mrem} / \mathrm{hr}$ & & & \\
\hline 2 & DRy & 1 & $<0.5$ & $\mathrm{mrem} / \mathrm{hr}$ & & & \\
\hline 3 & DRy & 1 & $<0.5$ & $\mathrm{mrem} / \mathrm{hr}$ & & & \\
\hline 4 & $\mathrm{DR} \gamma$ & 1 & $<0.5$ & $\mathrm{mrem} / \mathrm{hr}$ & & & \\
\hline 5 & $\mathrm{DR} \%$ & 1 & $<0.5$ & $\mathrm{mrem} / \mathrm{hr}$ & & & \\
\hline 6 & DR\% & 1 & $<0.5$ & mrem/hr & & & \\
\hline 7 & $\mathrm{DR} \%$ & 1 & $<0.5$ & mrem $/ \mathrm{hr}$ & & & \\
\hline 8 & DR\% & 1 & $<0.5$ & mrem $/ \mathrm{hr}$ & & & \\
\hline 9 & $\mathrm{DR}_{\gamma}$ & 1 & $<0.5$ & $\mathrm{mrem} / \mathrm{hr}$ & & & \\
\hline \multirow{2}{*}{1} & \multirow[t]{2}{*}{ Smear } & 3 & $B / Y<1000$ & $\mathrm{dpm} / 100 \mathrm{~cm} 2$ & & & \\
\hline & & 3 & $\alpha<20$ & $\mathrm{dpm} / 100 \mathrm{~cm} 2$ & & & \\
\hline \multirow[t]{2}{*}{2} & \multirow[t]{2}{*}{ Smear } & 3 & $B / Y<1000$ & $\mathrm{dpm} / 100 \mathrm{~cm} 2$ & & & \\
\hline & & 3 & $\alpha<20$ & $\mathrm{dpm} / 100 \mathrm{~cm} 2$ & & & \\
\hline \multirow[t]{2}{*}{3} & \multirow[t]{2}{*}{ Smear } & 3 & $\mathrm{~B} / \mathrm{Y}<1000$ & $\mathrm{dpm} / 100 \mathrm{~cm} 2$ & & & \\
\hline & & 3 & $a<20$ & $\mathrm{dpm} / 100 \mathrm{~cm} 2$ & & & \\
\hline \multirow[t]{2}{*}{4} & \multirow{2}{*}{ Smear } & 3 & $B / Y<1000$ & $\mathrm{dpm} / 100 \mathrm{~cm} 2$ & & & \\
\hline & & 3 & $a<20$ & dpm/100 cm2 & & & \\
\hline \multirow[t]{2}{*}{5} & \multirow[t]{2}{*}{ Smear } & 3 & $B / Y<1000$ & $\mathrm{dpm} / 100 \mathrm{~cm} 2$ & & & \\
\hline & & 3 & $\alpha<20$ & dpm/100 cm2 & & & \\
\hline \multirow{2}{*}{6} & \multirow{2}{*}{ Smear } & 3 & $\mathrm{~B} / \mathrm{Y}<1000$ & $\mathrm{dpm} / 100 \mathrm{~cm} 2$ & & & \\
\hline & & 3 & $\alpha<20$ & $\mathrm{dpm} / 100 \mathrm{~cm} 2$ & & & \\
\hline \multirow[t]{2}{*}{7} & \multirow[t]{2}{*}{ Smear } & 3 & $B / Y<1000$ & $\mathrm{dpm} / 100 \mathrm{~cm} 2$ & & & \\
\hline & & 3 & $a<20$ & $\mathrm{dpm} / 100 \mathrm{~cm} 2$ & & & \\
\hline 1 & Wipe & & $\beta / \gamma<1000$ & $\mathrm{dpm}$ & & & \\
\hline 2 & Wipe & & $\beta / \gamma<1000$ & $\mathrm{dpm}$ & & & \\
\hline 3 & Wipe & & $\beta / \gamma<1000$ & $\mathrm{dpm}$ & & & \\
\hline 4 & Wipe & & $\beta / \gamma<1000$ & dpm & & & \\
\hline 5 & Wipe & & $\beta / \gamma<1000$ & $\mathrm{dpm}$ & & & \\
\hline 6 & Wipe & & $\beta / \gamma<1000$ & $\mathrm{dpm}$ & & & \\
\hline 7 & Wipe & & $\beta / \gamma<1000$ & dpm & & & \\
\hline 1 & Direct & 2 & $\beta / \gamma<5000$ & $\mathrm{dpm} / 100 \mathrm{~cm} 2$ & & & \\
\hline 2 & Direct & 2 & $\beta / \gamma<5000$ & $\mathrm{dpm} / 100 \mathrm{~cm} 2$ & & & \\
\hline 3 & Direct & 2 & $\beta / \gamma<5000$ & $\mathrm{dpm} / 100 \mathrm{~cm} 2$ & & & \\
\hline 4 & Direct & 2 & $\beta / \gamma<5000$ & $\mathrm{dpm} / 100 \mathrm{~cm} 2$ & & & \\
\hline 5 & Direct & 2 & $\beta / \gamma<5000$ & $\mathrm{dpm} / 100 \mathrm{~cm} 2$ & & & \\
\hline 6 & Direct & 2 & $\beta / \gamma<5000$ & $\mathrm{dpm} / 100 \mathrm{~cm} 2$ & & & \\
\hline 7 & Direct & 2 & $\beta / \gamma<5000$ & $\mathrm{dpm} / 100 \mathrm{~cm} 2$ & & & \\
\hline & Posting & & RMA & & & & \\
\hline & Posting & & RMA & & & & \\
\hline \multicolumn{5}{|c|}{ Document \#: N/A } & \multicolumn{3}{|c|}{ Image File: MFCISPF 799ISPF barrel melt and holding room } \\
\hline \multirow{2}{*}{\multicolumn{8}{|c|}{ Reference: MCP-139 - 0 pages }} \\
\hline Surve & : & 4-24. & & & & & Page 3 of 3 \\
\hline
\end{tabular}




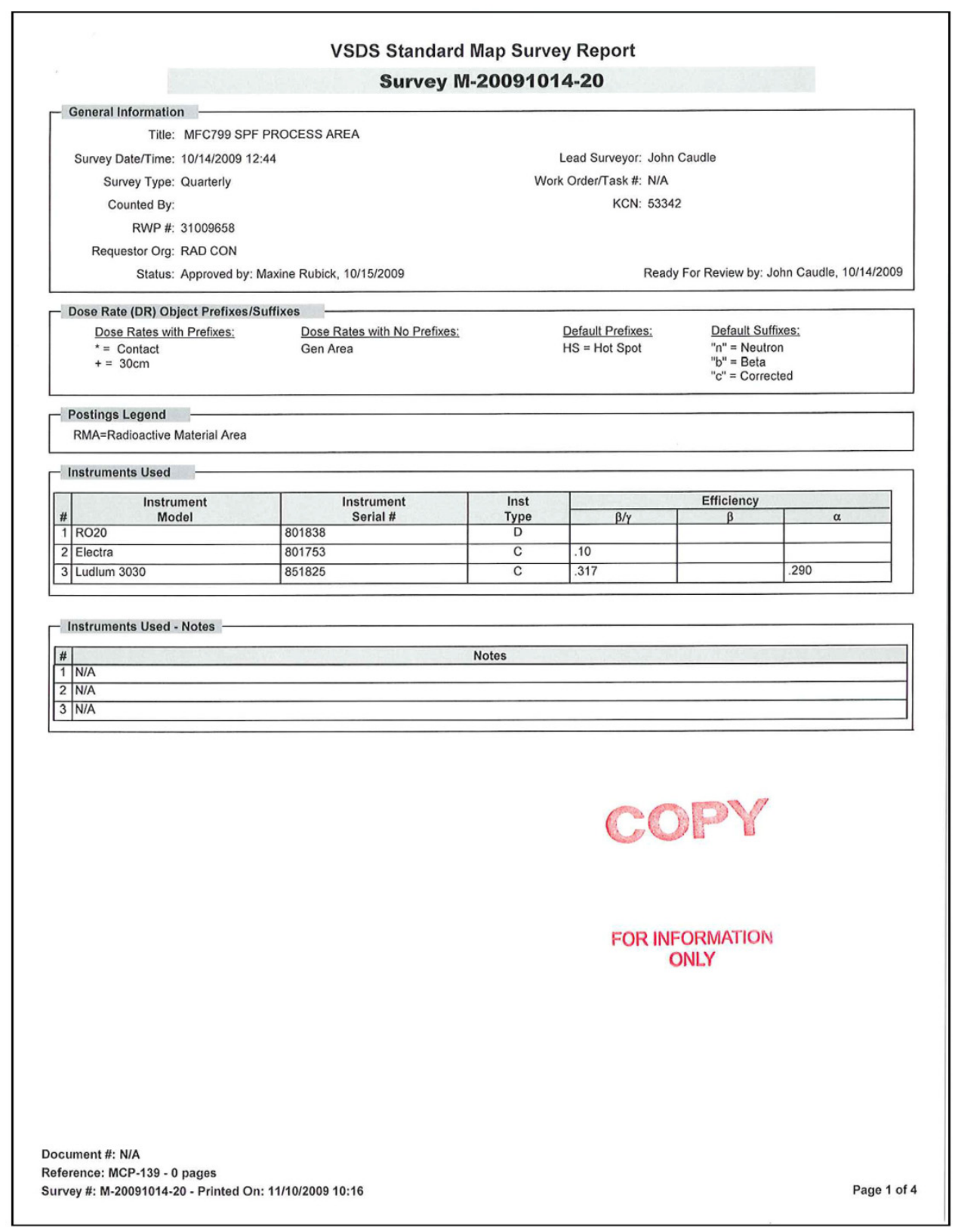

167 


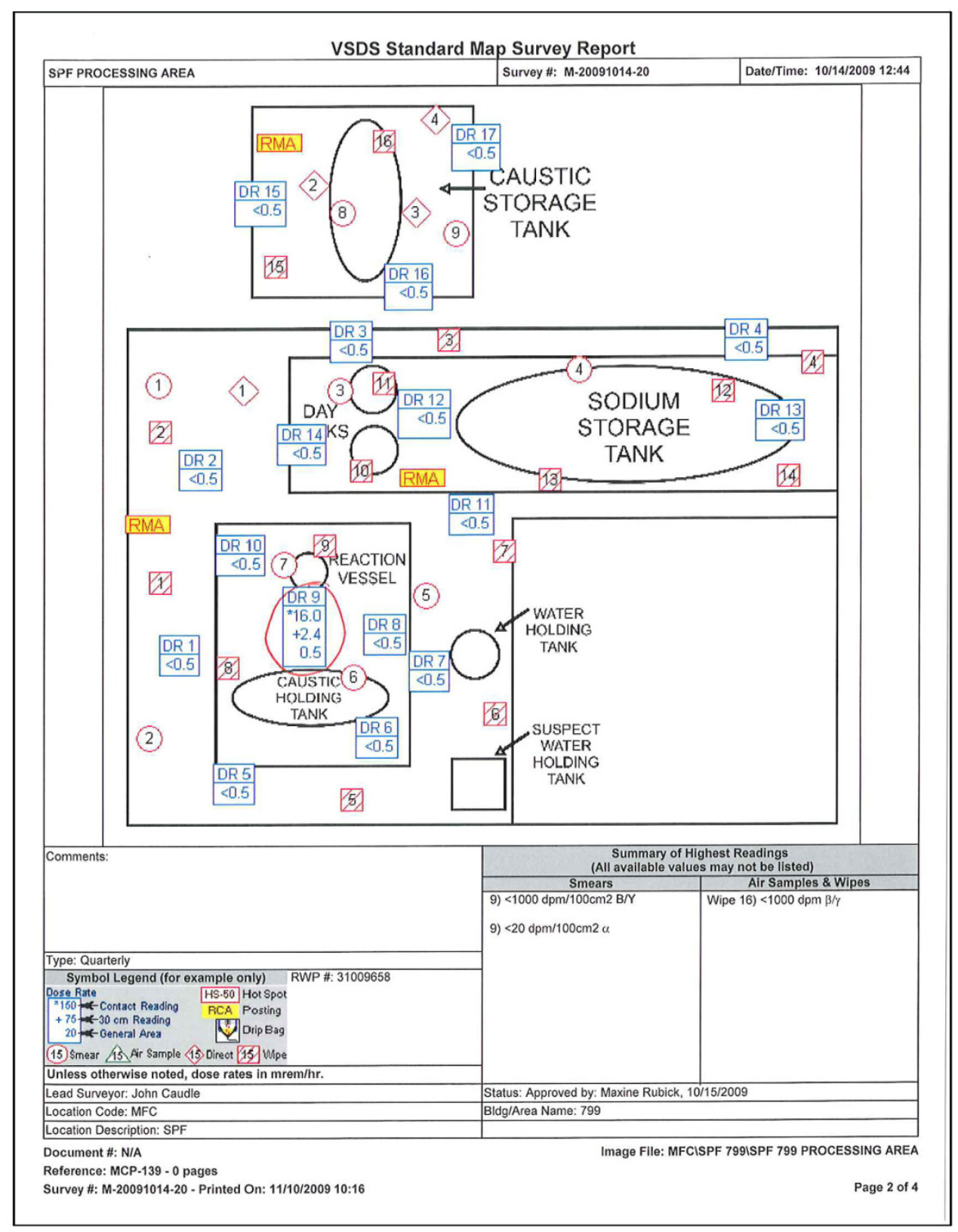

168 


\begin{tabular}{|c|c|c|c|c|c|c|}
\hline \multicolumn{7}{|c|}{ VSDS Standard Map Survey Report } \\
\hline \multicolumn{7}{|c|}{$\begin{array}{c}\text { Data Point Details } \\
\text { Survey \#: M-20091014-20 } \\
\text { Map: SPF PROCESSING AREA }\end{array}$} \\
\hline \# & Type & Inst. & Value & Units & Position & Notes \\
\hline 1 & $\mathrm{DR}_{\gamma}$ & 1 & $<0.5$ & $\mathrm{mrem} / \mathrm{hr}$ & & \\
\hline 2 & DRy & 1 & $<0.5$ & mrem $/ \mathrm{hr}$ & & \\
\hline 3 & $\mathrm{DR}_{\gamma}$ & 1 & $<0.5$ & $\mathrm{mrem} / \mathrm{hr}$ & & \\
\hline 4 & DRy & 1 & $<0.5$ & mrem/hr & & \\
\hline 5 & $\mathrm{DR}_{\gamma}$ & 1 & $<0.5$ & $\mathrm{mrem} / \mathrm{hr}$ & & \\
\hline 6 & DRy & 1 & $<0.5$ & mrem $/ \mathrm{hr}$ & & \\
\hline 7 & DR\% & 1 & $<0.5$ & $\mathrm{mrem} / \mathrm{hr}$ & & \\
\hline 8 & $\mathrm{DR}_{\gamma}$ & 1 & $<0.5$ & $\mathrm{mrem} / \mathrm{hr}$ & & \\
\hline \multirow[t]{3}{*}{9} & \multirow[t]{3}{*}{ DRy } & 1 & 416.0 & $\mathrm{mrem} / \mathrm{hr}$ & & \\
\hline & & 1 & +2.4 & mrem/hr & & \\
\hline & & 1 & 0.5 & mrem/hr & & \\
\hline 10 & DRy & 1 & $<0.5$ & mrem/hr & & \\
\hline 11 & $\mathrm{DR}_{\gamma}$ & 1 & $<0.5$ & $\mathrm{mrem} / \mathrm{hr}$ & & \\
\hline 12 & $\mathrm{DR}_{\gamma}$ & 1 & $<0.5$ & $\mathrm{mrem} / \mathrm{hr}$ & & \\
\hline 13 & DRy & 1 & $<0.5$ & $\mathrm{mrem} / \mathrm{hr}$ & & \\
\hline 14 & $\mathrm{DR}_{\gamma}$ & 1 & $<0.5$ & $\mathrm{mrem} / \mathrm{hr}$ & & \\
\hline 15 & $\mathrm{DR}_{y}$ & 1 & $<0.5$ & $\mathrm{mrem} / \mathrm{hr}$ & & \\
\hline 16 & DRy & 1 & $<0.5$ & mrem/hr & & \\
\hline 17 & DRy & 1 & $<0.5$ & $\mathrm{mrem} / \mathrm{hr}$ & & \\
\hline \multirow[t]{2}{*}{1} & \multirow[t]{2}{*}{ Smear } & 3 & $\mathrm{~B} / \mathrm{Y}<1000$ & $\mathrm{dpm} / 100 \mathrm{~cm} 2$ & & \\
\hline & & 3 & $a<20$ & $\mathrm{dpm} / 100 \mathrm{~cm} 2$ & & \\
\hline \multirow[t]{2}{*}{2} & \multirow[t]{2}{*}{ Smear } & 3 & $B / Y<1000$ & $\mathrm{dpm} / 100 \mathrm{~cm} 2$ & & \\
\hline & & 3 & $a<20$ & dpm/100 cm2 & & \\
\hline \multirow[t]{2}{*}{3} & \multirow[t]{2}{*}{ Smear } & 3 & $B / Y<1000$ & $\mathrm{dpm} / 100 \mathrm{~cm} 2$ & & \\
\hline & & 3 & $\alpha<20$ & dpm/100 cm2 & & \\
\hline \multirow[t]{2}{*}{4} & \multirow[t]{2}{*}{ Smear } & 3 & $\mathrm{~B} / \mathrm{Y}<1000$ & $\mathrm{dpm} / 100 \mathrm{~cm} 2$ & & \\
\hline & & 3 & $\alpha<20$ & $\mathrm{dpm} / 100 \mathrm{~cm} 2$ & & \\
\hline \multirow[t]{2}{*}{5} & \multirow[t]{2}{*}{ Smear } & 3 & $\mathrm{~B} / \mathrm{Y}<1000$ & $\mathrm{dpm} / 100 \mathrm{~cm} 2$ & & \\
\hline & & 3 & $\alpha<20$ & $\mathrm{dpm} / 100 \mathrm{~cm} 2$ & & \\
\hline \multirow[t]{2}{*}{6} & \multirow[t]{2}{*}{ Smear } & 3 & $B / Y<1000$ & $\mathrm{dpm} / 100 \mathrm{~cm} 2$ & & \\
\hline & & 3 & $a<20$ & $\mathrm{dpm} / 100 \mathrm{~cm} 2$ & & \\
\hline \multirow[t]{2}{*}{7} & \multirow[t]{2}{*}{ Smear } & 3 & $B / Y<1000$ & $\mathrm{dpm} / 100 \mathrm{~cm} 2$ & & \\
\hline & & 3 & $\alpha<20$ & $\mathrm{dpm} / 100 \mathrm{~cm} 2$ & & \\
\hline 8 & Smear & 3 & $B / Y<1000$ & $\mathrm{dpm} / 100 \mathrm{~cm} 2$ & & \\
\hline & & 3 & $\alpha<20$ & $\mathrm{dpm} / 100 \mathrm{~cm} 2$ & & \\
\hline 9 & Smear & 3 & $\mathrm{~B} / \mathrm{Y}<1000$ & $\mathrm{dpm} / 100 \mathrm{~cm} 2$ & & \\
\hline & & 3 & $\alpha<20$ & $\mathrm{dpm} / 100 \mathrm{~cm} 2$ & & \\
\hline 1 & Wipe & & $\beta / y<1000$ & $\mathrm{dpm}$ & & \\
\hline 2 & Wipe & & $\beta / y<1000$ & $d p m$ & & \\
\hline 3 & Wipe & & $\beta / y<1000$ & $d p m$ & & \\
\hline 4 & Wipe & & $\beta / \gamma<1000$ & $\mathrm{dpm}$ & & \\
\hline 5 & Wipe & & $\beta / \gamma<1000$ & $\mathrm{dpm}$ & & \\
\hline 6 & Wipe & & $\beta / \gamma<1000$ & $\mathrm{dpm}$ & & \\
\hline 7 & Wipe & & $\beta / y<1000$ & $\mathrm{dpm}$ & & \\
\hline 8 & Wipe & & $\beta / y<1000$ & $\mathrm{dpm}$ & & \\
\hline 9 & Wipe & & $\beta / y<1000$ & dpm & & \\
\hline 10 & Wipe & & $\beta / y<1000$ & $d p m$ & & \\
\hline 11 & Wipe & & $\beta / y<1000$ & $d p m$ & & \\
\hline 12 & Wipe & & $\beta / \gamma<1000$ & $d p m$ & & \\
\hline 13 & Wipe & & $\beta / \gamma<1000$ & $\mathrm{dpm}$ & & \\
\hline & $n t \#: N / A$ & & & & & ge File: MFCISPF 799ISPF 799 PROCESSING AREA \\
\hline Refer & MCP-1 & $1.0 \mathrm{pa}$ & & & & \\
\hline Surve & M-20091 & 14-20. & Printed On: $11 / 10 / 200$ & 19:16 & & Page 3 of 4 \\
\hline
\end{tabular}




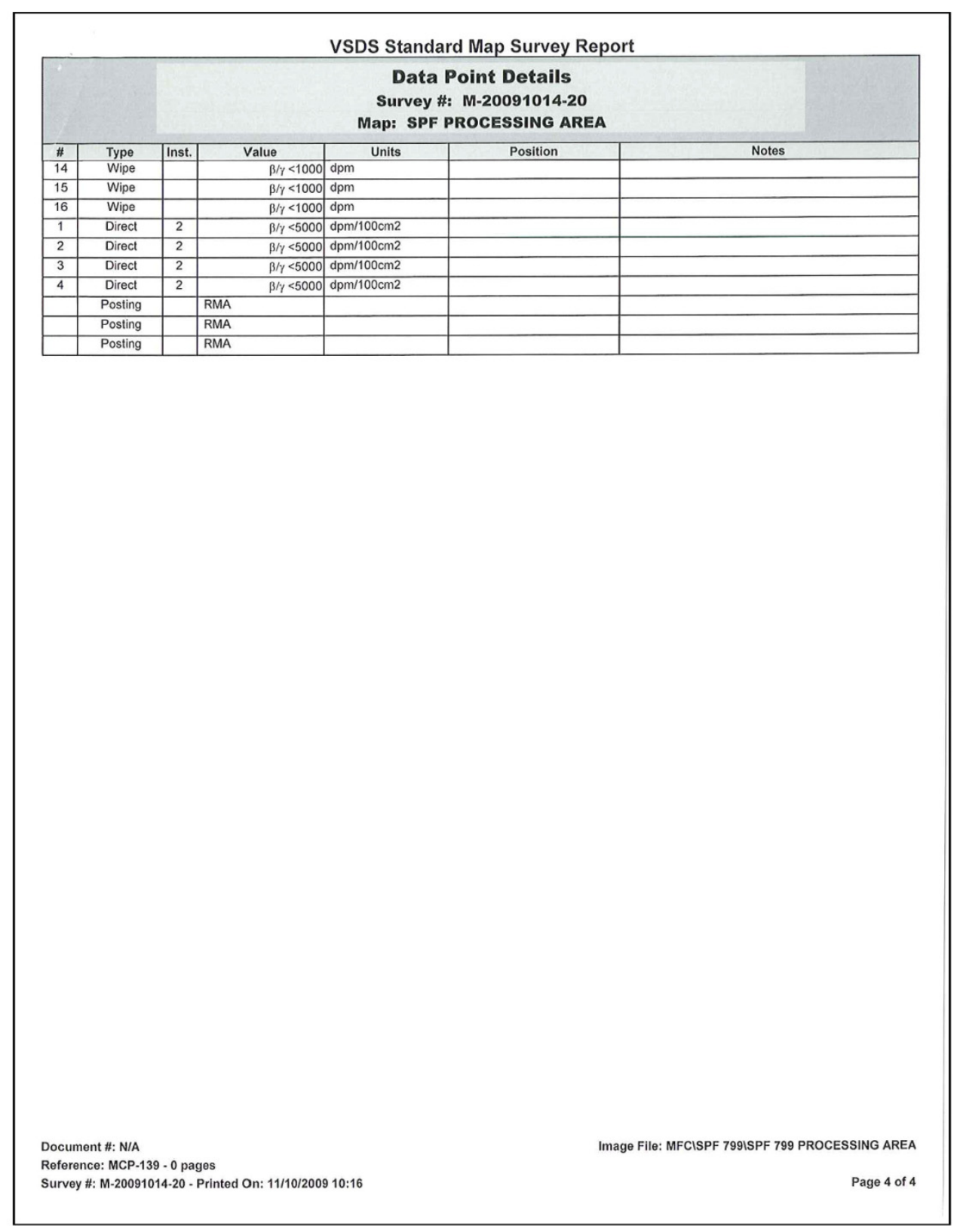

170 
Appendix E

Cost Estimate Information 
Rev. 03-04-10

Battelle Energy Alliance, LLC

COST ESTIMATE SUPPORT DATA RECAPITULATION

Project Title: $\quad$ Facility Transition - INL/EXT-09-17292 - MFC-799, 799A, 770C

Estimator: R. R. Honsinger

Date: $\quad$ May 14,2010

Estimate Type: Class 3

File:

$9 \mathrm{~A} 70$

Approved By:

Page 1 of 6

I. PURPOSE: Brief description of the intent of how the estimate is to be tised, i.e., for engineering study, comparative analysis, request for funding, proposal, etc.

The purpose of this estimate is to provide a cost estimate to support project planning and budget development. This estimate will be used to support execution of facility transition pre-requisite work scope as stated below.

II. SCOPE OF WORK: Brief statement of the project's objective. Thorough overview and description of the proposed project. Identify work to be accomplished, as well as any specific work to be excluded.

\section{A. Objective:}

The objective is to complete the actions that are required prior to facility transfer from the Office of Nuclear Energy (NE) to the Office of Environmental Management (EM). The project includes buildings MFC-799, 799A, and 770C, at the Materials and Fuels Complex (MFC) located at Idaho National Laboratory (INL).

\section{B. Included:}

The scope of work required to achieve this objective includes the following:

1. Providing Project Management oversight.

2. Providing Construction Management for oversight of subcontractor construction activities.

3. Providing subsurface investigations in support of subcontractor construction activities.

4. Developing the work planning documents.

5. Actions required to be completed prior to transfer include the following:

a. Remove the serviceable equipment and materials at MFC-799 and $799 \mathrm{~A}$.

b. Remove and dispose of the Cs137 source at MFC-770C.

c. Perform a hazardous materials and waste characterization at MFC-799 and 799A. Limited characterization sampling and laboratory analysis will be performed for the caustic and sodium tanks.

d. Prepare a final End State Transition Report.

e. Perform modifications to the electrical power feed to building MFC-771, which currently receives electrical power from MFC-799. The modifications will require isolating the electrical service feed from MFC-799 and construction of 247 linear feet of new underground electrical duct bank from an existing power pole to MFC-771. 


\section{COST ESTIMATE SUPPORT DATA RECAPITULATION}

\section{Continued -}

Project Title: $\quad$ Facility Transition - INL/EXT-09-17292 - MFC-799, 799A, 770C

C. Excluded:

This scope of work specifically excludes the following:

1. Surveillance and maintenance (S\&M) costs prior to facility transfer.

2. Isolating building utilities or modifications to building structural components prior to facility transfer, with the exception of the electrical modifications stated above.

III. ESTIMATE METHODOLOGY: Overall methodology and rationale of how the estimate was developed, i.e., parametric, forced detail, bottoms up, etc. Total dollars/hours and rough order magnitude (ROM) allocations of the methodologies used to develop the cost estimate.

A "forced detail" method was used to develop this estimate. The activities and resources were developed by the cost estimators and the project manager.

\begin{tabular}{lc}
\hline \multicolumn{1}{c}{ Estimate Methodology } & ROM Percentage (\%) \\
\hline Project Team & 50 \\
Recorded Actuals & 0 \\
Parametric & 0 \\
Vendor Quotes & 0 \\
Other (rough order of magnitude & \\
planning estimates) & 50 \\
\hline TOTAL & 100
\end{tabular}

IV. BASIS OF THE ESTIMATE: Overall explanation of sources for resource pricing and schedules.

A. Quantification Basis: The source for the measurable quantities in the estimate that can be used in support of earned value management. Source documents may include drawings, design reports, engineers' notes, and other documentation upon which the estimate is originated.

The requester provided a report, "Facilities Condition and Hazards Assessment for Materials and Fuel Complex Facilities MFC-799, 799A, and 770C. November 2009 (INL/EXT-09-17292), " that was used to establish the activities and quantities for this estimate. 


\title{
COST ESTIMATE SUPPORT DATA RECAPITULATION
}

\author{
Continued -
}

Project Title: $\quad$ Facility Transition - INL/EXT-09-17292-MFC-799, 799A, 770C

B. Planning Basis: The source for the execution and strategies of the work that can be used to support the project execution plan, acquisition strategy, schedules, and market conditions and other documentation upon which the estimate is originated.

1. Battelle Energy Alliance, LLC (BEA) will provide all engineering and project planning resources, with the exception of the engineering required for the electrical utility modifications stated above.

2. Engineering for the electrical utility modifications will be provided by a subcontractor.

3. BEA crafts and operations personnel will perform the property removal activities.

4. BEA personnel will perform characterization sampling

5. Laboratory analysis of the characterization samples will be performed by a subcontractor.

6. Subcontractor construction forces will perform the electrical utility modifications.

7. The estimate costs are presented as FY 2010 dollars. The time of execution is undetermined at the time of estimate preparation. Escalation adjustments will be made at a later time when the execution period is determined.

8. This work will be performed during standard working hours and no premium time will be required for off-shift or weekend work.

9. Work will be able to progress consecutively and will not require delays between work segments.

10. The cost estimate does not consider or address funding or labor resource restrictions. Sufficient funding and labor resources will be available in a manner allowing optimum usage of that funding and resources as estimated and scheduled.

C. Cost Basis: The source for the costing on the estimate that can be used in support of earned value management, funding profiles, and schedule of values. Sources may include published costing references, judgment, actual costs, preliminary quotes and or other documentation upon which the estimate is originated.

1. INL labor rates, fees, and burdens are based on the current published rates as provided by BEA Planning and Financial Controls.

2. Resources and costs to perform the transition activities are per the original rough order of magnitude activity based estimate for the "Facilities Condition and Hazards Assessment for Materials and Fuel Complex Facilities MFC-799, $799 \mathrm{~A}$, and $770 \mathrm{C}$, November 2009, (INL/EXT-09-17292)."

3. Resources and costs for construction of the electrical utility modifications are per a Class 2 estimate prepared by Walsh Engineering Services,

File \#WES-EST-10-014, May 7, 2010 (BEA Estimate File 1C32)

4. Sales tax on materials is based on the current $6 \%$ rate charged by the State of Idaho. 


\section{COST ESTIMATE SUPPORT DATA RECAPITULATION}

Continued -

Project Title: $\quad$ Facility Transition - INL/EXT-09-17292 - MFC-799, 799A, 770C

File: $9 \mathrm{~A} 70$

Page 4 of 6

5. Project management, construction management, work planning, and closeout costs are based upon input from the requester and this estimator's judgment.

V. ESTIMATE QUALITY ASSURANCE: $A$ listing of all estimate reviews that have taken place and the actions taken from those reviews.

A. A review of the cost estimate was held on May 13, 2010, with the requester and the cost estimators. This review allowed for the requester to review and comment, in detail, on the perceived scope, basis of estimates, assumptions, project risks, and the resources that make up this cost estimate. Comments from this review have been incorporated into this estimate to reflect a project team consensus of this document.

B. An internal organizational check has been performed on this estimate with the purpose of checking the methodology approach used, discussing the document with the estimator, and ensuring the document has been reviewed and discussed with the requester, reflects a team consensus, has adequately documented the basis, assumptions, and risks to the project, and has mitigated those risks.

VI. ASSUMPTIONS: Condition statements accepted or supposed true without proof of demonstration; statements adding clarification to scope. An assumption has a direct impact on total estimated cost.

A. The only actions that are required prior to building transfer are those actions listed in the report "Facilities Condition and Hazards Assessment for Materials and Fuel Complex Facilities MFC-799, 799A, and 770C, November 2009, (INL/EXT-09-17292)."

B. Radiological surveys and characterization sampling will not disclose any conditions that increase the work scope previously identified for this project.

C. Formal engineering drawings and specifications, produced by Facility and Site Services, will not be required for the work scope included in this estimate.

D. Assumptions related to the electrical utility modifications are noted in the estimate recapitulation report per Walsh Engineering Services, File \#WES-EST-10-014, May 7, 2010 - BEA Estimate File 1C32.

VII. MANAGEMENT RESERVE (MR) GUIDELINE IMPLEMENTATION:

Management Reserve Methodologies: Explanation of methodology used in determining overall management reserve. Identify any specific drivers or items of concern.

MR has been applied to this estimate for work that will be performed by BEA personnel and the subcontract cost for laboratory analysis of the characterization samples. The MR rates were developed by the estimator and the requester based upon an evaluation of the threats and opportunities stated below. A formal risk analysis was not performed for this estimate. MR rates of $15 \%$ were applied to the various BEA activities.

MR has also been applied to the subcontracted construction activities. The subcontractor construction only estimate is based upon preliminary approved for construction drawings 


\title{
COST ESTIMATE SUPPORT DATA RECAPITULATION
}

\author{
Continued -
}

Project Title: $\quad$ Facility Transition - INL/EXT-09-17292-MFC-799, 799A, 770C

File: $9 \mathrm{~A} 70$

Page 5 of 6

and specifications, which represent a good level of project definition. The project also has inherent risk associated with construction of underground duct banks and excavation within the MFC facility. Based upon these considerations and the judgment of the cost estimator, an MR rate of $20 \%$ was applied to the construction activities.

A. Threats: Uncertain events that are potentially negative or reduce the probability that the desired outcome will happen.

1. Average labor rates were used to estimate the rough order of magnitude costs for performing the actions required for facility transfer. There is uncertainty associated with the labor rates and the specific personnel performing the required work activities.

2. The lab analysis rates may be variable, depending on lab workloads, timing, and types of analysis required.

3. Work planning may require more rigor and resources than estimated.

4. Preciseness in the forced detail take-offs leaves little room if crews are unable to meet the estimated production rates. Factors could include, but are not limited to, changes to Integrated Safety Management requirements, equipment breakdowns, resource impacts, and/or availability.

5. Excavation and construction of the underground electrical duct bank may disclose unforeseen obstructions which could result in work stoppages and increased costs to remove or work around the obstructions.

6. Final construction drawings may include features which were not noted in the preliminary construction drawings, and cost of construction could increase.

B. Opportunities: Uncertain events that could improve the results or improve the probability that the desired outcome will happen.

1. Well-planned-out work activities and scheduling could result in increased production, thus producing lower costs for the required actions and lower operating contractor oversight costs than what have been estimated.

2. Removal of all serviceable equipment and materials residing in these facilities could be removed by other programs.

3. Deleting the requirement for characterization sampling and analysis would result in lower project costs. Characterization sampling and analysis may have to be performed by the EM contractor after facility transfer is completed.

Note: Management reserve does not increase the overall accuracy of the estimate; it does, however, reduce the level of risk associated with the estimate. Management reserve is intended to cover the inadequacies in the complete project scope definition, estimating methods, and estimating data. Management reserve specifically excludes changes in project scope, unexpected work stoppages (e.g., strikes, disasters, and earthquakes) and excessive and/or unexpected inflation or currency fluctuations. This estimate does not contain any contingencies and has not been evaluated to include any of the risks that pertain to Department of Energy. 


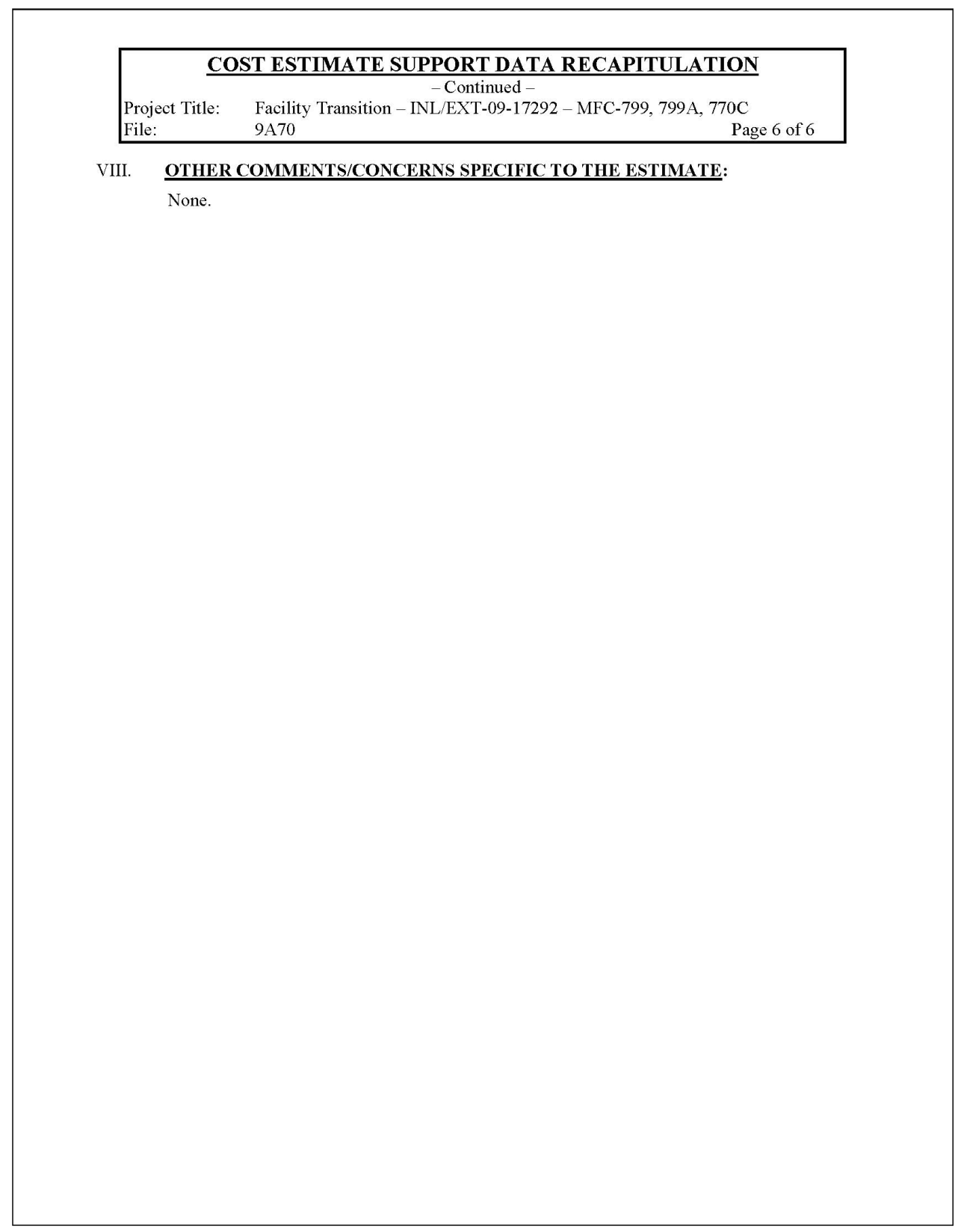




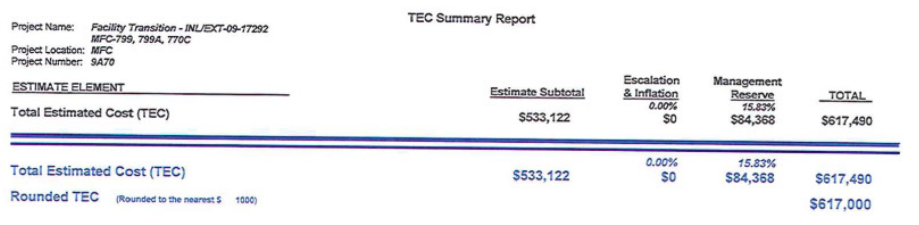
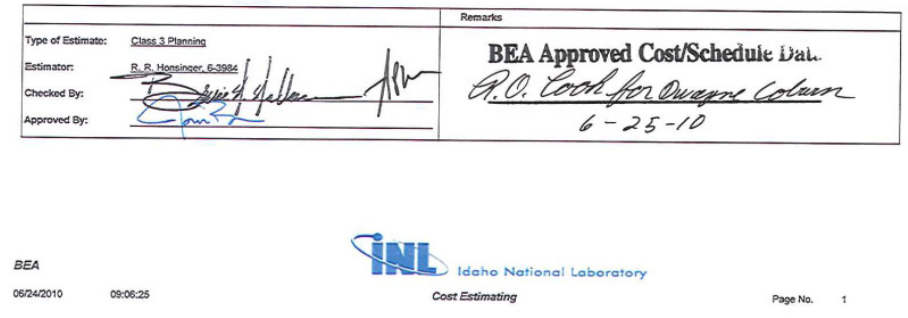

178

178 


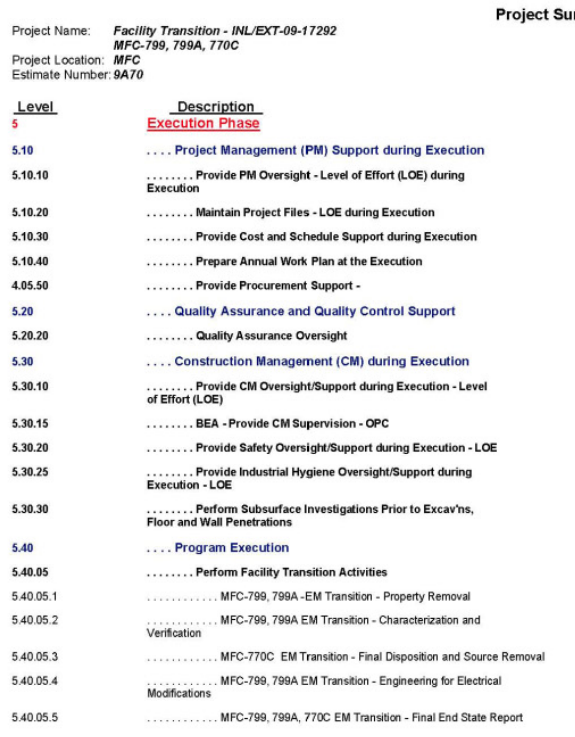

Project Summary Report

Client:
Prepared By: R. A. Harvego
Estimate Type: Classinger, 6-3984

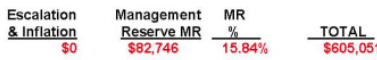

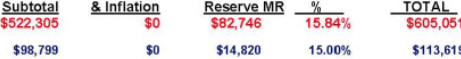

$\begin{array}{rrrrr}\$ 98,799 & \text { so } & \$ 11,556 & 15.00 \% & \$ 88,595\end{array}$

$\begin{array}{lllll}\mathbf{S 4 , 8 5 8} & \text { So } & 5729 & 15.00 \% & \$ 5,586\end{array}$

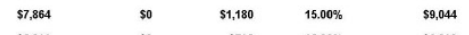

$\begin{array}{lllll}\$ 55,299 & 50 & \$ 795 & 15.00 \% & \$ 6,093\end{array}$

$\begin{array}{lllll}\mathbf{\$ 3}, 740 & \mathbf{\$ 0} & \$ 561 & 15.00 \% & \$ 4,301 \\ \mathbf{\$ 2 , 5 3 4} & \mathbf{\$ 0} & \mathbf{\$ 3 8 0} & 15.00 \% & \mathbf{\$ 2 , 9 1 4}\end{array}$

$\begin{array}{lllll}\$ 2,534 & \text { so } & \$ 3380 & 15.00 \% & \$ 2,914\end{array}$

$\begin{array}{rrrrr}\mathbf{\$ 6 8 , 4 4 1} & \mathbf{\$ 0} & \mathbf{\$ 1 0 , 2 6 6} & 15.00 \% & \mathbf{\$ 7 8 , 7 0 7} \\ \mathbf{\$ 2 5 , 2 8 3} & \mathbf{s 0} & \mathbf{\$ 3 , 7 9 2} & 15.00 \% & \mathbf{\$ 2 9 , 0 7 5}\end{array}$

$\begin{array}{lllll}\mathbf{S 5 , 7 1 4} & \text { so } & \mathbf{5 8 5 7} & \mathbf{1 5 . 0 0 \%} & \mathbf{5 6 , 5 7 1}\end{array}$

$\begin{array}{lllll}\mathbf{s 5 , 5 2 9} & \mathbf{s 0} & \$ 829 & 15.00 \% & \mathbf{5 6 , 3 5 8} \\ \mathbf{5 3 , 3 9 5} & \mathbf{s 0} & \$ 584 & 15.00 \% & \$ 4,479\end{array}$

$\begin{array}{lllll}\$ 28,021 & \text { so } & \$ 44,203 & 15.00 \% & \$ 32,224\end{array}$

$\begin{array}{lllll}\mathbf{\$ 3 5 0 , 3 5 1} & \mathbf{\$ 0} & \mathbf{\$ 5 6 , 9 5 3} & \mathbf{1 6 . 2 6 \%} & \mathbf{\$ 4 0 7 , 3 0 4}\end{array}$

$\begin{array}{lllll}\mathbf{\$ 2 4 2 , 7 5 7} & \text { so } & \mathbf{5 3 6 , 4 1 4} & 15.00 \% & \$ 279,171\end{array}$

$\begin{array}{lllll}\$ 66,287 & \text { so } & \$ 9.943 & 15.00 \% & \$ 76,230 \\ \$ 42,041 & \text { so } & \$ 6,306 & 15.00 \% & \$ 48,347\end{array}$

$\begin{array}{lllll}\$ 82,235 & \text { So } & \$ 12,335 & 15.00 \% & \$ 94,570\end{array}$

$\begin{array}{lllll}526,000 & 50 & \$ 3,900 & 15.00 \% & \$ 29,900\end{array}$

BEA

06/24/2010 10:31:29

Cost Estimating

Page No. $\quad 1$ 


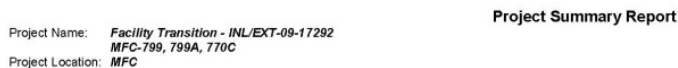

Project Summary Report

$\begin{array}{ll}\text { Client } & \text { L. A. Harvego } \\ \text { Prepared By: R.R. Honsinger, } 63984 \\ \text { Estimate Type: Class } 3 \text { Planning }\end{array}$

Project Location: $M F C$
Estimate Number: $: A A 70$

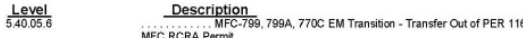
MFC RCRA Permit

5.40.10 ........ Provide Subcontracted Construction Services

5.40.10.10 …......... Modify Electrical Power to Buiding MFC.771 - Subcontractor

5.40.40 -....... Provide Construction Support

$5.40 .40 .10 \quad \ldots . . . . .$. Provide Radiation Control (Technical) Direat Work

5.0.40.20 $\quad$............ Provide Radiation Control (Technical) Oversight

$5.40 .55 \quad$......... Work Orders (wos)

5.40.55.10

$5.70 \quad$.... BEA Material Handling Fee and G\&A Costs - Execution Phase

6 Project Transition/Closeout Phase

6.10 .... Project Management (PM) Support during Transition/Closeout

6.10.10 Transition'Closeout Phase

6.10.20 -........ Closeout Project Files

$6.20 \quad$....... closure Engineering and Design Documents

6.20.10 incorporate into EDMS

6.20.20 $\quad \ldots . . .$. Prepare Project As-Buitt Drawings and Incorporate into

\begin{tabular}{|c|c|c|c|c|}
\hline \multirow[b]{2}{*}{$\begin{array}{l}\text { Estimate } \\
\frac{\text { Subtotal }}{\text { S8.3.355 }}\end{array}$} & \multicolumn{4}{|c|}{ 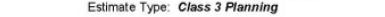 } \\
\hline & $\begin{array}{l}\text { Escalation } \\
\frac{8 \text { Inflation }}{50}\end{array}$ & $\begin{array}{c}\text { Management } \\
\text { Reserve MR } \\
1,258\end{array}$ & $\begin{array}{l}\text { MR } \\
\frac{\%}{15.00 \%}\end{array}$ & $\frac{\text { TOTAL }}{59.642}$ \\
\hline$\$ 88,000$ & so & $\mathbf{s 1 7 , 6 0 0}$ & $20.00 \%$ & \$105,600 \\
\hline$\$ 88,000$ & so & $\mathbf{s 1 7 , 6 0 0}$ & $20.00 \%$ & $\$ 105,600$ \\
\hline $\mathbf{s 8 , 9 9 3}$ & so & $\mathbf{s 1 , 3 4 9}$ & $15.00 \%$ & $\mathbf{s 1 0 , 3 4 1}$ \\
\hline$\$ 7,290$ & so & $\$ 1,094$ & $15.00 \%$ & $\$ 88,384$ \\
\hline $\mathbf{s 1 , 7 0 2}$ & so & $\$ 255$ & $15.00 \%$ & $\$ 1,957$ \\
\hline S10,601 & so & $\mathbf{s 1 , 5 9 0}$ & $15.00 \%$ & $\mathbf{s 1 2 , 1 9 1}$ \\
\hline$\$ 10,601$ & so & $\$ 1,590$ & $15.00 \%$ & $\$ 12,191$ \\
\hline$\$ 2,180$ & \$0 & $\mathbf{\$ 3 2 7}$ & $15.00 \%$ & $\$ 2,507$ \\
\hline$\$ 10,817$ & so & $\$ 1,622$ & $15.00 \%$ & $\$ 12,439$ \\
\hline$\$ 3,855$ & so & $\mathbf{S 5 7 8}$ & $15.00 \%$ & $\mathbf{S 4 , 4 3 3}$ \\
\hline$\$ 3,369$ & so & $\$ 505$ & $15.00 \%$ & $\mathbf{\$ 3 , 8 7 5}$ \\
\hline$\$ 486$ & so & 573 & $15.00 \%$ & $\$ 559$ \\
\hline $\mathbf{5 6 , 9 6 2}$ & \$0 & $\$ 1,044$ & $15.00 \%$ & $\mathbf{\$ 8 , 0 0 6}$ \\
\hline $\mathbf{s 3 , 4 8 1}$ & so & $\mathbf{s 5 2 2}$ & $15.00 \%$ & $\$ 4,003$ \\
\hline $\mathbf{s 3 , 4 8 1}$ & so & $\$ 522$ & $15.00 \%$ & $\$ 4,003$ \\
\hline
\end{tabular}

Total Facility Transition - MFC-799, 799A, 770C - INL-EXT-09-17292

$\$ 533,122$

BEA 
Appendix B

\section{Limited Characterization Report}


Hazardous Materials Verification and Limited Characterization Report on Sodium and Caustic Residuals in Materials and Fuel Complex Facilities MFC-799/799A

August 2010

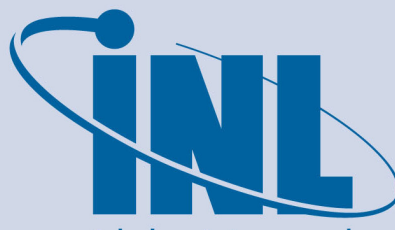

Idaho Nationa Laboratory

The INL is a U.S. Department of Energy National Laboratory operated by Battelle Energy Alliance 


\section{DISCLAIMER}

This information was prepared as an account of work sponsored by an agency of the U.S. Government. Neither the U.S. Government nor any

agency thereof, nor any of their employees, makes any warranty, expressed or implied, or assumes any legal liability or responsibility for the accuracy,

completeness, or usefulness, of any information, apparatus, product, or

process disclosed, or represents that its use would not infringe privately

owned rights. References herein to any specific commercial product,

process, or service by trade name, trade mark, manufacturer, or otherwise,

does not necessarily constitute or imply its endorsement, recommendation,

or favoring by the U.S. Government or any agency thereof. The views and

opinions of authors expressed herein do not necessarily state or reflect

those of the U.S. Government or any agency thereof. 
INL/EXT-10-19590

\title{
Hazardous Materials Verification and Limited Characterization Report on Sodium and Caustic Residuals in Materials and Fuel Complex Facilities MFC-799/799A
}

\author{
August 2010 \\ Idaho National Laboratory \\ Idaho Falls, Idaho 83415 \\ http://www.inl.gov \\ Prepared for the \\ U.S. Department of Energy \\ Office of Nuclear Energy \\ Under DOE Idaho Operations Office \\ Contract DE-AC07-05ID14517
}




\begin{abstract}
This report is a companion to the Facilities Condition and Hazard Assessment for Materials and Fuel Complex Sodium Processing Facilities MFC-799/799A and Nuclear Calibration Laboratory MFC-770C (referred to as the Facilities Condition and Hazards Assessment). This report specifically responds to the requirement of Section 9.2, Item 6, of the Facilities Condition and Hazards Assessment to provide an updated assessment and verification of the residual hazardous materials remaining in the Sodium Processing Facilities processing system. The hazardous materials of concern are sodium and sodium hydroxide (caustic).

The information supplied in this report supports the end-point objectives identified in the Transition Plan for Multiple Facilities at the Materials and Fuels Complex, Advanced Test Reactor, Central Facilities Area, and Power Burst Facility, as well as the deactivation and decommissioning critical decision milestone 1, as specified in U.S. Department of Energy Guide 413.3-8, "Environmental Management Cleanup Projects."

Using a tailored approach and based on information obtained through a combination of process knowledge, emergency management hazardous assessment documentation, and visual inspection, this report provides sufficient detail regarding the quantity of hazardous materials for the purposes of facility transfer; it also provides that further characterization/verification of these materials is unnecessary.
\end{abstract}




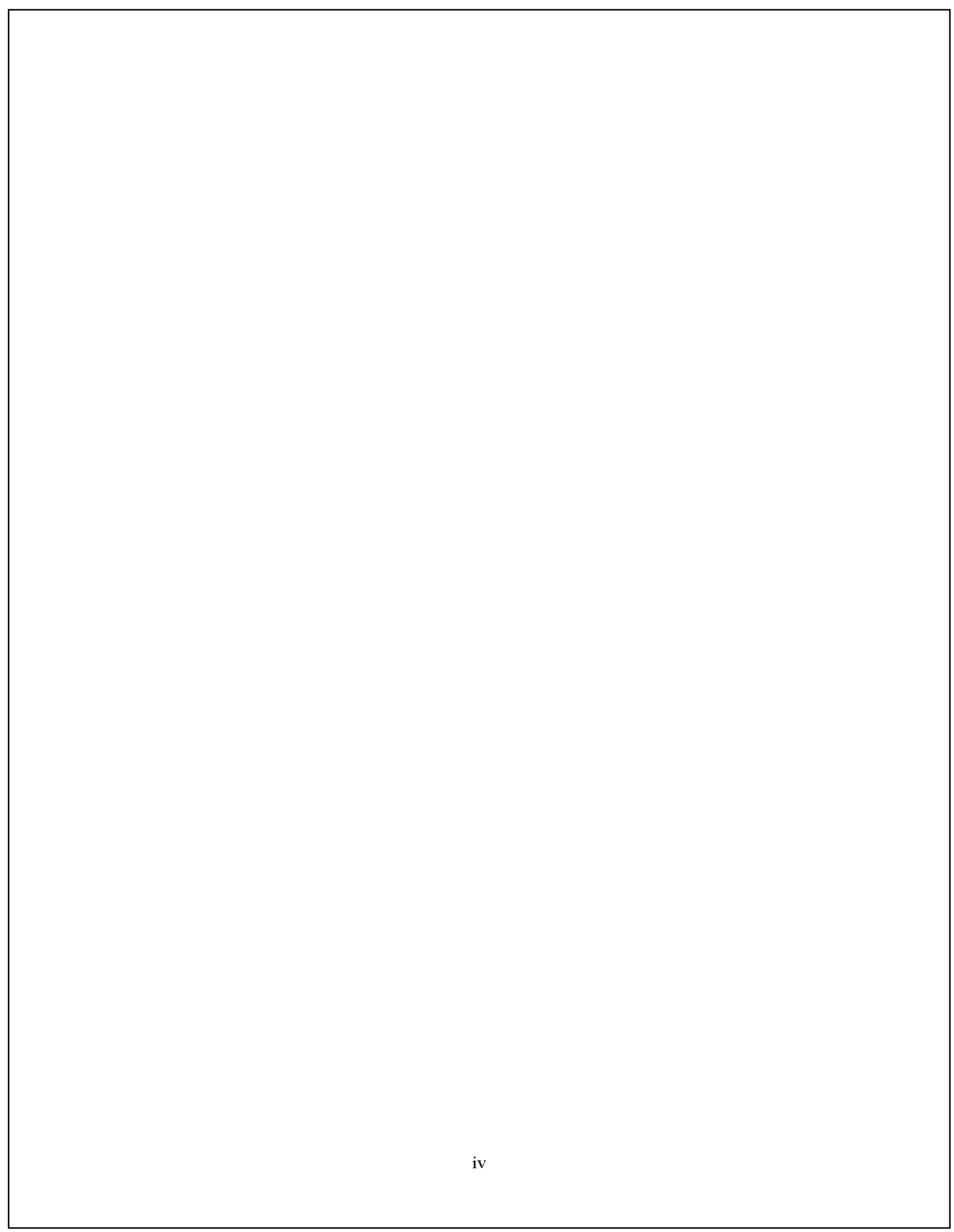

B-6 


\section{CONTENTS}

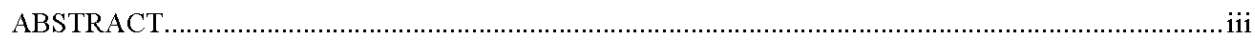

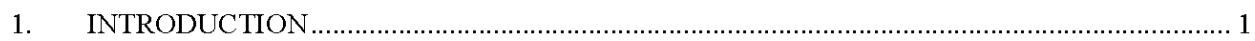

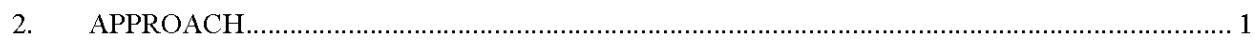

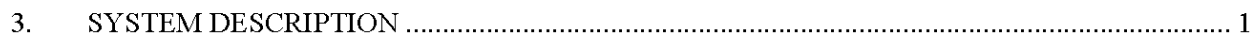

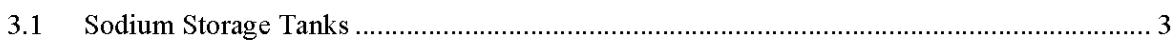

3.2 Sodium Reaction Vessel (A23-T-201) ....................................................................... 3

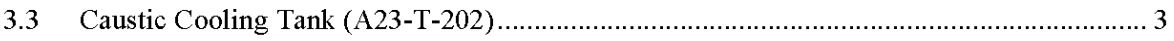

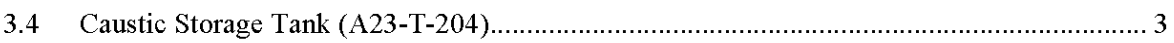

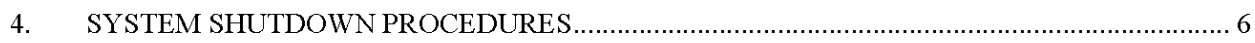

5. RESIDUAL HAZARDOUS MATERIAL QUANTITIES …............................................. 7

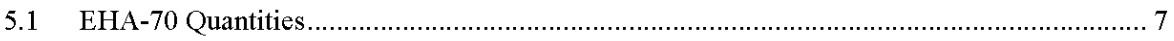

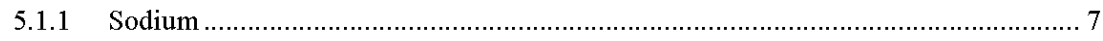

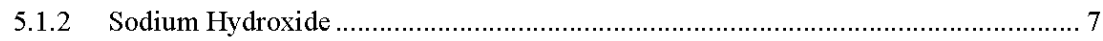

5.2 Resource Conservation and Recovery Act Permit Quantities........................................... 7

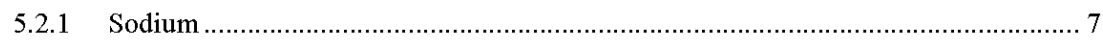

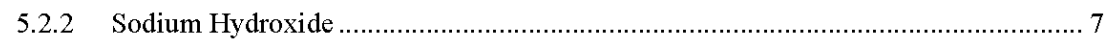

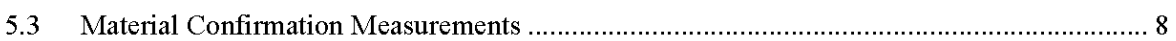

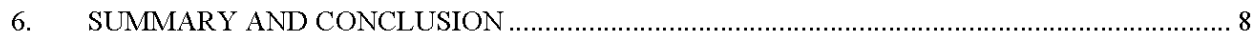

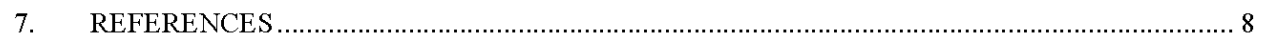

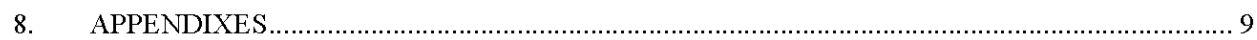

Appendix A, Sodium Process Facility General Arrangement Drawing ........................................ 10

Appendix B, Sodium Process Facility Sodium Process Piping and Instrumentation

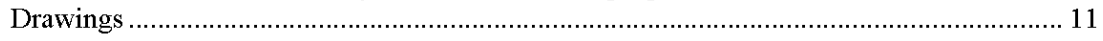




\section{FIGURES}

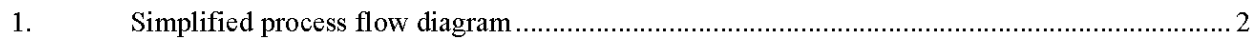

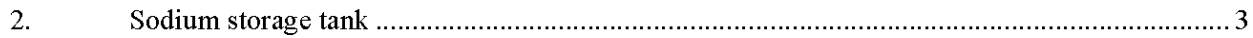

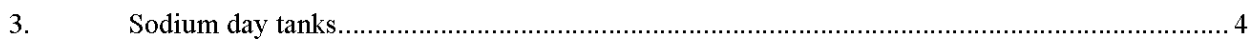

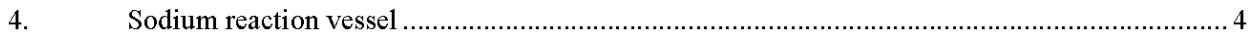

5. Sodium reaction vessel recirculation pumps and piping ….............................................. 5

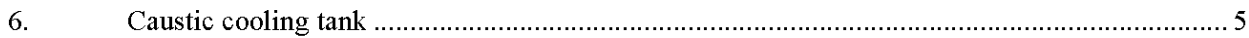

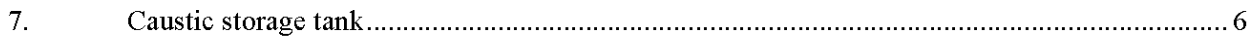




\section{Hazardous Materials Verification and Limited Characterization Report on Sodium and Caustic Residuals in Materials and Fuel Complex Facilities MFC-799/799A}

\section{INTRODUCTION}

This report is a companion to the Facilities Condition and Hazard Assessment for Materials and Fuel Complex Sodium Processing Facilities MFC-799/799A and Nuclear Calibration Laboratory MFC-770C (INL 2009; referred to as the Facilities Condition and Hazards Assessment). This report specifically responds to the requirement of Section 9.2, Item 6, of the Facilities Condition and Hazards Assessment to provide an updated assessment and verification of the residual hazardous materials remaining in the Sodium Processing Facilities processing system. The hazardous materials of concern are sodium and sodium hydroxide (caustic).

The information supplied in this report supports the end-point objectives identified in the Transition Plan for Multiple Facilities at the Materials and Fuels Complex, Advanced Test Reactor, Central Facilities Area, and Power Burst Facility (INL 2010), as well as the deactivation and decommissioning critical decision milestone 1, as specified in U.S. Department of Energy (DOE) Guide 413.3-8, "Environmental Management Cleanup Projects."

\section{APPROACH}

DOE Guide 450.3-3, "Tailoring for Integrated Safety Management Applications," demonstrates that tailoring is integral to the Integrated Safety Management System. Application of tailoring is appropriate for all phases of facility transitioning.

In keeping with tailoring principles, reliance on information compiled from the following sources, as opposed to intrusive sampling, is an adequate and prudent approach to meet the objectives of this report:

- Process knowledge relative to tank and pumping configurations and the procedures followed when the facilities were placed into operational standby

- Information contained in EHA-70, Appendix R, "Emergency Management Hazards Assessment for MFC-799, Sodium Process Facility, and MFC-799A, Caustic Storage Tank Building"

- Information contained in the Integrated Waste Tracking System for container profile CH-ANL-180 and Argonne Laboratory Memo FE-AL-(SAB)-97-003 summarizing chemical analysis of sodium feedstock for the Sodium Process Facility

- Confirmation measurements of materials, where practical.

\section{SYSTEM DESCRIPTION}

Residual hazardous materials are confined to the system process components depicted in the simplified process flow diagram in Figure 1. The Facilities Condition and Hazards Assessment (INL 2009) provides a detailed description of the MFC-799/799A equipment and process from which the following summary is extracted. 


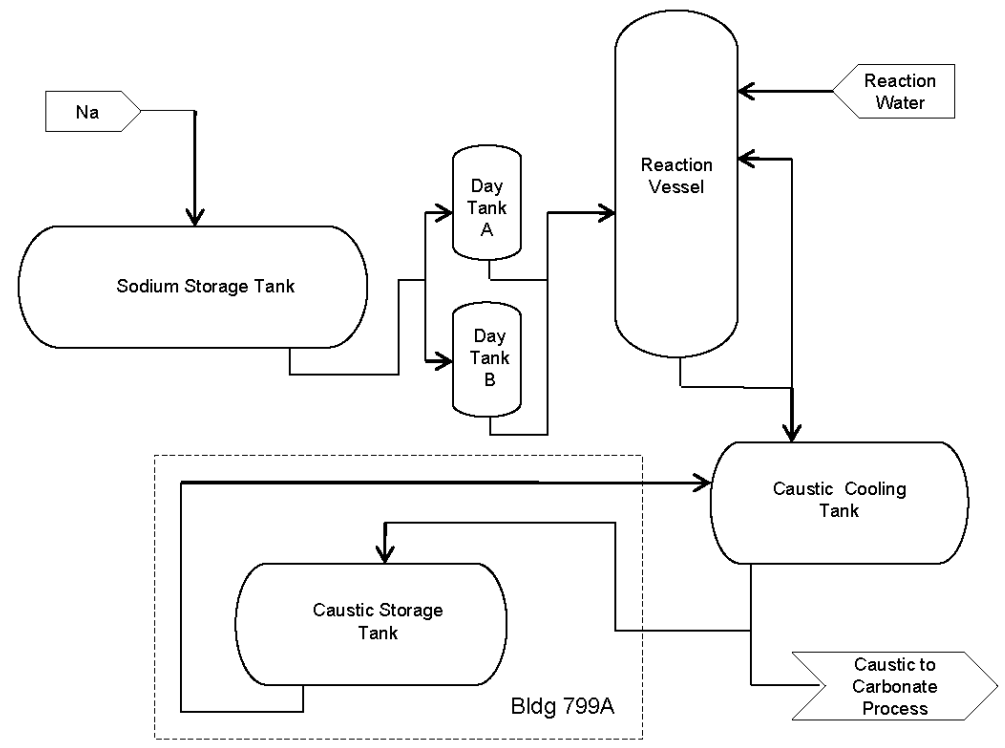

Figure 1. Simplified process flow diagram.

The Sodium Process Equipment Area was used to store and treat alkali metal hazardous waste/mixed waste. There are several major components in the sodium process area, including a 5,000-gal sodium storage tank, two 730-gal sodium day tanks (Tank A on the west side and Tank B on the east), sodium reaction vessel, 1,000-gal caustic cooling tank, and a 4,000-gal caustic storage tank.

The sodium storage tank received alkali metal from the barrel drain stations (supply lines are all drained). The storage tank filled the day tanks, which fed the alkali metal to the reaction vessel. The reaction vessel converted the alkali metal to a liquid hydroxide waste form, which was then loaded into drums and allowed to cool to solidify. The caustic cooling tank and the caustic storage tank allowed for storage of caustic during reaction vessel shutdowns. The caustic storage tank was included to provide for backup storage only. The caustic storage tank is located in a separate building (MFC-799A) just west of the Sodium Process Equipment Area.

Pressurized nitrogen gas was the motive force for transfer of sodium to the reaction vessel, whereas pumps were used to transfer and recirculate caustic within the system.

In the reaction vessel, the sodium/sodium potassium reacted with water to produce sodium hydroxide/potassium hydroxide and hydrogen. The hydroxide in the reaction vessel was recirculated with approximately 1 to 2 gallons per minute (gpm) of the 8 to $10 \mathrm{gpm}$ recirculated solution continuously diverted to either the drum fill station (during operation) or to the 1,000-gal caustic cooling tank (during shutdown operations).

The caustic metering pump transferred the $50 \mathrm{wt} \%$ hydroxide solution from the 1,000 -gal caustic cooling tank directly to the reaction vessel upon startup or if backup hydroxide storage was needed. The 4,000-gal caustic storage tank was intended to be used, in an emergency only, to transfer hydroxide solution to or from the caustic storage tank to the reaction vessel. The caustic recirculation pump, metering pump, and caustic cooling tank are located in the sodium process area; the caustic storage tank and caustic transfer pump are housed in MFC-799A. 
Drawing W7990-0207-ED-01, Sodium Process Facility Building 799 General Arrangement (see Appendix A), depicts the layout of these system components. Each of the tanks and the reaction vessel are installed in below-grade, lined containment wells with associated recirculation and pumping equipment mounted below the vessel bottoms, all of which allows for gravity draining of the systems

\subsection{Sodium Storage Tanks}

Figures 2 and 3 show the 5,000-gal sodium storage tank (A1-T-101) and the two 750-gal sodium day tanks (A1-T-102 and A1-T-103), respectively.

As depicted in drawing E5274-0013-ED-19, Sheet 1 of 4, Sodium Process Facility, Sodium Process Piping and Instrumentation Diagram (see Appendix B), all three tanks have rounded bottoms and the sodium storage tank has a dip tube well on the end closest to the day tanks. All three tanks have low point drain ports.

\subsection{Sodium Reaction Vessel (A23-T-201)}

Figure 4 shows the sodium reaction vessel and Figure 5 depicts the associated recirculation pumps.

The sodium reaction vessel also has a rounded bottom and drains to the recirculation pump from the low point (see drawing E5274-0013-ED-19, Sheet 2 of 4, Sodium Process Facility, Sodium Process Piping and Instrumentation Diagram [see Appendix B])

\subsection{Caustic Cooling Tank (A23-T-202)}

Figure 6 shows the 1,000-gal caustic cooling tank. This tank also has a round bottom and drains at the tank low point (see drawing E4-5274-0013-ED-19, Sheet 3 of 4, Sodium Process Facility, Sodium Process Piping and Instrumentation Diagram [see Appendix B])

\subsection{Caustic Storage Tank (A23-T-204)}

Figure 7 shows the 4,000-gal caustic storage tank located in MFC-799A and is depicted in drawing E4-5274-0013-ED-19, Sheet 3 of 4, Sodium Process Facility, Sodium Process Piping and Instrumentation Diagram (see Appendix B). It also has a round bottom and drains from the tank low point

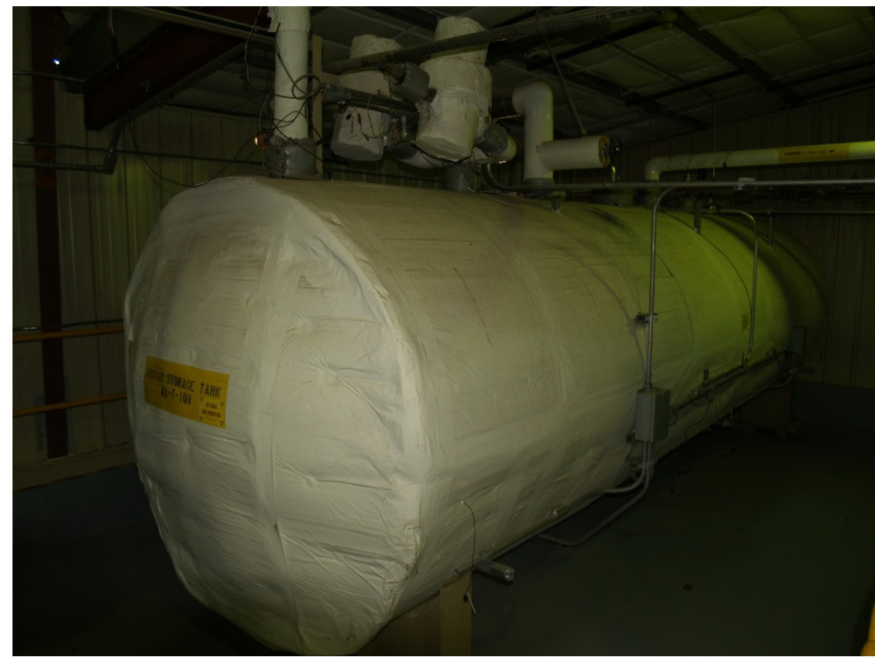

Figure 2. Sodium storage tank. 


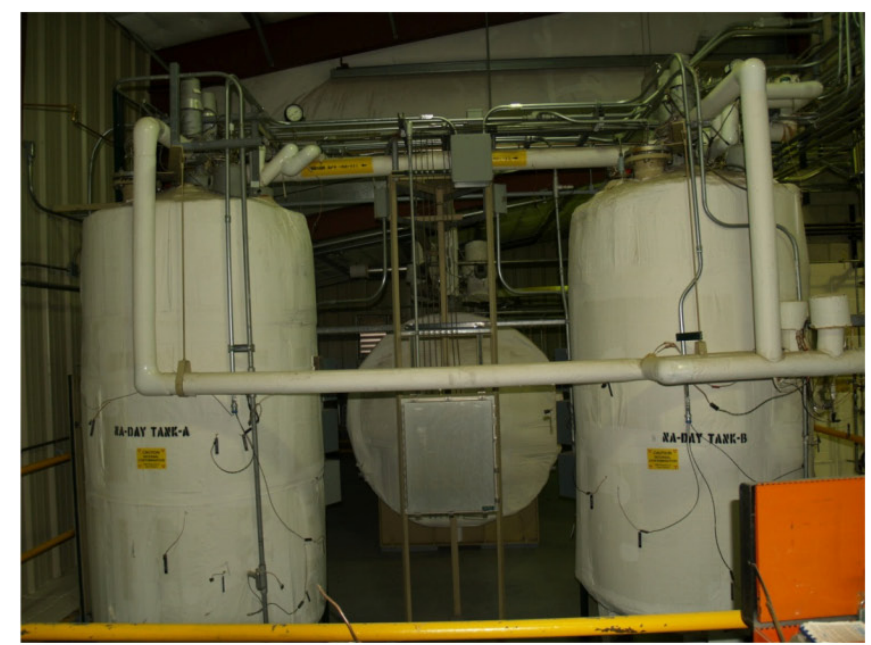

Figure 3. Sodium day tanks.

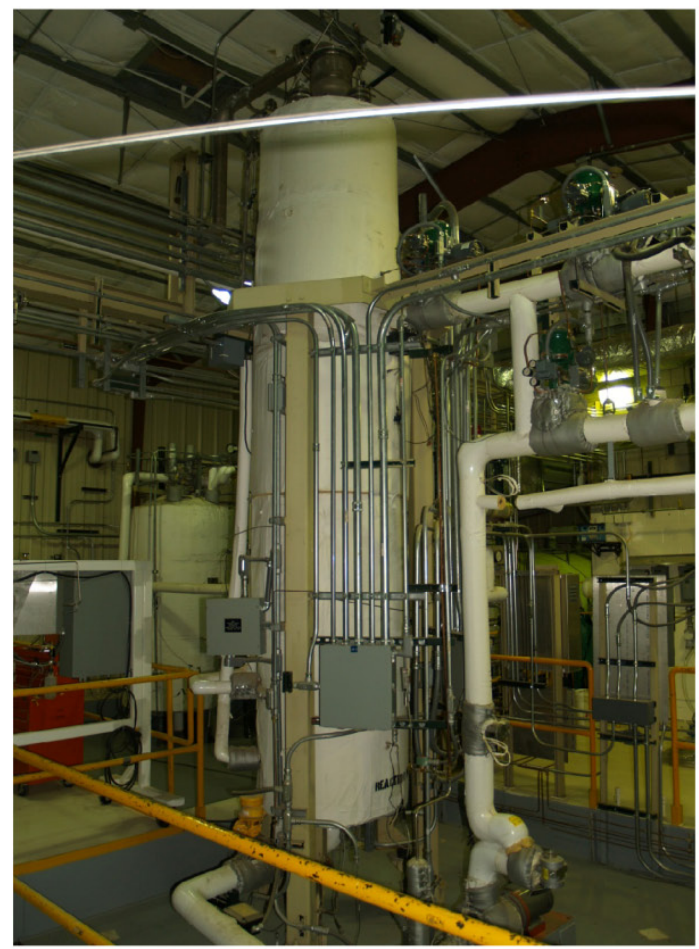

Figure 4. Sodium reaction vessel. 


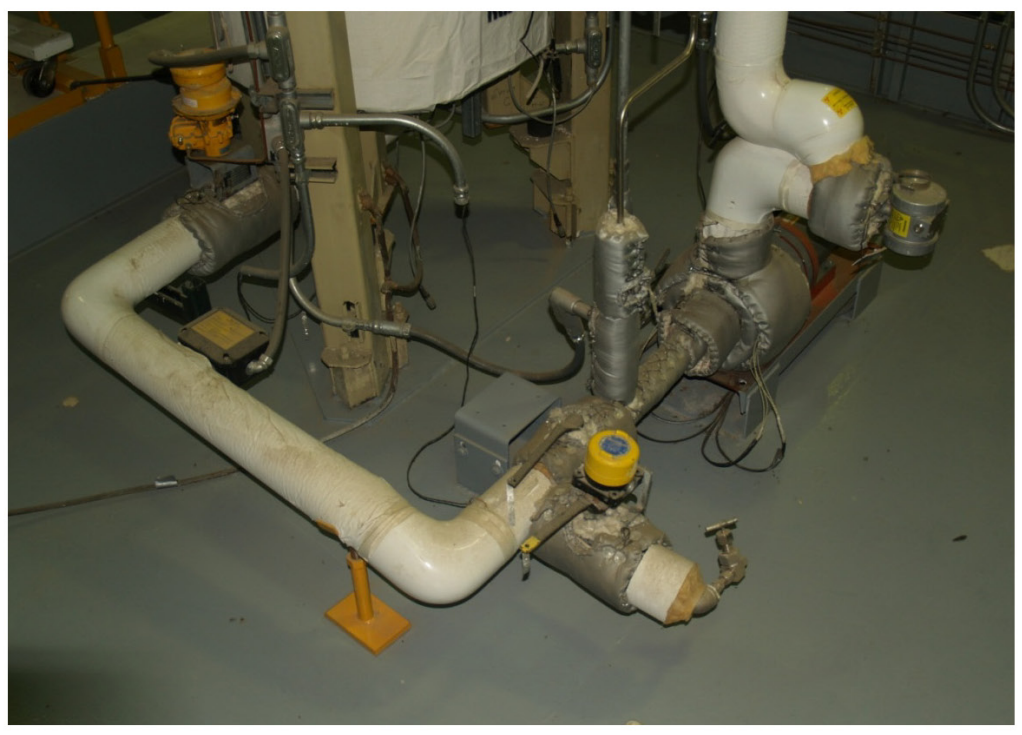

Figure 5. Sodium reaction vessel recirculation pumps and piping.

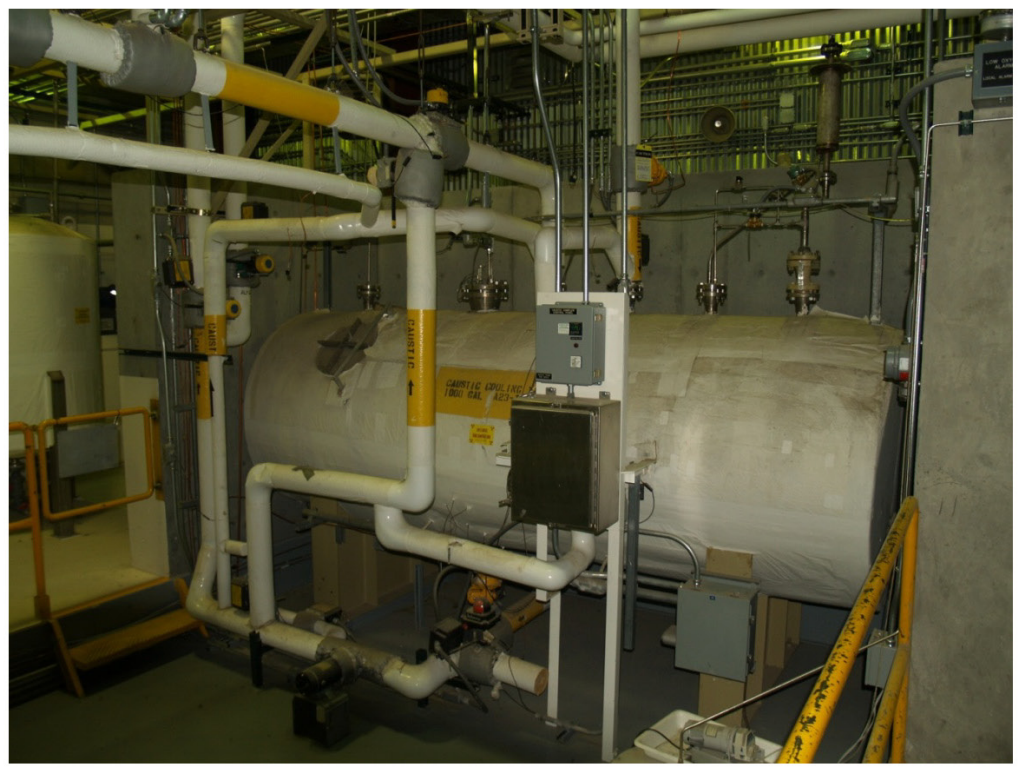

Figure 6. Caustic cooling tank. 


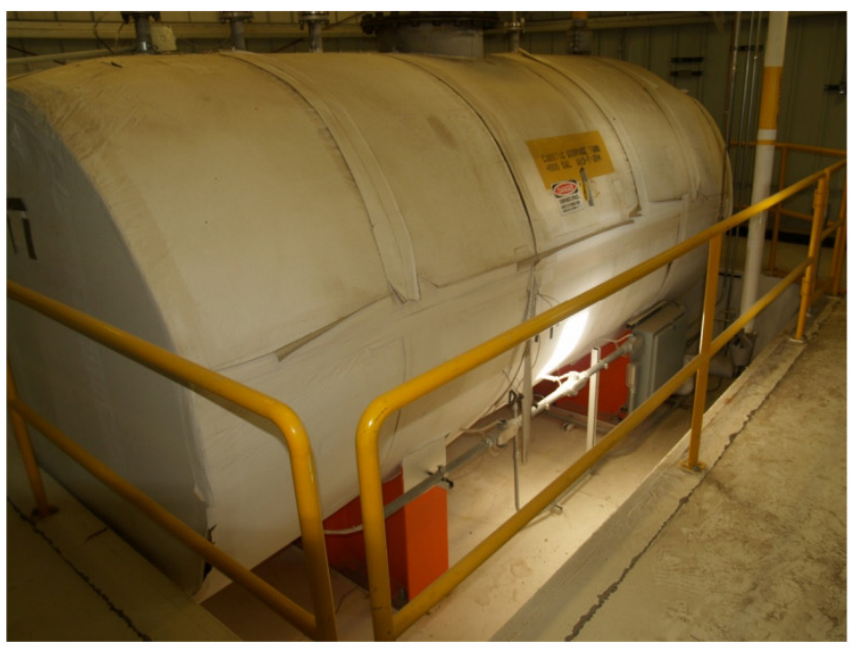

Figure 7. Caustic storage tank.

\section{SYSTEM SHUTDOWN PROCEDURES}

According to the entries in A Summary of the Operational and Maintenance Activities at the Sodium Processing Facility for the Period Covering December 1995 through March 2001 (Sandifer 2001), all processing of Experimental Breeder Reactor II primary sodium was completed on February 16, 2001. Once Experimental Breeder Reactor II processing was finished, the remainder of the FERMI sodium transferred to the Idaho National Laboratory (INL) was processed as a system flush ${ }^{\mathrm{a}}$. Processing of FERMI sodium was completed on March 5, 2001, at which time, a non-routine procedure was performed to minimize the residual amounts of sodium and caustic left in all tanks/containers at the Sodium Processing Facility. The Sodium Processing Facility was then shutdown to a facility standby status.

The non-routine procedure consisted of pressurizing the nitrogen system and forcing out and collecting as much residual material within the sodium transfer piping and storage tanks as possible. The process continued until the system pressure could not be maintained, indicating there was an insufficient quantity of sodium remaining to create a backpressure seal against the nitrogen purge.

Residual caustic in the reaction vessel was pumped from the bottom of the vessel and into the caustic cooling tank until pump vacuum could no longer be contained, indicating the reaction vessel had been evacuated to as low a level as possible. The residual caustic pumped into the caustic cooling tank during this process remains, and the tank level is monitored via an active bubbler measurement system.

Contaminated caustic was never stored in the caustic storage tank in MFC-799A. A clean, 50\% solution was pumped into the tank for initial system testing but was later pumped back out via the tank bottom drain. Pumping continued until suction was lost, indicating the tank is empty and any residual is limited to what is contained within the associated recirculation pump and lower piping connection.

\footnotetext{
${ }^{\text {a }}$ Conversation with Darrell Pfannenstiel on June 29, 2010, confirmed that the reason FERMI sodium was considered a system flush is because the FERMI sodium was less radioactively contaminated than Experimental Breeder Reactor II sodium. Actual activity readings are not available nor are they considered significant for purposes of this report.
} 
It is reasonable to assume that further draining of the system would require opening the tanks, pumps, and drains, which would be neither prudent nor cost effective. Residuals are considered minimal and isolated to readily identifiable locations.

The facilities have been well maintained since shutdown, with regular inspections. No evidence of leakage has been observed and regular checks of the caustic cooling tank bubbler measurements indicate that the tank level has not changed since system shutdown.

\section{RESIDUAL HAZARDOUS MATERIAL QUANTITIES}

Two documents provide information relative to residual hazardous materials remaining in the system in the Sodium Processing Facility. The first is the Materials and Fuels Complex Emergency Management Hazards Assessment (EHA-70), Appendix R (prepared in 2006). The second is the Sodium Processing Facility Systems Log, which is maintained in accordance with the requirements of the Materials and Fuels Complex Hazardous Waste Management Act Resource Conservation and Recovery Act (RCRA) Storage and Treatment Permit.

\subsection{EHA-70 Quantities}

\subsubsection{Sodium}

The MFC-799 sodium tanks are drained as low as practical and the remaining heels are estimated to be so low a quantity that sodium, while still likely present, is minimal and exempted from further evaluation as a hazard. Components that held sodium were identified in the Integrated Waste Tracking System in Material Profile ANL-180-CH.

\subsubsection{Sodium Hydroxide}

EHA-70 estimates that there are approximately 200 to 240 gallons of $50 \%$ by weight solution of radioactively contaminated sodium hydroxide resident in the caustic cooling tank in MFC-799 and approximately 50 gallons of residual non-radioactive $50 \%$ by weight solution sodium hydroxide associated with the caustic storage tank in MFC-799A. This calculates to roughly $1,520 \mathrm{lb}$ and $315 \mathrm{lb}$ of dry caustic residual, respectively.

\subsection{Resource Conservation and Recovery Act Permit Quantities}

\subsubsection{Sodium}

Sodium quantities are minimal (because the sodium systems essentially were drained completely). Minimal sodium quantities were tracked for radiological inventory purposes as follows:

- Day Tank A (Container Profile, DTA) lists 0.25 gallons

- Day Tank B (Container Profile, DTB) lists 0.25 gallons

- Sodium storage tank (container profile, SST) lists 1 gallon.

\subsubsection{Sodium Hydroxide}

- MFC-799A Caustic Storage Tank. This tank is not monitored in the permit because the material is non-radioactive and the volume is well below reportable quantities. 
- MFC-799 Caustic Cooling Tank. The $50 \%$ caustic solution in this tank is radiologically contaminated and subject to daily RCRA monitoring. Fluid-level monitoring is done using a calibrated bubbler measurement system in which the logs indicate a constant liquid volume of 450 gallons. This correlates to approximately $2,852 \mathrm{lb}$ of dry weight sodium hydroxide. This quantity does not agree with the EHA-70 number.

\subsection{Material Confirmation Measurements}

There is a disagreement between the EHA-70 and RCRA reported volume of contaminated residual caustic solution. Upon further investigation, it was determined that the volume recorded in EHA-70 was an approximate volume based on verbal information provided to the preparer(s) of the EHA rather than an onsite physical verification. The RCRA volume, on the other hand, is monitored daily via calibrated, realtime instrumentation. The RCRA volume is considered accurate and takes precedence over the EHA quantity.

Only the caustic cooling tank is instrumented for direct readings. The other tanks are sealed systems and would have to be opened and physically dipped or visually inspected to verify any residual levels. The risks and costs associated with such individual entries are not commensurate with the value of any additional information gained given what is already known and discussed above.

The caustic cooling tank bubbler measurement system was physically checked on an inspection visit made to the facility on June 29,2010 . The measurement system was operational and the calibration was current. The observed reading was $23 \mathrm{in}$., which correlates to a 450 -gal liquid volume. According to facility management, this reading has remained constant since system shutdown in March 2001.

\section{SUMMARY AND CONCLUSION}

The processing system at the Sodium Processing Facility is well defined and the orderly process followed at shutdown gives assurance that the hazardous sodium and caustic materials internal to the system were drained to the lowest levels achievable.

Any sodium residual is limited to heels in the tanks, associated lower transfer piping sections, and is considered as such a minimal quantity as to be exempted from further consideration.

There is an estimated 450 gallons of residual radioactively ${ }^{\mathrm{b}}$ contaminated $50 \%$ weight solution sodium hydroxide (caustic) contained in the caustic cooling tank in MFC-799. An additional estimated 50 gallons of non-radioactive $50 \%$ weight solution caustic is trapped in the lower pump and piping sections of the caustic storage tank in MFC-799A. In terms of dry weight of chemical, these liquid volumes translate to roughly $2,850 \mathrm{lb}$ and $315 \mathrm{lb}$ of sodium hydroxide, respectively.

The above estimates reflect maximum quantities and are less than $20 \%$ of the reportable quantity of the screening threshold in 40 CFR 302.4, Table 302.4. However, the quantities do exceed laboratory quantities (approximately 5 gal or $40 \mathrm{lb}$ ), and merit a National Fire Protection Association Health Hazard Rating of 3.

Based on the information, sufficient detail is known for the purposes of facility transfer and further characterization/verification is unnecessary.

\section{REFERENCES}

40 CFR 302.4, 2002, Title 40, "Protection of Environment," Part 302, "Designation, Reportable Quantities, and Notification," Section 302.4, "Designation of hazardous substances," Code of Federal Regulations, Office of the Federal Register.

${ }^{\mathrm{b}}$ Per EHA-70, MFC-799/799A are less than Hazard Category 3 facilities. 
DOE Guide 413.3-8, Environmental Management Cleanup Project, September 24, 2008, MFC Hazardous Waste Management Act) RCRA Storage and Treatment Permit, No. ID4890008952, dated August 16, 2004, and modified on October 2, 2008, U.S. Department of Energy.

DOE Guide 450.3-3, Tailoring For Integrated Safety Management Applications, U.S. Department of Energy, February 1997.

EHA-70, Appendix R, "Emergency Management Hazards Assessment for MFC-799, Sodium Process Facility, and MFC-799A, Caustic Storage Tank Building," Revision 0, Effective Date July 5, 2006, eCR Number 506092.

INL, 2009, Facilities Condition and Hazard Assessment for Materials and Fuel Complex Sodium Processing Facilities (SPF) MFC-799/799A and Nuclear Calibration Laboratory MFC-770C, INL/EXT-09-17292, Idaho National Laboratory, November 2009.

INL, 2010, Transition Plan for Multiple Facilities at the Materials and Fuels Complex, Advanced Test Reactor, Central Facilities Area, and Power Burst Facility, PLN-3352, Idaho National Laboratory, January 2010.

MFC Hazardous Waste Management Act (HWMA), RCRA Storage and Treatment Permit, No. ID4890008952, dated August 16, 2004, and modified on October 2, 2008.

Sandifer, V., 2001, "A Summary of the Operational and Maintenance Activities at the Sodium Processing Facility for the Period Covering December 1995 through March 2001," prepared by Van Sandifer, EBR-II/SPF Operations Manager.

\section{APPENDIXES}

Appendix A, Sodium Process Facility General Arrangement Drawing

Appendix B, Sodium Process Facility Sodium Process Piping and Instrumentation Drawings 


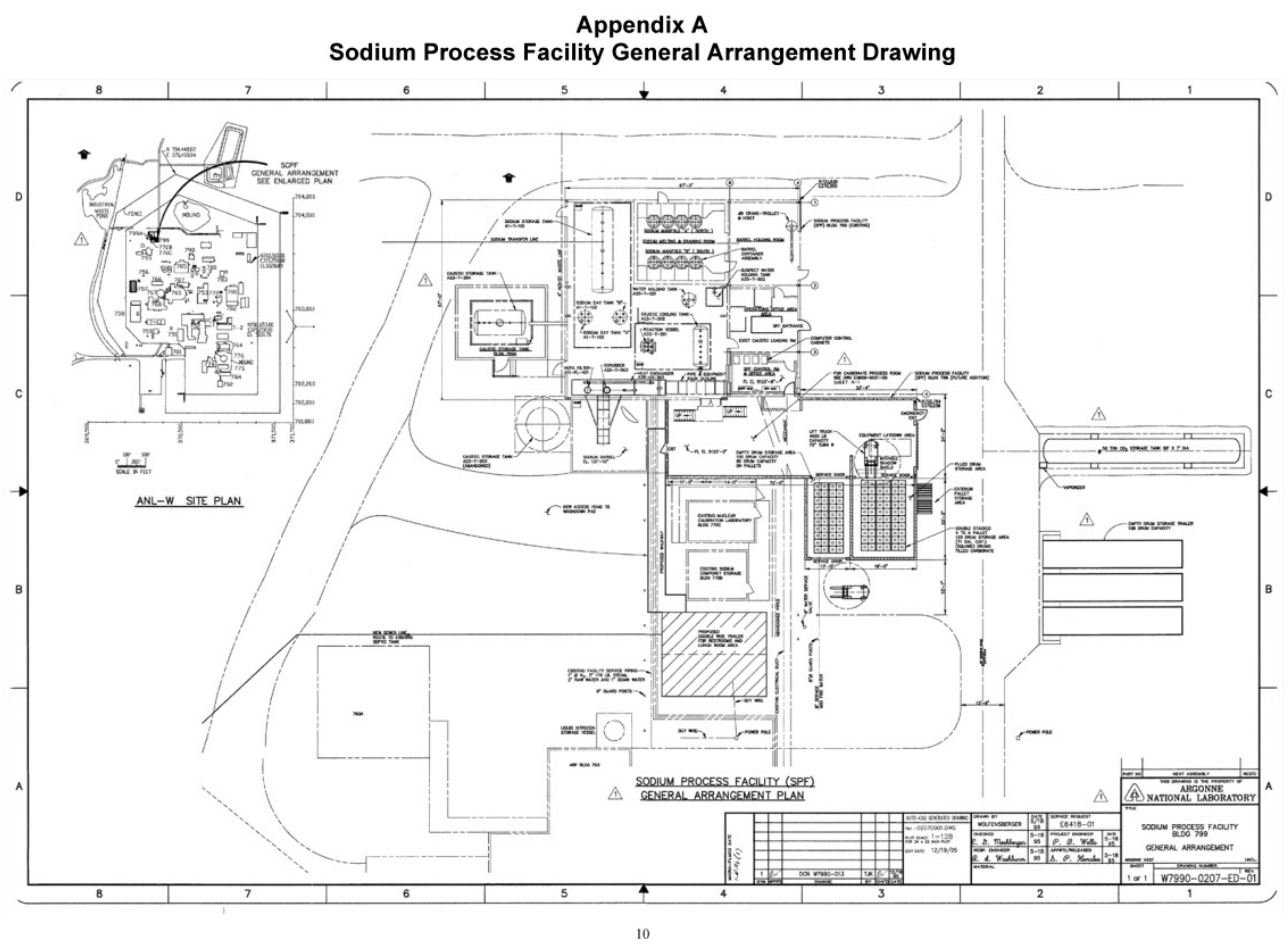

Appendix B

Sodium Process Facility

Sodium Process Piping and Instrumentation Drawings

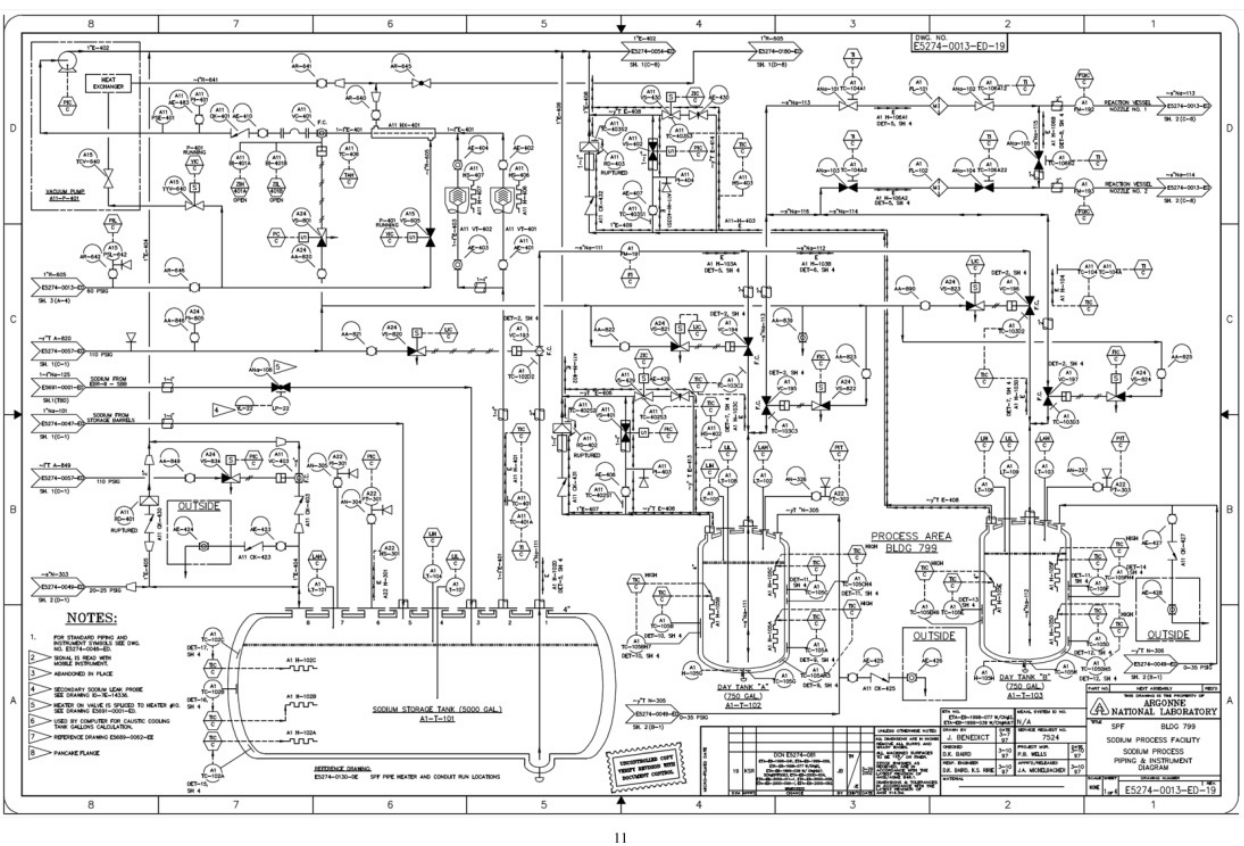



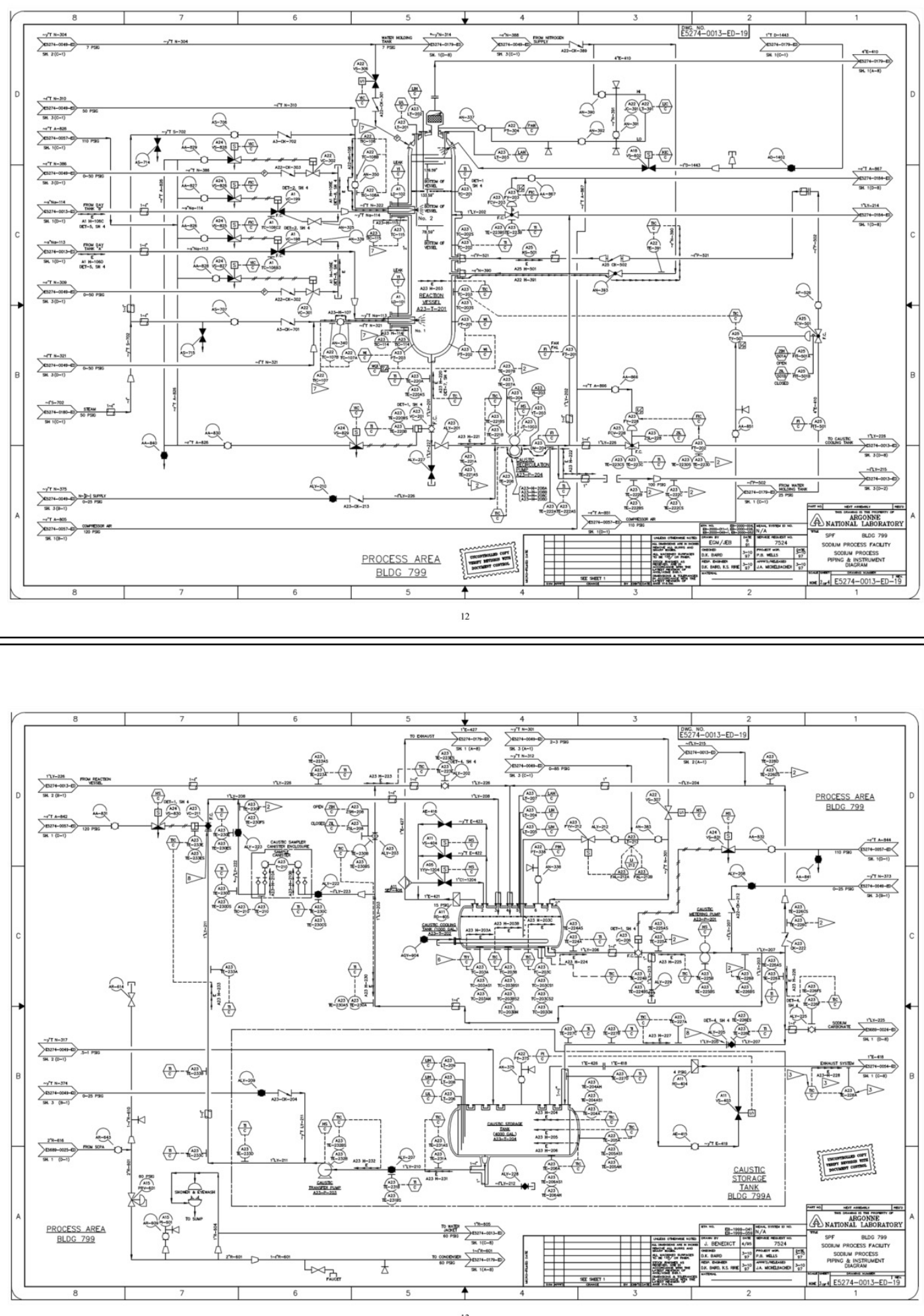


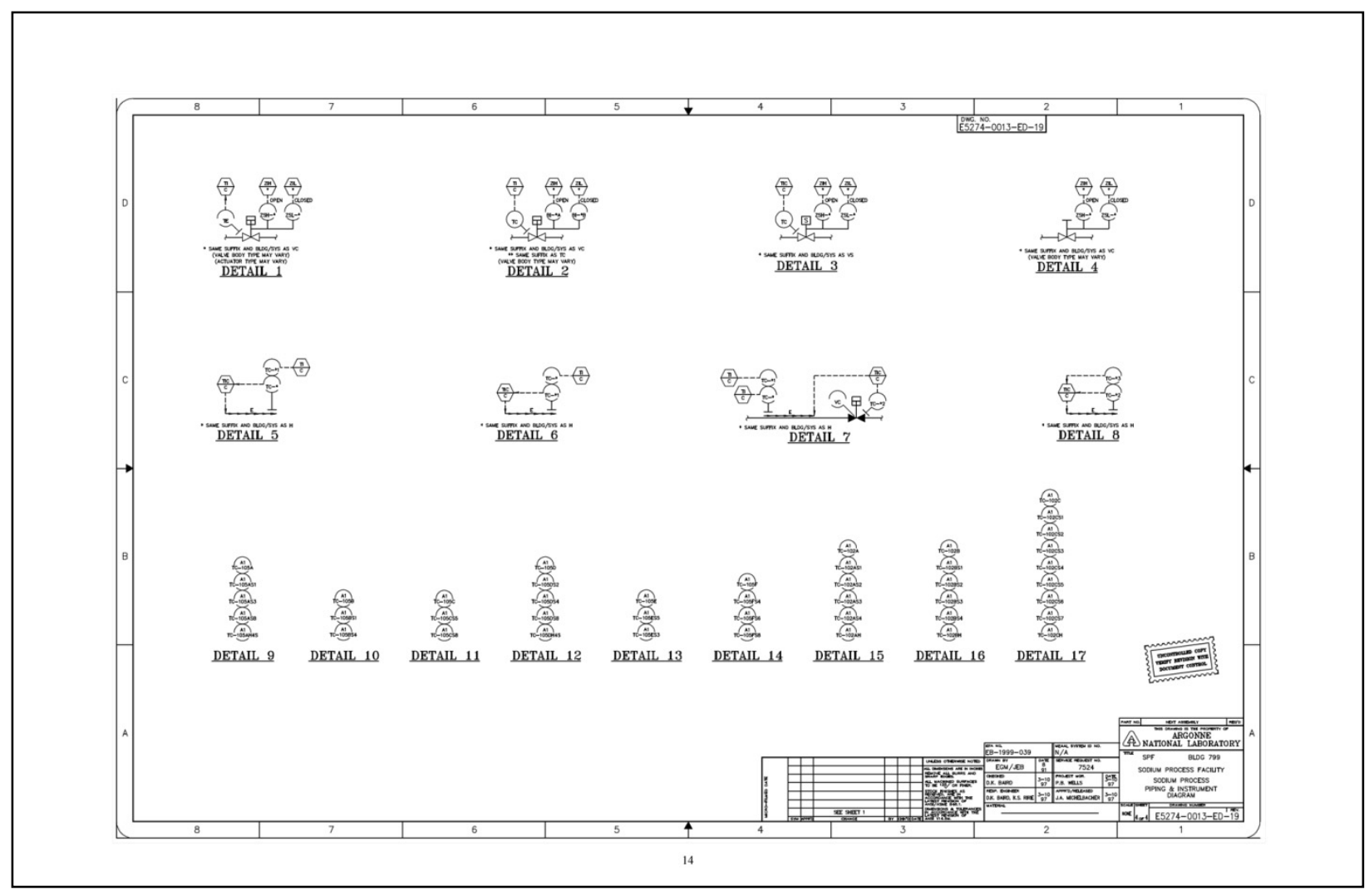




\section{Appendix C}

\section{Cs-137 Source Disposition Documents}




\section{Department of Energy \\ National Nuclear Security Administration \\ Nevada Site Office \\ P.O. Box 98518 \\ Las Vegas, NV 89193-8518}

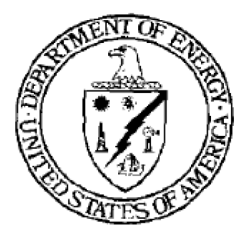

\section{AUG 202010}

Julie E. Conner, DOE Idaho Operations Office, Idaho Falls, ID

\section{APPROVAL TO SHIP BATTELLE ENERGY ALLIANCE (BEA) LOW-LEVEL RADIOACTIVE WASTE TO THE NEVADA TEST SITE (NTS)}

BEA has completed the waste profile approval process described in the Nevada Test Site Waste Acceptance Criteria (NTSWAC), Revision 7-01. The National Nuclear Security Administration Nevada Site Office (NNSA/NSO) reviewed and commented on the following waste profile:

Waste Profile

NEID-CHCS137SS
Revision and Date

Rev. 0, 08/13/2010
Description

CH Cs-137 Sealed Source

NNSA/NSO approves the shipment and disposal of the subject waste stream under the requirements of the NTSWAC, Revision 7-01, and the BEA Waste Certification Program. The enclosure lists the current BEA approvals and supersedes all previous approval memoranda.

Prior to initiating shipment of this waste stream, please notify National Security Technologies, LLC (NSTec) Disposal Operations personnel at (702) 295-6811 with a planned shipping date. NSTec will ensure sufficient disposal capacity is available and provide the necessary equipment and personnel for disposal activities.

If you have any questions or comments, please contact James J. Cebe, Waste Management Project, at (702) 295-0957.

WMP:6722.JJC

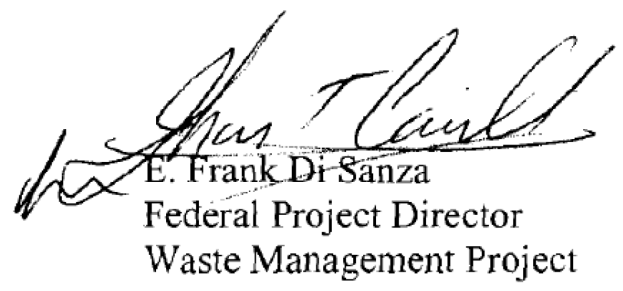

Enclosure:

As stated 
cc w/encl. via e-mail:

J. J. MacDougall, NDEP, Las Vegas, NV

T. H. Murphy, NDEP, Las Vegas, NV

L. A. Harvego, BEA, Idaho Falls, ID

R. M. Guertal, EnergySolutions, Idaho Falls, ID

J. D. Freter, NSTec, Mercury, NV

R. G. Geisinger, NSTec, Las Vegas, NV

K. C. Tanaka, NSTec, Las Vegas, NV

NSTec Correspondence Control, MS NLV008

J. J. Cebe, WMP, NNSA/NSO, Las Vegas, NV

K. K. Snyder, PSG, NNSA/NSO, Las Vegas, NV

S. A. Hejazi, SC, NNSA/NSO, Las Vegas, NV

D. J. Morgan, OPA, NNSA/NSO, Las Vegas, NV

NNSA/NSO Read File 


\section{Nevada Test Site Approval Status - 08/18/2010 \\ Battelle Energy Alliance (BEA), Idaho Falls, Idaho}

\section{WASTE STREAM(s)}

Waste Profile Number

NEID-04SMC0001

NEID-04SMC0002

NEID-04ATR2328

NEID-05SMC3056

NEID-06SMC0001

NEID-0900RALLW

NEID-0900RESIN

NEID-09INLCLLW

Revision \# and Date Current Approval Date Waste Profile Name

$\begin{array}{llll}0 & 10 / 09 / 2009 & 10 / 29 / 2009 & \text { DU Material }\end{array}$

$1 \quad 06 / 29 / 2010 \quad 08 / 12 / 2010 \quad$ DU Contaminated Material, Classified

$\begin{array}{lll}0 & 11 / 18 / 2009 & 12 / 10 / 2009\end{array}$

Routinely Generated CH LLW at ATR Complex*

$\begin{array}{lll}0 & 10 / 09 / 2009 & 10 / 29 / 2009\end{array}$

DU Contaminated Material

$\begin{array}{ll}0 & 10 / 09 / 2009\end{array}$

$10 / 29 / 2009$

DU Waste Material

$\begin{array}{lll}0 & 11 / 04 / 2009 & 12 / 09 / 2009\end{array}$

$\begin{array}{lll}0 & 11 / 17 / 2009 & 01 / 06 / 2010\end{array}$

INL Regulated Asbestos LLW*

NEID-09MFCCLLW

$\begin{array}{lll}0 & 02 / 02 / 2010 \quad 03 / 04 / 2010\end{array}$

Ion Exchange Resins from ATR Complex*

NEID-09MFCRLLW

$0 \quad 02 / 01 / 2010$

$02 / 11 / 2010$

INL Routinely Generated Contact Handled Low-Level Waste*

$1 \quad 08 / 05 / 2010 \quad 08 / 12 / 2010$ MFC Routinely Generated Contact Handled Low-Level Waste*

NEID-CHCS137SS

$0 \quad 08 / 13 / 2010$

Cvr Ltr Date MFC Routinely Generated Remote Handled Low-Level Waste* CH Cs-137 Sealed Source

* Shipments containing tritium (H-3) should arrive at the Nevada Test Site no later than 1200 hours to allow ample time for off loading, survey, and swipe analysis.

\section{WASTE CERTIFICATION PROGRAM}

WCPP - QAP Designation

PLN-522

NIC Rev Date:

$10 / 22 / 2009$

NIC Revision Due:
WCPP - QAP Title

Quality Assurance Program Plan for the Waste Management/Waste Certification Program

\section{ASSESSMENT STATUS}

Last RWAP Facility Evaluation:

RWAP-S-10-15, 05/2010

Page 1 of 1 


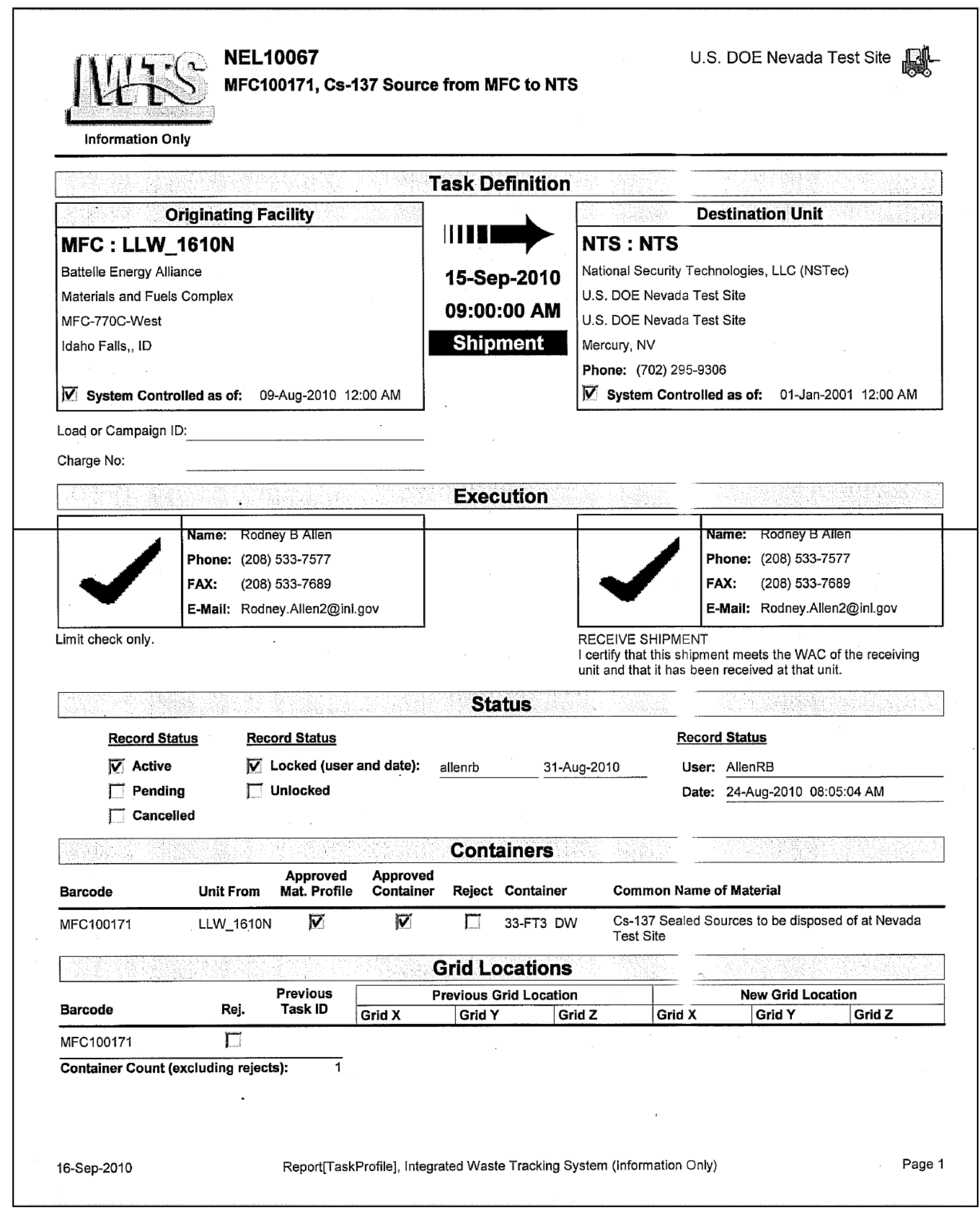


Information Only

\begin{tabular}{|l|}
\hline \multicolumn{1}{|c|}{ Disposal Facility } \\
\hline NTS : NTS \\
National Security Technologies, LLC (NSTec) \\
U.S. DOE Nevada Test Site . \\
U.S. DOE Nevada Test Site \\
Mercury, NV \\
Phone: (702) 295-9306 \\
IV System Controlled as of: 01-Jan-2001 12:00 AM \\
\hline
\end{tabular}

Load or Campaign ID:

Charge No:

Task Definition

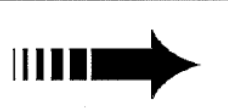

15-Sep-2010

09:30:00 AM

Disposal

\section{Disposal Unit}

NTS : NTS_DSPSL

National Security Technologies, LLC (NSTec)

U.S. DOE Nevada Test Site

Nevada Test Site LLW Disposal

Mercury, NV

Phone: (702) 295-9306

$\sqrt{V}$ System Controlled as of: 01-Jan-2001 12:00 AM

DISPOSAL COMPLETE

I certify that this task has been completed as indicated and that all associated containers are properly characterized.

Execution

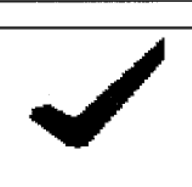

Name: Rodney BA Allen

Phone: (208) 533-7577

FAX: (208) 533-7689

E-Mail: Rodney.Allen2@inl.gov

DISPOSAL COMPLETE

I certify that this task has been completed as indicated and

that all associated containers are properly characterized.

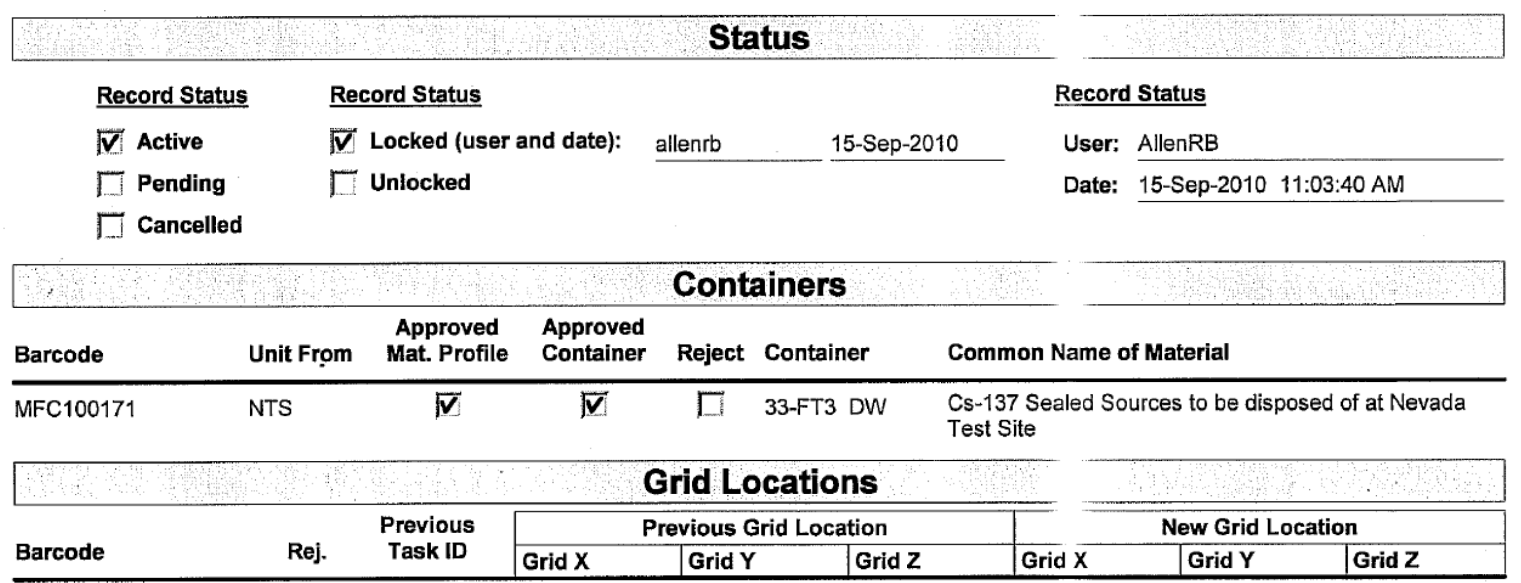

MFC100171 NEL10067

Container Count (excluding rejects): 1 